\title{
THE COBALT CYCLE IN THE TROPICAL PACIFIC OCEAN
}

By

Nicholas James Hawco

B.A., Washington University in St. Louis, 2011

Submitted in partial fulfillment of the requirements for the degree of

Doctor of Philosophy

at the

MASSACHUSETTS INSTITUTE OF TECHNOLOGY

and the

WOODS HOLE OCEANOGRAPHIC INSTITUTION

February 2017

(C) 2017 Nicholas Hawco

All rights reserved.

The author hereby grants to MIT and WHOI permission to reproduce and to distribute publically paper and electronic copies of this thesis document

in whole or in part in any medium now known or hereafter created.

Signature of Author

Joint Program in Oceanography/Applied Ocean Science and Engineering Massachusetts Institute of Technology

And Woods Hole Oceanographic Institution

January 23, 2017

Certified by

Dr. Mak A. Saito

Thesis Supervisor

Accepted by

Professor Shuhei Ono

Chair, Joint Committee for Chemical Oceanography

Massachusetts Institute of Technology 


\section{THE COBALT CYCLE IN THE TROPICAL PACIFIC OCEAN}

By

Nicholas James Hawco

Submitted to the MIT/WHOI Joint Program in Chemical Oceanography on December 23, 2016 in partial fulfillment of the requirements for the degree of Doctor of Philosophy

\section{Thesis Abstract}

Although over a dozen elements are needed to support phytoplankton growth, only a few are considered to be growth-limiting. As the central atom in vitamin $\mathrm{B}_{12}$, cobalt is crucial for metabolism, but its status as a limiting nutrient is uncertain. This thesis investigates the geochemical controls on oceanic cobalt scarcity and their biological consequences.

Analysis of over 1000 samples collected in the Tropical Pacific Ocean reveals a dissolved cobalt distribution that is strongly coupled to dissolved oxygen, with peak concentrations where oxygen is lowest. Large cobalt plumes within anoxic waters are maintained by three processes: 1) a cobalt supply from organic matter remineralization, 2) an amplified sedimentary source from oxygen-depleted coastlines, and 3) low-oxygen inhibition of manganese oxidation, which scavenges cobalt from the water column. Rates of scavenging are calculated from a global synthesis of recent GEOTRACES data and agree with cobalt accumulation rates in pelagic sediments. Because both sources and sinks are tied to the extent of oxygen minimum zones, oceanic cobalt inventories are likely dynamic on the span of decades.

Despite extremely low cobalt in the South Pacific gyre, the cyanobacterium Prochlorococcus thrives. Minimum cobalt and iron requirements of a Prochlorococcus strain isolated from the Equatorial Pacific are quantified. Cobalt quotas are related to demand for ribonucleotide reductase and methionine synthase enzymes, which catalyze critical steps in DNA and protein biosynthesis, respectively. Compared to other cyanobacteria, a streamlined metal physiology makes Prochlorococcus susceptible to competitive inhibition of cobalt uptake by low levels of zinc. Although phytoplankton in the Equatorial Pacific are subject to chronic iron-limitation, widespread cobalt scarcity and vulnerability to zinc inhibition observed in culture imply that wild Prochlorococcus are not far from a cobalt-limitation threshold.

Thesis supervisor: Dr. Mak Saito, Associate Scientist with Tenure 


\section{Acknowledgements.}

I am lucky to have benefitted from major financial support of the Saito Lab by the National Science Foundation and the Gordon and Betty Moore Foundation. Specifically, National Science Foundation grants for the Center for Microbial Oceanography Research and Education (CMORE, DBI-0424599), GEOTRACES Pacific and Artic projects (OCE-1233261 and OCE1540254), and OCE-1220484 funded my thesis work. National Science Foundation grants OCE1031271 and OCE-1337780 and Gordon and Betty Moore Foundation grants 3782 and 3934 to the Saito lab also provided instrumentation and funded field expeditions that enabled this work.

In addition to his herculean funding efforts, I am enormously grateful to have had the privilege of trading ideas with Mak over the last 5 years. It will take at least another 5 years to realize how much I have learned from him. As an advisor, Mak is a paragon of patience and encouragement. In no other place on earth would I have been able to do this thesis and it's a credit to Mak that he has the vision and the capability to maintain the lab and populate it with such great scientists.

To that end, I have learned so much from the other members of the Saito Lab. I cannot overstate the effect that Dawn Moran and Matt McIlvin have had on this work. The skills I have learned over the last five years are merely imitations of Dawn's uncompromising commitment to her experiments and Matt's analytical poise and finesse. Erin Bertrand, Kate Mackey, Sarah Bender, Julia Gauglitz, Alysia Cox and Tyler Goepfert have each provided small fortunes worth of culturing tips, trace metal expertise, and general advice. In particular, Tyler's fantastic particulate metal dataset greatly improved Chapter 4 of this work. Not only have Randie Bundy and Abigail Noble helped me become a more thoughtful analyst, but their interest in cobalt has been enormously, existentially validating. I'm glad to have shared the lab with Noelle Held over the last few years, whose optimism and perspective has been a welcome addition to the group.

I'd also like to thank my thesis committee: Liz Kujawinski, Mick Follows and Phoebe Lam, for their diverse perspectives and contributions over the last few years, especially for the attention to detail they gave in their reading of the defendable draft. Same goes for Tristan Horner for chairing my defense and for his enthusiasm and interest. In addition to scientific contributions, the four of you have been really excellent role models of kind and successful scientists that I would be lucky to emulate in the future.

There is a vast network of GEOTRACES-associated people to whom I am indebted. This is only a partial list. The results presented in Chapter 2 would not have been possible without the enormous sampling effort undertaken by Claire Till, Cheryl Zurbrick, Greg Cutter and Geo Smith on the GP16 cruise nor without the vision of Chief Scientists Jim Moffett and Chris German, as well as a lot of people behind the scenes in the GEOTRACES office. I am especially grateful to co-authors Joe Resing, Dan Ohnemus and Ben Twining for sharing their data and expertise, as well as Sara Rauschenberg and Rob Sherrell for their role in collecting particulate samples. Melissa Miller, Susan Becker and the rest of the Ocean Data Facility provided extremely high quality nutrient data in almost real time. More broadly, the Captain, Crew of the Thomas G. Thompson and the GP16 science party also deserve credit, especially Brian Peters, Jim Happell, and Virginie Sanial for providing morale boosts ship-board and on land. 
Jong-Mi Lee provided McLane pump particulate trace metal data from GP16 that was used heavily in Chapter 3. Maeve Lohan and Neil Wyatt shared their unpublished cobalt section from the GA10 cruise which was also used in this chapter. I'd also like to thank Mike Kubicsko and Luca Pini for their assistance in voltammetry.

I am grateful for the mentorship of Carl Lamborg, and for his efforts as Chief Scientist on the Metzyme cruise and the subsequent equator crossing. Giacomo Ditullio and his group provided pigment data and Joe Jennings at the OSU provided nutrient measurements used in Chapter 4. I am also grateful to Alyson Santoro, David Wang, and the captain and crew of the R/V Kilo Moana.

None of the culture experiments would have been possible without access to starter cultures of Prochlorococcus from the Chisholm lab, thanks to Alison Coe. I also wish to thank John Waterbury and Freddie Valois for sharing their culturing expertise and providing space to conduct growth experiments, as well as David Beaudoin for assistance with flow cytometry.

The GEOTRACES workshops on Catalina Island and at Lamont were especially insightful, and helped me think more broadly about my experiments and more warmly to the trace-metal community at large. To this end, I am thankful for Bill Sunda's comments and stories, and to Alessandro Tagliabue's galvanizing interest in the cobalt cycle.

Mary Zawoysky has been a patient and positive presence in Watson and I am grateful for her administrative and baking prowess. Similarly, Sheila Clifford, Mary Murphy, Donna Mortimer, and the Academic Programs office at WHOI deserve a lot of credit for making life in the MC\&G department and as a JP student so smooth. I'd specifically like to acknowledge Julia Westwater and Meg Tivey for being consistently positive presences over the last 5+ years.

I had the enormous privilege of starting the Joint Program with a class of 10 other chemists that enabled a much broader perspective of ocean science than I would have been able to achieve in isolation. Thanks to Greg and Alex for 5+ years of tolerating me as a roommate and filling me with homebrew, Winn and Emily for helping me through the most terrifying parts of Twin Peaks, and Sophie and Sarah for playing softball with me. To that end, Justin Ossolinski deserves a lot of credit for his long tenure as Chemistry Softball Coach. I'd like to thank my instructors at WHOI and MIT for their efforts in teaching, especially Bernhard Peucker-Ehrenbrink and Phil Gschwend for their enthusiasm for geochemistry and, in the latter case, softball. Thanks to Ann Dunlea for being my cobalt-friend, Rene Boiteau for unbridled enthusiasm about all things iron and/or mass spectrometry and/or just about anything else. Thanks to Kathleen Munson and Tristan Kading for helping me feel immediately welcome when I first arrived in Woods Hole, and to Kelsey Poulson-Ellestad, Kristen Whalen, and Shiye Zhao for cohabiting Watson 111.

I would be remiss if I didn't thank Kyrstin Fornace and her dinosaur cartoons and for her limitless support, illustrated or otherwise. Finally, my parents, their dogs, and Ryan have been constant beacons of support, distraction, and friendship. I really hope they know that already. 
Abstract

Acknowledgements

Table of Contents

\begin{tabular}{lrr} 
Chapter 1. Introduction & 11 \\
\hline 1. & A case for cobalt limitation & 11 \\
2. & An incomplete history of cobalt in seawater & 14 \\
3. & References & 16 \\
& Figures & 21
\end{tabular}

Chapter 2. A cobalt plume in the oxygen minimum zone of the Eastern Tropical South Pacific.

1. Introduction 24

2. Methods 26

2.1 Sample collection and handling 26

2.2 Cobalt determination by cathodic stripping voltammetry 26

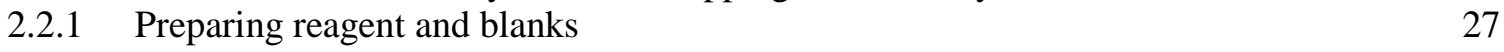

2.2.2 Automated cobalt analyses 28

2.2.3 Signal processing 29

2.2.4 Intercalibration and internal laboratory standard 29

$2.3 \quad$ Particulate metal analyses 30

3 Results 31

3.1 Dissolved Cobalt (dCo) 31

3.2 Particulate Cobalt $\quad 32$

3.3 Labile dissolved cobalt 33

4 Discussion 34

4.1 Processes generating the OMZ cobalt plume in the Eastern South Pacific Ocean 35

4.1.1 Basin-scale remineralization and circulation couple dCo with $\mathrm{O}_{2} \quad 35$

4.1.2 Distinct surface and mesopelagic Co:P relationships 36

4.1.3 Suppression of cobalt scavenging in the OMZ 38

4.2 A major cobalt source from the Peruvian margin 39

4.2.1 Water column signatures of a dCo source 39

4.2.2 Potential redox sensitivity of coastal cobalt sources 41

4.2.3 Comparing coastal sources with the OMZ cobalt plume $\quad 42$

4.2.4 Comparison to atmospheric deposition 43

4.2.5 An inefficient cobalt source in hydrothermal vents 43

4.3 Cobalt scarcity in the euphotic zone 44

4.3.1 The South Pacific Gyre 44

4.3.2 Depletion of labile dissolved cobalt in the Peru Upwelling Ecosystem 45

5 Conclusions $\quad 47$

References $\quad 48$

Tables $\quad 55$

$\begin{array}{ll}\text { Figures } & 57\end{array}$ 
Chapter 3. Cobalt scavenging and mass balance in the global ocean.

Abstract 71

1 Introduction $\quad 71$

2 Methods $\quad 72$

$\begin{array}{lll}2.1 & \text { Radiocarbon data matching procedure } & 72\end{array}$

$\begin{array}{lll}2.2 & \text { Global Cobalt cycle calculations } & 74\end{array}$

$\begin{array}{lll}2.3 & \text { Cobalt composition of sinking particles } & 74\end{array}$

$\begin{array}{lll}2.4 & \text { Isopycnal Scavenging Calculations } & 75\end{array}$

3 Results and Discussion $\quad 78$

$\begin{array}{lll}3.1 & \text { The Marine Co sink } & 78\end{array}$

3.2 Deep ocean scavenging $\quad 80$

3.3 Upper ocean scavenging $\quad 82$

3.3.1 Authigenic cobalt formation in the mesopelagic 82

3.3.2 A remineralization - scavenging framework 83

3.4 Sources of Cobalt to the ocean 88

3.5 A dynamic or stable cobalt cycle? $\quad 90$

4 Conclusions 92

5 References 92

Tables $\quad 99$

Figures 105

$\begin{array}{ll}\text { Supplementary Figures } & 115\end{array}$

Chapter 4. The minimum cobalt and iron requirement of Prochlorococcus: implications for cobalt limitation in the Equatorial Pacific Ocean.

$\begin{array}{llr} & \text { Abstract } & 121 \\ 1 & \text { Introduction } & 121 \\ 2 & \text { Methods } & 123 \\ 2.1 & \text { Culturing } & 123 \\ 2.2 & \text { Preparation of trace-metal clean media } & 124 \\ 2.3 & \text { Measuring Cell Quotas by Inductively Coupled Plasma Mass Spectrometry } & 125 \\ 2.4 & \text { Quantitative Protein measurements } & 126 \\ 2.5 & \text { Dissolved and particulate cobalt distributions in the Equatorial Pacific Ocean. } & 129 \\ 3 & \text { Results } & 131 \\ 3.1 & \text { Iron and cobalt limitation of Prochlorococcus growth } & 131 \\ 3.2 & \text { Quantitative peptide measurements of cobalamin-requiring enzymes } & 132 \\ 3.3 & \text { The distribution of cobalt in the Equatorial Pacific Ocean } & 133 \\ 4 & \text { Discussion } & 136 \\ 4.1 & \text { The Cobalt requirement of marine cyanobacteria } & 136 \\ 4.2 & \text { Minimum iron requirements of Prochlorococcus } \text { MIT9215 } & 139 \\ 4.3 & \text { Potential for Cobalt limitation in Equatorial Pacific Ocean } & 141 \\ 5 & \text { Conclusions } & 143 \\ 6 & \text { References } & 143 \\ & \text { Tables } & 151 \\ & \text { Figures } & 154\end{array}$




\section{Chapter 5. Competitive inhibition of cobalt uptake by zinc}

and manganese in Prochlorococcus MIT9215.

Abstract

Introduction

2 Methods

$2.1 \quad$ Culturing

2.2 Preparation of trace-metal clean media

2.3 Measuring Cell Quotas by ICPMS

3.1 Zinc inhibition of cobalt uptake

3.2 Cobalt uptake inhibition by other metals

3.3 Prochlorococcus metal quotas and uptake experiments.

3.4 Chemical Affinity of Prochlorococcus Metal Transport

4.1 Metal competition in Prochlorococcus cobalt uptake

4.2 Implications for oceanic Prochlorococcus

6 References 188

$\begin{array}{ll}\text { Tables } & 195\end{array}$

$\begin{array}{ll}\text { Figures } & 198\end{array}$

$\begin{array}{ll}\text { Supplementary tables and figures } & 208\end{array}$

\section{Chapter 6. Conclusions}


... and kill my blemishes with cobalt ...

-Don Delillo, Endzone (1986) 


\section{Chapter 1.}

\section{Introduction}

\section{A case for cobalt limitation}

The intrinsic reactivity of transition metals makes them valuable components of biological systems, but this intrinsic reactivity can also render such metals unavailable. In the ocean, the balance between these two chemical trajectories results in a hybrid of nutrient-like and scavenged distributions for iron, cobalt and manganese where microbial uptake in the surface ocean and oxidation and sorption onto particles at depth produce separate concentration minima (Bruland and Lohan, 2003; Noble et al., 2008). Particle scavenging concentrates these metals in marine sediments and depresses dissolved metal:macro-nutrient ratios relative to their biological stoichiometries; without exogenous metal inputs from atmospheric deposition, hydrothermal venting, or terrigenous input, surface phytoplankton in upwelling regions (and elsewhere) can quickly become physiologically stressed for these hybrid metals; their growth, limited (Krishnaswami, 1976; Moore et al., 2013). From these differences in nutrient supply, an estimated $30 \%$ of surface ocean photosynthesis and a perhaps larger fraction of nitrogen fixation are limited by iron availability (Moore et al., 2013).

The least abundant of these hybrid metals, cobalt is unique as the only transition metal that can covalently bond with carbon. To engage in this chemistry, cobalt must be transformed into cobalamin, a >10 step process of ligation, reorganization, and tuning (Rodionov et al., 2003). Cobalamins (including vitamin $B_{12}$ ) enable methyl transfer in methionine biosynthesis, and radical chain initiation required for ribonucleotide reduction to deoxy-ribonucleotides, the building blocks of DNA (Banerjee and Ragsdale, 2003). Marine cyanobacteria have the genetic resources to synthesize cobalamins, (Palenik et al., 2003; Rocap et al., 2003), whereas eukaryotic phytoplankton acquire the completed vitamin from seawater (Bertrand et al., 2012; Droop, 1957), competing with heterotrophic bacteria for uptake (Koch et al., 2011). Analytical advances over the last decade have revealed a surprising diversity in the structure of cobalamins 
(Taga and Walker, 2008; Watanabe et al., 1999). In contrast to humans and other eukaryotes, cyanobacteria actually synthesize the pseudocobalamin molecule, whose lower arm is composed of adenine instead of the dimethyl benzimidazole moiety in vitamin $\mathrm{B}_{12}$ (Figure 1; Heal et al., 2016; Helliwell et al., 2016; Watanabe et al., 1999). While both molecules catalyze the same enzymatic reactions, steric differences due to lower ligand structure may prevent eukaryotic phytoplankton from using pseudocobalamin in vitamin $\mathrm{B}_{12}$-dependent enzymes (Heal et al., 2016; Helliwell et al., 2016). The evolutionary drive for this structural difference is unclear, as are its ecological ramifications.

For many phytoplankton, use of cobalt ion, $\mathrm{Co}^{2+}$, in metalloenzymes may overshadow cobalamin (Sunda and Huntsman, 1995). The size and electron configuration of $\mathrm{Co}^{2+}$ is similar to $\mathrm{Zn}^{2+}$, resulting in cobalt-activation of many zinc proteins (Maret and Vallee, 1993; Maret, 2010; Yee and Morel, 1996). When zinc is scarce or strongly bound to organic ligands in the surface ocean, eukaryotic phytoplankton can use cobalt to activate carbonic anhydrase, maintaining high intracellular $\mathrm{pCO}_{2}$ for undisturbed carbon fixation during periods of fast growth (and leading to extracellular $\mathrm{pCO}_{2}$ drawdown; Sunda and Huntsman, 1995; Yee and Morel, 1996).

Dichotomy of biological cobalt use is mirrored in its chemical speciation in seawater. Based on electrochemical characterization, dissolved cobalt in the oceans is a combination of labile cobalt, which can be bound by synthetic chelators added to seawater, and cobalt complexed by natural organic ligands, which cannot (Figure 2; Ellwood and van den Berg, 2001; Saito and Moffett, 2001). Although the concentration of complexed cobalt species is greater than direct measurements of cobalamins in seawater $(<0.5 \mathrm{pM})$, the cobalt atom in cobalamin is similarly resistant to exchange with strong ligands (Ellwood and van den Berg, 2001; Heal et al., 2016). As such, complexed cobalt may represent cobalamin biosynthetic intermediates and degradation products. Labile cobalt ( $\mathrm{LCo}$ ) is composed of inorganic cobalt species such as $\mathrm{Co}^{2+}$, $\mathrm{CoCl}^{+}, \mathrm{CoCO}_{3}$, etc. - collectively referred to as $\mathrm{Co}^{\prime}-$ as well as cobalt bound to weak ligands. Lower LCo in the deep ocean suggests that both forms are more susceptible to scavenging than the stronger, cobalamin-like cobalt complexes (Figure 2; Noble et al., submitted; Moffett and Ho, 1996). Similarly, depletion of LCo in the surface ocean implies preferential uptake by phytoplankton (Saito and Moffett, 2001).

As vitamin and ion, biological cobalt utilization results in low $\mathrm{pM}$ concentrations in surface waters (Noble et al., 2008; Saito and Moffett, 2002). Furthermore, in two distinct ocean 
regions - a Synechococcus-dominated bloom along the Costa Rica upwelling dome (Saito et al., 2005) and the Prochlorococcus-dominated South Atlantic gyre (Saito and Goepfert, unpublished; Moore et al., 2013) - cobalt addition to surface seawater stimulated chlorophyll production and cyanobacterial growth, indicating that it can be a (co)limiting nutrient for these organisms. Because cobalt use in cyanobacteria is distinct from its role as a zinc substitute in eukaryotic metabolism (Saito et al., 2005; Sunda and Huntsman, 1995), cobalt availability has the potential to serve as a potent determinant of phytoplankton community composition and the resultant export fluxes of carbon and other nutrients. If elevated cobalt does indeed support cyanobacterial growth, the smaller size and absence of protecting mineral shells in these organisms may result in a smaller export flux of carbon from the surface ocean. At a grand scale, cobalt fertilization might be expected to weaken the ocean's biological pump, thereby increasing atmospheric $\mathrm{CO}_{2}$.

In order for cobalt-limitation of phytoplankton to be widespread, phytoplankton demand for this metal must exceed its supply by ocean mixing and external sources. This thesis aims to evaluate this possibility from both geochemical and biological standpoints. The research presented here is organized around two central questions: 1) what controls the amount of cobalt in seawater and how might this be altered? and 2) how much cobalt do phytoplankton need, and can they meet this need given the amount of cobalt presently in seawater?

Chapters 2 and 3 examine the distribution of cobalt on regional and global scales. In both cases, large sources from deoxygenated margins and sinks by oxidative scavenging are emphasized. The dynamic nature of oxygen in the ocean may be a fundamental driver of the cobalt cycle, controlling the amount of cobalt available for phytoplankton use. If climate forces cause deoxygenated waters to shrink, so too may cobalt sources.

Chapters 4 and 5, in turn, examine cobalt demand by Prochlorococcus, an oligotrophic specialist that may be more sensitive to cobalt scarcity than other phytoplankton. In Chapter 4, the minimum cobalt and iron requirements of a Pacific strain of Prochlorococcus is quantified. Despite widespread cobalt scarcity in the Equatorial Pacific, Prochlorococcus populations appear to maintain a high cobalt quota, suggesting that this metal does not limit their growth here, or that any potential biological control by cobalt is overshadowed by chronic ironlimitation. Chapter 5, however, highlights the precarious nature of cobalt uptake by this 
Prochlorococcus strain, which can be inhibited in the presence of low levels of zinc relevant to the open ocean.

\section{A short history of cobalt limitation}

The idea of limitation of growth by cobalt, or at least by cobalamin, is not necessarily new (Droop, 1957), or exclusive to ocean-dwelling life. Pernicious anemia - a disease so named because of its gradual but ultimately ruinous consequences - results from insufficient absorption of cobalamin due to poor diet or the absence of binding factors in the stomach (Rickes et al., 1948a). Insufficient cobalamin leads to a build-up of toxic metabolites (homocysteine, methylmalonate) that manifest through reduced blood cell counts (anemia), psychosis and dementia (Baik and Russel, 1999). Pernicious anemia was fatal before 1920, when it was discovered that daily ingestion of raw liver could stave off symptoms. From liver extract, cobalamin was first purified and found to contain cobalt (Rickes et al., 1948b). Its molecular structure was solved progressively over the next decade (Bonnett et al., 1955; Brink et al., 1954; Hodgkin et al., 1955).

For a discipline that can seem disconnected from biomedical sciences, it is perhaps surprising how quickly oceanographers become interested in cobalamin and its influence on phytoplankton physiology. Between its isolation in 1948 and its structural characterization in 1956, ecologists had already begun to speculate if vitamin $B_{12}$ could influence phytoplankton yields and growth rates (Droop, 1955, 1957; Lewin, 1954). Elements of these early investigations persist today (Bertrand et al., 2007, 2012; Taylor and Sullivan, 2008).

At the same time, the oceanographic behavior of cobalt was being described by investigators that took advantage of parts per million concentrations of metals in sediments, rocks and other solid phases, which could be more confidently detected (Carr and Turekian, 1961; Goldberg and Arrhenius, 1958; Turekian and Imbrie, 1966). From these measurements, it was first realized that cobalt levels are elevated in marine sediments and manganese nodules, and that their high concentrations probably originate from precipitation from seawater (Goldberg and Arrhenius, 1958; Halbach et al., 1983; Krishnaswami, 1976; Manheim, 1986). Follow-up studies suggested that cobalt supply to the ocean from continental weathering was probably sufficient to account for the excess cobalt in marine sediments (Bewers and Yeats P. A., 1977; Kharkar et al., 1968; Krishnaswami, 1976), a first - and mostly correct - glimpse of the ocean's cobalt cycle. 
But without accurate seawater measurements, connecting the biological importance of cobalamin with the geochemical delivery of cobalt remained challenging. Early measurements of cobalt in seawater suggested typical concentrations on the order of $1 \mathrm{nM}, 10-100$ times greater than values accepted today (Goldberg and Arrhenius, 1958; Schutz and Turekian, 1965a, 1965b). If it was known that cobalt concentrations were actually much lower, perhaps an interest in phytoplankton cobalt/cobalamin nutrition would have been sustained.

With one of the first 'reliable' profiles published, Knauer et al. 1982 presented a new view of cobalt in the ocean. Cobalt had low deep water inventories and a rapid biogeochemical cycle. Could it be limiting phytoplankton growth? Their paper draws to a close by acknowledging the potential for cobalt limitation:

"If the Mn-Co similarity is also true for open ocean waters, much lower Co levels $\left(\sim 1.0 \mathrm{ng} \mathrm{L}^{-1}\right)$ can be expected in oligotrophic surface waters, judging by Mn data $\left(\sim 35 \mathrm{ng} \mathrm{L}^{-1}\right)$ reported by Landing and Bruland. Because Co is an important element in many essential biological compounds, notably the central atom of vitamin $\mathrm{B}_{12}$, the low amounts of this element in the environment suggests the possibility of its being a limiting nutrient in some conditions, or at least that the massive amounts $\left(5 \mu \mathrm{g} \mathrm{L}^{-1}\right)$ routinely added to phytoplankton culture media are unnecessary" (Knauer et al., 1982)

In essence, they argue that the biological need for cobalt contrasts with its scarcity in seawater. Overshadowed by the discovery of widespread iron limitation of phytoplankton a few years later, Knauer et al.'s hypothetical threshold of $1 \mathrm{ng}$ Co per liter (17 pM) was soon crossed, without much excitement:

"For example, Co levels fall to less than $10 \mathrm{pmol} \mathrm{kg}^{-1}$ at Sta. T-5 south of the Gulf of Alaska; nevertheless, normal $\mathrm{NO}_{3}$ depletion is observed. In comparison, $\mathrm{Co}$ concentrations at $\mathrm{NO}_{3}$-rich Stations T-6 and T-7 exceed $25 \mathrm{pmol} \mathrm{kg}^{-1}$. This suggests that these amounts of Co are probably sufficient for the microbial synthesis of vitamin $B_{12 .}$ " (Martin et al., 1989)

Thus, the fact that cobalt concentrations in open ocean waters are lower than coastal waters was taken as evidence for the feasibility of cobalt limitation by Knauer et al. (1982) but the fact that cobalt concentrations are able to be drawn down so low is taken as evidence for the absence of cobalt limitation by Martin et al. (1989) [N.B. John Martin is an author on both papers]. The same gradient in Co concentration, then, produces opposite conclusions. Ultimately, these conflicting interpretations arise because the amount of cobalt that phytoplankton need to grow 
was not defined, nor were the chemical species and/or concentration thresholds relevant to phytoplankton uptake.

Developing methods to assess the chemical speciation of cobalt in seawater (Donat and Bruland, 1988; Ellwood and van den Berg, 2001; Saito and Moffett, 2001) and examinations of the breadth and sensitivity of cobalt (and $\mathrm{B}_{12}$ ) requirements across phytoplankton species (Bertrand et al., 2012; Saito and Goepfert, 2008; Saito et al., 2002; Sunda and Huntsman, 1995), chipped away at this ambiguity, as did the increased frequency (and quality) of cobalt measurements in seawater (Bown et al., 2011; Dulaquais et al., 2014; Noble et al., 2012).

The last decade has witnessed the onset of the GEOTRACES program, and with it, thousands of new measurements of cobalt in seawater to add to the few hundred measurements published previously. The next 10 years will bring several thousands more. At this midway point - having the benefit of all of this new information but the promise of even more - perhaps this thesis provides an occasion to return to this elusive question: Are some phytoplankton limited by cobalt? What follows is an incomplete, but earnest attempt to answer.

\section{References}

Baik, H. W. and Russel, R. M.: Vitamin B 12 deficiency in the elderly, Annu. Rev. Nutr., 19, 357-77, doi:10.1146/annurev.nutr.19.1.357, 1999.

Banerjee, R. and Ragsdale, S. W.: The Many Faces of Vitamin B 12 : Catalysis by CobalaminDependent Enzymes1, Annu. Rev. Biochem., 72(1), 209-247, doi:10.1146/annurev.biochem.72.121801.161828, 2003.

Bertrand, E. M., Saito, M. A., Rose, J. M., Riesselman, C. R., Lohan, M. C., Noble, A. E., Lee, P. A. and DiTullio, G. R.: Vitamin B 12 and iron colimitation of phytoplankton growth in the Ross Sea, Limnol. Oceanogr., 52(3), 1079-1093 [online] Available from: http://www.jstor.org/stable/4499680 (Accessed 10 September 2011), 2007.

Bertrand, E. M., Allen, A. E., Dupont, C. L., Norden-Krichmar, T. M., Bai, J., Valas, R. E. and Saito, M. a: Influence of cobalamin scarcity on diatom molecular physiology and identification of a cobalamin acquisition protein., Proc. Natl. Acad. Sci. U. S. A., 109(26), E1762-71, doi:10.1073/pnas.1201731109, 2012.

Bewers, J. M. and Yeats P. A.: Oceanic residence times of trace metals, Nature, 268(18), 595598, 1977.

Bonnett, R., Cannon, J. R., Johnson, A. W., Sutherland, I., Todd, A. R. and Smith, E. L.: The structure of vitamin B12 and its hexacarboxylic acid degradation product., Nature, 176, 328-330, 1955.

Bown, J., Boye, M., Baker, A., Duvieilbourg, E., Lacan, F., Le Moigne, F., Planchon, F., Speich, 
S. and Nelson, D. M.: The biogeochemical cycle of dissolved cobalt in the Atlantic and the Southern Ocean south off the coast of South Africa, Mar. Chem., 126(1-4), 193-206, doi:10.1016/j.marchem.2011.03.008, 2011.

Brink, C., Hodgkin, D. C., Lindsey, J., Pickworth, J., Robertson, J. H. and WHITE, J. G.: X-ray crystallographic evidence on the structure of vitamin B12., Nature, 174, 1169-1171, 1954.

Bruland, K. W. and Lohan, M. C.: Controls of Trace Metals in Seawater, Treatise Geochemistry Second Ed., 6, 23-47, doi:10.1016/B978-0-08-095975-7.00602-1, 2003.

Carr, M. . and Turekian, K. .: The geochesmitry of cobalt, 1Geochimica Cosmochim. Acta, 23, 9-60, doi:10.1016/0016-7037(61)90087-4, 1961.

Donat, J. R. and Bruland, K. W.: Direct determination of dissolved cobalt and nickel in seawater by differential pulse cathodic stripping voltammetry preceded by adsorptive collection of cyclohexane-1,2-dione dioxime complexes, Anal. Chem., 60(3), 240-244, doi:10.1021/ac00154a011, 1988.

Droop, M. R.: A pelagic marine diatom requiring cobalamin, J. Mar. Biol. Assoc. United Kingdom, 34(02), 229-231, 1955.

Droop, M. R.: Vitamin B12 in marine ecology, Nature, 180(4594), 1041-1042, doi:10.1038/1801041a0, 1957.

Dulaquais, G., Boye, M., Rijkenberg, M. J. a and Carton, X.: Physical and remineralization processes govern the cobalt distribution in the deep western Atlantic Ocean, Biogeosciences, 11(6), 1561-1580, doi:10.5194/bg-11-1561-2014, 2014.

Ellwood, M. J. and van den Berg, C. M. .: Determination of organic complexation of cobalt in seawater by cathodic stripping voltammetry, Mar. Chem., 75(1-2), 33-47, doi:10.1016/S03044203(01)00024-X, 2001.

Goldberg, E. D. and Arrhenius, G. O. S.: Chemistry of Pacific pelagic sediments, Geochim. Cosmochim. Acta, 13(2-3), 153-212, doi:10.1016/0016-7037(58)90046-2, 1958.

Halbach, P., Segl, M., Puteanus, D. and Mangini, A.: Co-fluxes and growth rates in ferromanganes deposits from central Pacific seamount seas, Nature, 304, 716-719, 1983.

Heal, K. R., Qin, W., Ribalet, F., Bertagnolli, A. D., Coyote-Maestas, W., Hmelo, L. R., Moffett, J. W., Devol, A. H., Armbrust, E. V., Stahl, D. A. and Ingalls, A. E.: Two distinct pools of B 12 analogs reveal community interdependencies in the ocean, Proc. Natl. Acad. Sci., 114(2), 201608462, doi:10.1073/pnas.1608462114, 2016.

Helliwell, K. E., Lawrence, A. D., Holzer, A., Kudahl, U. J., Sasso, S., Kräutler, B., Scanlan, D. J., Warren, M. J. and Smith, A. G.: Cyanobacteria and Eukaryotic Algae Use Different Chemical Variants of Vitamin B12, Curr. Biol., 26(8), 999-1008, doi:10.1016/j.cub.2016.02.041, 2016.

Hodgkin, D. C., Pickworth, J., Robertson, J. H., TRUEBLOOD, K. N., PROSEN, R. J. and WHITE, J. G.: The crystal structure of the hexacarboxylic acid derived from B12 and the molecular structure of the vitamin., Nature, 176, 325-328, 1955.

Kharkar, D. P., Turekian, K. K. and Bertine, K. K.: Stream supply of dissolved silver, molybdenum, antimony, selenium, chromium, cobalt, rubidium and cesium to the oceans, Geochim. Cosmochim. Acta, 32, 285-298, 1968. 
Knauer, G. a., Martin, J. H. and Gordon, R. M.: Cobalt in north-east Pacific waters, Nature, 297(5861), 49-51, doi:10.1038/297049a0, 1982.

Koch, F., Alejandra Marcoval, M., Panzeca, C., Bruland, K. W., Sañudo-Wilhelmy, S. a. and Gobler, C. J.: The effect of vitamin B12 on phytoplankton growth and community structure in the Gulf of Alaska, Limnol. Oceanogr., 56(3), 1023-1034, doi:10.4319/lo.2011.56.3.1023, 2011.

Krishnaswami, S.: Authigenic transition elements in Pacific pelagic clays, Geochim. Cosmochim. Acta, 40(4), 425-434, doi:10.1016/0016-7037(76)90007-7, 1976.

Lewin, R. A.: A Marine Stichococcus sp. which requires Vitamin B12 (Cobalamin), J. gen. Microbiol., 10, 93-96, 1954.

Manheim, F. T.: Marine Cobalt resources, Science (80-. )., 1986.

Maret, W.: Metalloproteomics, metalloproteomes, and the annotation of metalloproteins., Metallomics, 2(2), 117-25, doi:10.1039/b915804a, 2010.

Maret, W. and Vallee, B. L.: Cobalt as probe and label of proteins, Methods Enzymol., 226(1973), 52-70, doi:10.1016/0076-6879(93)26005-T, 1993.

Martin, J. H., Gordon, R. M., Fitzwater, S. and Broenkow, W. W.: Vertex: phytoplankton/iron studies in the Gulf of Alaska, Deep Sea Res. Part A. Oceanogr. Res. Pap., 36(5), 649-680, doi:10.1016/0198-0149(89)90144-1, 1989.

Moffett, J. W. and Ho, J.: Oxidation of cobalt and manganese in seawater via a common microbially catalyzed pathway, Geochim. Cosmochim. Acta, 60(18), 3415-3424, doi:10.1016/0016-7037(96)00176-7, 1996.

Moore, C. M., Mills, M. M., Arrigo, K. R., Berman-Frank, I., Bopp, L., Boyd, P. W., Galbraith, E. D., Geider, R. J., Guieu, C., Jaccard, S. L., Jickells, T. D., La Roche, J., Lenton, T. M., Mahowald, N. M., Marañón, E., Marinov, I., Moore, J. K., Nakatsuka, T., Oschlies, A., Saito, M. a, Thingstad, T. F., Tsuda, A. and Ulloa, O.: Processes and patterns of oceanic nutrient limitation, Nat. Geosci., 6(9), 701-710, doi:10.1038/ngeo1765, 2013.

Noble, A. E., Saito, M. A., Maiti, K. and Benitez-Nelson, C. R.: Cobalt, manganese, and iron near the Hawaiian Islands: A potential concentrating mechanism for cobalt within a cyclonic eddy and implications for the hybrid-type trace metals, Deep Sea Res. Part II Top. Stud. Oceanogr., 55(10-13), 1473-1490, doi:10.1016/j.dsr2.2008.02.010, 2008.

Noble, A. E., Lamborg, C. H., Ohnemus, D. C., Lam, P. J., Goepfert, T. J., Measures, C. I., Frame, C. H., Casciotti, K. L., DiTullio, G. R., Jennings, J. and Saito, M. A.: Basin-scale inputs of cobalt, iron, and manganese from the Benguela-Angola front to the South Atlantic Ocean, Limnol. Oceanogr., 57(4), 989-1010, doi:10.4319/lo.2012.57.4.0989, 2012.

Palenik, B., Brahamsha, B., Larimer, F. W., Land, M., Hauser, L., Chain, P., Lamerdin, J., Regala, W., Allen, E. E. and McCarren, J.: The genome of a motile marine Synechococcus, Nature, 424(6952), 1037-1042, 2003.

Rickes, E. L., Brink, N. G., Koniuszy, F. R., Wood, T. R. and Folkers, K.: Crystalline vitamin B12., Am. Assoc. Adv. Sci. Sci., 107, 396-397, 1948a.

Rickes, E. L., Brink, N. G., KONIUSZY, P. R., Wood, T. R. and Folkers, K.: Vitamin B12, a cobalt complex., Am. Assoc. Adv. Sci. Sci., 108, 1948 b. 
Rocap, G., Larimer, F. W., Lamerdin, J., Malfatti, S., Chain, P., Ahlgren, N. a, Arellano, A., Coleman, M., Hauser, L., Hess, W. R., Johnson, Z. I., Land, M., Lindell, D., Post, A. F., Regala, W., Shah, M., Shaw, S. L., Steglich, C., Sullivan, M. B., Ting, C. S., Tolonen, A., Webb, E. a, Zinser, E. R. and Chisholm, S. W.: Genome divergence in two Prochlorococcus ecotypes reflects oceanic niche differentiation., Nature, 424(6952), 1042-7, doi:10.1038/nature01947, 2003.

Rodionov, D. a, Vitreschak, A. G., Mironov, A. a and Gelfand, M. S.: Comparative genomics of the vitamin B12 metabolism and regulation in prokaryotes., J. Biol. Chem., 278(42), 41148-59, doi:10.1074/jbc.M305837200, 2003.

Saito, M. A. and Goepfert, T. J.: Zinc-cobalt colimitation of Phaeocystis antarctica, Limnol. Oceanogr., 53(1), 266-275, doi:10.4319/lo.2008.53.1.0266, 2008.

Saito, M. A. and Moffett, J. W.: Complexation of cobalt by natural organic ligands in the Sargasso Sea as determined by a new high-sensitivity electrochemical cobalt speciation method suitable for open ocean work, Mar. Chem., 75(1-2), 49-68, doi:10.1016/S0304-4203(01)00025$1,2001$.

Saito, M. A. and Moffett, J. W.: Temporal and spatial variability of cobalt in the Atlantic Ocean, Geochim. Cosmochim. Acta, 66(11), 1943-1953, doi:10.1016/S0016-7037(02)00829-3, 2002.

Saito, M. A., Moffett, J. W., Chisholm, S. W. and Waterbury, J. B.: Cobalt limitation and uptake in Prochlorococcus, Limnol. Oceanogr., 47(6), 1629-1636, doi:10.4319/lo.2002.47.6.1629, 2002.

Saito, M. A., Rocap, G. and Moffett, J. W.: Production of cobalt binding ligands in a Synechococcus feature at the Costa Rica upwelling dome, Limnol. Oceanogr., 50(1), 279-290, doi:10.4319/lo.2005.50.1.0279, 2005.

Schutz, D. F. and Turekian, K. K.: The distribution of cobalt, nickel, and silver in the ocean water profiles around pacific antarctica, J. Geophys. Res., 70(22), doi:10.1029/JZ070i022p05519, 1965a.

Schutz, D. F. and Turekian, K. K.: The investigation of the geographical and vertical distribution of several trace elements in sea water using neutron activation analysis, Geochim. Cosmochim. Acta, 29(4), 259-313, doi:10.1016/0016-7037(65)90022-0, 1965 b.

Sunda, W. G. and Huntsman, S. A.: Cobalt and zinc interreplacement in marine phytoplankton: Biological and geochemical implications, Limnol. Oceanogr., 40(8), 1404-1417, doi:10.4319/lo.1995.40.8.1404, 1995.

Taga, M. E. and Walker, G. C.: Pseudo-B12 joins the cofactor family, J. Bacteriol., 190(4), 1157-1159, doi:10.1128/JB.01892-07, 2008.

Taylor, G. T. and Sullivan, C. W.: Vitamin B12 and cobalt cycling among diatoms and bacteria in Antarctic sea ice microbial communities, Limnol. Oceanogr., 53(5), 1862-1877, doi:10.4319/lo.2008.53.5.1862, 2008.

Turekian, K. and Imbrie, J.: The distribution of trace elements in deep-sea sediments of the Atlantic Ocean, Earth Planet. Sci. Lett., 1, 161-168 [online] Available from: http://www.sciencedirect.com/science/article/pii/0012821X6690063X, 1966.

Watanabe, F., Katsura, H., Takenaka, S., Fujita, T., Abe, K., Tamura, Y., Nakatsuka, T. and Nakano, Y.: Pseudovitamin B12 is the predominant cobamide of an algal health food, spirulina 
tablets, J. Agric. Food Chem., 47(11), 4736-4741, doi:10.1021/jf990541b, 1999.

Yee, D. and Morel, F. M. M.: In vivo substitution of zinc by cobalt in carbonic anhydrase of a marine diatom, Limnol. Oceanogr., 41(3), 573-577, doi:10.4319/lo.1996.41.3.0573, 1996. 

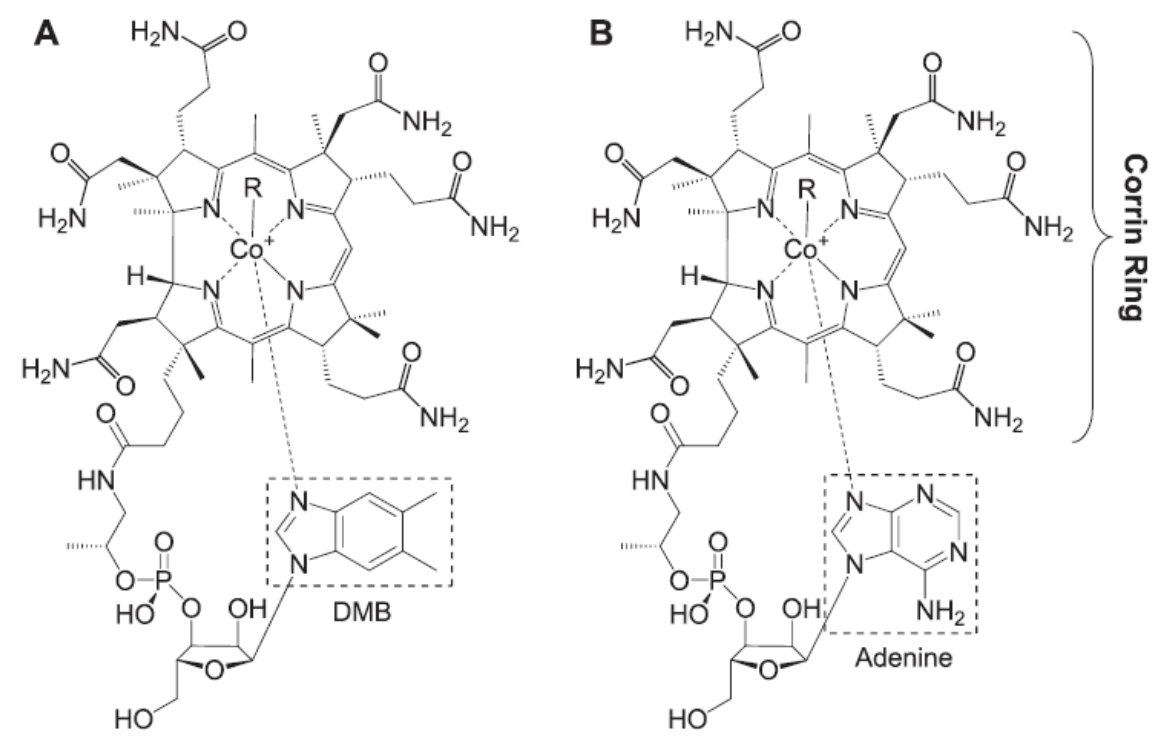

Figure 1. Chemical structures of cobalamin $\left(A\right.$, vitamin $\left.B_{12}\right)$ and pseudocobalamin $(B$, pseudoB ${ }_{12}$ ). Both molecules have identical corrin ring structures, but differ in the composition of the lower ligand. The lower ligand of cobalamin contains a dimethyl benzimidazole (DMB) group while pseudocobalamin contains an adenine. This figure originally appeared in Taga and Walker (2008) and is published in the public domain. 


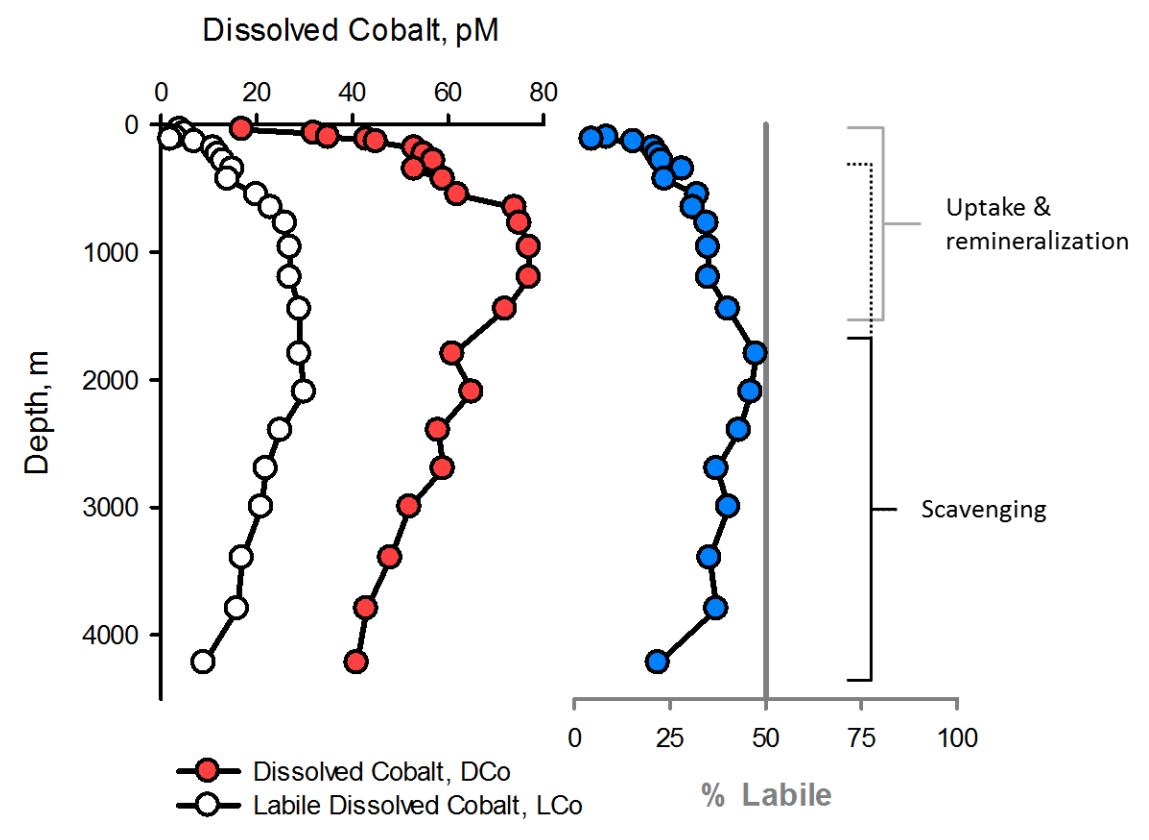

Figure 2. A representative profile of dissolved cobalt (dCo, red circles) and labile dissolved cobalt (LCo, white circles) from the North Atlantic Ocean. The cobalt profile is influenced by nutrient cycling in the upper ocean and scavenging at depth. Both of these processes preferentially act on LCo, resulting in a lower percentage of LCo at the ocean surface and bottom (blue circles). The profile shown is from Station 14 on the GA03 cruise at $27.6{ }^{\circ} \mathrm{N}$ and $49.6^{\circ} \mathrm{W}$, from Noble et al. submitted. Uncertainty in the depth horizon of cobalt scavenging is noted in the dotted bracket. 


\title{
Chapter 2.
}

\section{A dissolved cobalt plume in the oxygen minimum zone of the Eastern Tropical South Pacific}

This chapter was published open access in Biogeosciences by Copernicus Publications in 2016 and is reprinted here.

Hawco, N.J., Ohnemus, D.C., Resing, J.A., Twining, B. S., Saito, M. A.. 2016. A dissolved cobalt plume in the oxygen minimum zone of the Eastern Tropical South Pacific.

Biogeosciences, 13, 5697-5717, 2016. doi:10.5194/bg-13-5697-2016 @ Authors 2016.

\begin{abstract}
Cobalt is a nutrient to phytoplankton, but knowledge about its biogeochemical cycling is limited, especially in the Pacific Ocean. Here, we report sections of dissolved cobalt and labile dissolved cobalt from the US GEOTRACES GP16 transect in the South Pacific. The cobalt distribution is closely tied to the extent and intensity of the oxygen minimum zone in the eastern South Pacific with highest concentrations measured at the oxycline near the Peru margin. Below $200 \mathrm{~m}$, remineralization and circulation produce an inverse relationship between cobalt and dissolved oxygen that extends throughout the basin. Within the oxygen minimum zone, elevated concentrations of labile cobalt are generated by input from coastal sources and reduced scavenging at low $\mathrm{O}_{2}$. As these high cobalt waters are upwelled and advected offshore, phytoplankton export returns cobalt to low-oxygen water masses underneath. West of the Peru upwelling region, dissolved cobalt is less than $10 \mathrm{pM}$ in the euphotic zone and strongly bound by organic ligands. Because the cobalt nutricline within the South Pacific gyre is deeper than in oligotrophic regions in the North and South Atlantic, cobalt involved in sustaining phytoplankton productivity in the gyre is heavily recycled and ultimately arrives from lateral transport of upwelled waters from the eastern margin. In contrast to large coastal inputs, atmospheric deposition and hydrothermal vents along the Eastern Pacific Rise appear to be minor sources of cobalt. Overall, these results demonstrate that oxygen biogeochemistry exerts a strong influence on cobalt cycling.
\end{abstract}




\section{Introduction}

Cobalt is the least abundant inorganic nutrient in seawater and its scarcity may affect phytoplankton growth in certain regions (Moore et al., 2013). In the high macronutrient waters of the Costa Rica upwelling dome, for instance, $\mathrm{Co}$ and iron (Fe) amendments to surface seawater increased phytoplankton production more than Fe alone, promoting growth of the cyanobacterium Synechococcus (Ahlgren et al., 2014; Saito et al., 2005). While eukaryotic phytoplankton mainly use cobalt to compensate for insufficient zinc (Sunda and Huntsman, 1995), populating the same enzymes with either metal (Yee and Morel, 1996), marine cyanobacteria have an absolute growth requirement for Co that cannot be substituted, which suggests they may be more prone to limitation (Saito et al., 2002). Yet, the extent to which their growth in situ is affected by cobalt scarcity ultimately depends on the processes that add Co to, or remove it from, the surface ocean relative to other limiting nutrients.

Biological cycling of dissolved cobalt $(\mathrm{dCo})$ is apparent in vertical profiles, showing uptake and export in the surface and regeneration in the thermocline (Bown et al., 2011; Dulaquais et al., 2014a; Noble et al., 2012). While dCo in the euphotic zone can be entirely bound by strong organic ligands, a substantial portion of subsurface dCo is unbound and labile (10-50 \%, Bown et al., 2012; Ellwood and van den Berg, 2001; Saito and Moffett, 2001; Saito et al., 2005) and therefore vulnerable to scavenging (Moffett and Ho, 1996). The similar ionic radii and redox potentials of cobalt and manganese $(\mathrm{Mn})$ cause dCo to be actively incorporated into bacterially produced Mn-oxides, which sink from the water column and accumulate in marine sediments (Cowen and Bruland, 1985; Moffett and Ho, 1996; Swanner et al., 2014). Below the euphotic zone, the persistence of labile dissolved cobalt (LCo) throughout the Atlantic indicates that scavenging of dCo, unlike Fe, is slow (Noble et al., 2012). On timescales of ocean circulation, however, scavenging is responsible for decreasing dCo concentrations with depth and for the low ratio between $\mathrm{dCo}$ and macronutrients in deep waters relative to phytoplankton biomass (Moore et al., 2013). As these deep waters are repackaged into thermocline water masses and eventually brought to the surface (Sarmiento et al., 2011), the upper ocean would become depleted in cobalt - as well as other hybrid metals like Fe and Mn - without external sources that keep pace with scavenging (Bruland and Lohan, 2003; Noble et al., 2008).

Yet, the nature of marine cobalt sources is uncertain. In zonal sections of the North and South Atlantic, sources appear to be concentrated along continental margins (Noble and Saito, in 
prep; Noble et al., 2012). In the western Atlantic, dCo concentrations exceeding 100 pM were associated with the flow of Upper Labrador Seawater, likely gained through intense sediment resuspension along the shelf or input prior to subduction (Noble and Saito, In prep). dCo in fresh and estuarine waters can be 100-1000x greater than seawater (Gaillardet et al., 2003; Knauer et al., 1982; Tovar-Sánchez et al., 2004) and Co is less prone to flocculation in estuaries than other metals (Sholkovitz and Copland, 1982). Terrigenous inputs from the American continent can be clearly seen in lower salinity surface waters influenced by the Gulf Stream (Noble and Saito, in prep; Saito and Moffett, 2002) and Amazon discharge (Dulaquais et al., 2014b). Yet, in both the North and South Atlantic, a much larger dCo plume was associated with the oxygen minimum zones along the Mauritanian and Namibian coasts (Noble and Saito, in prep, Noble et al., 2012). Although these waters are not anoxic, the dCo plumes imply that $\mathrm{O}_{2}$ over the continental shelf is sufficiently low that reductive dissolution of $\mathrm{Mn}$ and Fe oxides in sediments releases a large flux of dCo to the water column (Heggie and Lewis, 1984; Sundby et al., 1986). Drawing from large inventories in the Atlantic OMZs, upwelling along eastern margins provides a large dCo flux to the surface ocean. While surface dCo maxima from atmospheric deposition generally do not appear in vertical profiles, this process may be important for regions that are isolated from continental input or receive very high levels of dust (e.g. the Sargasso Sea, Dulaquais et al., 2014a; Shelley et al., 2012).

To date, sectional datasets for dCo have been confined to the Atlantic and, as such, our understanding of cobalt cycling may be biased by the dominant processes occurring there. In comparison, the South Pacific receives considerably less dust deposition and river input (Mahowald et al., 2005; Milliman and Farnsworth, 2011), but hosts a much larger and more reducing oxygen minimum zone. Surface transects off Peru and the Costa Rica Dome suggest a large source from upwelling (Ahlgren et al., 2014; Saito et al., 2004, 2005); however, profiles in the tropical Pacific are sparse (Noble et al., 2008; Saito et al., 2014). We measured the concentration of dissolved cobalt and labile dissolved cobalt in over 750 samples collected onboard the 2013 US GEOTRACES GP16 expedition across the South Pacific along $12^{\circ} \mathrm{S}$, intersecting coastal upwelling along the Peru margin, hydrothermal venting over the East Pacific Rise, and oligotrophic conditions near Polynesia (Fig. 1). Across this section, the distribution of $\mathrm{dCo}$ and LCo follow the intensity of the oxygen minimum zone, with highest concentrations near 
the South American shelf and low concentrations in both deep waters and oligotrophic surface waters, matching OMZ-associated plumes observed in the Atlantic.

\section{Methods}

\subsection{Sample collection and handling}

Sampling on GP16 was conducted with a 24-position trace metal clean titanium rosette attached to a non-metallic Kevlar cable designed for the U.S. GEOTRACES program (Cutter and Bruland, 2012). An additional sample was collected from a surface towfish at each station. Subsamples were collected in a Class-100 sampling van from 12 L Go-Flo bottles (General Oceanics) and passed through 0.2 $\mathrm{MM}$ Acropack filters (Pall). All bottles were rinsed 3x with sample seawater before being filled entirely, leaving no headspace. For samples analyzed at sea, both dissolved and labile cobalt were measured from the same bottle. All samples were kept refrigerated at $4^{\circ} \mathrm{C}$ until analysis in a HEPA filtered clean van. All of the LCo samples and more than $90 \%$ of dCo samples were analyzed at sea. Samples not analyzed at sea were preserved for dCo immediately after sampling using metal-free gas adsorbing satchels (Mitsubishi Gas Chemical, model RP-3K), using 3-4 satchels per 6 seawater samples. Gas-impermeable plastic bags (Ampac) were heat sealed and were hand carried directly to Woods Hole at $4^{\circ} \mathrm{C}$ following disembarkation.

\subsection{Cobalt determination by cathodic stripping voltammetry}

$\mathrm{dCo}$ and LCo were measured using a cathodic stripping voltammetry (CSV) method optimized for organic speciation by Saito and Moffett, 2001. This method relies on the complexation of inorganic Co species by a strong synthetic ligand, dimethylglyoxime (DMG, $\mathrm{K}^{\text {cond }}=10^{11.5 \pm 0.3}$, which forms a bis-complex, $\mathrm{Co}(\mathrm{DMG})_{2}$, with $\mathrm{Co}^{2+}$ that readily absorbs to a hanging mercury drop (Saito and Moffett, 2001). The Co(DMG) 2 complex is measured following a fast, $10 \mathrm{~V} \mathrm{~s}^{-1}$ sweep that reduces both the $\mathrm{Co}(\mathrm{II})$ to $\mathrm{Co}(0)$ and the DMG to 2,3bis(hydroxylamino)butane, producing an 8-10 electron decrease in current for each $\mathrm{Co}(\mathrm{DMG})_{2}$ complex (Baxter et al., 1998). The height of the $\mathrm{Co}(\mathrm{DMG})_{2}$ reduction peak at $-1.15 \mathrm{~V}$ is directly proportional to the Co concentration.

Triplicate scans of the seawater sample were followed by four standard cobalt additions (25 pM per addition) and the slope of their linear regression (mean $\mathrm{R}^{2}=0.998$ ) was used to 
calculate the sample specific sensitivity (in $\mathrm{nA} \mathrm{pM}^{-1}$ ). The cobalt concentration was determined by dividing the mean of the three baseline peaks by the sensitivity, and correcting for reagent volume. The average deviation for these triplicate scans was $1.5 \mathrm{pM}$.

dCo analyses were conducted after a 1-hour UV oxidation procedure to remove strong organic ligands that prevent DMG from binding Co. UV digestion was performed in $15 \mathrm{~mL}$ quartz glass tubes using a Metrohm 705 UV digester (Metrohm USA). Temperature was maintained below $20^{\circ} \mathrm{C}$ to minimize evaporation losses. After UV digestion, $11 \mathrm{~mL}$ of sample was pipetted into $15 \mathrm{~mL}$ polypropylene tubes and DMG and a buffering agent, EPPS, were added to final concentrations of $400 \mu \mathrm{M}$ and $3.8 \mathrm{mM}$, respectively. $8.5 \mathrm{~mL}$ of sample solution was added to a Teflon analysis cup and mixed with $1.5 \mathrm{~mL}$ of $1.5 \mathrm{M} \mathrm{NaNO}_{2}$, making a final analysis volume of $10 \mathrm{~mL}$.

LCo was measured after $>8$ hour incubation of $11 \mathrm{~mL}$ of seawater with $400 \mu \mathrm{M}$ DMG in a Teflon vial. LCo is therefore the concentration that will readily exchange with DMG. After this time, the sample was poured into an autosampler-compatible $15 \mathrm{~mL}$ poly-propylene tube (separate from those used for dCo analyses) and EPPS was added to $3.8 \mathrm{mM}$.

\subsubsection{Preparing reagent and blanks}

All bottles and sample tubes were soaked for $>1$ week in the acidic detergent Citranox, rinsed thoroughly with $18.2 \mathrm{M} \Omega$ water (Millipore), filled with $10 \%$ trace metal grade HCl (J.T. Baker) to soak for 10 days, and rinsed thoroughly with 10 mM TM-grade HCl. DMG (SigmaAldrich) was purified by recrystallization in a $1 \mathrm{mM}$ EDTA solution (Sigma-Aldrich). Crystals were filtered, dried, and dissolved in HPLC grade methanol to a concentration of 0.1 M (Saito and Moffett, 2001). EPPS (Fischer) and Sodium Nitrite (Millipore) were both dissolved in Milli$\mathrm{Q}$ water to $0.5 \mathrm{M}$ and $1.5 \mathrm{M}$, respectively, and treated with separate batches of thoroughly cleaned Chelex-100 beads (Bio-Rad) to remove background Co and Ni (Price et al., 1989). Standard additions of cobalt were generated by diluting a $1 \mathrm{ppm}$ certified reference standard (SPEX Certiprep) with $10 \mathrm{mM} \mathrm{HCl}$ to a concentration of $5.00 \mathrm{nM}$. $50 \mu \mathrm{l}$ of this solution was added to the $10 \mathrm{~mL}$ sample volume for each standard addition ( $25 \mathrm{pM}$ addition).

To determine reagent blanks, Co-free seawater was generated by treating UV-seawater with cleaned Chelex-100 beads. The seawater was then UV digested a second time to remove any ligands leached during Chelex treatment. Any dCo measured in the Chelexed seawater 
derives from addition of Co from analytical reagents. The mean blank for at sea analysis was consistently low: $3.7 \pm 1.2 \mathrm{pM}(\mathrm{n}=28)$. For analyses at Woods Hole, mean blank was $4.7 \pm 1.4$ pM $(n=12)$. Blanks were subtracted from all measured values. Detection limits were calculated as triple the standard deviation of the blank: $3.6 \mathrm{pM}$ for at-sea analyses and $4.2 \mathrm{pM}$ for samples measured in Woods Hole.

\subsubsection{Automated cobalt analyses}

To accommodate a greater number of samples, our previous workflow (Noble et al., 2008) was modified to incorporate fully automated sample analyses using the Metrohm 858 Sample Processor autosampler. All measurements were performed using an Eco-Chemie $\mu$ AutolabIII system connected to a Metrohm 663 VA stand. A hanging drop mercury electrode (Metrohm) was set to semi-hanging drop mode and accompanied by a $3 \mathrm{M} \mathrm{KCl} / \mathrm{AgCl}$ reference electrode and glassy carbon auxiliary electrode. Scheduling and data acquisition were controlled using NOVA 1.8 software (Metrohm Autolab B.V). Automated delivery of seawater, sodium nitrite, and Co standard to the analysis cup was accomplished by three dedicated Dosino 800 burettes (Metrohm). Sample volume was increased to allow $\sim 2 \mathrm{~mL}$ for conditioning tubing and analysis cup prior of sample delivery.

Tubes containing $11 \mathrm{~mL}$ seawater, DMG, and EPPS were inverted several times and placed onto a sampling rack where $8.5 \mathrm{~mL}$ of the mixture was dosed into the Teflon analysis cup. $1.5 \mathrm{~mL}$ of $1.5 \mathrm{M}$ sodium nitrite was added directly to the sample cup. Samples were purged with high-purity $\mathrm{N}_{2}(>99.99 \%)$ for $180 \mathrm{~s}$ and then conditioned for $90 \mathrm{~s}$ at $-0.6 \mathrm{~V}$. Scan sweeps were run at $10 \mathrm{~V} \mathrm{~s}^{-1}$ from $-0.6 \mathrm{~V}$ to $-1.4 \mathrm{~V}$. Before each analysis, the sample cup was rinsed fully with Milli-Q water and $1 \mathrm{~mL}$ sample before measurement. Between uses, autosampler tubes, quartz vials, and Teflon cups were rinsed with $10 \mathrm{mM} \mathrm{HCl}, 18.2 \mathrm{M} \Omega$ water, and 1-2 $\mathrm{mL}$ of new sample. The autosampler uptake line was rinsed with $10 \mathrm{mM} \mathrm{HCl}$ and $18.2 \mathrm{M} \Omega$ water when transitioning from LCo analyses to dCo analyses.

We noticed a decrease in sensitivity of preserved samples relative to those analyzed at sea, possibly caused by an increase in the sample $\mathrm{pH}$ during storage. Sensitivity was restored by doubling the concentration of our buffering agent, EPPS, in the sample to a final concentration of $7.6 \mathrm{mM}$. We tested a broad range of EPPS additions in UV seawater and found the cobalt concentration unchanged while the variance between triplicate scans was reduced markedly by 
the increase in sensitivity (data not shown). We tentatively attribute this decrease in sensitivity in preserved samples to $\mathrm{CO}_{2}$ adsorption by gas satchels, which would increase sample $\mathrm{pH}$.

\subsubsection{Signal processing}

Analyses conducted at sea were characterized with a mild to moderate electrical interference that mandated additional processing before peak height could be reliably measured (Fig. 2). We opted for a simplified least squared fitting routine included in the NOVA software package that conducts a 15-point weighted moving average - equivalent to a $36.9 \mathrm{mV}$ window according to a $2^{\text {nd }}$ order polynomial. This method did not distort measured peak height when noise was low (Fig. 2a, b). A small fraction of scans $(\sim 3 \%)$ were not adequately fit using this routine and were instead smoothed using a 9-point linear moving average $(22.1 \mathrm{mV}$ window, Fig. 2c), also included in NOVA. For all samples, peak height was measured manually to minimize peak distortion due to added noise.

Subsequent analyses in the laboratory at Woods Hole were able to remove this signal by increasing the current sampling step from $2.46 \mathrm{mV}$ (341 points between $-0.6 \mathrm{~V}$ to $-1.4 \mathrm{~V}$ ) to 4.88 $\mathrm{mV}$ (174 points) which eliminated the need for smoothing prior to sample analysis. We observed good agreement between samples analyzed at sea and in the lab, indicating that the smoothing procedures applied at sea did not bias the data and that gas adsorbing satchels preserved original concentrations (Noble and Saito, in prep).

\subsubsection{Intercalibration and internal laboratory standard}

All data reported in this manuscript have been submitted to the Biological and Chemical Oceanography Data Management Center (BCO-DMO, http://www.bcodmo.org/dataset/647250). Our laboratory continues to participate in international intercalibration efforts through the GEOTRACES program in anticipation of the release of the $2^{\text {nd }}$ Intermediate Data Product, Summer 2017. The sampling scheme for GP16 included 2 overlapping samples per full depth profile where the shallowest sample of the deep cast was collected at the same depth as the deepest sample for the mid cast, and the shallowest sample from the mid cast was collected at the same depth as the deepest sample from the shallow cast (i.e. a 36-point profile is composed of 34 discreet depths and 2 overlapping depths). Comparing overlapping samples collected at the same depth and location on separate hydrocasts provides a measure of 
reproducibility. The average difference between dCo analyses across 40 overlapping depth samples was $5.7 \mathrm{pM}$ with a median difference of $3.5 \mathrm{pM}$. For labile cobalt, average deviation was $2.1 \mathrm{pM}$ (median of $2.0 \mathrm{pM}, \mathrm{n}=41$ ). Least-squares regression of these samples yielded slopes close to 1 ( 0.98 for $\mathrm{dCo}$ and 0.96 for LCo; y-intercept forced to 0 ), indicating good reproducability. Furthermore, comparisons with other groups measuring dCo in the same samples reported here suggest strong agreement between groups despite major methodological differences (C. Parker and K. Bruland, personal communication).

Because acidified community reference materials such as the SAFe standards require a delicate neutralization to $\mathrm{pH} 7.5-8$ prior to analysis, a large batch of UV oligotrophic seawater was generated prior to the cruise and used to assess instrument performance during at-sea analysis. This consistency seawater standard was run $\sim 3 \mathrm{x}$ per week, as were blanks, and values were stable over several reagent batches for the duration of the cruise $(4.5 \pm 2.1 \mathrm{pM}, \mathrm{n}=28)$. SAFe standard D1 was measured at sea $(48.5 \pm 2.4 \mathrm{pM}, \mathrm{n}=3)$ and fell within $1 \mathrm{SD}$ of the consensus value $(46.6 \pm 4.8 \mathrm{pM})$. SAFe standard D2 and GEOTRACES standard GSP were run at higher frequency for analyses at Woods Hole. Our measurements of D2 $(46.9 \pm 3.0$ pM, n = 7) agreed with consensus values $(45.7 \pm 2.9 \mathrm{pM})$ and concentrations from our lab published previously (Noble et al., 2012). While the GSP standard does not have a consensus value, our determinations $(2.5 \pm 2.0 \mathrm{pM}, \mathrm{n}=10)$ are within the range for SAFe $\mathrm{S}(4.9 \pm 1.2 \mathrm{pM})$, which was collected at the same offshore location as GSP. Acidified SAFe and GEOTRACES standards were neutralized with concentrated ammonium hydroxide (Seastar), mixing the entire sample between drops, prior to UV digestion. When base was added more quickly, measured dCo was halved, presumably due to adsorption or co-precipitation onto magnesium hydroxides formed during base addition. For analysis of neutralized standards, we found a $~ 6: 1$ EPPS: $\mathrm{NH}_{4} \mathrm{OH}$ (M:M) buffer improved $\mathrm{pH}$ stability during analysis and removed significant baseline drift observed with samples solely buffered with EPPS.

\subsection{Particulate metal analyses}

Particulate material collected from Go-Flo bottles was filtered onto acid-cleaned $0.45 \mu \mathrm{m}$ polyethersulfone filters $(25 \mathrm{~mm})$. Digestion protocol and analyses are identical to those used to measure particulate metal concentrations during the North Atlantic GA03 cruise, described in Twining et al., 2015. After filtration, filters were halved, digested at $135^{\circ} \mathrm{C}$ in sealed Teflon 
vials containing $4 \mathrm{M} \mathrm{HCL}, 4 \mathrm{M} \mathrm{HNO}_{3}$, and $4 \mathrm{M} \mathrm{HF}$; digests were then dried, and re-dissolved in $0.32 \mathrm{M} \mathrm{HNO}_{3}$ before analysis. $\mathrm{pCo}, \mathrm{pMn}$ and $\mathrm{pP}$ concentrations were measured by ICP-MS (Element 2, Thermo Scientific), calibrated using external multi-element standard curves, and corrected for instrument drift and sample recovery by In and Cs internal standards. More detailed methods for this dataset can be found elsewhere (Ohnemus et al., In Press).

\section{Results}

We report 680 determinations of dissolved cobalt $(\mathrm{dCo})$ and 783 determinations of labile dissolved cobalt (LCo) measured at sea, onboard the GP16 expedition in October-December 2013, as well as an additional 140 measurements of dCo measured from preserved samples on land. In this section, we describe the distributions of dCo, particulate cobalt (pCo), and LCo in the South Pacific Ocean.

\subsection{Dissolved Cobalt (dCo)}

Throughout the GP16 transect, nutrient uptake and scavenging result in a hybrid-type profile for dCo (Fig. 3), similar to dCo profiles from the Atlantic (Bown et al., 2011; Dulaquais et al., 2014b; Noble et al., 2012; Noble and Saito, in prep) and North Pacific (Ahlgren et al., 2014; Knauer et al., 1982; Saito et al., 2014). dCo ranged from <3 pM (below detection) in the South Pacific Gyre (e.g. Stations 23, 36) to 210 pM beneath the oxycline near the Peru Margin (Station 1). In the deep Pacific, concentrations fell between 20-40 pM but increased slightly at deepest stations below $4500 \mathrm{~m}$. These values are much less than those observed in zonal transects surveying the North and South Atlantic (Noble et al., 2012; Noble and Saito, in prep) but are similar to measurements in the Southern Ocean (Bown et al., 2011), indicating that dCo is scavenged in the deep ocean along the meridional overturning circulation. Below $3000 \mathrm{~m}$, dCo is somewhat lower east of the Eastern Pacific Rise (EPR), and matches less oxygenated, older waters than in the western portion of the transect (Fig. 4). While many profiles west of the EPR show considerable variation between 2000-3000 m suggestive of hydrothermal influence, the range is small $(<10 \mathrm{pM})$ relative to background concentrations $(30-40 \mathrm{pM})$ and unlike the 50fold excess of hydrothermal $\mathrm{dFe}$ and $\mathrm{dMn}$ above background seawater measured at Station 18 (Resing et al., 2015). 
dCo peaks in the mesopelagic, typically between 300-500 m. Towards the Peru shelf, this maximum shoals and increases, following the position and intensity of the oxygen minimum zone (OMZ, defined here as $\left.<20 \mu \mathrm{M} \mathrm{O}_{2}\right)$. Although the $\mathrm{OMZ}$ is several hundred meters thick near the eastern margin (Fig. 3), dCo concentrations $>100 \mathrm{pM}$ are restricted to samples collected just below the oxycline. Despite this narrow depth range, $>100 \mathrm{pM}$ dCo extends as far as $100^{\circ}$ W. For all depths below $200 \mathrm{~m}$, dCo follows a negative linear relationship with $\mathrm{O}_{2}$ (Fig. 5a). Over the Peru shelf, maximum dCo was measured at the top of the OMZ and dCo decreased with depth (except for the shallowest and most shoreward Station 2). Only at the western edge of the section do dCo and $\mathrm{O}_{2}$ decouple: the dCo maximum at Station 36 is deeper (500-1000 m) than the oxygen minimum (300-500 m), seemingly independent of the influence of the South Pacific OMZ (Fig. 3).

All profiles show a surface or near-surface minimum that indicates biological uptake and export. As a result, dCo is well traced by dissolved phosphate, $\mathrm{PO}_{4}$, in the upper $200 \mathrm{~m}$ of the ETSP (Fig. 5c). This relationship holds despite sharp transitions to high dCo in the oxycline near the Peru shelf. Upwelling of $\mathrm{O}_{2}$-depleted, $\mathrm{PO}_{4}$-rich waters contributes to high dCo in the surface ocean along the eastern margin with concentrations decreasing westward due to mixing and export. A secondary surface dCo maximum marked a cyclonic eddy sampled at $89^{\circ} \mathrm{W}$ (Station 9, V. Sanial, personal communication), which appeared to transport a shelf-like dCo and LCo signature for the upper $300 \mathrm{~m}$ into the offshore OMZ (Figs. 6a, b). In the South Pacific gyre, dCo in the euphotic zone falls below 10 pM. While the lowest $\mathrm{PO}_{4}$ was found in low salinity surface waters west of $140^{\circ} \mathrm{W}$, minimum dCo and deepest nutriclines corresponded to a southwestward excursion in the transect between Stations 17-23 (109-120 $\mathrm{W})$, which were accompanied by high salinities (>36) associated with the eastern part of the subtropical gyre. In contrast to the deep, smooth dCo nutricline further to the east, stations at the western edge of the section (Stations 32, 34, and 36) contained 20 pM Co until $\sim 50 \mathrm{~m}$ where concentrations decrease sharply surfaceward, resembling profiles in the North Atlantic (Fig. 3; Noble and Saito, in prep).

\subsection{Particulate Cobalt}

The surface minimum in dCo is mirrored by a near-surface maximum in particulate cobalt (pCo) from biological uptake throughout the GP16 section. The distribution of pCo (Fig. 6c) resembles particulate phosphorus (pP), chlorophyll, and other indicators of phytoplankton 
biomass. Very high pCo (>10 pM) was measured in the highly productive waters in the Peru upwelling ecosystem while lower concentrations $(2-4 \mathrm{pM})$ were found in oligotrophic surface waters. West of $100^{\circ} \mathrm{W}$ on the GP16 transect, a secondary pCo maximum between 300-500 m overlaps with high particulate $\mathrm{Mn}$ (pMn), reflecting Co incorporation into Mn-oxides in oxygenated thermocline waters (Fig. 6c). Elevated pCo was also found at the top of the OMZ in the eastern half of the transect, corresponding with high dCo from remineralization. High $\mathrm{pP}$ and low pMn in these samples suggest that pCo may be present as biomass in anoxic bacterial and archaeal communities (Ohnemus et al., In Press), rather than incorporation into bacterial Mnoxides by co-oxidation.

\subsection{Labile dissolved cobalt}

dCo can be bound by extremely strong organic ligands that affect its reactivity (Ellwood and van den Berg, 2001; Saito and Moffett, 2001). These ligands may be composed of degradation products of the cobalt-bearing cofactor vitamin $\mathrm{B}_{12}$ and may be stabilized following oxidation of $\mathrm{Co}(\mathrm{II})$ to $\mathrm{Co}$ (III) (Baars and Croot, 2015). Unlike other metals such as Fe, dCo bound to natural ligands is kinetically inert to ligand exchange (although some forms may still be bioavailable) and strong $\mathrm{Co}$ (II) ligands are not in excess of dCo, largely due to binding competition with nanomolar levels of labile nickel (Saito and Moffett, 2001; Saito et al., 2005). These properties can result in a significant fraction of labile dissolved cobalt (LCo) that can be measured without the UV-oxidation procedure necessary to measure $\mathrm{dCo}$, especially in the mesopelagic (Noble et al., 2012).

On GP16, the distribution of LCo is similar to that of dCo (Figs. 3, 4, 6). Except for samples from the upper $50 \mathrm{~m}$, dCo and LCo form a linear relationship $\left(\mathrm{R}^{2}=0.88\right)$ whose slope indicates that $\sim 33 \%$ of dCo is labile (Fig. 7a). Major exceptions are confined to the highly productive waters over the Peru shelf (Stations 1-6) where LCo is much lower than expected. In these waters, LCo decreases in step with silicate (Fig. 7c). As in the North and South Atlantic (Noble et al., 2012; Noble and Saito, in prep), LCo is undetectable in the surface ocean outside

of the waters influenced by upwelling (beyond $100^{\circ} \mathrm{W}$, Fig. $6 \mathrm{~b}$ ). The absence of LCo from the upper $300 \mathrm{~m}$ of the water column is deeper than corresponding gradients in the Atlantic, suggesting cobalt depletion is more intense in the South Pacific. 
In the deep Pacific (>3000 m), where dCo is low, LCo is undetectable. LCo remains low $(<15 \mathrm{pM})$ in the mesopelagic, except where the OMZ is most intense (Fig. 4). Within the OMZ, LCo maxima coincide with dCo maxima (Stations 1-15), but further to the west these LCo maxima are much less pronounced and occur deeper than dCo maxima (Fig. 3). The LCo plume from the OMZ also extends deeper (below $2000 \mathrm{~m}$ ) than the corresponding $\mathrm{dCo}(<2000 \mathrm{~m})$, suggesting that remineralization and scavenging affect these quantities in different ways. Slight secondary maxima between $1500-2000 \mathrm{~m}(10-15 \mathrm{pM})$ appear in the center of the section on $\sigma_{\theta}=$ $27.7-8 \mathrm{~kg} \mathrm{~m}^{-3}$ isopycnal layers (Fig. $4 \mathrm{c}, 105^{\circ} \mathrm{W}-115^{\circ} \mathrm{W}$ ), perhaps tracing transport of LCo remineralized in the eastern basin as these waters flow over the mid ocean ridge.

\section{Discussion}

The most striking aspect of the dCo distribution in the ETSP is the very high concentrations present in the OMZ (Figs. 3-5). Similar distributions have been observed in both the North and South Atlantic, where $>100 \mathrm{pM}$ dCo plumes corresponded to low oxygen waters underneath the Benguela and Mauritanian upwelling systems (Noble et al., 2012; Noble and Saito, in prep). In the North Pacific, profiles from the Costa Rica Dome (Ahlgren et al., 2014), the California margin (Biller and Bruland, 2013; Knauer et al., 1982), and the Central Pacific along $155^{\circ} \mathrm{W}$ (Saito et al., 2014) support an OMZ-cobalt plume there as well. Based on measurements from these four OMZs, oxygen biogeochemistry seems to exert a major control on cobalt cycling throughout the oceans. It is interesting to note that the magnitude of the observed dCo plumes does not appear to scale with minimum $\mathrm{O}_{2}$ between Atlantic and Pacific OMZs. While minimum $\mathrm{O}_{2}$ in the Atlantic OMZs exceeds $20 \mu \mathrm{M}$, much of the ETSP is anoxic (Karstensen et al., 2008; Ulloa et al., 2012). Yet, dCo in the ETSP occupies a similar 100-200 pM range reported for the North and South Atlantic OMZs (Noble et al., 2012; Noble and Saito, in prep). Clearly, other factors besides $\mathrm{O}_{2}$ alone contribute to large scale plumes of dissolved cobalt in the oceans.

In the following, we describe the oceanographic processes that lead to elevated dCo and LCo concentrations in low-oxygen waters (Section 4.1). At the basin scale, the combined effects of remineralization and circulation link dCo with $\mathrm{O}_{2}$ throughout the water column in the ETSP (Section 4.1.1). The cobalt plume in the OMZ, however, is more than an extrapolation of these mechanisms, requiring a large coastal source (Section 4.1.2), and suppression of dCo scavenging 
at very low $\mathrm{O}_{2}$ (Section 4.1.3). The mechanism, magnitude, and redox sensitivity of the coastal Co source are then examined in greater detail (Section 4.2). Finally, we highlight the scarcity of $\mathrm{dCo}$ - a critical micronutrient to phytoplankton - in the surface ocean of the South Pacific and the dependence of surface ocean dCo supply on coastal sources (Section 4.3).

\subsection{Processes generating the OMZ cobalt plume in the Eastern South Pacific Ocean}

\subsubsection{Basin-scale remineralization and circulation couple dCo with $\mathrm{O}_{2}$}

In the ETSP, tight coupling between $\mathrm{dCo}$ and $\mathrm{O}_{2}$ is evident in the strong, inverse relationship that describes all samples below $200 \mathrm{~m}$ (Fig. 5a). In light of the nutrient-like dCo depletion in the surface of the ETSP and elsewhere (Fig. 6, Ahlgren et al., 2014; Dulaquais et al., 2014b; Noble et al., 2012), this negative correlation might be attributed to remineralization: dCo is returned to the dissolved phase from a sinking biogenic phase following respiration (i.e. $\mathrm{O}_{2}$ consumption). The slope of the $\mathrm{dCo}: \mathrm{O}_{2}$ line $\left(-0.33 \mu \mathrm{M} \mathrm{M}^{-1}, \mathrm{R}^{2}=0.75\right.$ for $\left.200-5500 \mathrm{~m}\right)$ would then represent the biological stoichiometry of the exported organic material in the ETSP. However, Co:P ratios in particulate material collected in the upper $50 \mathrm{~m}$ on GP16 indicate greater phytoplankton cobalt utilization (median pCo:pP of $140 \mu \mathrm{M} \mathrm{M}^{-1} \div 118 \mathrm{O}_{2}: \mathrm{P} \mathrm{M} \mathrm{M}^{-1}=1.2$ $\mathrm{Co}: \mathrm{O}_{2} \mu \mathrm{M} \mathrm{M}^{-1}$; DeVries and Deutsch, 2014). If the $\mathrm{dCo}: \mathrm{O}_{2}$ trend is borne solely from remineralization, a greater slope would be expected, implying removal of dCo by scavenging. The linearity in the $\mathrm{dCo}: \mathrm{O}_{2}$ relationship is also not reproduced upon conversion of $\mathrm{O}_{2}$ to apparent oxygen utilization (AOU $=\mathrm{O}_{2 \text {,saturation }}-\mathrm{O}_{2}$, measured, Fig. $5 \mathrm{~b}, \mathrm{R}^{2}=0.49$ ), further suggesting that other factors besides remineralization (such as circulation and scavenging) shape the subsurface dCo distribution.

In the deep ocean, near-conservative mixing of low $\mathrm{O}_{2}$ /high dCo water masses with high $\mathrm{O}_{2} /$ low dCo water masses probably contributes to the observed $\mathrm{dCo}: \mathrm{O}_{2}$ relationship. The enormous depth range $\left(>5000 \mathrm{~m}\right.$ ) described by the linear $\mathrm{dCo}: \mathrm{O}_{2}$ relationship contrasts with the near-exponential decrease in remineralization rates with depth (e.g. Karstensen et al., 2008). It is likely that deep Pacific circulation acts to spread signals of local dCo remineralization throughout the water column, aggregating a multitude of export stoichiometries and remineralization processes into a single, coherent relationship across the basin. LCo is undetectable below $\sim 2500 \mathrm{~m}$ and the shallower slope of the $\mathrm{LCo}: \mathrm{O}_{2}$ trend $\left(-0.11 \mu \mathrm{M} \mathrm{M}^{-1}, \mathrm{R}^{2}=\right.$ 0.67 , not shown) implies that the $\mathrm{dCo}: \mathrm{O}_{2}$ relationship is driven mostly by strongly complexed 
species, which are less vulnerable to co-oxidation by Mn-oxidizing bacteria in the water column (Moffett and Ho, 1996). Since the deep Pacific can be broadly regarded as a mixture of oxygenated circumpolar waters and OMZs (especially from the North Pacific), the linear dCo: $\mathrm{O}_{2}$ relationship between 200 and 5500 m may reflect mixing of a dCo pool that is largely inert to losses by scavenging.

In the upper $200 \mathrm{~m}$, dCo is not well coupled with $\mathrm{O}_{2}$ and almost all samples fall above the line established by deeper samples (Fig. 5a). Near the South American margin, the dCo maximum in the upper $\mathrm{OMZ}$ is more than twice the $\mathrm{dCo}$ concentration expected by extrapolation of the basin-scale $\mathrm{dCo}: \mathrm{O}_{2}$ relationship to the $0 \mu \mathrm{M} \mathrm{O}_{2}$ intercept (77 pM, Fig. 5a). The similarity of dCo profiles to profiles of excess $\mathrm{N}_{2}$ from denitrification from this region (e.g. Chang et al., 2010) implies that both the dCo maximum in the OMZ and its decrease with depth are driven by factors that also affect nitrogen loss: namely in-situ remineralization of sinking biogenic particles and lateral transport of coastal waters that experience high rates of denitrification and are also rich in dCo (DeVries et al., 2012).

\subsubsection{Distinct surface and mesopelagic Co:P relationships}

In the upper ocean (0-200 m), dCo is linearly related to $\mathrm{PO}_{4}$ (Figs. 5c), indicating that the processes controlling $\mathrm{PO}_{4}$ in the surface - upwelling, mixing, biological uptake and export - are the main drivers of dCo as well. In the upper $50 \mathrm{~m}$, the $\mathrm{dCo}: \mathrm{PO}_{4}$ slope $\left(69 \mu \mathrm{M}: \mathrm{M}, \mathrm{R}^{2}=0.89\right.$, Fig. 7b) may describe export stoichiometry throughout the Eastern Pacific. That the surface dCo: $\mathrm{PO}_{4}$ slope intercepts the highest dCo concentrations (below the $50 \mathrm{~m}$ depth range of the regression, Fig. 5c, cyan line) indicates that new cobalt sourced from the shelf is rapidly incorporated into the biological cycle and that the capacity for phytoplankton Co uptake is not overwhelmed by the order of magnitude higher dCo in coastal waters relative to the open ocean. Culture experiments with model diatoms and coccolithophores demonstrate this capacity (Shaked et al., 2006; Sunda and Huntsman, 1995; Yee and Morel, 1996), deploying Co to zinc enzymes to maintain activity when $\mathrm{Zn}$ becomes scarce. When $\mathrm{Zn}$ is limiting, Co quotas, as observed in open ocean phytoplankton, are 10-100x greater than Co quotas when $\mathrm{Zn}$ is replete (Sunda and Huntsman, 1992; Twining and Baines, 2013). Therefore, minor substitution of Zn quotas by Co ( 10 \%) can double cellular Co levels in eukaryotes, resulting in nearly complete uptake of dCo from the surface ocean. 
A separate nutrient-like $\mathrm{dCo}: \mathrm{PO}_{4}$ trend arises from gradients of both elements in the open ocean nutricline (Fig. 5c). The slope of the mesopelagic trend (16 $\mu \mathrm{M}: \mathrm{M}$, for 200-1000 m, red line in Fig. 5c) is much less than that measured for the upper $50 \mathrm{~m}(69 \mu \mathrm{M}: \mathrm{M}$, cyan line). Due to considerable preformed $\mathrm{PO}_{4}$ in deep waters, as well as elevated $\mathrm{dCo}: \mathrm{PO}_{4}$ ratios in the $\mathrm{OMZ}$, the mesopelagic dCo: $\mathrm{PO}_{4}$ regression is less robust than in the surface $\left(\mathrm{R}^{2}=0.21\right)$, though the slope does reflect dCo and $\mathrm{PO}_{4}$ covariation in this depth range when $\mathrm{PO}_{4}$ is $<2 \mu \mathrm{M}$ (Fig. 5c, red line). Regardless, there seems to be a fundamental mismatch between $\mathrm{dCo}: \mathrm{PO}_{4}$ from the upper water column (0-200 m) and that observed deeper (200-1000 m).

In the eastern margin, the surface and mesopelagic $\mathrm{dCo}: \mathrm{PO}_{4}$ vectors are joined at $2.6 \mu \mathrm{M}$ $\mathrm{PO}_{4}$ by a near-vertical line that makes the $\mathrm{dCo}: \mathrm{PO}_{4}$ domain triangular. Interpretation of this line depends largely on its perceived direction: a downward vector can be a fingerprint of scavenging while an upward vector describes a cobalt source (Noble et al., 2008; Saito et al., 2010). This ambiguity is clarified by examining $\mathrm{dCo}: \mathrm{PO}_{4}$ gradients within isopycnal surfaces, which strongly indicate a source at low $\mathrm{O}_{2}$. In the ETSP, $\sigma_{\theta} 26.2$ and 26.4 isopycnals host the upper OMZ and the oxygenated thermocline waters west of $100^{\circ} \mathrm{W}$. Water masses on these surfaces can be distinguished on the basis of salinity; from the GP16 dataset, mixing between salty and deoxygenated equatorial sub-surface waters (ESSW or $13^{\circ} \mathrm{C}$ water) with fresher, ventilated SubAntarctic waters is apparent (Fiedler and Talley, 2006; Toggweiler et al., 1991). Oxygenated waters on $\sigma_{\theta}=26.2$ and 26.4 show a tight coupling between $\mathrm{dCo}$ and $\mathrm{PO}_{4}$ from remineralization of both elements (Fig. 8a). For samples with $<20 \mu \mathrm{M} \mathrm{O}_{2}$, however, deviation from the oxic $\mathrm{dCo}: \mathrm{PO}_{4}$ trend is always positive, indicating a dCo source within the OMZ. When oxygen is low, dCo follows salinity (Fig. 8b). Mixing of high salinity (34.9-35.0), high dCo ESSW from the northeast with low salinity, low dCo Subantarctic waters explains the dCo:salinity covariation on these isopycnal surfaces. While ESSW is fed by the equatorial undercurrent (EUC), which originates near Papua New Guinea and transports a large Fe and Al source eastward (Slemons et al., 2010), it is low in dCo (as measured at $155^{\circ} \mathrm{W}$, Hawco and Saito, unpublished; Saito et al., 2014). When the EUC bifurcates near the Galapagos, it mixes with coastal waters north and south of the equator (Fiedler and Talley, 2006; Stramma et al., 2010), where its high dCo signature is likely acquired. 


\subsubsection{Suppression of cobalt scavenging in the OMZ}

The isopycnal dCo:salinity relationship implies cobalt scavenging in the $\mathrm{OMZ}$ is low (Fig. 8b). This is not surprising given the slower rates of $\mathrm{MnO}_{2}$ formation at low $\mathrm{O}_{2}$ (Johnson et al., 1996; von Langen et al., 1997) and very low particulate Mn measured in the ETSP OMZ (Ohnemus et al. In Press). In the OMZ, both pCo:pP and pMn:pP ratios in the OMZ are consistent with micronutrient use by microbial communities and resemble biomass collected in the euphotic zone on GP16 (Co:P $=0.5-4 \times 10^{-4} \mathrm{M} \mathrm{M}^{-1}$, Mn:P $\sim 10^{-3} \mathrm{M} \mathrm{M}^{-1}$; Fig. 9, pink and cyan lines). These low, biomass-like pCo:pP and pMn:pP signatures in the ETSP OMZ are consistent with thermodynamic and kinetic barriers to Mn oxidation at very low $\mathrm{O}_{2}$ (Ohnemus et al., In Review).

Crossing the anoxic/oxic transition at $100^{\circ} \mathrm{W}$ in the thermocline $\left(\sigma_{\theta} 26.2-27.0\right.$, centered at $300 \mathrm{~m}$ ) results in a factor of ten higher pMn concentrations and implies a redox threshold to Mn oxidation in the mesopelagic (Fig. 9, blue circles). Heterotrophic Mn-oxidizing bacteria are known to incorporate Co by enzymatic co-oxidation into the Mn-oxide lattice and are prevalent throughout the water column (Cowen and Bruland, 1985; Moffett and Ho, 1996). While particulate Co profiles in the ETSP have a near-surface maximum from biological uptake (Fig. $6 \mathrm{c}), \mathrm{pCo}$ attenuates much less with depth than $\mathrm{pP}$ in oxic thermocline waters. Very high $\mathrm{pCo}$ :pP ratios (up to $10^{-3} \mathrm{M} \mathrm{M}^{-1}$ ) are found in the oxygenated thermocline but not in the OMZ (Fig. 9, pink circles). The coincidence of high pCo:pP and high $\mathrm{pMn}$ throughout the mesopelagic is consistent with pCo being present in an authigenic Mn-oxide phase, marking an important transition between nutrient-like cobalt cycling in the surface ocean (where pCo is almost entirely biogenic) to Mn-oxide driven scavenging at depth.

The stimulation of cobalt scavenging across the anoxic/oxic transition at $100^{\circ} \mathrm{W}$ was also reflected in a sharp decrease in $\mathrm{LCo}: \mathrm{PO}_{4}$ as scavenging removed LCo from the water column (Fig. 9, black circles). Indeed, the same oxygenated thermocline samples with high $\mathrm{pMn}$ and pCo:pP are responsible for the gradual slope in $\mathrm{dCo}: \mathrm{PO}_{4}$ space $\left(16 \mu \mathrm{M} \mathrm{M}^{-1}\right.$, Fig. $5 \mathrm{c}$, red line). The offset between high surface and low mesopelagic dCo: $\mathrm{PO}_{4}$ is mirrored by the lower surface and higher mesopelagic pCo:pP. While scavenging is often presumed to draw chiefly from metals in the dissolved phase, the heterotrophic nature of Mn-oxidizing bacteria and their abundance in sediment traps hint that Mn-oxidizing bacteria may access biogenic metal pools within sinking particles (Cowen and Bruland, 1985). In such a case, pCo may be shunted directly 
from a biogenic to an authigenic phase without being truly remineralized, preventing the equal return of $\mathrm{dCo}$ at depth relative to that exported from the surface, as documented here by the disparity between deep and shallow dCo: $\mathrm{PO}_{4}$ slopes (Fig. 5c). An important consequence of mesopelagic scavenging is that ventilation of these waters by upwelling without an exogenous source (e.g. the continental margin) would create conditions whereby $\mathrm{dCo}$, relative to $\mathrm{PO}_{4}$, is not supplied to the same extent it is presently utilized and exported. Because these scavenged waters are relatively shallow and have short ventilation ages (Fiedler and Talley, 2006), fluxes of cobalt to the South Pacific from margin sources must be large in order to balance these scavenging losses.

\subsection{A major cobalt source from the Peruvian margin}

\subsubsection{Water column signatures of a dCo source}

The strong covariation between high dCo and low $\mathrm{O}_{2}$ in the ETSP and the intersection of the $\mathrm{OMZ}$ with the South American margin suggests that the continental shelf may be an important cobalt source. Sections from the North and South Atlantic (Noble et al., 2012; Noble and Saito, in prep) and profiles from the North Pacific (Ahlgren et al., 2014; Knauer et al., 1982) have resulted in similar assertions, but the coincidence of high phytoplankton productivity along eastern margins also imprints signals from elevated remineralization. This is certainly the case for the ETSP, where Stations 2 and 3 on the Peru shelf featured $>1.5 \mu \mathrm{g}$ chlorophyll $\mathrm{L}^{-1}$ in the euphotic layer, and $>4 \mu \mathrm{M}$ nitrite throughout the $\mathrm{OMZ}$ from intensified anoxic remineralization. As a result, the dCo profile in Peru shelf waters strongly resembles $\mathrm{PO}_{4}$ and other nutrients above the oxycline (Fig. 10). Unlike $\mathrm{PO}_{4}$, however, these shelf stations show a dCo maximum at the oxycline and decreasing concentrations with depth that more strongly resembles the Mn profile (Fig. 10), implying that additional processes contribute to the dCo profile over the shelf.

Positive correlations between dCo, LCo and dMn within the OMZ on the Peru shelf reflect a shared source (Fig. 11). The slope of the LCo:dMn relationship $\left(18 \pm 2 \mathrm{mM} \mathrm{M}^{-1} \mathrm{R}^{2}=\right.$ $0.76)$ is nearly identical to that in upper continental crust and Andesite (21-26 $\mathrm{mM} \mathrm{M}^{-1}$, McLennan, 2001; Taylor and McLennan, 1995), matching expectations that mineral dissolution should provide labile Co. However, the steeper slope for the $\mathrm{dCo}$ : $\mathrm{Mn}$ relationship (42 $\pm 5 \mathrm{mM}$ $\mathrm{M}^{-1} \mathrm{R}^{2}=0.67$ ) exceeds crustal endmembers. Addition of a second, Co-enriched component is needed to explain the observed relationship. Given the massive productivity over the Peru shelf, 
biological export and remineralization of $\mathrm{dCo}$ and $\mathrm{dMn}$ in the $\mathrm{OMZ}$ is a reasonable cause for the high Co:Mn ratio in the shelf OMZ. From particulate material in the upper $40 \mathrm{~m}$ of shelf stations (1-5), the average Co:Mn ratio in local biomass is between 100 and $110 \mathrm{mM} \mathrm{M}^{-1}$ (median and mean), roughly 5 times higher than continental crust, and falling within the range reported for single cell analysis of phytoplankton cells from other regions (70-400 $\mathrm{mM} \mathrm{M}^{-1}$, Twining and Baines, 2013). The combination, then, of a high biotic Co:Mn ratio and a lower ratio from a sedimentary source can produce the slope observed in the water column, but requires remineralized dCo to be chiefly ligand-bound in order to preserve the near-crustal LCo:Mn slope. The higher Co:Mn ratio in biomass relative to their shared sedimentary source also results in a nutrient trap that returns upwelled dCo to the $\mathrm{OMZ}$ more efficiently than $\mathrm{dMn}$ and implies that input of dCo from the shelf is rapidly followed by biological utilization, evident in the immediate transition from a dMn-like profile below the oxycline to a $\mathrm{PO}_{4}$-like profile above it (Fig. 10).

Water column observations of a large dCo source are also mirrored in the depleted Co contents of continental shelf sediments along the Peru margin. A survey of continental shelf sediments underlying the Peru OMZ found low Co/Al ratios $\left(1.2 \pm 0.3 \times 10^{-4} \mathrm{~g} \mathrm{~g}^{-1}\right.$, Böning et al., 2004) relative to Andesitic and upper continental crusts (2.63 and $2.11 \times 10^{-4} \mathrm{~g} \mathrm{~g}^{-1}$ respectively, McLennan, 2001; Taylor and McLennan, 1995), requiring that about half of the Co delivered to the continental shelf from crustal sources dissolved prior to long-term burial on the shelf. The only other element to have a similar depletion was Mn, which covaried with Co across all samples in the Böning et al. study, consistent with release of both metals by reductive dissolution. Yet the exact mechanism for dCo release is unclear: mass balance calculations for $\mathrm{Mn}$ indicate that diffusive fluxes from sediment porewaters on the Peru Shelf are much too slow to account for solid-phase $\mathrm{Mn} / \mathrm{Al}$ deficits that accumulate in the sediment column (Scholz et al. 2011). Therefore, most Mn is released prior to sedimentation on the margin, either by dissolving directly in the water column or through upstream release in estuaries. Since Co covaries with $\mathrm{Mn}$ in both dissolved and sediment phases (Fig. 11, Böning et al., 2004), the ultimate source of the dCo plume in the Peruvian OMZ may not be generated by diffusion from margin sediments either. 


\subsubsection{Potential redox sensitivity of coastal cobalt sources}

The $\mathrm{Co} / \mathrm{Al}$ ratio in buried sediments on the continental shelf can provide a coarse measure of how much Co has been released to the ocean. Sub-crustal Co/Al ratios in Peruvian sediments between $9-14^{\circ} \mathrm{S}$ (Böning et al., 2004) match similar measurements in Chilean OMZ sediments at $36^{\circ} \mathrm{S}$ (Table $2, \mathrm{Co} / \mathrm{Al}=1.3 \times 10^{-4} \mathrm{~g} \mathrm{~g}^{-1}$, Böning et al., 2009) and the Gulf of California (1.4 x $10^{-4} \mathrm{~g} \mathrm{~g}^{-1}$, Brumsack, 1989). The deficit between these values and continental crust $\left(2.11 \times 10^{-4} \mathrm{~g} \mathrm{~g}^{-1}\right)$ implies that dissolution of crustal materials along the eastern margin provides a large source of dCo and LCo to the Pacific. In the absence of large hydrothermal inputs (see Section 4.2.5, Swanner et al. 2014), burial of Co depleted sediments on the margin is needed to balance extremely high $\mathrm{Co} / \mathrm{Al}$ ratios in Pacific pelagic sediments, which collect Co scavenged from the water column (e.g. Dunlea et al., 2015; Goldberg and Arrhenius, 1958).

In contrast to depleted Co along the South American shelf, the Co/Al ratio in shelf sediments from the western margin of the Pacific appears crustal (Table 2). Holocene records from the Pearl River delta and shelf slope in the South China Sea $20^{\circ} \mathrm{N}$ (Hu et al., 2012, 2013) show mean $\mathrm{Co} / \mathrm{Al}$ ratios of 2.2 and $2.1 \times 10^{-4} \mathrm{~g} \mathrm{~g}^{-1}$, respectively, similar to sediments from the Gulf of Papua at $9^{\circ} \mathrm{S}\left(2.3 \times 10^{-4} \mathrm{~g} \mathrm{~g}^{-1}\right.$, Alongi et al., 1996). Crustal Co/Al in these sedimentary systems implies that most of the Co provided from fluvial sediment delivery either does not dissolve or is quickly reburied by water column Mn oxidation, rates of which can be very high in estuaries and coastal seas (Moffett and Ho, 1996; Moffett, 1994; Sunda and Huntsman, 1987; Sunda and Huntsman, 1990).

It is likely that oxidizing conditions in the water column and surface sediments limit the release of cobalt on the western margin, leading to crustal $\mathrm{Co} / \mathrm{Al}$ ratios in shelf sediments, while suboxic conditions on the eastern margin mobilize Co, evident in depleted $\mathrm{Co} / \mathrm{Al}$ ratios observed there. Although sedimentary anoxia releases Co bound in Mn oxides, even a thin layer of $\mathrm{O}_{2}$ penetration into sediments results in a near-zero diffusive flux into the water column (Heggie and Lewis, 1984). Indeed, El Niño-driven oxygenation events on the Peru shelf are associated with deposition of Mn-oxides in shallow sediments (Scholz et al. 2011). Bottom water deoxygenation restores Co fluxes to the water column (Johnson et al., 1988, Sundby et al., 1986), but Co is also incorporated into sulfide minerals, analogous to the 'Goldilocks' mechanism for benthic Fe release where flux is maximized when redox conditions are low enough to promote oxide dissolution but still high enough to avoid pyrite burial (into which cobalt is incorporated; Morse 
and Luther, 1999, Scholz et al., 2014). Cobalt burial in pyrite is evident in high Co/Al content of Black Sea sediments (Brumsack, 2006) and sulfide-rich pockets of Namibian sediments near Walvis Bay (2.9 x 10 g g $^{-1}$, Borchers et al., 2005), despite more widespread Co/Al depletion in suboxic (but not sulfidic) terrigenous sediments underneath the Benguela upwelling region (Bremner and Willis, 1993). Prevailing suboxic conditions along the Namibian coast ultimately lead to an extensive dCo plume that reaches across the South Atlantic basin (Noble et al., 2012). Similarly, depleted sedimentary Co/Al on the Peruvian margin and high dCo in the water column perhaps reflect sustained anoxia that, in the present, is unlikely outside the domain of OMZs.

Altogether, the accumulating evidence that the oceans' major OMZs harbor dCo plumes (Noble et al., 2012, Alhgren et al., 2014, Noble et al., in prep) indicates a strong chemical connection between the efficiency of dCo sources and local redox conditions where these OMZs interact with the continental margin. While reductive dissolution is the most likely mechanism at play, whether this process predominantly occurs in estuaries, the OMZ water column, or margin sediments is presently unclear, but will ultimately dictate how the dCo source (and the resulting OMZ plumes) are affected by climate-driven changes in the size and intensity of OMZs (e.g. Scholz et al. 2011, 2014). As such, there is a significant need for future experimental and field studies that address the redox sensitivity of dCo and other metal fluxes from coastal environments.

\subsubsection{Comparing coastal sources with the OMZ cobalt plume}

Can a terrigenous cobalt source account for the observed OMZ plume? Because lithogenic sediments along the Peru margin are delivered primarily by rivers (Scheidegger and Krissek, 1982), we can estimate a dCo flux to OMZ waters as the product of the fluvial sediment delivery to the continental shelf and the difference in $\mathrm{Co} / \mathrm{Al}$ ratios between original rocks and buried shelf sediments:

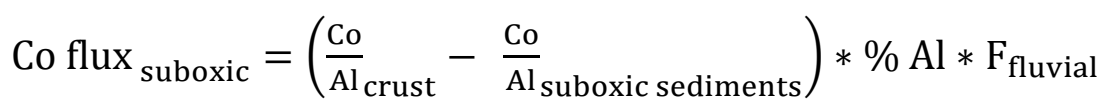

where $\mathrm{F}_{\text {fluvial }}$ is the riverine flux of terrigenous sediments from Ecuador, Peru and Northern Chile to oxygen-depleted coastlines in the ETSP. If this supply is approximately $200 \mathrm{MT}$ year $^{-1}$ (Lyle, 1981; Milliman and Farnsworth, 2011), the Co deficit in Peruvian sediments from Böning et al., 2004 corresponds to a 2.5-4.6 x $10^{7}$ mol per year flux from the South American shelf, depending on the crustal endmember applied (upper continental crust vs. andesite, Table 2). When scaled to 
the size of the ETSP OMZ $\left(2.2 \times 10^{6} \mathrm{~km}^{3}\right.$ defined at $20 \mu \mathrm{M} \mathrm{O}_{2}$, Fuenzalida et al., 2009) a terrigenous cobalt supply of 11-21 pM year ${ }^{-1}$ would be expected.

The extent to which the coastal flux and dCo inventory are in agreement depends on the residence time of OMZ waters. Models and CFC distributions from WOCE imply an approximately decadal recirculation time in $\mathrm{OMZ}$ waters relative to mesopelagic gyre circulation in the ETSP (Deutsch et al., 2001, 2011). Integrating our terrigenous Co flux estimate over 10 years yields an expected concentration of 120-230 pM within the OMZ. This is of similar magnitude, but greater than the concentrations measured on the GP16 transect (mean of $100 \pm 30$ $\mathrm{pM})$. The difference between estimated and actual dCo inventories in the OMZ is probably due to upwelling and advection by surface currents, readily seen in the dCo section (Fig. 6), which carries the remainder to the gyre.

\subsubsection{Comparison to atmospheric deposition}

We can compare the calculated sedimentary flux to an expected flux from aerosol dust dissolution. Aeolian deposition is extremely low over the South Pacific basin (Mahowald et al., 2005), except immediately offshore of Peru, where dust from the Altiplano interacts with the prevailing northward winds (Prospero and Bonatti, 1969; Scheidegger and Krissek, 1982). Model results (Mahowald et al., 2005) suggest that deposition does not exceed $0.5 \mathrm{~g} \mathrm{~m}^{-2} \mathrm{yr}^{-1}$, except very close to the coastline. Using this estimate, crustal cobalt abundances, and the aerial extent of the OMZ (9.8 x $10^{6} \mathrm{~km}^{2}$, Fuenzalida et al., 2009), we estimate the aerial flux of cobalt from dust to be $1.4 \times 10^{6} \mathrm{~mol}$ per year. A $10 \%$ fractional solubility for cobalt (Shelley et al., 2012) indicates a soluble cobalt flux from dust of $0.065 \mathrm{pM} \mathrm{dCo} \mathrm{year}^{-1}, \sim 0.5 \%$ of the expected sedimentary flux. Over a decade, dust deposition accounts for $<1 \mathrm{pM}$ of the OMZ dCo plume. $\mathrm{dCo}$ profiles also lack surface maxima near shore despite corresponding features for dissolved $\mathrm{Al}$ and Mn at Stations 1 and 5 (Fig. 10, Resing et al., 2015). Fluvial sediment delivery to the margin, therefore, is a much more plausible source for the elevated dCo in the ETSP OMZ.

\subsubsection{An inefficient cobalt source in hydrothermal vents}

Hydrothermal venting along the Eastern Pacific Rise (EPR) provides a major source of $\mathrm{dFe}$ and dMn to the deep South Pacific (Resing et al., 2015) where nanomolar concentrations of both metals were measured between 2000-3000 m at the ridge crest and concentrations exceeded 
background values for several thousand kilometers westward. In contrast, dCo concentrations are only slightly elevated at the ridge crest (Station 18, Fig. 3), reaching 36 pM at 2400m (against a background of $\sim 25 \mathrm{pM}$ ); at the same station, $\mathrm{dFe}$ and $\mathrm{dMn}$ both exceeded $15 \mathrm{nM}$ (background $<1$ nM, Fig. 12a). Unambiguous hydrothermal input is evident from the LCo profile, which peaks at $14 \mathrm{pM}$ at the dCo maximum (Fig. 12b), roughly consistent with a 10,000-fold dilution of high temperature endmember sources containing 100-1000 nM dCo (Lupton et al., 1985; Metz and Trefry, 2000).

However, both dCo and LCo maxima are offset from dFe and dMn plumes. At Station $18, \mathrm{dFe}$ and $\mathrm{dMn}$ peak at 2500-2600 m. At this depth, LCo is undetectable and dCo values are at - or slightly lower than - background levels (Fig. 12b), suggesting that Mn and/or Fe scavenging in the heart of the hydrothermal plume has removed most of the hydrothermal Co from the water column before being transported away from the ridge crest. Indeed, Co is strongly associated with Mn phases in near-axis metalliferous sediment in the EPR at $14^{\circ} \mathrm{S}$ (Dunk and Mills, 2006). The position of the LCo maximum above the $\mathrm{dMn}$ and $\mathrm{dFe}$ maxima probably reflects lower scavenging rates outside the main plume, which may spare a fraction of the hydrothermal Co source from an otherwise immediate and total removal. Even without scavenging losses, global hydrothermal Co fluxes (2.2 Mmol year ${ }^{-1}$; Swanner et al., 2014) are 10-25x less than our estimated source from the Peru Shelf alone, highlighting the importance of upper ocean sources in maintaining the dCo inventory.

\subsection{Cobalt scarcity in the euphotic zone}

\subsubsection{The South Pacific Gyre}

The combination of eastern boundary upwelling and a continental source produces large dCo gradients across the surface of the South Pacific Ocean (Fig. 6a). Westward, decreasing surface dCo results from phytoplankton uptake and export, reflected in strong correlations with $\mathrm{PO}_{4}$, as well as mixing with low dCo waters from the subtropical gyre. It is interesting to note that the intercept for the $\mathrm{dCo}: \mathrm{PO}_{4}$ relationship is negative $\left(-12.8 \pm 2.6 \mu \mathrm{M} \mathrm{M}{ }^{-1}\right.$, Fig. $\left.7 \mathrm{~b}\right)$; cobalt was depleted before $\mathrm{PO}_{4}$. This is opposite to what was observed in the Sargasso Sea, where extreme $\mathrm{PO}_{4}$ scarcity results in a positive $\mathrm{dCo}: \mathrm{PO}_{4}$ intercept (Jakuba et al., 2008). The dCo nutricline in the South Pacific gyre ( $200 \mathrm{~m}$, Fig. 6) is also deeper than corresponding features in the North and South Atlantic (Noble et al., 2012; Noble and Saito, in prep). Because winter 
mixed layers in the tropical South Pacific generally do not exceed $100 \mathrm{~m}$ and strong haloclines separate the oxygen minimum layer from the surface (Fiedler and Talley, 2006), convective overturn does not reach the dCo nutricline at 150-250 m. Low vertical cobalt supply makes the South Pacific gyre an interesting counterpart to the Sargasso Sea, which experiences deep winter mixing and higher dCo (10-30 pM, Dulaquais et al., 2014b; Jakuba et al., 2008; Noble and Saito, in prep), and emphasizes the importance of lateral supply mechanisms, especially eastern boundary upwelling, in maintaining the surface dCo inventory of the tropical Pacific (Saito et al., 2004).

While productivity in the South Pacific is thought to be limited by scarcity of iron and nitrogen (Moore et al., 2013; Saito et al., 2014), the extremely low dCo measured here implies that it may be important as well. Because marine cyanobacteria such as Prochlorococcus and Synechococcus have an absolute Co requirement (Saito et al., 2002; Sunda and Huntsman, 1995), they are vulnerable to limitation. Indeed, a Synechococcus bloom in the Costa Rica Dome was found to be co-limited by iron and cobalt (Saito et al., 2005). Despite dCo concentrations below $10 \mathrm{pM}$ (sometimes below the $3 \mathrm{pM}$ detection limit), the South Pacific gyre contains a significant Prochlorococcus population - evident in the high proportion of divinyl chlorophyll A to total chlorophyll (Fig. 13a). As LCo was undetectable beyond $100^{\circ} \mathrm{W}$, biological uptake must occur either by accessing strongly bound dCo or through fast recycling of LCo at very low steady-state concentrations. On GP16, particulate Co concentrations in the upper $50 \mathrm{~m}$ were steady $(3.5 \pm 1.2$ $\mathrm{pM}$ ) and mostly reflect Co bound in biomass (Ohnemus et al., In Press), sometimes rivaling dissolved cobalt concentrations (Fig. 13b). Compared to low pCo:dCo ratios observed in the South Atlantic (<1:12, Noble et al., 2012), the high ratio in the South Pacific gyre $(\sim 1: 3$, Fig. 13b) indicates that resident Prochlorococcus are extremely well-adapted to widespread dCo scarcity and that efficient recycling of biogenic pCo may be crucial to survival of Prochlorococcus and other cyanobacteria (e.g. Synechococcus, Ahlgren et al. 2014).

\subsubsection{Depletion of labile dissolved cobalt in the Peru Upwelling Ecosystem}

Unlike its near uniform relationship with dCo in the underlying OMZ, LCo measured on GP16 is low relative to dCo in the surface ocean $(0-50 \mathrm{~m})$, especially along the Peru Margin (Figs. 7a, 13c). This might result either from microbial production of cobalt ligands - as observed in a Synechococcus-dominated community in the Costa Rica Dome (Saito et al., 2005) 
and with cultured Prochlorococcus strains (Saito et al. 2002) - or if LCo is the preferred species for uptake. The latter has been demonstrated in culture with model eukaryotic algae (Sunda and Huntsman, 1995), where free Co ion is acquired by high affinity Zn-transporters. Because the Peru upwelling region is dominated by diatoms (Bruland et al., 2005), preferential uptake of free Co ion by these organisms is realistic and is corroborated by a strong correlation between LCo and dissolved silicate $(\mathrm{Si})$ in the upper $50 \mathrm{~m}$ of the section $\left(\mathrm{R}^{2}=0.90\right.$, Fig. 7c).

As a result of diatom-driven export, LCo in shelf surface waters is nearly depleted (1-12 pM) despite high concentrations of dCo (40-80 pM, Fig. 13c). Very low surface LCo at $12^{\circ} \mathrm{S}$ on GP16 contrasts with previous observations showing high concentrations of LCo in the Peru upwelling region during August-September 2000 (Saito et al., 2004). Between 5-10 S, much higher surface dCo was measured in freshly upwelled waters (up to $315 \mathrm{pM}$ ) and dCo was >50 \% labile in surface transects (Saito et al., 2004). Surface dFe during August-September 2000 was also higher between 5-10 $\mathrm{S}$ than on GP16 at $12^{\circ} \mathrm{S}$ (Bruland et al., 2005; Resing et al., 2015). Decreasing surface dFe from North to South followed decreasing gradients in shelf width and fluvial sediment supply (Bruland et al., 2005; Milliman and Farnsworth, 2011), implying that the high $\mathrm{dFe}$ was due to stronger benthic sources to the North. Because coastal sources are expected to provide labile cobalt (e.g. Fig. 11), the high concentrations of LCo measured between 5-10 $\mathrm{S}$ during August-September 2000 indicate a similar gradient in coastal dCo input and LCo availability in surface waters.

Spatial and temporal variability of margin dCo sources may ultimately affect carbon flow through the Peru upwelling ecosystem. Considering the very low dissolved $\mathrm{Zn}$ in surface waters on GP16 ( $<100 \mathrm{pM}$ east of $90^{\circ} \mathrm{W}, \mathrm{S}$. John, personal communication) and that $>95 \%$ of the dZn is typically complexed by organic ligands (Bruland, 1989), coastal diatoms in the Peru upwelling region may be subject to diffusion limitation when free $\mathrm{Zn}$ ion falls below a $1-10 \mathrm{pM}$ threshold (Sunda and Huntsman, 1992). Because Co can replace Zn in carbonic anhydrase enzymes (Sunda and Huntsman, 1995; Yee and Morel, 1996), LCo supplied from the margin may maintain fast rates of carbon fixation and export in the Peru Upwelling region despite low $\mathrm{dZn}$. The relatively low concentrations measured on GP16, however, imply that the LCo supply may not always be sufficient. 


\section{Conclusions}

A schematic of the cobalt cycle in the Eastern Tropical South Pacific Ocean - and how these processes lead to covariation of dissolved cobalt with $\mathrm{O}_{2}$ and $\mathrm{PO}_{4}$ - is shown in Figure 14 . High dCo and LCo on the Peru shelf match depleted Co content reported in Peru shelf sediments and indicate a large source to the water column (Böning et al., 2004). Correlations between dMn and LCo in anoxic shelf waters, and crust-like $\mathrm{Co} / \mathrm{Al}$ ratios in oxic western boundary sediments suggest that margin cobalt sources are redox sensitive and that the sustained presence of the OMZ on the Peru margin amplifies coastal Co fluxes. The high dCo within the OMZ leads to a large flux to the surface ocean by upwelling along the Peru margin, where it is readily accessed by phytoplankton. The significance of cobalt as a micronutrient is emphasized by strong correlations with phosphate throughout the surface ocean.

The basin scale association between high dCo and low $\mathrm{O}_{2}$ throughout the GP16 section testifies to the importance of remineralization in maintaining the dCo distribution in the Eastern South Pacific (Fig. 14). Additionally, low oxygen suppresses particulate Mn accumulation and Co scavenging, contributing to the OMZ cobalt plume. Scavenging in oxic mesopelagic waters limits the full return of Co to the dissolved phase during remineralization, resulting in low dissolved Co:P ratios relative to biomass exported from the euphotic zone. Oxidative scavenging also seems to limit the flux of Co from hydrothermal venting over the East Pacific rise, further emphasizing the Peru margin as the most important Co source to the South Pacific. Given that deep nutriclines in the South Pacific Gyre limit dCo supply from vertical mixing outside of the upwelling zone, phytoplankton Co nutrition depends largely on lateral supply from the Eastern Margin.

Ultimately, the dCo inventory in the South Pacific - and its availability to surface phytoplankton - may be changing considerably as the size of the OMZ fluctuates. Recent warming and stratification appear to have expanded the volume of low oxygen waters in the tropics (Stramma et al., 2008, 2010). As such, dCo inventories may increase as lower $\mathrm{O}_{2}$ hinders mesopelagic Mn oxide production and scavenging. However, decreased wind-driven upwelling and carbon export may cause anoxic waters along the shelf to contract (Deutsch et al., 2011, 2014) and decrease the efficiency of the coastal dCo source. Changes in the dCo inventory then depend on the relative redox sensitivities of margin Co sources versus offshore scavenging in the mesopelagic, neither of which is well understood. Considering the 100-200 year residence time 
of Co in the ocean (Saito and Moffett, 2002), feedbacks on the surface dCo supply may manifest more quickly than for other nutrients and may alleviate or exacerbate any existing Co limitation. Improved definition of biological Co limitation thresholds and efforts to reconstruct the Co cycle in past climates may resolve whether future changes in OMZ structure will have meaningful impacts on phytoplankton nutrition in the coming century.

\section{References}

Ahlgren, N. A., Noble, A. E., Patton, A. P., Roache-Johnson, K., Jackson, L., Robinson, D., McKay, C., Moore, L. R., Saito, M. A. and Rocap, G.: The unique trace metal and mixed layer conditions of the Costa Rica upwelling dome support a distinct and dense community of Synechococcus, Limnol. Oceanogr., 59(6), 2166-2184, doi:10.4319/lo.2014.59.6.2166, 2014.

Alongi, D. M., Boyle, S. G., Tirendi, F. and Payn, C.: Composition and Behaviour of Trace Metals in Post-oxic Sediments of the Gulf of Papua, Papua New Guinea, Estuar. Coast. Shelf Sci., 42(2), 197-211, doi:10.1006/ecss.1996.0015, 1996.

Baars, O. and Croot, P. L.: Dissolved cobalt speciation and reactivity in the eastern tropical North Atlantic, Mar. Chem., doi:10.1016/j.marchem.2014.10.006, 2015.

Baxter, L. A., Bobrowski, A., Bond, A. M., Heath, G. A, Paul, R. L., Mrzljak, R. and Zarebski, J.: Electrochemical and spectroscopic investigation of the reduction of dimethylglyoxime at mercury electrodes in the presence of cobalt and nickel, Anal. Chem., 70(7), 1312-23, doi:10.1021/ac9703616, 1998.

Biller, D. V. and Bruland, K. W.: Sources and distributions of Mn, Fe, Co, Ni, Cu, Zn, and Cd relative to macronutrients along the central California coast during the spring and summer upwelling season, Mar. Chem., 155, 50-70, doi:10.1016/j.marchem.2013.06.003, 2013.

Böning, P., Brumsack, H. J., Böttcher, M. E., Schnetger, B., Kriete, C., Kallmeyer, J. and Borchers, S. L.: Geochemistry of Peruvian near-surface sediments, Geochim. Cosmochim. Acta, 68(21), 4429-4451, doi:10.1016/j.gca.2004.04.027, 2004.

Böning, P., Brumsack, H. J., Schnetger, B. and Grunwald, M.: Trace element signatures of Chilean upwelling sediments at $\sim 36^{\circ} \mathrm{S}$, Mar. Geol., 259(1-4), 112-121, doi:10.1016/j.margeo.2009.01.004, 2009.

Borchers, S. L., Schnetger, B., Böning, P. and Brumsack, H.-J.: Geochemical signatures of the Namibian diatom belt: Perennial upwelling and intermittent anoxia, Geochem., Geophys. Geosyst., 6(6), doi:10.1029/2004GC000886, 2005.

Bown, J., Boye, M., Baker, A., Duvieilbourg, E., Lacan, F., Le Moigne, F., Planchon, F., Speich, S. and Nelson, D. M.: The biogeochemical cycle of dissolved cobalt in the Atlantic and the Southern Ocean south off the coast of South Africa, Mar. Chem., 126(1-4), 193-206, doi:10.1016/j.marchem.2011.03.008, 2011.

Bown, J., Boye, M. and Nelson, D. M.: New insights on the role of organic speciation in the 
biogeochemical cycle of dissolved cobalt in the southeastern Atlantic and the Southern Ocean, Biogeosciences, 9(7), 2719-2736, doi:10.5194/bg-9-2719-2012, 2012.

Bremner, J. M. and Willis, J. P.: Mineralogy and geochemistry of the clay fraction of sediments from the Namibian continental margin and the adjacent hinterland, Mar. Geol., 115(1-2), 85116, doi:10.1016/0025-3227(93)90076-8, 1993.

Bruland, K. W.: Complexation of zinc by natural organic ligands in the central North Pacific, Limnol. Oceanogr., 34(2), 269-285, doi:10.4319/lo.1989.34.2.0269, 1989.

Bruland, K. W. and Lohan, M. C.: Controls of Trace Metals in Seawater, Treatise Geochemistry Second Ed., 6, 23-47, doi:10.1016/B978-0-08-095975-7.00602-1, 2003.

Bruland, K. W., Rue, E. L., Smith, G. J. and DiTullio, G. R.: Iron, macronutrients and diatom blooms in the Peru upwelling regime: brown and blue waters of Peru, Mar. Chem., 93(2-4), 81103, doi:10.1016/j.marchem.2004.06.011, 2005.

Brumsack, H. J.: Geochemistry of recent TOC-rich sediments from the Gulf of California and the Black Sea, Geol. Rundschau, 78(3), 851-882, doi:10.1007/BF01829327, 1989.

Brumsack, H. J.: The trace metal content of recent organic carbon-rich sediments: Implications for Cretaceous black shale formation, Palaeogeogr. Palaeoclimatol. Palaeoecol., 232(2-4), 344361, doi:10.1016/j.palaeo.2005.05.011, 2006.

Chang, B. X., Devol, A. H. and Emerson, S. R.: Denitrification and the nitrogen gas excess in the eastern tropical South Pacific oxygen deficient zone, Deep Sea Res. Part I Oceanogr. Res. Pap., 57(9), 1092-1101, doi:10.1016/j.dsr.2010.05.009, 2010.

Cowen, J. P. and Bruland, K. W.: Metal deposits associated with bacteria: implications for Fe and Mn marine biogeochemistry, Deep Sea Res. Part A. Oceanogr. Res. Pap., 32(3), 253-272, doi:10.1016/0198-0149(85)90078-0, 1985.

Cutter, G. A. and Bruland, K. W.: Rapid and noncontaminating sampling system for trace elements in global ocean surveys, Limnol. Oceanogr. Methods, 10(6), 425-436, doi:10.4319/lom.2012.10.425, 2012.

Deutsch, C., Gruber, N., Key, R. M., Sarmiento, J. L. and Ganachaud, A.: Denitrification and N2 fixation in the Pacific Ocean, Global Biogeochem. Cycles, 15(2), 483-506, doi:10.1029/2000GB001291, 2001.

Deutsch, C., Brix, H., Ito, T. and Thompson, L.: Climate-forced variability of ocean hypoxia, Science, 333(6040), 336-339, doi:10.1126/science.1202422, 2011.

Deutsch, C., Berelson, W., Thunell, R., Weber, T., Tems, C., McManus, J., Crusius, J., Ito, T., Baumgartner, T., Ferreira, V., Mey, J. and van Geen, A.: Centennial changes in North Pacific anoxia linked to tropical trade winds, Science (80-. )., 345(6197), 665-668, doi:10.1126/science.1252332, 2014.

DeVries, T. and Deutsch, C.: Large-scale variations in the stoichiometry of marine organic matter respiration, Nat. Geosci., 7(November), 1-5, doi:10.1038/ngeo2300, 2014.

DeVries, T., Deutsch, C., Primeau, F., Chang, B. and Devol, A.: Global rates of water-column denitrification derived from nitrogen gas measurements, Nat. Geosci., 5(8), 547-550, doi:10.1038/ngeo1515, 2012. 
Dulaquais, G., Boye, M., Middag, R., Owens, S., Puigcorbe, V., Buesseler, K., Masqué, P., de Baar, H. J. W. and Carton, X.: Contrasting biogeochemical cycles of cobalt in the surface western Atlantic Ocean, Global Biogeochem. Cycles, 28(12), 1387-1412, doi:10.1002/2014GB004903, 2014a.

Dulaquais, G., Boye, M., Rijkenberg, M. J. and Carton, X.: Physical and remineralization processes govern the cobalt distribution in the deep western Atlantic Ocean, Biogeosciences, 11(6), 1561-1580, doi:10.5194/bg-11-1561-2014, 2014 b.

Dunk, R. M. and Mills, R. A.: The impact of oxic alteration on plume-derived transition metals in ridge flank sediments from the East Pacific Rise, Mar. Geol., 229(3-4), 133-157, doi:10.1016/j.margeo.2006.03.007, 2006.

Dunlea, A. G., Murray, R. W. and Harris, R. N.: Cobalt-based age models of pelagic clay in the South Pacific Gyre, Geochem., Geophys. Geosyst., 16(8), 2964-2710, doi:10.1029/2004GC000886, 2015.

Ellwood, M. J. and van den Berg, C. M.: Determination of organic complexation of cobalt in seawater by cathodic stripping voltammetry, Mar. Chem., 75(1-2), 33-47, doi:10.1016/S03044203(01)00024-X, 2001.

Fiedler, P. C. and Talley, L. D.: Hydrography of the eastern tropical Pacific: A review, Prog. Oceanogr., 69(2-4), 143-180, doi:10.1016/j.pocean.2006.03.008, 2006.

Fuenzalida, R., Schneider, W., Garcés-Vargas, J., Bravo, L. and Lange, C.: Vertical and horizontal extension of the oxygen minimum zone in the eastern South Pacific Ocean, Deep Sea Res. Part II Top. Stud. Oceanogr., 56(16), 992-1003, doi:10.1016/j.dsr2.2008.11.001, 2009.

Gaillardet, J., Viers, J. and Dupré, B.: Trace Elements in River Waters, in Treatise on Geochemistry, vol. 5, pp. 225-272, Elsevier., 2003.

Goldberg, E. D. and Arrhenius, G.O.S.: Chemistry of Pacific pelagic sediments, Geochim. Cosmochim. Acta, 13(2), 153-212, doi:10.1016/0016-7037(58)90046-2, 1958.

Heggie, D. and Lewis, T.: Cobalt in pore waters of marine sediments, Nature, 311(5985), 453455, doi:10.1038/311453a0, 1984.

Hu, D., Böning, P., Köhler, C. M., Hillier, S., Pressling, N., Wan, S., Brumsack, H. J. and Clift, P. D.: Deep sea records of the continental weathering and erosion response to East Asian monsoon intensification since 14ka in the South China Sea, Chem. Geol., 326-327, 1-18, doi:10.1016/j.chemgeo.2012.07.024, 2012.

Hu, D., Clift, P. D., Boning, P., Hannigan, R., Hillier, S., Blusztajn, J., Wan, S. and Fuller, D. Q.: Holocene evolution in weathering and erosion patterns in the Pearl River delta, Geochem., Geophys. Geosyst., 14(7), 2349-2368, doi:10.1002/ggge.20166, 2013.

Jakuba, R. W., Moffett, J. W. and Dyhrman, S. T.: Evidence for the linked biogeochemical cycling of zinc, cobalt, and phosphorus in the western North Atlantic Ocean, Global Biogeochem. Cycles, 22(4), 1-13, doi:10.1029/2007GB003119, 2008.

Johnson, K. S., Stout, P. M., Berelson, W. M. and Sakamoto-Arnold, C. M.: Cobalt and copper distributions in the waters of Santa Monica Basin, California, Nature, 332(6164), 527-530, doi:10.1038/332527a0, 1988. 
Johnson, K. S., Coale, K. H., Berelson, W. M. and Michael Gordon, R.: On the formation of the manganese maximum in the oxygen minimum, Geochim. Cosmochim. Acta, 60(8), 1291-1299, doi:10.1016/0016-7037(96)00005-1, 1996.

Karstensen, J., Stramma, L. and Visbeck, M.: Oxygen minimum zones in the eastern tropical Atlantic and Pacific oceans, Prog. Oceanogr., 77(4), 331-350, doi:10.1016/j.pocean.2007.05.009, 2008.

Knauer, G. A., Martin, J. H. and Gordon, R. M.: Cobalt in north-east Pacific waters, Nature, 297(5861), 49-51, doi:10.1038/297049a0, 1982.

von Langen, P. J., Johnson, K. S., Coale, K. H. and Elrod, V. A.: Oxidation kinetics of manganese (II) in seawater at nanomolar concentrations, Geochim. Cosmochim. Acta, 61(23), 4945-4954, doi:10.1016/S0016-7037(97)00355-4, 1997.

Lupton, J. E., Delaney, J. R., Johnson, H. P. and Tivey, M. K.: Entrainment and vertical transport of deep-ocean water by buoyant hydrothermal plumes, Nature, 316(6029), 621-623, doi:10.1038/316621a0, 1985.

Lyle, M.: Formation and growth of ferromanganese oxides on the Nazca plate, Geological Society of America Memoirs, 154, 269-295, doi:10.1130/MEM154-p269, 1981.

Mahowald, N. M., Baker, A. R., Bergametti, G., Brooks, N., Duce, R. a., Jickells, T. D., Kubilay, N., Prospero, J. M. and Tegen, I.: Atmospheric global dust cycle and iron inputs to the ocean, Global Biogeochem. Cycles, 19(4), doi:10.1029/2004GB002402, 2005.

McLennan, S. M.: Relationships between the trace element composition of sedimentary rocks and upper continental crust, Geochem., Geophys. Geosyst., 2(4), doi:10.1029/2000GC000109, 2001.

Metz, S. and Trefry, J. H.: Chemical and mineralogical influences on concentrations of trace metals in hydrothermal fluids, Geochim. Cosmochim. Acta, 64(13), 2267-2279, doi:10.1016/S0016-7037(00)00354-9, 2000.

Milliman, J. D. and Farnsworth, K. L.: River Discharge to the Coastal Ocean, Cambridge University Press, Cambridge., 2011.

Moffett, J. W.: A radiotracer study of cerium and manganese uptake onto suspended particles in Chesapeake Bay, Geochim. Cosmochim. Acta, 58(2), 695-703, doi:10.1016/00167037(94)90499-5, 1994.

Moffett, J. W. and Ho, J.: Oxidation of cobalt and manganese in seawater via a common microbially catalyzed pathway, Geochim. Cosmochim. Acta, 60(18), 3415-3424, doi:10.1016/0016-7037(96)00176-7, 1996.

Moore, C. M., Mills, M. M., Arrigo, K. R., Berman-Frank, I., Bopp, L., Boyd, P. W., Galbraith, E. D., Geider, R. J., Guieu, C., Jaccard, S. L., Jickells, T. D., La Roche, J., Lenton, T. M., Mahowald, N. M., Marañón, E., Marinov, I., Moore, J. K., Nakatsuka, T., Oschlies, A., Saito, M. A, Thingstad, T. F., Tsuda, A. and Ulloa, O.: Processes and patterns of oceanic nutrient limitation, Nat. Geosci., 6(9), 701-710, doi:10.1038/ngeo1765, 2013.

Morse, J. W. and Luther, G. W.: Chemical influence on trace metal-sulfide interactions in anoxic sediments, Geochim. Cosmochim. Acta, 63(3373-3378), 3378, 1999. 
Noble, A. E. and Saito, M. A.: Total Dissolved Cobalt and Cobalt Speciation from the US North Atlantic GEOTRACES Zonal Transect, in prep.

Noble, A. E., Saito, M. A., Maiti, K. and Benitez-Nelson, C. R.: Cobalt, manganese, and iron near the Hawaiian Islands: A potential concentrating mechanism for cobalt within a cyclonic eddy and implications for the hybrid-type trace metals, Deep Sea Res. Part II Top. Stud. Oceanogr., 55(10-13), 1473-1490, doi:10.1016/j.dsr2.2008.02.010, 2008.

Noble, A. E., Lamborg, C. H., Ohnemus, D. C., Lam, P. J., Goepfert, T. J., Measures, C. I., Frame, C. H., Casciotti, K. L., DiTullio, G. R., Jennings, J. and Saito, M. A.: Basin-scale inputs of cobalt, iron, and manganese from the Benguela-Angola front to the South Atlantic Ocean, Limnol. Oceanogr., 57(4), 989-1010, doi:10.4319/lo.2012.57.4.0989, 2012.

Ohnemus, D., Rauschenberg, S., Cutter, G. A. and Twining, B. S.: Elevated trace metal content of prokaryotic plankton communities associated with anoxic marine zones. Limnol. Oceanogr., doi:10.1002/lno.10363, In Press.

Price, N. M., Harrison, G. I., Hering, J. G., Hudson, R. J., Nirel, P. M. V., Palenik, B. and Morel, F. M. M.: Preparation and Chemistry of the Artificial Algal Culture Medium Aquil, Biol. Oceanogr., 6(5-6), 443-461, doi:10.1080/01965581.1988.10749544, 1989.

Prospero, J. M. and Bonatti, E.: Continental dust in the atmosphere of the Eastern Equatorial Pacific, J. Geophys. Res., 74(13), 3362-3371, doi:10.1029/JC074i013p03362, 1969.

Resing, J. A., Sedwick, P. N., German, C. R., Jenkins, W. J., Moffett, J. W., Sohst, B. M. and Tagliabue, A.: Basin-scale transport of hydrothermal dissolved metals across the South Pacific Ocean, Nature, 523(7559), 200-203, doi:10.1038/nature14577, 2015.

Saito, M. A. and Moffett, J. W.: Complexation of cobalt by natural organic ligands in the Sargasso Sea as determined by a new high-sensitivity electrochemical cobalt speciation method suitable for open ocean work, Mar. Chem., 75(1-2), 49-68, doi:10.1016/S0304-4203(01)00025$1,2001$.

Saito, M. A. and Moffett, J. W.: Temporal and spatial variability of cobalt in the Atlantic Ocean, Geochim. Cosmochim. Acta, 66(11), 1943-1953, doi:10.1016/S0016-7037(02)00829-3, 2002.

Saito, M. A., Moffett, J. W., Chisholm, S. W. and Waterbury, J. B.: Cobalt limitation and uptake in Prochlorococcus, Limnol. Oceanogr., 47(6), 1629-1636, doi:10.4319/lo.2002.47.6.1629, 2002.

Saito, M. A., Moffett, J. W. and DiTullio, G. R.: Cobalt and nickel in the Peru upwelling region: A major flux of labile cobalt utilized as a micronutrient, Global Biogeochem. Cycles, 18(4), doi:10.1029/2003GB002216, 2004.

Saito, M. A., Rocap, G. and Moffett, J. W.: Production of cobalt binding ligands in a Synechococcus feature at the Costa Rica upwelling dome, Limnol. Oceanogr., 50(1), 279-290, doi:10.4319/lo.2005.50.1.0279, 2005.

Saito, M. A., Goepfert, T. J., Noble, A. E., Bertrand, E. M., Sedwick, P. N. and DiTullio, G. R.: A seasonal study of dissolved cobalt in the Ross Sea, Antarctica: micronutrient behavior, absence of scavenging, and relationships with Zn, Cd, and P, Biogeosciences, 7(12), 4059-4082, doi:10.5194/bg-7-4059-2010, 2010.

Saito, M. A., McIlvin, M. R., Moran, D. M., Goepfert, T. J., DiTullio, G. R., Post, A. F. and 
Lamborg, C. H.: Multiple nutrient stresses at intersecting Pacific Ocean biomes detected by protein biomarkers, Science, 345(6201), 1173-1177, doi:10.1126/science.1256450, 2014.

Sarmiento, J. L., Gruber, N., Brzezinski, M. A. and Dunne, J. P.: High-latitude controls of thermocline nutrients and low latitude biological productivity, Nature, 479(7374), 556-556, doi:10.1038/nature10605, 2011.

Scheidegger, K. F. and Krissek, L. A.: Dispersal and deposition of eolian and fluvial sediments off Peru and northern Chile, Geol. Soc. Am. Bull., 93(2), 150, doi:10.1130/00167606(1982)93<150:DADOEA>2.0.CO;2, 1982.

Scholz, F., Hensen, C., Noffke, A., Rohde, A., Liebetrau, V. and Wallmann, K.: Early diagenesis of redox-sensitive trace metals in the Peru upwelling area - response to ENSO-related oxygen fluctuations in the water column, Geochim. Cosmochim. Acta, 75(22), 7257-7276, doi:10.1016/j.gca.2011.08.007, 2011.

Scholz, F., McManus, J., Mix, A. C., Hensen, C. and Schneider, R. R.: The impact of ocean deoxygenation on iron release from continental margin sediments, Nat. Geosci., 7(May), 433437, doi:10.1038/ngeo2162, 2014.

Shaked, Y., Xu, Y., Leblanc, K. and Morel, F. M. M.: Zinc availability and alkaline phosphatase activity in Emiliania huxleyi: Implications for Zn-P co-limitation in the ocean, Limnol. Oceanogr., 51(1), 299-309, doi:10.4319/lo.2006.51.1.0299, 2006.

Shelley, R. U., Sedwick, P. N., Bibby, T. S., Cabedo-Sanz, P., Church, T. M., Johnson, R. J., Macey, A. I., Marsay, C. M., Sholkovitz, E. R., Ussher, S. J., Worsfold, P. J. and Lohan, M. C.: Controls on dissolved cobalt in surface waters of the Sargasso Sea: Comparisons with iron and aluminum, Global Biogeochem. Cycles, 26(2), doi:10.1029/2011GB004155, 2012.

Sholkovitz, E. R. and Copland, D.: The coagulation, solubility and adsorption properties of Fe, $\mathrm{Mn}, \mathrm{Cu}, \mathrm{Ni}, \mathrm{Cd}$, Co and humic acids in a river water, Geochim. Cosmochim. Acta, 45(2), 181189, doi:10.1016/0016-7037(81)90161-7, 1981.

Slemons, L. O., Murray, J. W., Resing, J., Paul, B. and Dutrieux, P.: Western Pacific coastal sources of iron, manganese, and aluminum to the Equatorial Undercurrent, Global Biogeochem. Cycles, 24(3), doi:10.1029/2009GB003693, 2010.

Stramma, L., Johnson, G. C., Sprintall, J. and Mohrholz, V.: Expanding Oxygen-Minimum Zones in the Tropical Oceans, Science, 320(5876), 655-658, doi:10.1126/science.1153847, 2008.

Stramma, L., Johnson, G. C., Firing, E. and Schmidtko, S.: Eastern Pacific oxygen minimum zones: Supply paths and multidecadal changes, J. Geophys. Res., 115(C9), C09011, doi:10.1029/2009JC005976, 2010.

Sunda, W. G. and Huntsman, S. A.: Diel cycles in microbial manganese oxidation and manganese redox speciation in coastal waters of the Bahama Islands, Limnol. Oceanogr., 35(2), 325-338, doi:10.4319/lo.1990.35.2.0325, 1990.

Sunda, W. G. and Huntsman, S. A.: Microbial oxidation of manganese in a North Carolina estuary, Limnol. Oceanogr., 32(3), 552-564, doi:10.4319/lo.1987.32.3.0552, 1987.

Sunda, W. G. and Huntsman, S. A.: Feedback interactions between zinc and phytoplankton in 
seawater, Limnol. Oceanogr., 37(1), 25-40, doi:10.4319/1o.1992.37.1.0025, 1992.

Sunda, W. G. and Huntsman, S. A.: Cobalt and zinc interreplacement in marine phytoplankton: biological and geochemical implications, Limnol. Oceanogr., 40(8), 1404-1417, doi:10.4319/lo.1995.40.8.1404, 1995.

Sundby, B., Anderson, L. G., Hall, P. O. J., Iverfeldt, Å, van der Loeff, M. M. R. and Westerlund, S. F. G.: The effect of oxygen on release and uptake of cobalt, manganese, iron and phosphate at the sediment-water interface, Geochim. Cosmochim. Acta, 50(6), 1281-1288, doi:10.1016/0016-7037(86)90411-4, 1986.

Swanner, E. D., Planavsky, N. J., Lalonde, S. V., Robbins, L. J., Bekker, A., Rouxel, O. J., Saito, M. A., Kappler, A., Mojzsis, S. J. and Konhauser, K. O.: Cobalt and marine redox evolution, Earth Planet. Sci. Lett., 390, 253-263, doi:10.1016/j.epsl.2014.01.001, 2014.

Taylor, S. R. and McLennan, S. M.: The geochemical evolution of the continental crust, Rev. Geophys., 33(2), 241, doi:10.1029/95RG00262, 1995.

Toggweiler, J. R., Dixon, K. and Broecker, W. S.: The Peru upwelling and the ventilation of the South Pacific thermocline, J. Geophys. Res., 96(C11), 20467, doi:10.1029/91JC02063, 1991.

Tovar-Sánchez, A., Sañudo-Wilhelmy, S. A. and Flegal, A. R.: Temporal and spatial variations in the biogeochemical cycling of cobalt in two urban estuaries: Hudson River Estuary and San Francisco Bay, Estuar. Coast. Shelf Sci., 60(4), 717-728, doi:10.1016/j.ecss.2004.03.010, 2004.

Twining, B. S. and Baines, S. B.: The Trace Metal Composition of Marine Phytoplankton, Ann. Rev. Mar. Sci., 5(1), 191-215, doi:10.1146/annurev-marine-121211-172322, 2013.

Ulloa, O., Canfield, D. E., DeLong, E. F., Letelier, R. M. and Stewart, F. J.: Microbial oceanography of anoxic oxygen minimum zones., Proc. Natl. Acad. Sci. U. S. A., 109(40), 15996-6003, doi:10.1073/pnas.1205009109, 2012.

Yee, D. and Morel, F. M. M.: In vivo substitution of zinc by cobalt in carbonic anhydrase of a marine diatom, Limnol. Oceanogr., 41(3), 573-577, doi:10.4319/lo.1996.41.3.0573, 1996. 
Table 1. Blanks and standards used during analyses.

\begin{tabular}{|c|c|c|c|c|c|}
\hline & \multicolumn{2}{|c|}{$\mathrm{dCo}, \mathrm{pM}$} & $+/-$ & n & Consensus \\
\hline \multirow{3}{*}{$\begin{array}{l}\text { At sea } \\
\text { Oct - Dec, } \\
2013\end{array}$} & Blank & 3.7 & 1.2 & 28 & \multirow[b]{3}{*}{$46.6 \pm 4.8$} \\
\hline & $\mathrm{Lab} \mathrm{SW}^{*}$ & 4.5 & 2.1 & 28 & \\
\hline & D1 & 48.5 & 2.4 & 3 & \\
\hline \multirow{4}{*}{$\begin{array}{l}\text { At WHOI, } \\
\text { Sept - Nov, } \\
2014\end{array}$} & Bla & 4.7 & 1.4 & 12 & \multirow{4}{*}{$\begin{array}{l}4.9 \pm 1.2 * * \\
46.9 \pm 3.0 \\
* * *\end{array}$} \\
\hline & GSP & 2.5 & 2.0 & 10 & \\
\hline & D2 & 45.0 & 2.7 & 7 & \\
\hline & GSC & 77.7 & 2.4 & 4 & \\
\hline
\end{tabular}

* South Pacific surface seawater, collected Nov. 2011

***Refers to SAFe standard S, collected at the same location as GSP

$* * *$ No consensus 
Table 2. Co/Al ratios in sediments from different redox regimes.

\begin{tabular}{|c|c|c|c|}
\hline Location & \multicolumn{2}{|c|}{$\mathrm{Co} / \mathrm{Al} \times \mathrm{10}^{-4}\left(\mathrm{~g} \mathrm{~g}^{-1}\right)$} & Reference \\
\hline \multicolumn{4}{|l|}{ Crust } \\
\hline Upper continental crust & \multicolumn{2}{|l|}{2.11} & McLennan 2001 \\
\hline Andesitic crust & \multicolumn{2}{|l|}{2.63} & Taylor and McLennan 1995 \\
\hline \multicolumn{4}{|l|}{ Eastern Boundary sediments } \\
\hline Peru Upwelling Sediments & $1.2 \pm 0.3$ & $9-14^{\circ} \mathrm{S}$ & Boning et al. 2004 \\
\hline Chile upwelling Sediments & $1.3 \pm 0.1$ & $36^{\circ} \mathrm{S}$ & Boning et al. 2009 \\
\hline Gulf of California & 1.4 & $22-30^{\circ} \mathrm{N}$ & Brumsack 1989 \\
\hline Namibian Shelf & $1.0 \pm 0.3$ & $17-25^{\circ} \mathrm{S}$, 'Terrigenous' & Bremner and Willis 1993 \\
\hline \multicolumn{4}{|l|}{ Sulfidic Sediments } \\
\hline Namibian diatom belt & $2.9 \pm 0.7$ & Near Walvis Bay, $22.5^{\circ} \mathrm{S}$ & Borchers et al. 2005 \\
\hline Black Sea & $3.8-6.2$ & & Brumsack 2006 \\
\hline \multicolumn{4}{|l|}{ Western Boundary Sediments } \\
\hline Papua New Guinea & 2.3 & $8^{\circ} \mathrm{S}$, Gulf of Papua & Alongi et al. 1996 \\
\hline Pearl River Delta & $2.2 \pm 0.4$ & $22^{\circ} \mathrm{N},(10-0 \mathrm{ka})$ & Hu et al. 2013 \\
\hline South China Sea Shelf Slope & $2.1 \pm 0.2$ & $20^{\circ} \mathrm{N}, 2037 \mathrm{~m}(14-0 \mathrm{ka})$ & Hu et al. 2012 \\
\hline \multicolumn{4}{|l|}{ Deep Ocean Sediments } \\
\hline South Pacific Gyre & $35(2.9-101)$ & $22^{\circ} \mathrm{S}-32^{\circ} \mathrm{S}, 100-0 \mathrm{Ma}$ & Dunlea et al. 2015 \\
\hline Pelagic Pacific & $17(2-58)$ & $50^{\circ} \mathrm{N}-20^{\circ} \mathrm{S}$ & Goldberg and Arrhenius 195 \\
\hline
\end{tabular}




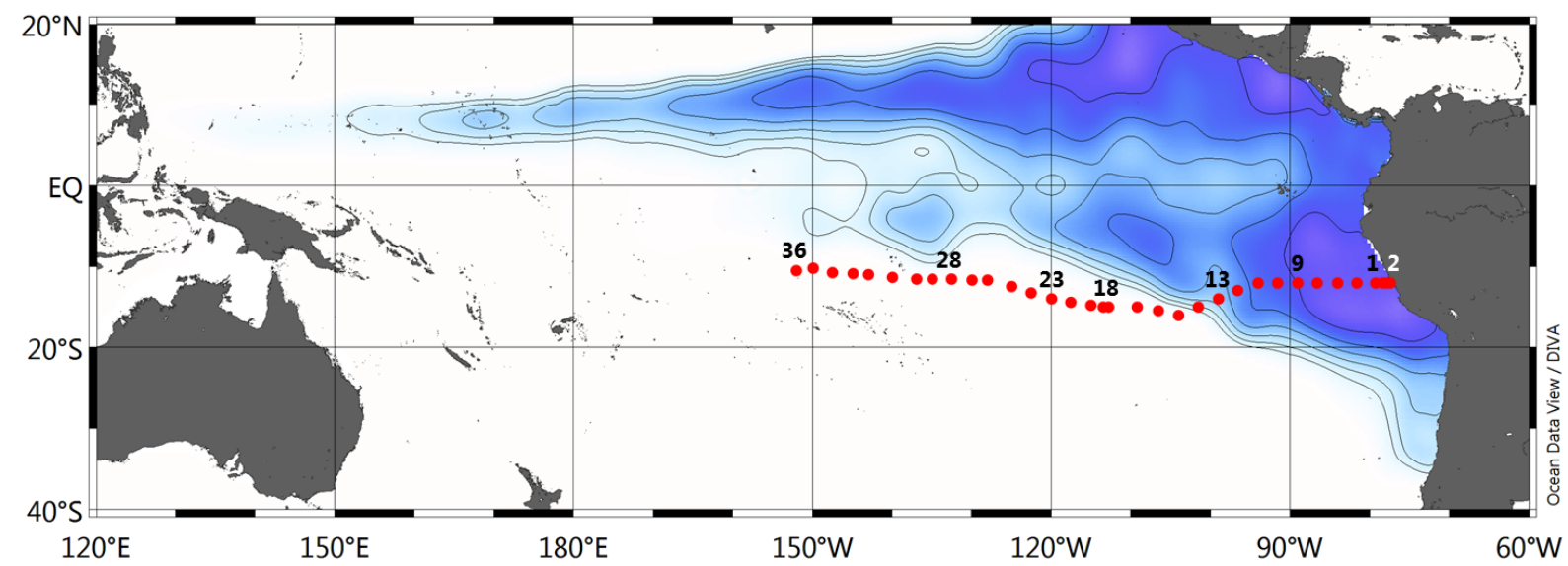

Figure 1. The GP16 transect in the tropical South Pacific. Red circles indicate sampling stations. Dissolved oxygen at a depth of $300 \mathrm{~m}$ from the WOCE dataset is plotted in blue and $10 \mu \mathrm{M}$ contours are shown between $0-60 \mu \mathrm{M} \mathrm{O}_{2}$. Station number increases sequentially westward, with the exception of Station 1. 


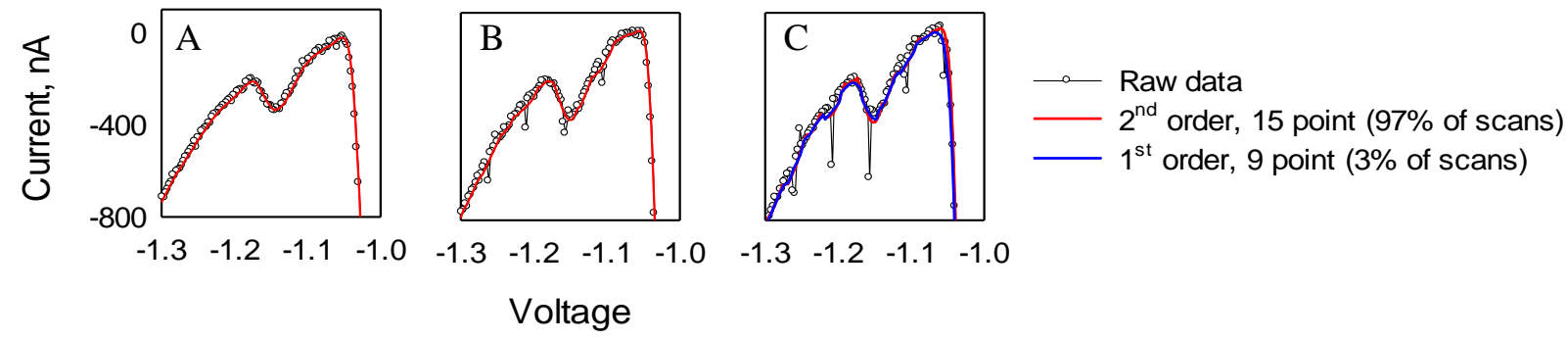

Figure 2. Signal processing of voltammetry scans. Varying instrumental noise imprinted negative current excursions during measurement and necessitated data smoothing to correctly measure the $\mathrm{Co}(\mathrm{DMG})_{2}$ reduction peak at $-1.15 \mathrm{~V}$. For mild (a) and moderate (b) noise levels, a $2^{\text {nd }}$ order, 17-point smoothing was applied (red line, $97 \%$ of scans). Increases in noise caused this routine to overestimate peak height (c, red line) and a first order, 13-point smoothing was applied instead ( $3 \%$ of scans, blue line). 

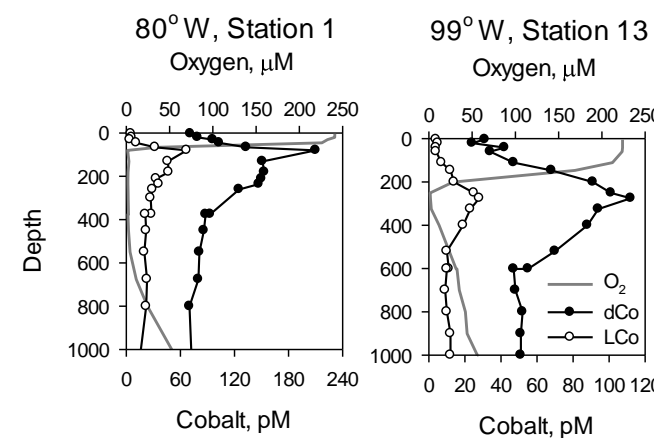

50100150200250
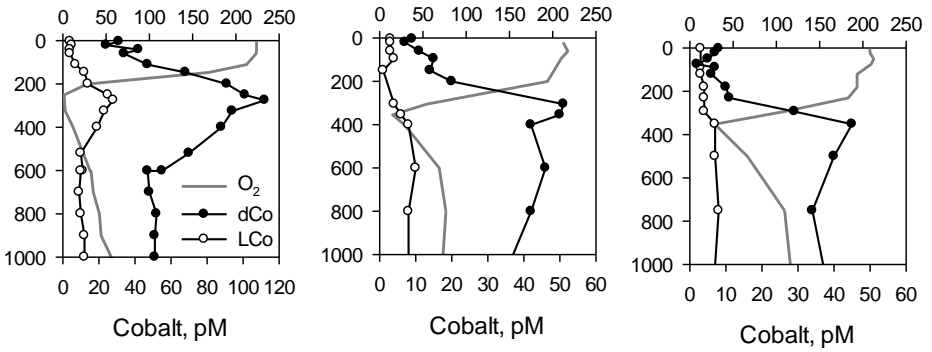

Oxygen, $\mu \mathrm{M}$
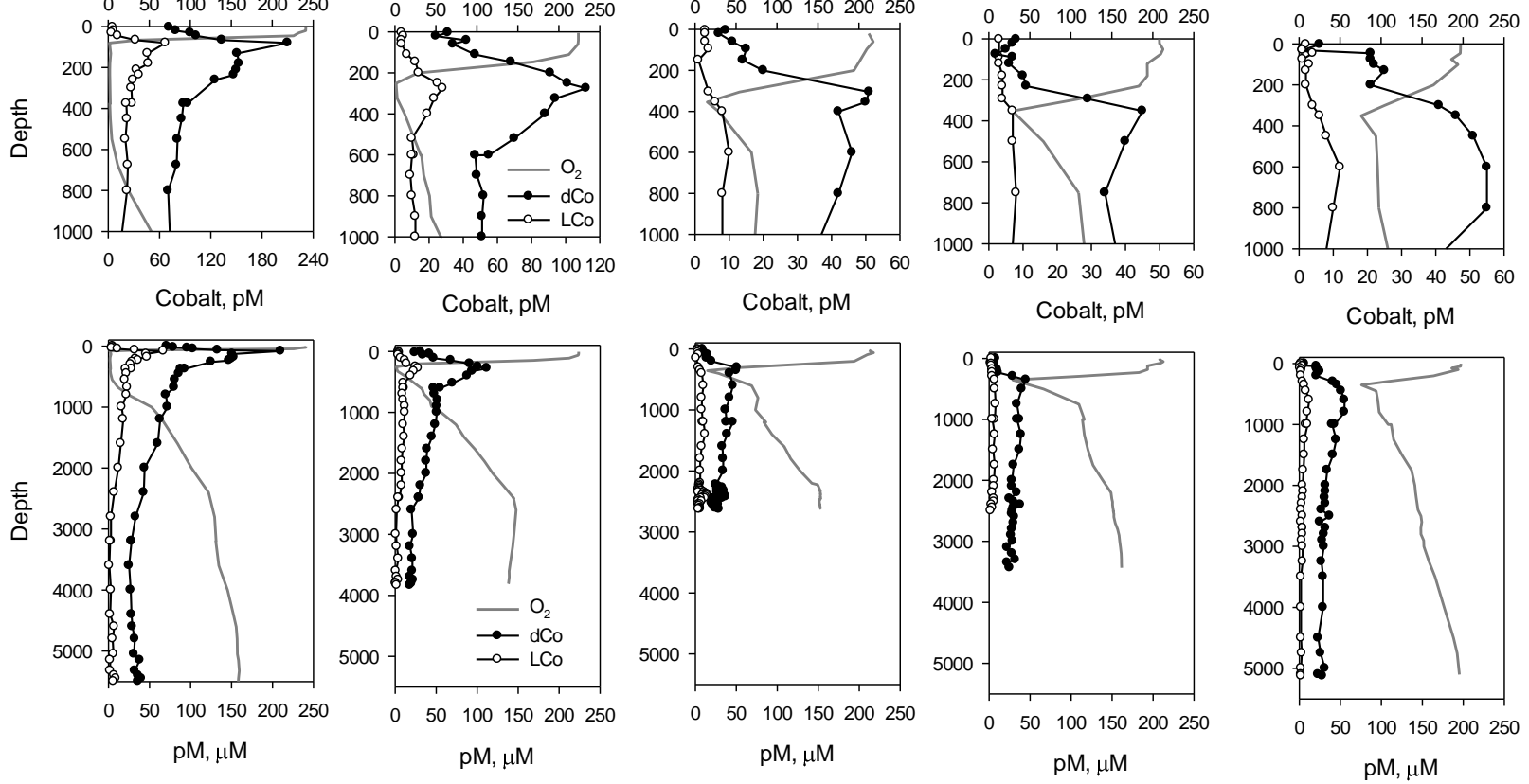

Figure 3. Profiles of dissolved cobalt (dCo, closed circles), labile dissolved cobalt (LCo, open circles) and $\mathrm{O}_{2}$ (grey lines) across the South Pacific. Upper panels show a 0-1000 $\mathrm{m}$ depth range; bottom panel show full profiles. dCo and LCo are highest close to the Peru Margin (Station 1) and decrease westward. $\mathrm{O}_{2}$ follows the opposite trend. The small peak at $2400 \mathrm{~m}$ at Station 18 shows peak hydrothermal input from the East Pacific Rise. Note that the dCo and LCo scales in the upper panel are adjusted to highlight gradients and differ from the lower panels. 

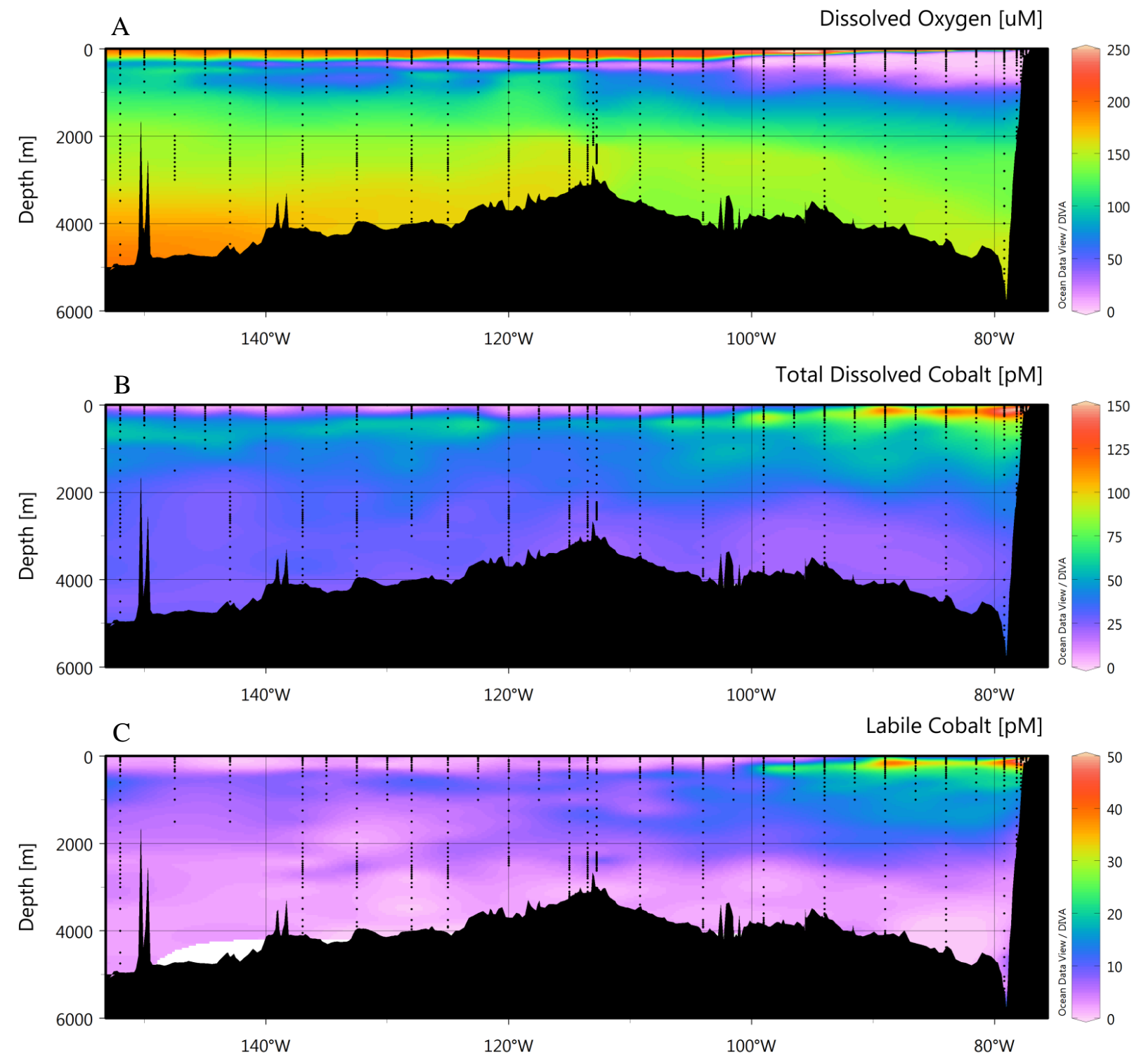

Figure 4. Dissolved oxygen (a), dissolved cobalt (b) and labile dissolved cobalt (c) sections along GP16, projected on a longitudinal axis. Note high dCo and LCo stem from the Peru margin and overlap with the low $\mathrm{O}_{2}$. Interpolations were made using Ocean Data View with DIVA gridding, with negative gridded values suppressed. The signal to noise ratio was set to 15 for dissolved cobalt and labile dissolved cobalt. Signal to noise for $\mathrm{O}_{2}$ was set to the default, 50 . 


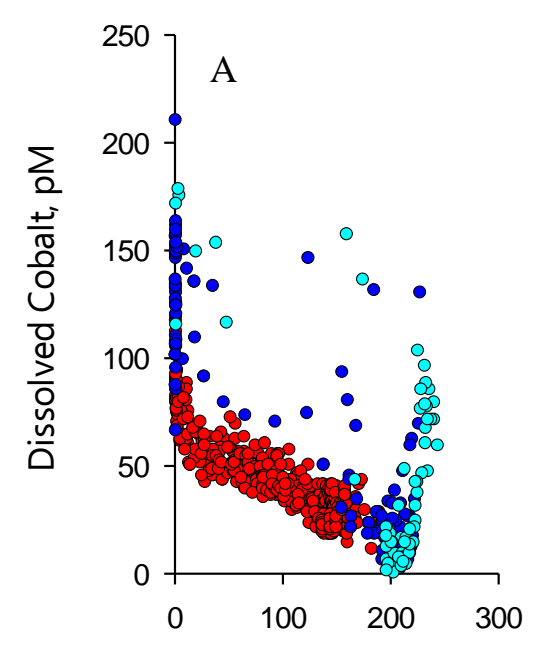

Dissolved Oxygen, $\mu \mathrm{M}$

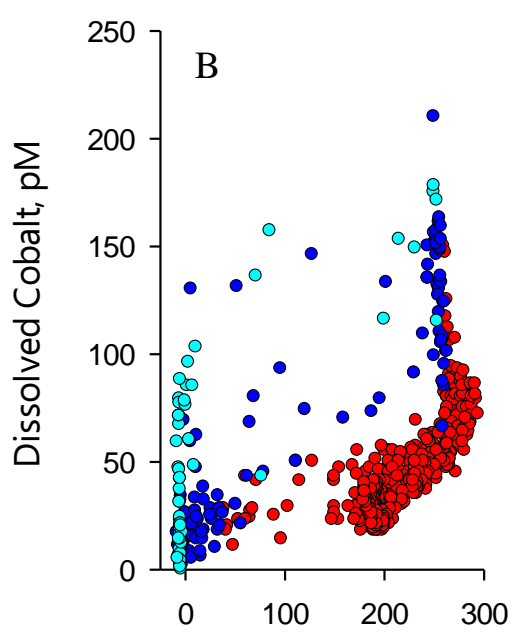

Apparent Oxygen Utilization, $\mu \mathrm{M}$

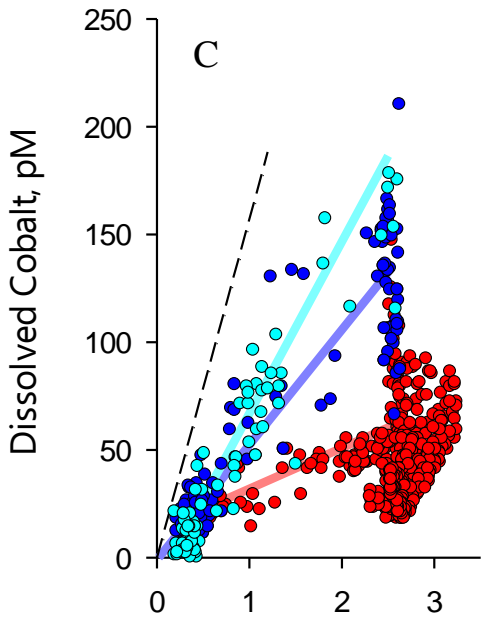

Dissolved Phosphate, $\mu \mathrm{M}$

Figure 5. Coupling between dissolved cobalt with $\mathrm{O}_{2}$ (a), $\mathrm{AOU}$ (b), and $\mathrm{PO}_{4}$ (c). Below $200 \mathrm{~m}$ (red circles), dCo shows a decreasing linear trend with dissolved oxygen that is obscured upon conversion of $\mathrm{O}_{2}$ to apparent oxygen utilization, $\mathrm{AOU}$, and a weak relationship with $\mathrm{PO}_{4}$. In the surface ocean (0-50 m, cyan circles), $\mathrm{dCo}$ and $\mathrm{PO}_{4}$ are strongly coupled but dCo shows no relationship with $\mathrm{O}_{2}$ or AOU. Samples from 50-200 m are plotted in blue. Trend lines in (c) show least-squares regressions of dCo and $\mathrm{PO}_{4}(0-50 \mathrm{~m}$, cyan; 50-200 m, blue; 200-1000 m, red). Also plotted is the median particulate Co:P ratio for $0-50 \mathrm{~m}\left(146 \mu \mathrm{M} \mathrm{M}^{-1}\right.$, dashed line). Major processes affecting these plots are described in vector legends. 

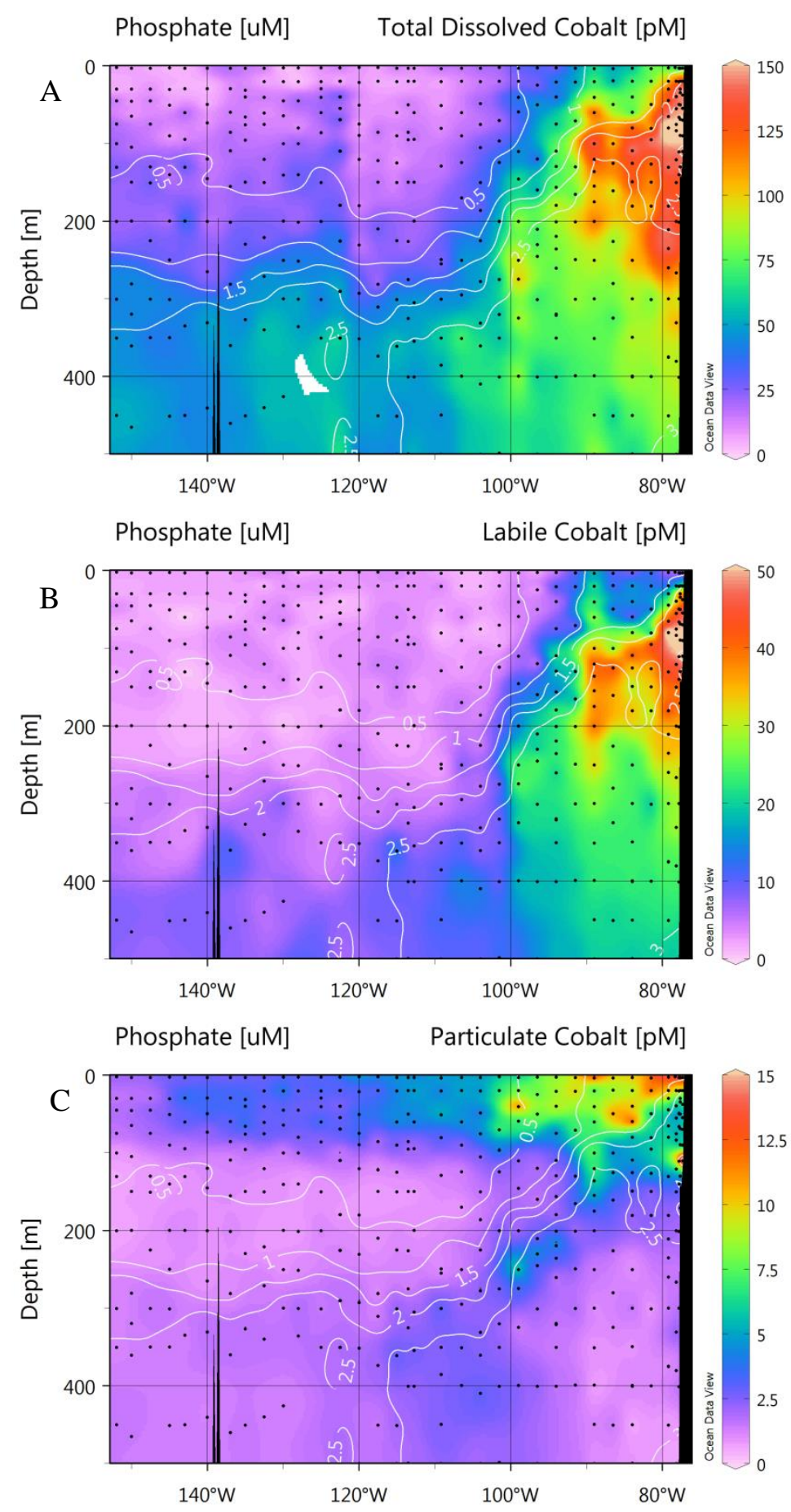

Figure 6. Dissolved cobalt (a), labile dissolved cobalt (b), and particulate cobalt (c) gradients in the upper $500 \mathrm{~m}$ of the ETSP. White lines in both panels show dissolved $\mathrm{PO}_{4}$ contours at $0.5 \mu \mathrm{M}$ increments. Interpolation was conducted using weight averaged gridding with 40 and $46 \%$ length scales in the $\mathrm{x}$ and $\mathrm{y}$ directions, respectively. 

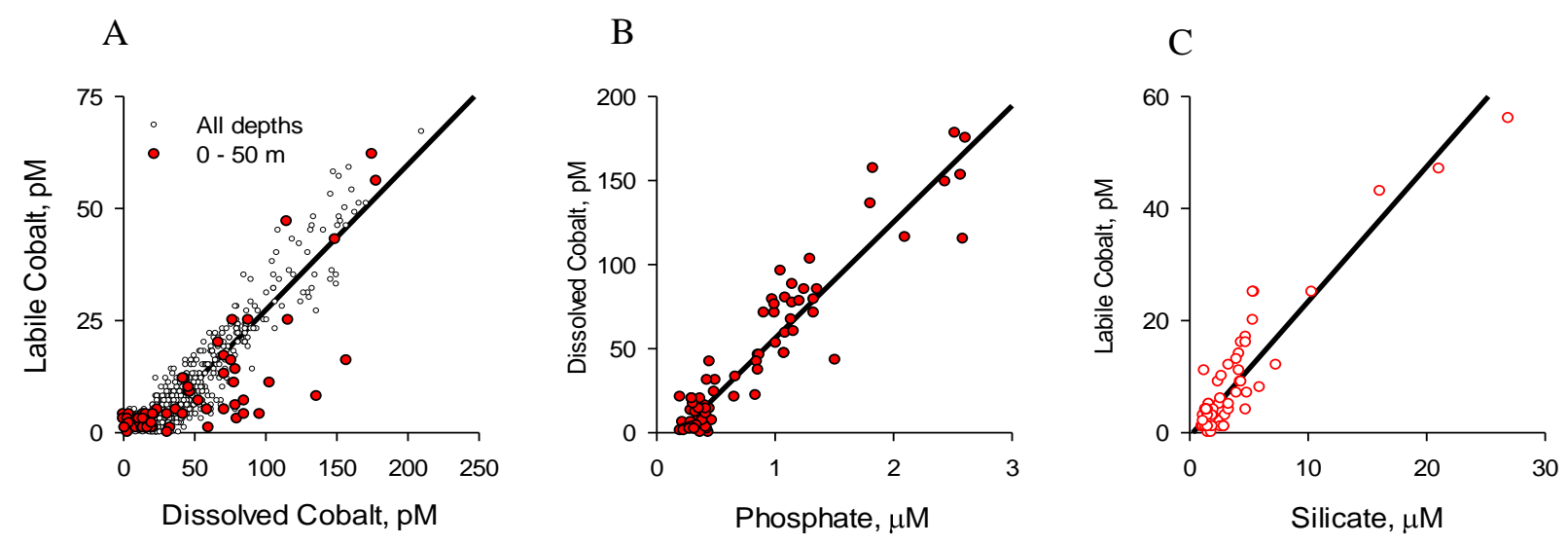

Figure 7. (a) The relationship between dissolved cobalt (dCo) and labile cobalt (LCo) in the South Pacific. LCo increases linearly with dCo with a slope of 0.33 (black dots, $\mathrm{R}^{2}=0.88$ ), except for the upper $50 \mathrm{~m}$ (red dots), where samples fall below this trend due to preferential depletion of LCo by phytoplankton. (b) In the 0-50 m range, dCo strongly correlates with phosphate $\left(R^{2}=0.89\right)$. (c) LCo is preferentially removed from surface waters $(0-50 \mathrm{~m})$ and tracks silicate $\left(\mathrm{R}^{2}=0.90\right)$. 
A

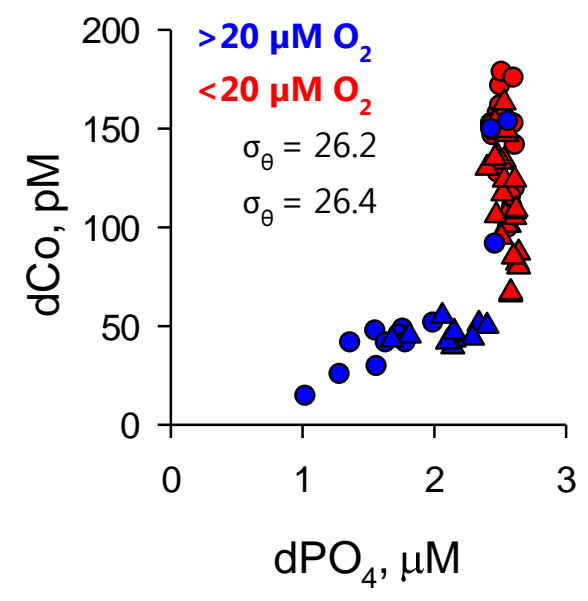

B

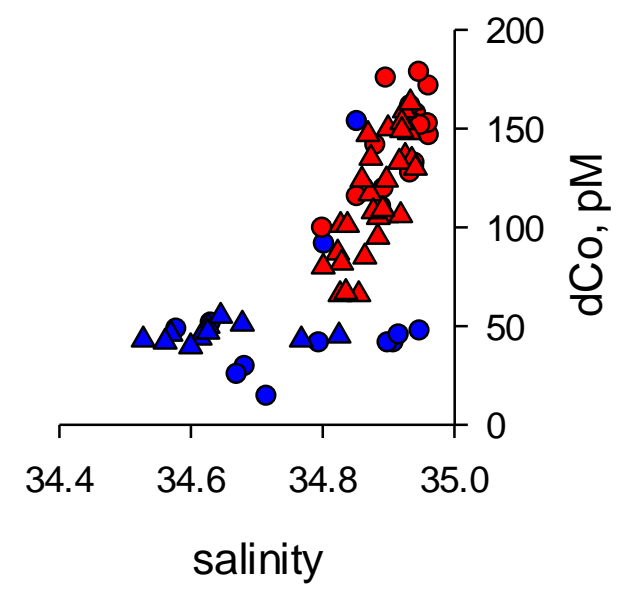

Figure 8. Transition in dCo cycling at the OMZ boundary in the upper South Pacific thermocline. (a) Isopycnal windows centered at $\sigma_{\theta}=26.2 \pm 0.1 \mathrm{~kg} \mathrm{~m}^{-3}$ (circles) and $\sigma_{\theta}=26.4 \pm$ $0.1 \mathrm{~kg} \mathrm{~m}^{-3}$ (triangles) show $\mathrm{PO}_{4}$-coupled cycling in oxygenated waters (blue) but not in $\mathrm{OMZ}$ waters with $<20 \mu \mathrm{M} \mathrm{O}_{2}$ (red). (b) In the OMZ, dCo follows salinity, indicating mixing between a high dCo endmember at a salinity of 35.0 and a fresher water mass that is low in dCo. 


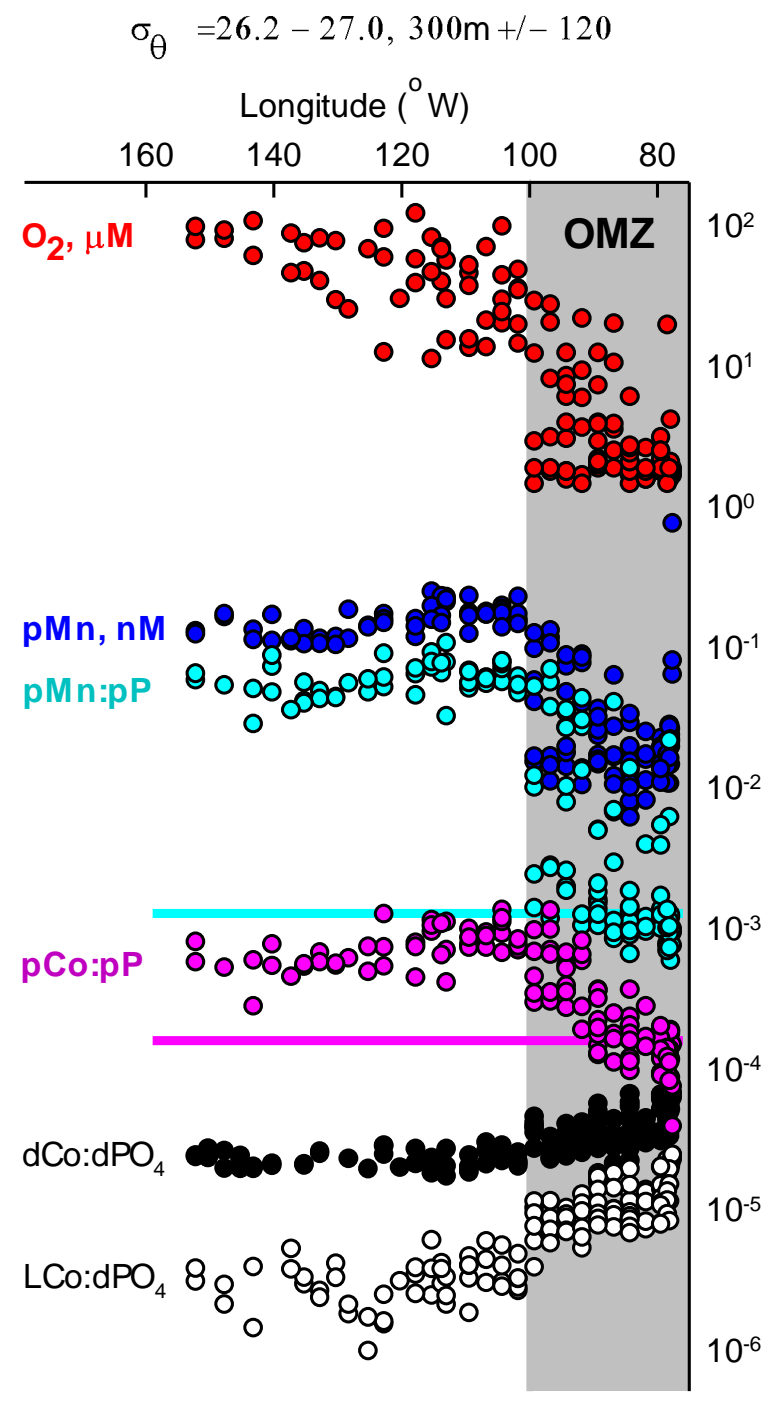

Figure 9. Redox control of Co and Mn scavenging. Within mesopelagic waters $\left(\sigma_{\theta}=26.2-27.0\right.$ $\mathrm{kg} \mathrm{m}^{-3}$, mean depth of $300 \mathrm{~m}$ ), high $\mathrm{O}_{2}$ in ventilating water masses result in a sharp redox boundary at the edge of the OMZ (red circles, scale in $\mu \mathrm{M}$ ). Particulate $\mathrm{Mn}(\mathrm{pMn})$ increases across the oxic/anoxic boundary at $100^{\circ} \mathrm{W}$ (blue circles, in $\mathrm{nM}$ ) and imply stabilization of $\mathrm{Mn}$ oxides. Both pMn:pP and pCo:pP (cyan and pink circles, respectively; units are $\mathrm{M} \mathrm{M}^{-1}$ ) increase across the $\mathrm{OMZ}$ boundary, exceeding predicted values from remineralization of biogenic material from the surface ocean ( $1.26 \times 10^{-3}$ mean pMn:pP and $1.57 \times 10^{-4} \mathrm{pCo}$ :pP for $0-50 \mathrm{~m}$ $\left(\mathrm{M} \mathrm{M}^{-1}\right)$, cyan and pink lines, respectively). Dissolved phase $\mathrm{dCo}: \mathrm{dPO}_{4}$ (black circles) and LCo: $\mathrm{PO}_{4}$ (white circles) also decrease west of the OMZ boundary show scavenging of the dCo and LCo in the mesopelagic (units are $\mathrm{M} \mathrm{M}^{-1}$ ). 

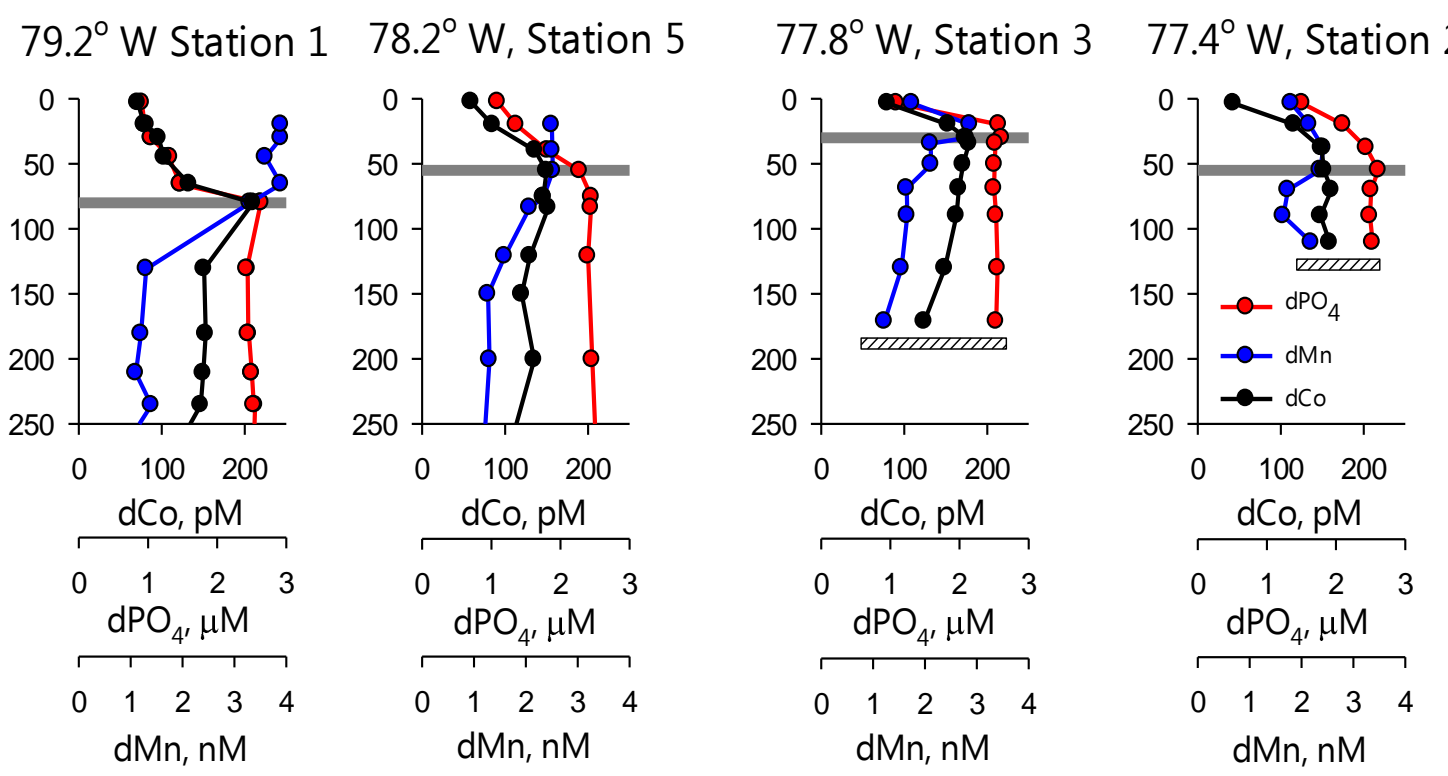

Figure 10. Profiles of dissolved cobalt (dCo, black), $\mathrm{PO}_{4}$ (red) and dMn (blue) over the Peru shelf at $12^{\circ} \mathrm{S}$. The oxycline (grey bar, defined by the first sample where $\mathrm{O}_{2}<10 \mu \mathrm{M}$ ) marks the transition between the OMZ and oxygenated surface waters. Station 2 is the closest to the coast. Note the similarity between $\mathrm{dCo}$ and $\mathrm{PO}_{4}$ above the oxycline and the transition to a $\mathrm{dMn}$-like profile beneath. 


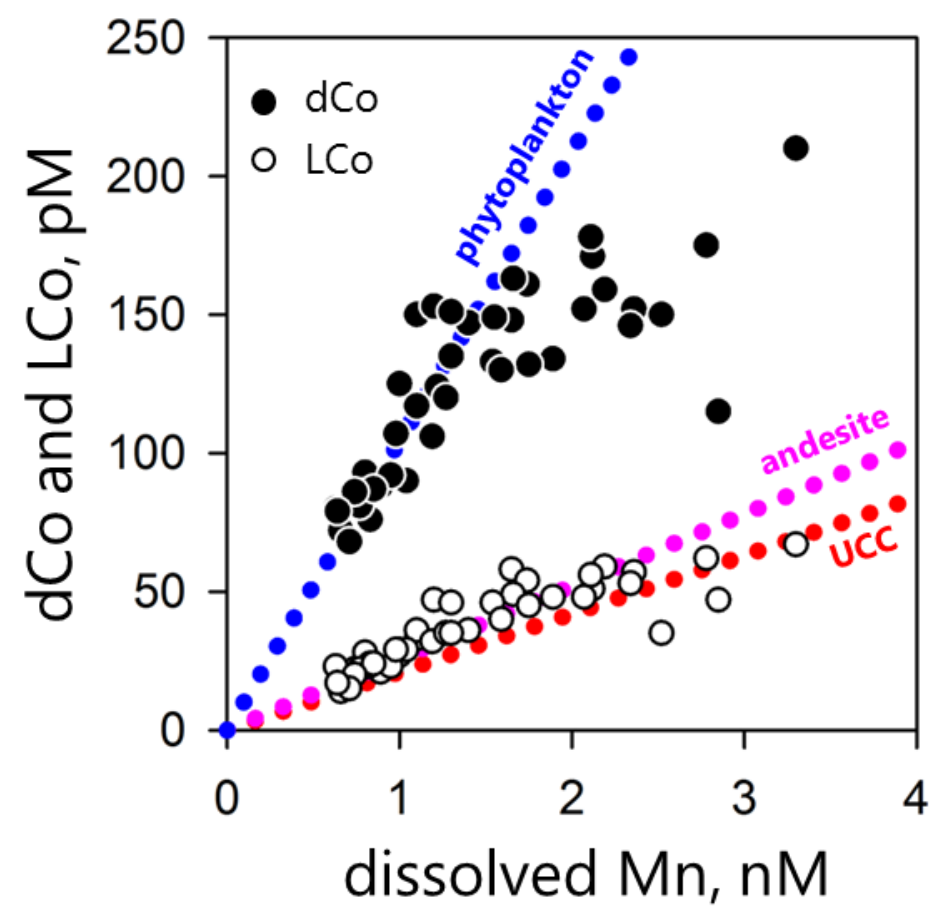

Figure 11. Cobalt and Mn in the Peru shelf OMZ (GP16 Stations 1-5, $\mathrm{O}_{2}<20 \mathrm{uM}$ ). Dissolved cobalt (dCo, closed circled) and labile cobalt (LCo, white) follow positive linear relationships with $\mathrm{dMn}$. The LCo slope $\left(18 \mathrm{mM} \mathrm{M}^{-1}\right)$ approximates the Co:Mn ratio in upper continental crust and Andesite (red and pink lines 21 and $26 \mathrm{mM} \mathrm{M}^{-1}$, respectively), suggesting it derives from a crustal source. The mean pCo:pMn ratio from phytoplankton dominated particles collected in the upper $40 \mathrm{~m}$ over the shelf (blue line, $\left.105 \mathrm{mM} \mathrm{M}^{-1}\right)$ is greater than $\mathrm{dCo}: \mathrm{dMn}$ slope $\left(42 \mathrm{mM} \mathrm{M}^{-1}\right)$, indicating that $\mathrm{dCo}$ and $\mathrm{dMn}$ concentrations in the Peru shelf OMZ represent a combination of biomass remineralization and sedimentary input. 

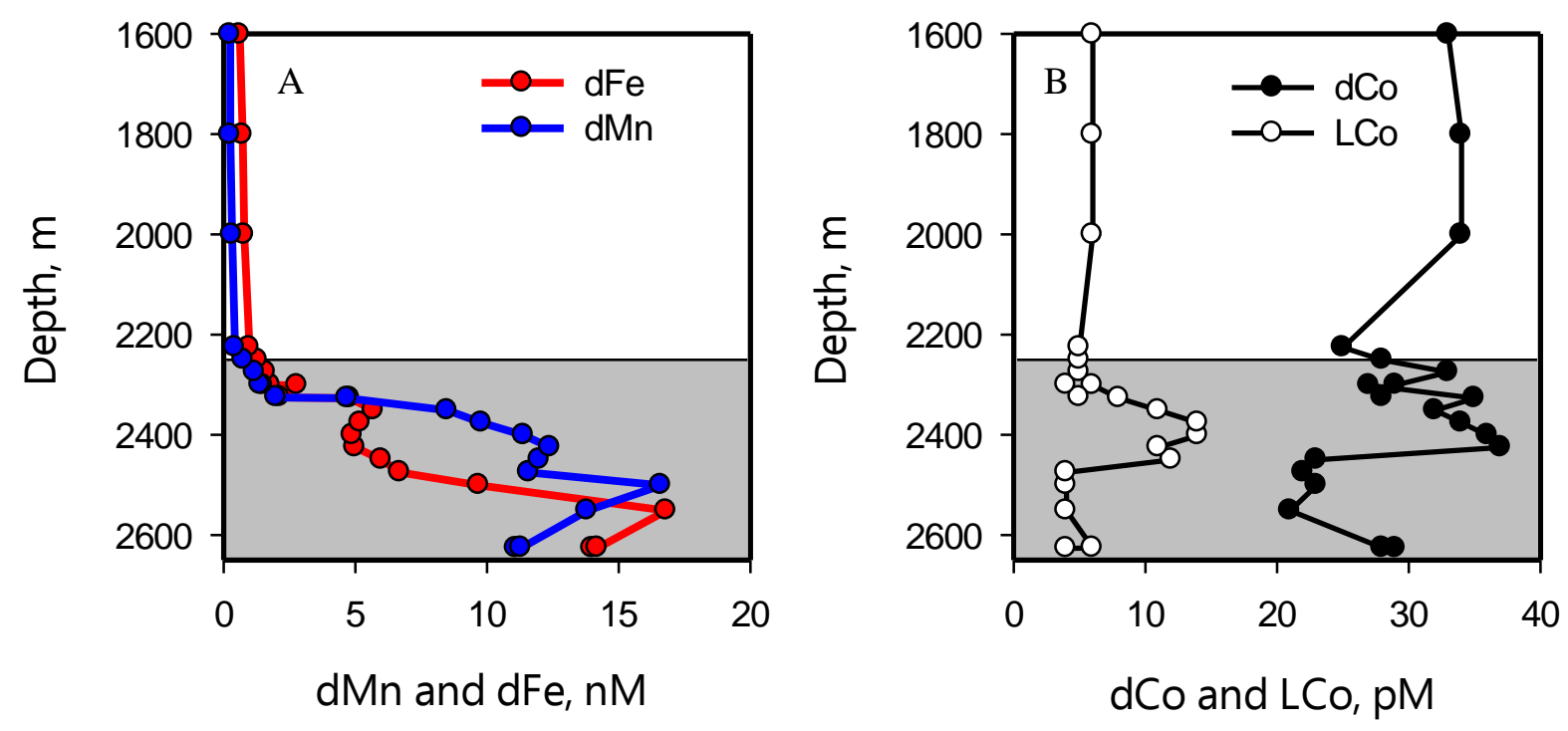

Figure 12. Profiles from Station 18 at the East Pacific Rise ridge crest at $113{ }^{\circ} \mathrm{W}, 15^{\circ} \mathrm{S}$. (a) dMn (blue lines) and dFe profiles (red) replotted from Resing et al. 2015 clearly show hydrothermal input. Grey shading below $2250 \mathrm{~m}$ indicates area of hydrothermal influence where dFe and dMn are $>1 \mathrm{nM}$. (b) Dissolved cobalt (dCo, black circles) and labile cobalt (LCo, white) in the East Pacific Rise hydrothermal plume. 

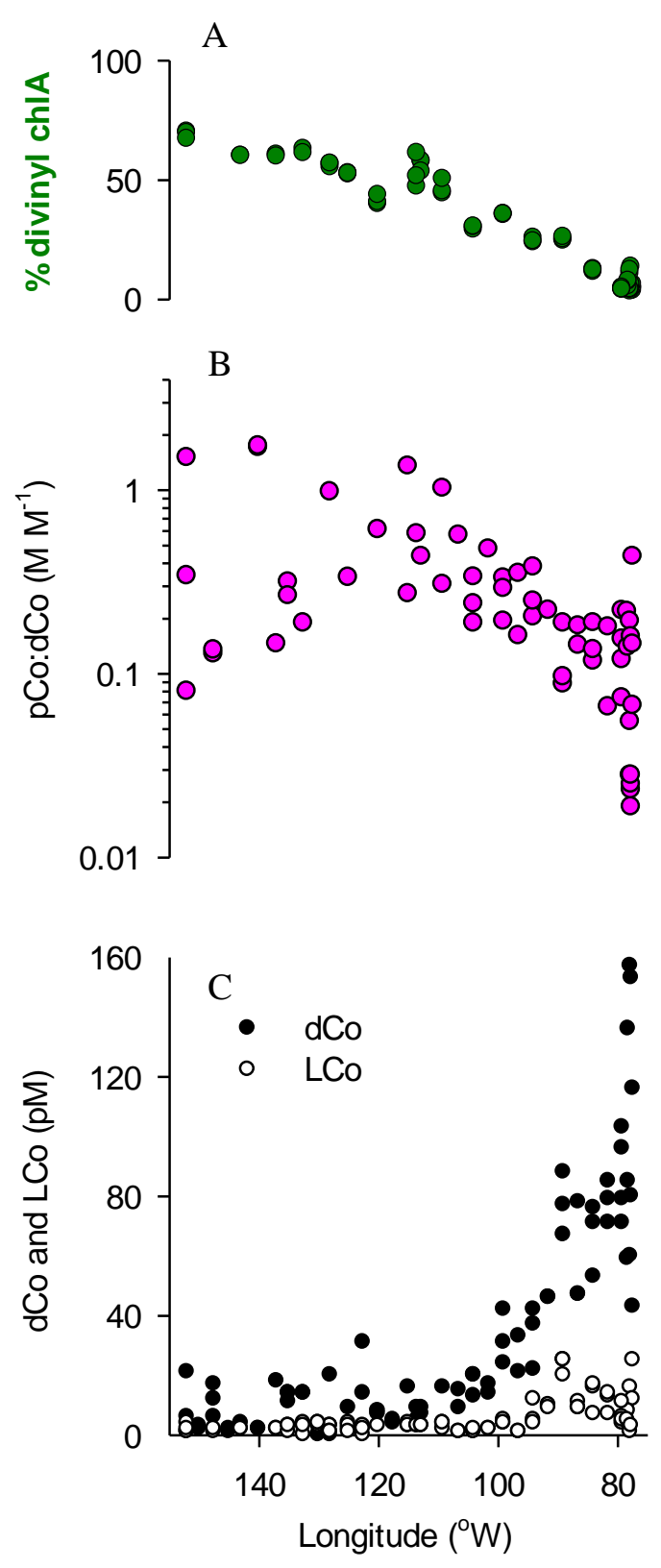

Figure 13. (a) The ratio of divinyl chlorophyll A to total chlorophyll (green circles), an indication of Prochlorococcus abundance relative to other phytoplankton. (b) The particulate to dissolved ratio of cobalt ( $\mathrm{pCo}: \mathrm{dCo}$, in $\mathrm{M} \mathrm{M}^{-1}$, pink circles) in near-surface samples (0-50m) measured on GP16; a value of 1 indicates equal concentrations in each phase. (c) The nearsurface distribution of dissolved cobalt (dCo, black circles) and labile cobalt (LCo, white circles), showing higher concentrations near the Peru margin $\left(<80^{\circ} \mathrm{W}\right)$ and very low dCo to the west. 


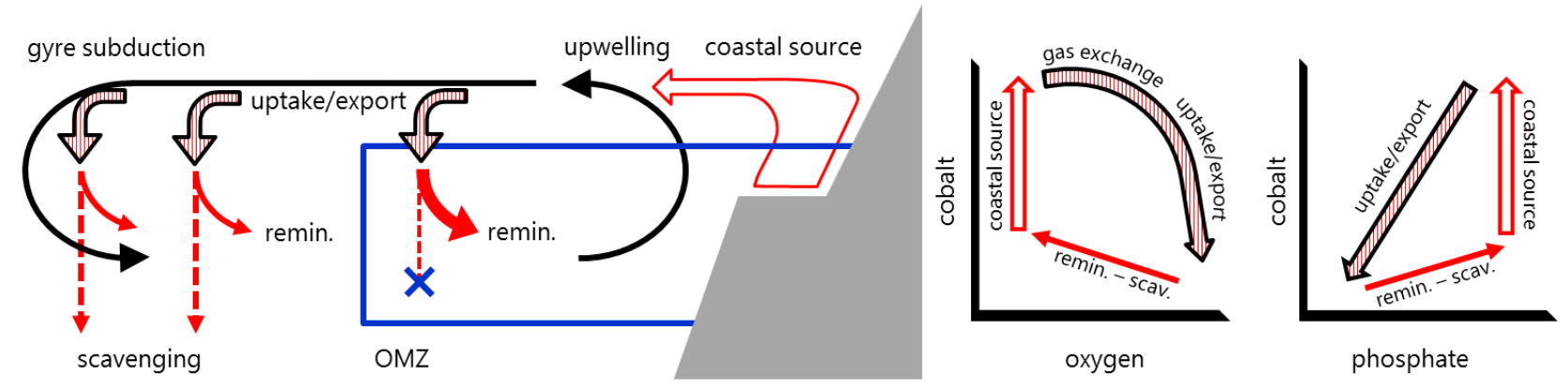

Figure 14. Schematic cross-section of the cobalt cycle in the Eastern Tropical South Pacific. Black arrows describe idealized physical circulation, showing upwelling near the Peru margin, advection westward and subduction in the South Pacific gyre. Biological Co export is shown in the red-hashed arrows, and solid and dashed red arrows show remineralization and scavenging, respectively. The margin source is shown as a red-outlined arrow. These vectors are also plotted on idealized oxygen and phosphate axes, using the same color scheme, to show how these processes appear in $\mathrm{Co}: \mathrm{O}_{2}$ and $\mathrm{Co}: \mathrm{PO}_{4}$ space. 


\title{
Chapter 3.
}

\section{Cobalt scavenging and mass balance in the global ocean}

\begin{abstract}
In the ocean, dissolved cobalt is affected by both nutrient cycling and scavenging onto manganese oxides. The latter process concentrates Co in pelagic sediments, resulting in a small deep water inventory. While the flux of scavenged cobalt to sediments appears steady on timescales $>100,000$ years, its residence time in the water column is short: $\sim 130$ years. Using results from recent GEOTRACES expeditions, we show that Co scavenging in deep ocean water masses is too slow to match accumulation rates in marine sediments, requiring most of the scavenging flux to occur in the upper water column $(<1500 \mathrm{~m}$ depth) where nutrient cycling appears dominant. Based on discrepancies between phytoplankton Co quotas and the stoichiometry of Co remineralization relative to other nutrients, we calculate areal scavenging rates in the North Atlantic and South Pacific basins on the order of 1.4 and $0.6 \mu \mathrm{mol} \mathrm{m}^{-2}$ year $^{-1}$, respectively, which agree with long-term accumulation rates in Atlantic and Pacific sediments. An assessment of sources suggest that the marine cobalt cycle is approximately in balance, but that this inventory may be sensitive to long term trends in the intensity of oxygen minimum zones, which account for $\sim 25 \%$ of the annual cobalt source to the oceans.
\end{abstract}

\section{Introduction}

In pelagic sediments, cobalt is enriched over its crustal sources - shale, basalts, andesites - sometimes to a factor of 10 or higher (Goldberg and Arrhenius, 1958; Krishnaswami, 1976). This excess can be attributed to scavenging reactions occurring in the water column that incorporate cobalt into authigenic manganese oxides that then sink from the water column (Cowen and Bruland, 1985; Moffett and Ho, 1996). Manganese nodules and crusts can be appreciated as the extreme of this reaction, where Co concentrations can be several percent by mass in extremely slow growing specimens (Manheim, 1986). On long time scales, the flux of Co to marine sediments and nodules is steady, an observation that has been exploited to improve 
sedimentary age models when other dating techniques are unavailable (Dunlea et al., 2015; Halbach et al., 1983; Krishnaswami, 1976). Yet a full mechanistic explanation of this phenomenon is lacking. Radiotracer and microscopic evidence support a bacterial basis for Mnoxide production in the upper water column but Mn-oxides produced near the ocean surface are also subject to light-driven dissolution, resulting in a small residual that actually gets exported to the ocean floor and making these results difficult to apply at scale (Cowen and Bruland, 1985; Moffett and Ho, 1996; Sunda and Huntsman, 1988).

In the upper water column, however, cobalt cycling is dominated by its role as a nutrient. Cobalt is important for phytoplankton $\mathrm{CO}_{2}$ fixation via the metalloenzyme carbonic anhydrase and, as the central atom in vitamin $B_{12}$, cobalt is also required by many organisms for the biosynthesis of DNA and the amino acid methionine (Yee and Morel, 1996; Zhang et al., 2009). Profiles of dissolved cobalt, dCo, are strongly impacted by biological uptake and regeneration, resulting in strong correlations with phosphate in the upper water column (Saito and Moffett, 2002; Saito et al., 2010). Remineralization also contributes to elevated dCo within oxygen minimum zones in both the Atlantic and Pacific Oceans (Noble et al., 2012). In deeper waters, however, $\mathrm{dCo}$ and $\mathrm{PO}_{4}$ decouple as $\mathrm{dCo}$ is removed from the water column by scavenging, yet the exact locus or horizon where scavenging occurs is difficult to discern due to the combined effects of circulation and remineralization (Dulaquais et al., 2014b; Saito et al., 2010).

Here, we trace dCo removal by scavenging throughout the global ocean by synthesizing 1000s of recent water column measurements with Co accumulation rates in sediments and rates of supply from continents. Our calculations portray a fast and perturbable Co cycle that make its apparent steadiness on $>100,000$ year timescales all the more surprising.

\section{Methods}

\section{1 Radiocarbon data matching procedure}

The rate of dissolved cobalt ( $\mathrm{dCo}$ ) scavenging in the deep ocean can be calculated by comparison with the radiocarbon age of deep ocean waters. Dissolved cobalt datasets for GA03, GA10, GP16, GIPY4, GAc01-CoFeMUG, and the Metzyme transect were accessed from the literature and data repositories (Table 1, Figure S1). These datasets were generated either by voltammetry or flow-injection methods following UV-oxidation and authors report measurements of seawater standards that agree with community consensus values (Bown et al., 
2011; Hawco et al., 2016; Noble et al., 2012) (Wyatt and Lohan, unpublished, Hawco and Saito, unpublished [see chapter 4], Noble et al., submitted). Quality-controlled measurements of the radiocarbon content of dissolved inorganic carbon $\left(\Delta^{14} \mathrm{C}\right)$ in the GLODAP database were downloaded from the internet (http://cdiac.ornl.gov/oceans/glodap/) (Key et al., 2004). Stations containing $\Delta^{14} \mathrm{C}$ data were matched to individual GEOTRACES sections by defining a rectangle whose dimensions were extended $5^{\circ}$ latitude and longitude from the maximum extent of the GEOTRACES sections (Table 1, Figure S1) (Key et al., 2004). $\Delta^{14} \mathrm{C}$ and dCo datasets were then sorted into an upper bathypelagic bin (in practice 1490m - 2990m) and a bottom-water bin $(>2990 \mathrm{~m})$. Because $\Delta^{14} \mathrm{C}$ contains a variable amount of anthropogenic radiocarbon produced from nuclear weapons testing, pre-bomb $\Delta^{14} \mathrm{C}$ (Nat14C) from GLODAP were used to calculate age, according to the equation:

Age $=-8033 * \ln \left(1+0.001 *\left(\Delta^{14} C+67\right)\right)$

Which subtracts the 'preformed' value of $\Delta^{14} \mathrm{C}$ of North Atlantic Waters, -67\%o (Matsumoto, 2007). This corresponds to the 'Natural' radiocarbon age, which is not reset during ventilation in the Southern Ocean due to very long equilibration times of $\Delta^{14} \mathrm{C}$ with the atmosphere. 'Real' age, which accounts for this effect by determining the fraction of North Atlantic Deep water (NADW) vs. Antarctic Bottom waters $(\mathrm{AABW})$ using the $\mathrm{P} * \operatorname{tracer}\left(P^{*}=P O_{4}+\frac{1}{175} O_{2}-1.95\right)$, was also investigated (Figure S2). Endmember $\mathrm{P} *$ of $0.73 \mu \mathrm{M}$ was applied to NADW and $1.95 \mu \mathrm{M}$ was applied to AABW (Matsumoto, 2007). Preformed $\Delta^{14} \mathrm{C}$ is then calculated based on the fraction of NADW and AABW (endmember values of $-67 \%$ and $-140 \%$, respectively), and added to the exponent in Eq. 1 (Figure S2).

In addition, to basin averages, discreet pairing of individual $\Delta^{14} \mathrm{C}$ and $\mathrm{dCo}$ measurements was accomplished by matching GLODAP stations containing $\Delta^{14} \mathrm{C}$ and dCo stations. Stations within $5^{\circ}$ radius were matched and, in the case of multiple stations, minimum Pythagorean distance was used to determine the closest station. For each transect, no dCo station is matched to more than one $\Delta^{14} \mathrm{C}$ station. Within matched $\Delta^{14} \mathrm{C}$ and dCo stations, individual samples were paired if their depth offset was less than $100 \mathrm{~m}$. If more than one sample fit this requirement, the closest depth was used. 


\subsection{Global cobalt cycle calculations}

Ocean volumes and surface areas from the ETOPO1 dataset are used (Eakins and Sharman, 2010). In estimating global cobalt sinks, a paucity of data requires extrapolation of a small number of sedimentary fluxes in Table 2 to large areas. This estimate is aided by the observation that the flux of excess cobalt to marine sediments has a relatively constant spatial distribution (See section 3.1) (Goldberg and Arrhenius, 1958; Kadko, 1985; Krishnaswami, 1976), and from the fact that the largest two basins, the Atlantic and Pacific, are also the best characterized. Because circulation in the Arctic and Mediterranean basins is restricted, they have been excluded from global calculations. We are not aware of measurements of cobalt accumulation rates in the Indian and Southern Ocean sediments, which compose the remaining $30 \%$ of ocean surface area, and extrapolate Quaternary Pacific Ocean averages (Table 2, 1.1

$\left.\mu \mathrm{mol} \mathrm{m} \mathrm{mear}^{-1}\right)$ for these basins, which are lower than areal fluxes from the Atlantic $(\sim 1.9 \mu \mathrm{mol}$

$\mathrm{m}^{-2}$ year $^{-1}$ ) and therefore reflect a more conservative estimate. These estimates should be updated as new data becomes available.

Average oceanic cobalt was defined as the median of the datasets included in Fig. S1 $(\mathrm{n}=2920), 46 \mathrm{pM}$, which is similar to values used in previous residence time calculations (Saito and Moffett, 2002). For all lithogenic/detrital corrections, we have used a uniform Co:Ti ratio of upper continental crust $\left(3.37 \times 10^{-3} \mathrm{M} \mathrm{M}^{-1}\right)$, defined by McLennan 2001. If Ti was not available, a value of $17 \mathrm{ppm}$ was used to estimate detrital composition (McLennan, 2001). This approach assumes dissolution of aerosol cobalt is low. The 8-10\% dissolution of Saharan aerosols (Shelley et al., 2012) suggests that the above Ti-corrections are appropriate but might underestimate biogenic and authigenic phases when lithogenic contributions are high (e.g. the North Atlantic).

\subsection{Cobalt composition of sinking particles}

The cobalt content of large $(>51 \mu \mathrm{m})$ particles are analyzed from samples collected onboard the GA03 (Ohnemus and Lam, 2015) and GP16 transects (Lee and Lam, submitted). The large size of these particles suggests that they better characterize sinking material in the ocean than other size classes. Hence, we refer to these as sinking particles. The behavior of Co and $\mathrm{P}$ in large particles in both datasets is qualitatively similar to smaller, suspended particles collected by McLane pumps or Go-Flo bottles (at least with respect to Co, Saito et al. submitted)(Ohnemus and Lam, 2015; Ohnemus et al., 2016) 
Sinking particles were collected by McLane pump and analyzed as described by Ohnemus and Lam (2015) for both cruises. Filters were initially digested with a sulfuric acid/peroxide mixture and digested fully with $4 \mathrm{~N}$ each of $\mathrm{HCl}, \mathrm{HNO}_{3}$, and $\mathrm{HF}$ and analyzed by ICPMS (Ohnemus and Lam, 2015)(Lee et al., submitted). For data in the upper $100 \mathrm{~m}$, cobalt and $\mathrm{P}$ are corrected for contributions of lithogenic material using composition of upper continental crust, as described above (McLennan, 2001). This correction was negligible for P but was important for Co, especially in the GA03 dataset. Aerosol measurements on GA03 support the use of this crustal ratio (Shelley et al., 2015). Due to some variability in composition and high dust loadings, lithogenic correction sometimes resulted in negative cobalt concentrations. In determining basin scale averages of each datasets, these negative biogenic Co values were set to zero.

Although the Co:P ratio of Ti-corrected (and uncorrected) samples from the upper $100 \mathrm{~m}$ varied over two orders of magnitude, both datasets resembled a log-normal distribution (Fig. 7). The log-transformed Co:P ratio of these samples was binned into histograms of 0.25 log units and fit to a Gaussian function in Sigmaplot to calculate the center $\left(\mathrm{X}_{0}\right)$ of each distribution. $\mathrm{X}_{0}$ was stable over a range of bin sizes (Figure $\mathrm{S} 3$ ), but at coarser bin resolution, $\mathrm{X}_{0}$ increased and became less constrained, especially in the North Atlantic. The range in $\mathrm{X}_{0}$ between 0.1-0.5 log units is used to estimate the uncertainty from this approach.

\subsection{Isopycnal Scavenging Calculations}

The cobalt scavenging flux in the mesopelagic $(100-1500 \mathrm{~m})$ is calculated as the difference between the sinking flux of biogenic, particulate cobalt below $100 \mathrm{~m}$, and the remineralization of dissolved cobalt within the mesopelagic. Cobalt remineralization rates on individual isopycnal surfaces are calculated from the product of a dissolved Co:P stoichiometry and a modeled P remineralization rate. Dissolved Cobalt ( $\mathrm{dCo}$ ) and phosphate datasets from GP16 in the Eastern Tropical South Pacific and GA03 in the Subtropical North Atlantic were downloaded from the Biological and Chemical Oceanography Data Management Office (BCODMO, http://www.bco-dmo.org/) (Hawco et al., 2016)(Noble et al. submitted). Samples below $1500 \mathrm{~m}$ were discarded to avoid double counting with respect to the radiocarbon observations (Section 2.1). Datasets were then subdivided by potential density $\left(\sigma_{\theta}\right)$ into $0.25 \mathrm{~kg} \mathrm{~m}^{-3}$ isopycnal bins. This isopycnal bin size was chosen because it enabled $>10$ measurements per density strata 
to be included, even in narrow thermoclines. For GP16, exclusion of samples in the OMZ was necessary $\left(\mathrm{O}_{2}<20 \mu \mathrm{M}\right)$ due to a clear departure of dCo in these samples compared to the basin scale trend, due to the presence of a large cobalt source from the Peru Margin. Surface samples were also excluded.

The range of included isopycnal surfaces was chosen so that layers reside predominantly in the mesopelagic, between 100-1500 m. Shallower isopycnal surfaces were excluded (>25.375 $\mathrm{kg} \mathrm{m}^{-3}$ for the GP16 section and $>26.125 \mathrm{~kg} \mathrm{~m}^{-3}$ for the GA03 section), in part because they are mixed on timescales $<5$ years, especially in the North Atlantic, and therefore do not represent the same level of integration as the underlying surfaces (Fiedler and Talley, 2006; Jenkins et al., 2015). As a result, aggregate $\mathrm{dCo}: \mathrm{PO}_{4}$ relationships are more complex and require fine-scale approaches to derive stoichiometry (Saito et al. submitted). Several studies have also shown that manganese and cobalt scavenging in the upper $100 \mathrm{~m}$ is very low due to light-driven inhibition and dissolution of bacterial manganese oxides (Moffett and Ho, 1996; Sunda and Huntsman, 1990, 1988), suggesting that excluding these near-surface isopycnals affects scavenging calculations minimally.

Linear regression between dissolved cobalt and phosphate were used to calculate Co:P ratios of remineralization on individual isopycnal surfaces. Preformed concentrations of both Co and $\mathrm{P}$ are reflected in the intercepts of the linear regression rather than their slopes. The value and standard error of the isopycnal Co:P slope was calculated by least-squares linear regression with SigmaPlot 12. From the perspective of any given transect, mixing of subtropical and tropical water masses with distinct endmember concentrations of $\mathrm{Co}$ and $\mathrm{P}$ will affect the relationship between these two elements on an isopycnal surface. However, most of these water masses originate from a similar source region and differ primarily by their age, suggesting that the dominant control of endmember Co and $\mathrm{P}$ values is the amount of remineralization of both Co and $\mathrm{P}$ since ventilation, as well as the extent of Co scavenging. Isopycnal mixing will therefore integrate local variability in remineralization and/or scavenging at the basin scale. On individual isopycnal surfaces, there are probably regions where this simplified view is untenable (for instance in the oxygen minimum zone of the South Pacific (Fig. 6), which has been excluded from these calculations), but the strong covariation between Co and P on many of these surfaces implies that the influence of endmember mixing is second to that of remineralization. 
Mesopelagic P-remineralization rates were calculated from region-specific export models of phosphate. The vertical flux of phosphate follows a Martin-curve parameterization:

$F_{z}=F_{z *} *\left(\frac{z}{z *}\right)^{-b}$

fit to a global nutrient database via an inverse circulation model (Teng et al., 2014). Parameters used in these calculations are taken from values in Extended Data Figures 4 and 5 using flexible C:P stoichiometry from Teng et al. (2014). The critical depth of export, $\mathrm{z}^{*}$, was adjusted from $73.4 \mathrm{~m}$ (Teng et al., 2014) to $100 \mathrm{~m}$ in order to account for deeper euphotic zones on both cruises and to match the isopycnal depth range identified above for Co:P correlation. The amount of phosphate exported to a given depth is determined by the phosphate flux at $100 \mathrm{~m}$ and the attenuation coefficient, $b$. Both $\mathrm{F}_{100}$ and $\mathrm{b}$ in Teng et al. (2014) are unique to biogeochemical province (e.g. subtropical Atlantic, tropical Atlantic).

To counteract sampling bias associated with individual GEOTRACES transects, the mean depth $\left(z_{\text {mean }}\right)$ of each isopycnal surface was calculated from the WOCE Global Hydrographic Climatology (Gouretski and Koltermann 2004). The hydrographic domain associated with the zonal GP16 transect was defined by a rectangle spanning the Eastern South Pacific Ocean $\left(5-30^{\circ} \mathrm{S}, 71-150^{\circ} \mathrm{W}\right)$; the GA03 transect was defined by a domain between 10 $45^{\circ} \mathrm{N}$ and $10-80^{\circ} \mathrm{W}$. For consistency with dCo data, depths below $1500 \mathrm{~m}$ were removed. The height of each isopycnal box was calculated as the midpoint between $\mathrm{z}_{\text {mean }}$ of the isopycnal surface and the overlying and underlying boxes.

Optimized multi-parameter water mass analyses have indicated that mesopelagic waters sampled on both transects contain mixtures of subtropical and tropical water masses (Peters et al., submitted) (Jenkins et al., 2014). To account for the presence of remineralized nutrients exported from both subtropical and tropical provinces, P-remineralization equations were modified so that ' $b$ ' and $F_{100}$ express the weighted average of Eq. 2, based on the phosphate export at $100 \mathrm{~m}$ from both provinces (Table 3). Over $90 \%$ of the P-flux is remineralized between 100-1500 m, the size of the mesopelagic box used here. This is consistent with very low remineralization rates in the deep ocean inferred by correlations between radiocarbon age and AOU (Broecker et al., 1991; Karstensen et al., 2008).

Isopycnal $\mathrm{P}$ remineralization rates (in $\mathrm{mol} \mathrm{m}^{-2} \mathrm{year}^{-1}$ ) are calculated as the difference between the P flux at the upper bound and lower bound of a given isopycnal box. A $20 \%$ uncertainty in $\mathrm{P}$ remineralization rates is applied to these rates, which represents the upper end of 
uncertainty suggested by Teng et al. (2014). These values were used to weight isopycnal Co:P stoichiometries to derive a $\mathrm{Co}: \mathrm{P}$ ratio of remineralization $\left(\mathrm{Co}: \mathrm{P}_{\text {remin }}\right)$ from the $\mathrm{Co}: \mathrm{P}$ slope of individual isopycnals. Co: $\mathrm{P}_{\text {remin }}$ is independent of the actual magnitude of the $\mathrm{P}$ flux but depends on the attenuation of ' $b$ '. This dependence was evaluated for a range of ' $b$ ' relevant to the ocean (Figure S4; Teng et al. 2014). Co: $\mathrm{P}_{\text {remin }}$ increases somewhat with increasing b but the effect is small, at least in comparison to particulate Co:P ratios.

The major sources of uncertainty in calculating scavenging fluxes with this approach are 1) the $20 \%$ uncertainty in P-remineralization rates, 2) uncertainties in the slope of the isopycnal Co:P relationship, determined by standard error of the slope of linear regression and 3) the estimation of the mean exported Co:P ratio.

\section{Results and Discussion}

\subsection{The Marine Co sink}

Relative to its abundance in continental crust, Co is enriched in marine sediments, as well as ferromanganese nodules and crusts (Manheim, 1986). The degree of cobalt enrichment in marine sediments is inversely related to the rate of sediment accumulation: the highest cobalt content characterizes the slowest accumulating sediments (Fig. 1) (Krishnaswami, 1976). These observations have been explained by considering sedimentary Co content as a mixture of a major, Co-poor component from dust and continental detritus with a minor, Co-rich component from the water column, such as Mn-oxides (Goldberg and Arrhenius, 1958; Krishnaswami, 1976). Because oxygen is abundant in pelagic sediment porewaters and Co contents of other common sedimentary phases are low, complication of this simple model by hydrothermalism, biomineral deposition, or reductive remobilization of authigenic Co is minimal (D'Hondt et al., 2015; Dunlea et al., 2015; Kyte et al., 1993). Therefore, when the mass accumulation rate of sediments is known, the flux of the authigenic component $\left(\mathrm{K}\right.$, in $\mu \mathrm{mol} \mathrm{m}{ }^{-2}$ year $\left.^{-1}\right)$ can be calculated as:

$\mathrm{K}=\mathrm{S}_{\mathrm{m}} *\left(\mathrm{Co}_{\text {sediment }}-\mathrm{Co}_{\text {detrital }}\right)$

where $\mathrm{Co}_{\text {detrital }}$ reflects the Co content in upper continental crust (17 ppm, or by correction with Ti, McLennan 2001) and $S_{\mathrm{m}}$ is the mass accumulation rate for bulk sediments in $\mathrm{g} \mathrm{m}^{-2}$ year $^{-1}$. Early investigations noted the apparent similarity in $\mathrm{K}$ both downcore and across spatial gradients in surface sediments, resulting in the assertion that the rate of authigenic Co 
accumulation, $\mathrm{K}$, is nearly constant on timescales of $10^{5}$ years and longer (Kadko, 1985; Krishnaswami, 1976).

Yet, there is a 8 -fold variation in published rates of $\mathrm{K}$ (Table 2), ranging from $0.34 \mu \mathrm{mol}$ $\mathrm{m}^{-2}$ year $^{-1}$ from the South Pacific gyre to $2.3 \mu \mathrm{mol} \mathrm{m}{ }^{-2}$ year $^{-1}$ in the Sargasso Sea. Thus, as discussed previously, authigenic Co accumulation rates in sediments are not strictly constant (Dunlea et al., 2015). Determinations of K in Quaternary sediments tend to be higher in the Atlantic than the Pacific. Furthermore, in the Pacific Ocean, Quaternary sediments in Table 2 indicate higher rates of $\mathrm{K}$ than records that span the entire Cenozoic era (65 Mya). This suggestion echoes downcore observations from Kyte et al. (1993), who used stratigraphic constraints to show an increase in authigenic Co accumulation in the North Pacific since the onset of the Pliocene (2.5-5 Mya). It appears significant that Cenozoic estimates of K (.34-0.44 $\mu \mathrm{mol} \mathrm{m} \mathrm{m}^{-2}$ year $\left.^{-1}\right)$ converge with accumulation rates in Mn nodules and crusts $\left(0.32-0.40 \mu \mathrm{mol} \mathrm{m}^{-2}\right.$ year $^{-1}$ ), as both integrate over similar $10^{6}-10^{7}$ year timescales (Dunlea et al., 2015; Frank et al., 1999; Halbach et al., 1983; Kyte et al., 1993; Zhou and Kyte, 1992). This similarity suggests that sediments and nodules accumulate cobalt from a similar water column source and support the assertion that cobalt accumulation rates were lower before the Pleistocene (Kyte et al., 1993). We are unaware of records that span a similar timescale in the Atlantic, Indian or Southern Oceans to confirm or negate this hypothesis.

While the cause of the differences in $\mathrm{K}$ is unknown, general agreement in Quaternary sediments between multiple investigations enables a reasonable estimation of the pelagic cobalt sink for each basin. Average authigenic cobalt accumulation rates in Quaternary sediments in the Atlantic and Pacific (1.9 and $1.1 \mu \mathrm{mol} \mathrm{m} \mathrm{m}^{-2}$ year $^{-1}$, respectively) imply a global sink on the order of $450 \mathrm{Mmol} \mathrm{Co} \mathrm{year}{ }^{-1}$ (see Methods for details). Against an average oceanic concentration of 46 pM, estimated from recent GEOTRACES data, this sink corresponds to a total ocean residence time of 130 years. As the $\sim 10^{5}$ year time-scale of authigenic Co determination in sediments integrates over dozens of revolutions of the oceanic cobalt cycle, stabilizing mechanisms on either water column scavenging processes or sources must be substantial if the flux to marine sediments $(\mathrm{K})$ is actually steady. To shed light on these controls, water column scavenging processes are investigated in the following sections using a wealth of new dissolved and particulate cobalt measurements from GEOTRACES datasets in the Atlantic and Pacific basins. 


\subsection{Deep ocean scavenging}

Scaling cobalt accumulation rates in pelagic sediments to an average ocean depth of 3700 $\mathrm{m}$ suggests a mean scavenging rate of $0.3-0.5 \mathrm{pM}$ per year. But is this process uniform in the water column? Below $1000 \mathrm{~m}$, profiles from the Atlantic and Pacific show that dCo decreases along the path of the meridional overturning circulation (Fig. 2, Fig. S1). dCo concentrations decrease from 50-100 pM in the deep north Atlantic to $20-40 \mathrm{pM}$ in Antarctic and Pacific deep waters.

To trace the loss of dCo from deep waters during the meridional overturning circulation, recently collected dCo datasets were compared with the radiocarbon content of dissolved inorganic carbon $\left(\Delta^{14} \mathrm{C}\right)$, which enters the deep ocean almost exclusively via formation of North Atlantic Deep Water (NADW) (Broecker et al., 1991). Regional averages of dCo for each of these transects across bathypelagic (1500-3000m) and bottom waters (>3000m) were compared to $\Delta{ }^{14} \mathrm{C}$ measurements from the GLODAP atlas over a similar spatial domain (Key et al., 2004). $\mathrm{dCo}$ in the deep ocean follows a linear relationship with $\Delta{ }^{14} \mathrm{C}$. As $\Delta{ }^{14} \mathrm{C}$ describes both the mixing of NADW and the aging of those mixtures in the overturning circulation (Broecker et al., 1991; Matsumoto, 2007), the correlation with dCo implies that cobalt scavenging in the deep ocean occurs on a similar timescale to ${ }^{14} \mathrm{C}$ decay.

Converting to radiocarbon age by solving the half-life equation for ${ }^{14} \mathrm{C}$ produces an exponential relationship with dCo (Fig. 3). Fit to Figure 3a, deep ocean dCo follows the equation:

$\mathrm{dCo}=83 * e^{-1.02 * 10^{-3} * \tau}$

where $\tau$ is the natural $\Delta{ }^{14} \mathrm{C}$ age in years $\left(r^{2}=0.88\right)$. From this regression, the mean rate of scavenging over 1500 years is calculated as $0.043 \mathrm{pM} \mathrm{year}^{-1}$ and, from the reciprocal of the coefficient in the exponent $\left(1.02 \times 10^{-3}\right.$ year $\left.^{-1}\right)$, a residence time can be inferred. Dissolved cobalt in the deep ocean has a residence time of 980 years, nearly an order of magnitude longer than the whole ocean residence time calculated by cobalt accumulation rates in pelagic sediments!

Pairing over $300 \mathrm{dCo}$ measurements with co-located $\Delta^{14} \mathrm{C}$ measurements from GLODAP shows that the exponential relationship between $\mathrm{dCo}$ and age holds on a sample-by-sample basis (Fig. 3b), implying slow and steady removal of cobalt as the deep ocean ages. Because the dCo concentration of southern-sourced waters is considerably less than the deep north Atlantic, deep water formation in the Southern Ocean adds little dCo to deep waters. Unlike nanomolar dCo 
that is typical of temperate estuaries in North America, dCo in the Ross and Weddell Seas is typically $<100 \mathrm{pM}$, indicating only a small Co source from glacial weathering on the Antarctic continent (Bown et al., 2011; Saito et al., 2010; Sañudo-Wilhelmy et al., 2002; Tovar-Sánchez et al., 2004). Due to slow timescales of ${ }^{14} \mathrm{C}$ equilibration with the atmosphere, Antarctic deep water formation also lacks a distinct $\Delta^{14} \mathrm{C}$ signature. As a result, the relationship between $\mathrm{dCo}$ and $\Delta^{14} \mathrm{C}$ age is not improved by accounting for deep water formation in the Southern Ocean (e.g. Matsumoto 2007; Figure S2). Like $\Delta^{14} \mathrm{C}$, most dCo in deep waters derives from NADW.

This analysis expands on observations from a meridional transect in the Western Atlantic, which attributed decreasing dCo on isopycnal surfaces to mixing between NADW and Antarctic Bottom Water (AABW) water types (Dulaquais et al., 2014b). This was followed by the suggestion that dCo scavenging was negligible in Atlantic deep waters (Dulaquais et al., 2014b). While a shared source in NADW can generate a correlation between $\Delta^{14} \mathrm{C}$ and dCo by mixing, there must be some removal of cobalt in the deep ocean by scavenging in order to keep pace with the loss of $\Delta^{14} \mathrm{C}$ due to radioactive decay. As the meridional transit time of the NADW in the deep Atlantic is on the order of 200 years (Broecker et al., 1991; Matsumoto, 2007) - about a quarter of the cobalt scavenging half-life from Eq. 4 - it may be difficult to distinguish scavenging from water mass mixing in the deep Atlantic Ocean.

While this correlation constrains the timescale of cobalt scavenging, the underlying mechanism remains enigmatic. It is unlikely that cobalt scavenging in the deep ocean is restricted to specific environments such as hydrothermal plumes or continental slopes, as both have been sampled by the GEOTRACES program and do not show evidence for quantitative dCo removal (Noble et al. submitted)(Dulaquais et al., 2014b; Hawco et al., 2016). Abiotic rates of inorganic manganese oxidation in seawater are dependent on the concentrations of manganese (II) ion, hydroxide, and dissolved oxygen (von Langen et al., 1997). As the redox chemistry of cobalt and manganese are similar, this reaction may remove kinetically labile cobalt species via co-oxidation, implying that cobalt removal in the deep ocean may be steady. For cobalt bound to strong organic ligands, however, additional photochemical or biological processing may be required before it can be scavenged by this mechanism; there may be other pathway of cobalt removal in the deep sea. 


\subsection{Upper ocean scavenging}

Scaling the apparent rate of dCo removal in the deep ocean from Eq. 4 (0.043 pM year $\left.{ }^{-1}\right)$ to the depth of the deep ocean (1500-3700 m) suggests an areal flux of $0.09 \mu \mathrm{mol} \mathrm{m}^{-2}$ year $^{-1}$, far less than the 1-3 $\mu \mathrm{mol} \mathrm{m} \mathrm{m}^{-2}$ year $^{-1}$ expected from cobalt accumulation rates in Quaternary sediments (Table 2). More than half the volume of the ocean provides less than $10 \%$ of the Co delivered to marine sediments. Either these sediment fluxes are severely overestimated or the remainder of the scavenged Co flux to marine sediments must be balanced elsewhere, namely the epi- and mesopelagic.

In the upper ocean $(<1500 \mathrm{~m})$, Co is strongly influenced by nutrient uptake and regeneration, which mask signatures of water-column scavenging in the dissolved Co profile (Fig. 2) (Dulaquais et al., 2014b; Noble et al., 2012; Saito and Moffett, 2002). In order to appreciate how scavenging affects the Co inventory here, the biological Co cycle must first be understood and subtracted. Yet, phytoplankton Co quotas are not uniform across species and are influenced by both the availability of other nutrients (e.g. Zn, P) and by the complexation of dCo in the surface ocean, making the amount of remineralized Co in any given sample difficult to predict a priori (Jakuba et al., 2008; Saito and Moffett, 2001; Shaked et al., 2006; Sunda and Huntsman, 1995). Below, we describe an empirical approach to calculate cobalt scavenging rates in the upper ocean.

\subsubsection{Authigenic cobalt formation in the mesopelagic}

Examining particulate Co distributions can provide important constraints on cobalt scavenging in the upper ocean. Datasets from GEOTRACES sections in the North Atlantic (GA03) and South Pacific (GP16) indicate that cobalt in large (>51 $\mu \mathrm{m})$, sinking particles represents a combination of lithogenic, biogenic, and authigenic phases (Figure 4). Using Ti as a tracer of lithogenic material, particles containing a Co:Ti ratio near the continental crust ratio $\left(3.37 \times 10^{-3} \mathrm{~mol} \mathrm{~mol}^{-1}\right)$ are expected to reflect a large contribution of dust or continental sediments to the particulate Co inventory (McLennan, 2001; Ohnemus and Lam, 2015). This crustal Co:Ti ratio is almost identical to the slope of aerosol Co and Ti in the North Atlantic, 3.40 x $10^{-3} \mathrm{M} \mathrm{M}^{-1}\left(\mathrm{R}^{2}=0.995\right)$ (Shelley et al., 2015). Even in the dust-heavy North Atlantic, however, $\mathrm{Co}: \mathrm{Ti}$ is in excess of continental crust (i.e. dust) throughout most of the upper water column, 
especially in the upper $300 \mathrm{~m}$ of the water column, signifying the predominance of biogenic and authigenic (i.e. scavenged) components in these basins (Fig. 4a, S5).

Biogenic Co, in turn, can be traced by $\mathrm{P}$. Biological uptake of $\mathrm{PO}_{4}$ by phytoplankton results in a near-surface maximum of $\mathrm{pP}$ that decreases sharply with depth (Ohnemus and Lam, 2015). Although nutrient cycling of Co results in particulate Co profiles that share these features, this gradient is stunted in comparison to $\mathrm{P}$, leading to particulate $\mathrm{Co}: \mathrm{P}$ ratios that increase with depth (Fig. 4b). Thus, the Co concentration in sinking particles in the mesopelagic zone of the North Atlantic and South Pacific is too high to be accurately reflected by biogenic or lithogenic phases, signifying a major contribution from an authigenic (i.e. scavenged) phase at these depths. When normalized to Ti or P, particulate concentrations of Co and Mn between 100-1500 m are extremely well correlated (Fig. 4c, d), strongly suggesting Mn-oxide phases make up the bulk of the particulate cobalt sinking below the mesopelagic in both basins.

\subsubsection{A remineralization - scavenging framework}

Dissolved Co: $\mathrm{PO}_{4}$ ratios in the mesopelagic are lower than both particulate $\mathrm{Co}: \mathrm{PO}_{4}$ at the same depth and from those sampled in the euphotic zone. Assuming that most of the sinking flux of particulate $\mathrm{P}$ from the euphotic zone is remineralized to $\mathrm{PO}_{4}$ in the mesopelagic $(<1500 \mathrm{~m})$, the low dissolved $\mathrm{Co}: \mathrm{PO}_{4}$ ratios reflect an incomplete return of biogenic Co to the dissolved phase during remineralization due to cobalt scavenging onto manganese oxides.

As mixing in the oceans occurs predominantly between waters of similar density, integration over isopycnal surfaces can be used to trace Co and P remineralization on the basin scale. Narrow isopycnal surfaces $\left( \pm 0.125 \mathrm{~kg} \mathrm{~m}^{-3}\right)$ are well-sampled in the GA03 and GP16 datasets in the North Atlantic and South Pacific (>10 discrete measurements per density interval) and show strong coupling between dissolved $\mathrm{Co}$ and $\mathrm{PO}_{4}$ along almost all isopycnal windows in the mesopelagic zone (100-1500 m). Because these waters are constantly receiving a flux of organic matter from overlying waters (containing both Co and P), positive correlations between these two parameters in both the North Atlantic (Fig. 5) and South Pacific Oceans (Fig. 6) confirm that remineralization of $\mathrm{Co}$ is a major process affecting dCo distributions.

A major exception to these basin scale trends can be seen in the oxygen minimum zone (OMZ) of the South Pacific (Fig. 6). At $\mathrm{O}_{2}<20 \mu \mathrm{M}$, dCo shows sharp, P-independent increases that reflect redox-related Co cycling associated with a source from reducing shelf sediments 
(Hawco et al. 2016). As a result, we have excluded samples collected in the $\mathrm{OMZ}\left(\mathrm{O}_{2}<20 \mu \mathrm{M}\right)$ when interpreting isopycnal Co: $\mathrm{PO}_{4}$ slopes (see Methods). Oxic samples on these isopycnal layers, however, follow low Co:P slopes (Fig. 6, red circles), implying that lateral ventilation of OMZ waters by oxygenated, subtropical water masses removes the excess Co that had accumulated in the OMZ while reducing conditions prevailed.

Because of widespread correlations between $\mathrm{Co}$ and $\mathrm{PO}_{4}$ on isopycnal surfaces and the absence of meaningful $\mathrm{P}$ scavenging, we can use $\mathrm{P}$ remineralization to trace Co remineralization in the water column. On any isopycnal surface, the rate of Co remineralization from sinking biomass can be approximated as the rate of $\mathrm{P}$ remineralization and the slope of the Co:P relationship:

Co remin $=$ Co: $P_{\text {isopycnal }} * P_{\text {remin }}$ 5

where the rate of $\mathrm{P}$ remineralization is calculated from a depth-dependent power function fit to global phosphate distributions (Teng et al., 2014). By weighting each isopycnal Co:P slope by the amount of $\mathrm{P}$ remineralization within that isopycnal window, an areal remineralization stoichiometry, Co: $\mathrm{P}_{\text {remin }}$, can be derived (Table 4). The value of Co: $\mathrm{P}_{\text {remin }}$ in the North Atlantic, $58.4 \pm 5.6 \mu \mathrm{mol}: \mathrm{mol}$, is slightly lower than in the South Pacific, $72.1 \pm 5.7 \mu \mathrm{mol}: \mathrm{mol}$, largely due to the offset between dCo:P ratios in the shallowest isopycnal surfaces (Table 4).

Since large particles are subject to strong settling forces, the particulate Co and $\mathrm{P}$ datasets for large $(>51 \mu \mathrm{m})$ particles from the upper $100 \mathrm{~m}$ of the North Atlantic and South Pacific Geotraces transects (GA03 and GP16) can be compared to the Co:P remin ratios determined above. In order to estimate biogenic cobalt, the high contribution of dust in the North Atlantic first requires a subtraction of lithogenic $\mathrm{Co}$, calculated from the particulate Ti concentration and the molar Co:Ti ratio in upper continental crust, $3.37 \times 10^{-3}$. In the Atlantic, Co:P values in samples corrected for detrital Co composition are significantly lower than uncorrected (Fig. 7a), while in the South Pacific, detrital correction affects the Co:P ratio minimally (Fig 7b). Despite 100-fold variability in Ti-corrected Co:P, most of the measurements in both basins have biogenic Co:P ratios $>100 \mu \mathrm{mol}: \mathrm{mol}$, higher than the $\mathrm{Co}: \mathrm{P}_{\text {remin }}$ ratios calculated above. In fact only $15 \%$ of large particles in the upper $100 \mathrm{~m}$ of the South Pacific, and only $9 \%$ of the particles measured in the North Atlantic, have a biogenic Co:P ratio less than or equal to these remineralization stoichiometries. Thus, cobalt does not seem to be conserved during remineralization: there is more cobalt exported from the surface ocean than reappears in the mesopelagic. 
Discrepancies between upper ocean cycles of cobalt and phosphate can be exploited to estimate rates of mesopelagic cobalt scavenging. Here, it is useful to differentiate between two related processes: 1) pCo degradation and 2) dCo remineralization. pCo degradation is the disintegration of cobalt-bearing biogenic phases through heterotrophic respiration on sinking particles. dCo remineralization, instead, represents the explicit (and measurable) return of cobalt to the dissolved phase of seawater. The difference between the two is the scavenging flux of cobalt:

$C o_{\text {scavenging }}=p C o_{\text {degrad }}-C o_{\text {remin }}$

where the units for the above terms are $\mathrm{mol} \mathrm{m}^{-3}$ year $^{-1}$. For typical nutrients such as $\mathrm{P}$, particulate degradation and dissolved remineralization processes are identical; yet for elements with a propensity to scavenge, a 'degradation' flux may be larger than the observed remineralization of dissolved species, as suggested by higher Co:P in particles sinking from the euphotic zone than the $\mathrm{Co}: \mathrm{P}_{\text {remin }}$ determined in the mesopelagic.

The rate that sinking biogenic $\mathrm{Co}$ is degraded, $\mathrm{pCo}_{\text {degrad }}$, can be calculated as the product of the $\mathrm{P}$ remineralization rate and the $\mathrm{Co}: \mathrm{P}$ composition of sinking organic matter: $p C o_{\text {degrad }}=\left(\frac{C o}{P}\right)_{\text {export }} * P_{\text {remin }}$

Thus, Eq. 7 provides an expected return of Co to the water column during remineralization, whereas Eq. 6 describes the actual return. Diverse micronutrient use of cobalt contributes to variable phytoplankton Co:P in the euphotic zone (Saito et al. submitted)(Sunda and Huntsman, 1995), making it difficult to estimate a single value of Co: $P_{\text {export }}$. Despite this variability, histograms of the biogenic Co:P ratio in large particles approximate a log-normal distribution, whose center $\left(\mathrm{X}_{0}\right)$ can be interpreted as the most probable ratio of Co and $\mathrm{P}$ that would be supplied to the mesopelagic via the biological pump (Fig. 7, Table 4). For the North Atlantic, this value was $166 \mu \mathrm{mol}: \mathrm{mol}$ and $116 \mu \mathrm{mol}: \mathrm{mol}$ in the South Pacific, similar to mean and median Co:P for these datasets (Table 5).

In the South Pacific, Co remineralization and ingrowth rates are nearly equal in the shallow isopycnals, but decouple near $\sigma_{\theta}=26.25(\sim 230 \mathrm{~m})$, where remineralization rates are significantly less than pCo degradation rates (Fig. 8a, Table 4). In contrast, the North Atlantic shows consistent offsets between degradation and remineralization throughout the mesopelagic (Fig. 8c). Though North Atlantic dissolved Co:P slopes do eventually approach particulate Co:P ratios, such symmetry is restricted to extremely shallow waters where, in addition to greater 
biological demand, sunlight inhibits cobalt and manganese scavenging (Saito et al., submitted)(Sunda and Huntsman, 1988).

In both basins, rates of expected pCo degradation are greater than apparent remineralization of $\mathrm{dCo}$. If the difference in these processes is attributed to Co removal via scavenging, the rate of Co scavenging on an isopycnal surface can be estimated by substituting Eq. 5 and 7 into Eq. 6:

$C o_{\text {scavenging }}=P_{\text {remin }} *\left(\left(\frac{C o}{P}\right)_{\text {export }}-\left(\frac{C o}{P}\right)_{\text {isopyncal }}\right)$

Defined as such, the North Atlantic and South Pacific show distinct profiles of scavenging rates (Fig. 8b, d). In the North Atlantic, scavenging appears fastest at $\sim 150 \mathrm{~m}$ and decreases with depth (Fig. 8d). This is consistent with ${ }^{55} \mathrm{Mn}$ radiotracer experiments in the Sargasso Sea (Sunda and Huntsman, 1988), which showed that rates of heterotrophic Mn oxidation are highest just below the chlorophyll maximum where supply of labile organic matter is high but light levels are low enough to limit photo-reduction and dissolution of particulate Mn-oxides.

In contrast, the profile of the Co scavenging rate in the South Pacific shows low values in shallow waters $\left(\mathrm{z}_{\text {mean }}<200 \mathrm{~m}\right)$, and peak scavenging rates at $\sim 300 \mathrm{~m}$ (Fig. 8b). Faster rates of $\mathrm{P}$ remineralization and a smaller difference between Co: $\mathrm{P}_{\text {export }}$ and isopycnal Co:P on these shallow surfaces make the scavenging profile in the upper $300 \mathrm{~m}$ subject to large uncertainties. However, low scavenging rates calculated from Eq. 8 are corroborated by the absence of Mn oxidation observed in the upper 175m in the Equatorial Pacific (Moffett, 1997). Indeed, these radiotracer experiments suggest that particulate $\mathrm{Mn}$ formation in this region results from phytoplankton uptake of Mn rather than bacterial oxidation (Moffett 1997). Because microbial Mn-oxidation can occur via iron metalloenzymes, Moffett (1997) posited that low rates of Mn-oxidization in iron-limited Pacific waters occur because these bacteria are outcompeted by phytoplankton for iron uptake. Because cobalt scavenging probably follows this mechanism (Moffett and Ho, 1996), the deeper onset of cobalt scavenging in the South Pacific is consistent with these ideas. Alternatively, lower concentrations of labile cobalt in the South Pacific may limit cobalt scavenging in shallow isopycnals. There is, however, a narrow band of Mn oxidation near the Peru margin that forms between the euphotic zone and the oxygen minimum zone, whose effect may not be captured in these basin scale integrations (Lee et al. submitted). 
Below $300 \mathrm{~m}$, scavenging rates in both basins taper off. A caveat to the scavenging profiles shown in Figure 8 is that this shape will change if Co or P is preferentially remineralized. Preferential release of $P$ relative to Co would cause $C o: P_{\text {export }}$ to increase with depth, resulting in a more uniform scavenging rate with depth. Preferential Co remineralization, in contrast, would accentuate the features of each profile. The increasing particulate Co:P ratio with depth (Fig. 4b) and correlation between Co and Mn in mesopelagic particles (Fig. 4c, d) indicate that any form of preferential Co remineralization, at least, is overshadowed by a larger return of pCo by scavenging.

The integrated scavenging flux sums to $0.64 \mu \mathrm{mol} \mathrm{m}^{-2}$ year $^{-1}$ in the South Pacific and $1.36 \mu \mathrm{mol} \mathrm{m}^{-2}$ year $^{-1}$ in the North Atlantic (Fig. 9). In both basins, $>50 \%$ of the mesopelagic scavenging flux appears to be generated in the upper 400m. Given the difficulty in determining $\mathrm{Co}: \mathrm{P}_{\text {export }}$, the magnitude of the mesopelagic scavenging fluxes should be interpreted with caution. As there is more variability in particulate $\mathrm{Co}: \mathrm{P}$ above our chosen value of $\mathrm{Co}: \mathrm{P}_{\text {remin }}$ than below it (hence the log-normal distribution, Fig. 7), and because Ti-correction can sometimes be overzealous (Rauschenberg and Twining, 2015), our calculations may underestimate the cobalt scavenging flux. For instance, if the mean biogenic Co:P is used for Co:P export (Table 5), calculated scavenging flux increase to 1.2 and $3.0 \mu \mathrm{mol} \mathrm{m}{ }^{-2}$ year $^{-1}$ in the South Pacific and North Atlantic, respectively. Still, it is encouraging that our calculations are similar to authigenic Co fluxes to sediments in Table $2\left(0.3-3 \mu \mathrm{mol} \mathrm{m}^{-2}\right.$ year $\left.^{-1}\right)$, especially given the extremely low rates of apparent Co scavenging in deeper waters $\left(0.09 \mu \mathrm{mol} \mathrm{m}^{-2}\right.$ year $^{-1}$, Fig. 3$)$. This independent calculation also lends cautious support to the assertion that Co accumulation rates in Pacific Ocean sediments have increased since the Pliocene (Kyte et al., 1993).

The areal water column scavenging rate in the North Atlantic is also consistent with higher accumulation rates in the Atlantic relative to the Pacific (Table 2) and with multiyear averages from deep sediment traps in the Sargasso Sea (Huang and Conte, 2009). Higher scavenging rates in the Atlantic may be driven by a number of oceanographic factors such as greater biological cobalt utilization in the North Atlantic, or more extensive cobalt complexation and/or iron limitation of Mn-oxidizing bacteria in the Pacific (Hawco et al., 2016; Moffett, 1997; Noble et al., 2012).

The residence time of cobalt with respect to scavenging can also be calculated from isopycnal scavenging rates and median dCo concentrations on those isopycnal surfaces (Fig. 10). 
Both basins show an increasing residence time of cobalt with depth that approach the 1000-year turnover time of cobalt inferred by correlation with deep ocean $\Delta^{14} \mathrm{C}$ (Fig. 3). At the very least, the cobalt cycle described herein is internally consistent. The $\sim 50$ year residence time of cobalt in the upper ocean is surprisingly short, but necessary in order to reconcile bulk ocean residence time of 130 years with millennial turnover of cobalt in the deep ocean. The slightly higher residence times in the South Pacific are probably linked higher dCo and lack of manganese scavenging in OMZs, which were excluded from the preceding calculations. Based on integrated values of biogenic cobalt export (Table 4), the residence time of cobalt in the surface ocean has also been calculated. In both the North Atlantic and South Pacific Oceans, residence times with respect to biological export are $\sim 1$ year, consistent with previous estimations (Saito and Moffett, 2002). The short scavenging residence time of cobalt throughout the upper ocean suggests that inventories of this metal might be dynamic on very short timescales, which may affect the supply of cobalt to the upper ocean and the extent to which it can be utilized by phytoplankton as a nutrient.

\subsection{Sources of Cobalt to the ocean}

Under steady state, scavenging removal rates must be balanced by input of new Co to the ocean. The magnitude of these sources is therefore a crucial check on the validity of the water column calculations described above, which indicate a global cobalt sink in marine sediments on the order of 300-450 Mmol Co per year. High resolution datasets from the GEOTRACES era have identified myriad oceanic Co sources: including rivers, continental margins, reducing sediments, dust and hydrothermal vents. Our best attempt to evaluate all of these simultaneously is shown in Table 6. While these calculations are far from definitive, they emphasize the major role of reducing sediments along eastern margins in delivering $\sim 30 \%$ of Co to the ocean.

Evidence of a freshwater Co source is readily seen in the western Atlantic, where Gulf Stream waters are enriched to $\sim 100 \mathrm{pM}$ and present strong linear relationships with salinity (Dulaquais et al., 2014a; Saito and Moffett, 2002). Yet, calculating this source is not necessarily straightforward due to desorption of cobalt from terrigenous sediments across salinity gradients and complex redox cycles of $\mathrm{Mn}$ (and $\mathrm{Co}$ ) in estuarine water columns and sediments (Bewers and Yeats P. A., 1977; Moffett and Ho, 1996; Sunda and Huntsman, 1987). Scaled to the entire ocean, mass balance estimates from the St. Lawrence estuary imply a global cobalt source from 
these processes of $420 \mathrm{Mmol}$ per year (Bewers and Yeats P. A., 1977). Notably, this is much less than the total cobalt delivered to the coastal ocean by fluvial sediments every year $\left(1.8 \times 10^{16} \mathrm{~g}\right.$ year $^{-1}$ x $2.9 \times 10^{-7} \mathrm{~mol} \mathrm{~g}^{-1}$ upper continental crust $=5200 \mathrm{Mmol}$ per year). Therefore, only $\sim 8 \%$ (420/5200) of fluvial sources of dissolved and particulate cobalt actually make it to the open ocean. The vast majority is buried in estuaries and on the continental shelf.

Because almost $55 \%$ of terrigenous material is deposited into marginal seas in Southeast and East Asia, the accuracy of this extrapolation largely depends on the behavior of cobalt in these regions (Milliman and Farnsworth, 2011; Peucker-Ehrenbrink, 2009). A Holocene record of sedimentary Co accumulation in the South China Sea shows Co:Ti ratios $\left(3.12 \pm 0.24 \times 10^{-3}\right.$ $\mathrm{M} \mathrm{M}^{-1}$ ) that are slightly less than upper continental crust $\left(3.37 \times 10^{-3} \mathrm{M} \mathrm{M}^{-1}\right)(\mathrm{Hu}$ et al., 2012 ; McLennan, 2001), suggesting cobalt sources an efficiency of cobalt sources near 7\%, similar to that estimated by extrapolation of the Bewers and Yeats (1977) estimate (8\%). However, slow exchange with Pacific Ocean waters and/or elevated rates of Mn-oxidation may cause much of the cobalt released from Southeast and East Asian Estuaries to be scavenged before reaching the open ocean.

In contrast, eastern margin sediments underlying OMZs are strongly depleted in cobalt (Böning et al., 2004), implying that cobalt sources in these areas are more efficient than in oxygenated settings. These observations are corroborated by large plumes of dissolved cobalt in the Atlantic and Pacific OMZs (Hawco et al., 2016; Noble et al., 2012). Reductive dissolution of Mn-oxides on the margin probably amplifies coastal cobalt sources, resulting in less cobalt buried on the continental margin and a greater source to the ocean. Indeed, very low Co:Ti ratios underlying the Peru OMZ (1.96 $\left.\pm 0.55 \times 10^{-3} \mathrm{M} \mathrm{M}^{-1}\right)$ relative to crust $\left(3.37 \times 10^{-3} \mathrm{M} \mathrm{M}^{-1}\right)$ imply that $40 \%$ of the cobalt delivered to the margin by fluvial sediments is exported to the ocean (Böning et al., 2004). Scaling this observation to include fluvial delivery to the major OMZs in the Atlantic, Pacific, and Indian Oceans implies that, of the $480 \mathrm{Mmol}$ Co delivered to these regions every year by fluvial sediments (Milliman and Farnsworth, 2011), $200 \mathrm{Mmol}$ Co is released to the ocean. If these regions behaved like oxygenated margins such as the the St. Lawrence estuary or South China Sea, this source would only be 40 Mmol cobalt per year, implying that deoxygenated coastlines provide an additional source to the ocean on the order of $160 \mathrm{Mmol} \mathrm{Co} \mathrm{year}^{-1}$. 
Other sources are small. We calculate a dust source integrated from atmospheric deposition models (Jickells et al. 2005), and Co abundance in upper continental crust. Assuming a general 10\% solubility determined from in situ leaching of Saharan dust (Shelley et al., 2012), dust supplies $\sim 12 \mathrm{Mmol}$ Co year ${ }^{-1}$. Even in the dust-heavy North Atlantic, deposition is less than $10 \%$ of the Co supplied to the basin. Estimates for a hydrothermal Co flux are also small: 2 Mmol year ${ }^{-1}$ (Swanner et al., 2014) - even without consideration of rapid near-field scavenging that scrubs ocean sections of any visual evidence of far-field hydrothermal impact (German et al., 1991; Hawco et al., 2016; Noble et al., 2012). Together, atmospheric and hydrothermal input is less than $3 \%$ of the global source as outlined here.

In sum, our reckoning of global sources (590 Mmol Co $\mathrm{yr}^{-1}$, Table 6) is sufficient to account for water column scavenging rates (313 $\left.\mathrm{Mmol} \mathrm{Co} \mathrm{yr}^{-1}\right)$ and the accumulation in pelagic sediments (450 Mmol Co $\mathrm{yr}^{-1}$ ). Basin-scale budgets for the North Atlantic and South Pacific Oceans show strong agreement as well (Table 2) relying on maps of dust deposition and fluvial sediment delivery (Jickells et al., 2005; Milliman and Farnsworth, 2011). General agreement between cobalt sources and sinks at basin and global scales suggest that the cobalt cycle is approximately in balance.

\subsection{A dynamic or stable cobalt cycle?}

The high contribution of low-oxygen regions to global cobalt sources $(\sim 25 \%)$ is surprising and suggests that the supply of cobalt to the ocean may vary synchronously with these oceanographic features. Centennial-scale fluctuations in the volume of anoxic waters associated with modern OMZs in the Pacific have been reported and linked to increased trade wind intensity, which invigorates eastern-boundary upwelling, biological export, and mesopelagic oxygen consumption (Deutsch et al., 2014). Furthermore, anthropogenic warming and stratification appear to limit oxygen resupply from gas exchange on isopycnal outcrops, leading to a decline in mesopelagic $\mathrm{O}_{2}$ concentrations that is expected to continue over the next century (Stramma et al., 2008). Given the 50-100 year residence time of cobalt in the upper ocean, sustained expansion of OMZs may lead to substantial increases in oceanic cobalt inventories by exposing a larger swath of coastline to anoxic bottom waters (Noble et al., 2012). Similarly, the apparent contraction of OMZs during glacial periods, suggested by nitrogen isotope and trace metal records (Ganeshram et al., 2000; Jaccard and Galbraith, 2011), may have led to increased 
burial of cobalt on continental margins by exposing formerly anoxic sediments to oxygen. Hypothesized lower cobalt sources during this time may have affected phytoplankton that depend on this micronutrient for growth (Saito et al., 2002; Sunda and Huntsman, 1995).

This dynamic view of cobalt biogeochemistry, however, is counter to the welldocumented steadiness of cobalt accumulation in marine sediments (Dunlea et al., 2015; Kadko, 1985; Krishnaswami, 1976). Since such measurements integrate over dozens, if not hundreds, of revolutions of this cycle, large changes in marine cobalt inventories on 100-1000 year timescales are not inconsistent with these sedimentary observations, provided the existence of stabilizing mechanisms that keep the long-term mean steady. Such mechanisms have been observed on inter-annual timescales, at least. For instance, positive phases of the El Niño Southern Oscillation oxygenate the Peru shelf and have been linked to increased Mn-oxide flux to sediments, while negative phases (La Niña) increase anoxia and stimulate dissolution and mobilization of Mnoxides buried during El Niño years (Scholz et al., 2011). The similarity between Mn and Co cycling in coastal zones implies that cobalt shares a similar fate (Böning et al., 2004). If longterm contraction of OMZs (such as during glacial times) leads to the burial of reactive cobalt in Mn-oxide phases on the margin, this storage may reverse as OMZs expand and Mn-oxides dissolve (e.g. during deglaciation). Analogously, co-precipitation of cobalt during pyrite formation will also decrease the efficiency of anoxic cobalt sources if OMZs intensify to the point that water column sulfate reduction becomes widespread (Morse and Luther, 1999; Scholz et al., 2014). Therefore, there are plausible mechanisms that may stabilize cobalt sources, despite known variability of OMZs on long timescales.

The compilation of modern sources also lends support to the assertion that rates of cobalt accumulation in deep sea sediments of the Pacific are 2-3 times higher during the Quaternary than other times in the Cenozoic (Kyte et al., 1993). Consideration of OMZ sources alone is not enough to explain this change, even though there is some evidence from $\mathrm{N}$-isotope records that OMZs have expanded since the Pliocene (Robinson et al., 2014). Therefore, the increase in cobalt supply requires an increase in riverine/estuarine sources as well. Increased rates of chemical weathering since the Pliocene has been inferred from various isotope systems, and a parallel increase in the chemical weathering of cobalt could explain the shift to higher cobalt accumulation rates in sediments, but this remains controversial (Willenbring and von 
Blanckenburg, 2010). More thorough investigations into cobalt accumulation rates in marine sediments would lend greater confidence in these assertions.

\section{Conclusions}

In addition to biological cycling, gradients of dissolved cobalt concentrations in seawater are impacted by scavenging. The excess cobalt in marine sediments provides a record of the magnitude of the water column scavenging flux. Correlations between cobalt and radiocarbon age indicate that scavenging rates in the deep ocean are low while indirect calculations of cobalt scavenging in the mesopelagic can account for most of the cobalt flux to marine sediments. High rates of scavenging in the mesopelagic and slower scavenging in the deep ocean generate a bimodal distribution of oceanic residence times. Extraordinarily long-lived cobalt in the deep ocean has a turnover time of $\sim 1000$ years, while cobalt travels from source to sink in the upper ocean in a matter of decades. These fast and slow lanes of the cobalt cycle average to a mean residence time of 130 years.

Scavenging sinks are balanced by cobalt sources to the ocean and about $25 \%$ of cobalt sources may stem from low-oxygen regions on eastern margins, where burial of cobalt in Mnoxide phases is unfavorable. Despite its reputation as a 'constant' flux recorder in pelagic sediments and ferromanganese nodules and crusts, it seems not only possible but likely for climate-driven changes in oceanic OMZs to have a strong effect on the amount of cobalt supplied to the ocean. In addition to its role as a nutrient to phytoplankton, the potential for cobalt inventories to change with ocean oxygenation may be a useful paleo-oceanographic tool for constraining the variability of OMZs in past climates.

\section{References}

Bewers, J. M. and Yeats P. A.: Oceanic residence times of trace metals, Nature, 268(18), 595598, 1977.

Böning, P., Brumsack, H.-J., Böttcher, M. E., Schnetger, B., Kriete, C., Kallmeyer, J. and Borchers, S. L.: Geochemistry of Peruvian near-surface sediments, Geochim. Cosmochim. Acta, 68(21), 4429-4451, doi:10.1016/j.gca.2004.04.027, 2004.

Bown, J., Boye, M., Baker, A., Duvieilbourg, E., Lacan, F., Le Moigne, F., Planchon, F., Speich, S. and Nelson, D. M.: The biogeochemical cycle of dissolved cobalt in the Atlantic and the Southern Ocean south off the coast of South Africa, Mar. Chem., 126(1-4), 193-206, 
doi:10.1016/j.marchem.2011.03.008, 2011.

Broecker, W. S., Blanton, S. and Smethie, W. M.: Radiocarbon decay and oxygen utilization in the deep atlantic ocean, Global Biogeochem. Cycles, 5(1), 1991.

Cowen, J. P. and Bruland, K. W.: Metal deposits associated with bacteria: implications for Fe and Mn marine biogeochemistry, Deep Sea Res. Part A. Oceanogr. Res. Pap., 32(3), 253-272, doi:10.1016/0198-0149(85)90078-0, 1985.

D’Hondt, S., Inagaki, F., Zarikian, C. A., Abrams, L. J., Dubois, N., Engelhardt, T., Evans, H., Ferdelman, T., Gribsholt, B., Harris, R. N., Hoppie, B. W., Hyun, J.-H., Kallmeyer, J., Kim, J., Lynch, J. E., McKinley, C. C., Mitsunobu, S., Morono, Y., Murray, R. W., Pockalny, R., Sauvage, J., Shimono, T., Shiraishi, F., Smith, D. C., Smith-Duque, C. E., Spivack, A. J., Steinsbu, B. O., Suzuki, Y., Szpak, M., Toffin, L., Uramoto, G., Yamaguchi, Y. T., Zhang, G., Zhang, X.-H. and Ziebis, W.: Presence of oxygen and aerobic communities from sea floor to basement in deep-sea sediments, Nat. Geosci., 8(April), 299-304, doi:10.1038/ngeo2387, 2015.

Deutsch, C., Berelson, W., Thunell, R., Weber, T., Tems, C., McManus, J., Crusius, J., Ito, T., Baumgartner, T., Ferreira, V., Mey, J. and van Geen, A.: Centennial changes in North Pacific anoxia linked to tropical trade winds, Science (80-. )., 345(6197), 665-668, doi:10.1126/science.1252332, 2014.

Dulaquais, G., Boye, M., Middag, R., Owens, S., Puigcorbe, V., Buesseler, K., Masqué, P., de Baar, H. J. W. and Carton, X.: Contrasting biogeochemical cycles of cobalt in the surface western Atlantic Ocean, Global Biogeochem. Cycles, 28(12), 1387-1412, doi:10.1002/2014GB004903, 2014a.

Dulaquais, G., Boye, M., Rijkenberg, M. J. a and Carton, X.: Physical and remineralization processes govern the cobalt distribution in the deep western Atlantic Ocean, Biogeosciences, 11(6), 1561-1580, doi:10.5194/bg-11-1561-2014, 2014b.

Dunlea, A. G., Murray, R. W. and Harris, R. N.: Cobalt-based age models of pelagic clay in the South Pacific Gyre, 2015.

Eakins, B. W. and Sharman, G. F.: Volumes of the World's Oceans from ETOPO1, NOAA Natl. Geophys. Data Center, Boulder, CO, 2010.

Fiedler, P. C. and Talley, L. D.: Hydrography of the eastern tropical Pacific: A review, Prog. Oceanogr., 69(2-4), 143-180, doi:10.1016/j.pocean.2006.03.008, 2006.

Frank, M., O’Nions, R. K., Hein, J. R. and Banakar, V. K.: 60 Myr records of major elements and $\mathrm{Pb}-\mathrm{Nd}$ isotopes from hydrogenous ferromanganese crusts: Reconstruction of seawater paleochemistry, Geochim. Cosmochim. Acta, 63(11-12), 1689-1708, doi:10.1016/S00167037(99)00079-4, 1999.

Ganeshram, R. S., Pedersen, T. F., Calvert, S. E., McNeill, G. W. and Fontugne, M. R.: Glacialinterglacial variability in denitrification in the World's Oceans: Causes and consequences, Paleoceanography, 15(4), 361-376, 2000.

German, C. R., Campbell, A. C. and Edmond, J. M.: Hydrothermal scavenging at the Mid- 
Atlantic Ridge: Modification of trace element dissolved fluxes, Earth Planet. Sci. Lett., 107(1), 101-114, doi:10.1016/0012-821X(91)90047-L, 1991.

Goldberg, E. D. and Arrhenius, G. O. S.: Chemistry of Pacific pelagic sediments, Geochim. Cosmochim. Acta, 13(2-3), 153-212, doi:10.1016/0016-7037(58)90046-2, 1958.

Halbach, P., Segl, M., Puteanus, D. and Mangini, A.: Co-fluxes and growth rates in ferromanganes deposits from central Pacific seamount seas, Nature, 304, 716-719, 1983.

Hawco, N. J., Ohnemus, D. C., Resing, J. A., Twining, B. S. and Saito, M. A.: A cobalt plume in the oxygen minimum zone of the Eastern Tropical South Pacific, Biogeosciences, 13, 56975717, doi:10.5194/bg-2016-169, 2016.

Hu, D., Böning, P., Köhler, C. M., Hillier, S., Pressling, N., Wan, S., Brumsack, H. J. and Clift, P. D.: Deep sea records of the continental weathering and erosion response to East Asian monsoon intensification since 14ka in the South China Sea, Chem. Geol., 326-327, 1-18, doi:10.1016/j.chemgeo.2012.07.024, 2012.

Huang, S. and Conte, M. H.: Source/process apportionment of major and trace elements in sinking particles in the Sargasso sea, Geochim. Cosmochim. Acta, 73(1), 65-90, doi:10.1016/j.gca.2008.08.023, 2009.

Jaccard, S. L. and Galbraith, E. D.: Large climate-driven changes of oceanic oxygen concentrations during the last deglaciation, Nat. Geosci., 5(2), 151-156, doi:10.1038/ngeo1352, 2011.

Jakuba, R. W., Moffett, J. W. and Dyhrman, S. T.: Evidence for the linked biogeochemical cycling of zinc, cobalt, and phosphorus in the western North Atltic Ocean, Global Biogeochem. Cycles, 22(4), 1-13, doi:10.1029/2007GB003119, 2008.

Jenkins, W. J., Smethie, W.M., J., Boyle, E. a. and Cutter, G. a.: Water Mass Analysis for the U.S. GEOTRACES (GA03) North Atlantic Sections, Deep Sea Res. Part II Top. Stud. Oceanogr., 1-30, doi:10.1016/j.dsr2.2014.11.018, 2014.

Jenkins, W. J., Lott, D. E., Longworth, B. E., Curtice, J. M. and Cahill, K. L.: The distributions of helium isotopes and tritium along the U.S. GEOTRACES North Atlantic sections (GEOTRACES GAO3), Deep. Res. Part II Top. Stud. Oceanogr., 116, 21-28, doi:10.1016/j.dsr2.2014.11.017, 2015.

Jickells, T. D., An, Z. S., Andersen, K. K., Baker, A. R., Bergametti, G., Brooks, N., Cao, J. J., Boyd, P. W., Duce, R. A. and Hunter, K. A.: Global iron connections between desert dust, ocean biogeochemistry, and climate, Science (80-. )., 308(5718), 67-71, 2005.

Kadko, D.: Late Cenozoic sedimentation and metal deposition in the North Pacific, Geochim. Cosmochim. Acta, 49(3), 651-661, doi:10.1016/0016-7037(85)90160-7, 1985.

Karstensen, J., Stramma, L. and Visbeck, M.: Oxygen minimum zones in the eastern tropical Atlantic and Pacific oceans, Prog. Oceanogr., 77(4), 331-350, doi:10.1016/j.pocean.2007.05.009, 2008. 
Key, R. M., Kozyr, a., Sabine, C. L., Lee, K., Wanninkhof, R., Bullister, J. L., Feely, R. a., Millero, F. J., Mordy, C. and Peng, T. H.: A global ocean carbon climatology: Results from Global Data Analysis Project (GLODAP), Global Biogeochem. Cycles, 18(4), 1-23, doi:10.1029/2004GB002247, 2004.

Krishnaswami, S.: Authigenic transition elements in Pacific pelagic clays, Geochim. Cosmochim. Acta, 40(4), 425-434, doi:10.1016/0016-7037(76)90007-7, 1976.

Kyte, F. T., Leinen, M., Ross Heath, G. and Zhou, L.: Cenozoic sedimentation history of the central North Pacific: Inferences from the elemental geochemistry of core LL44-GPC3, Geochim. Cosmochim. Acta, 57(8), 1719-1740, doi:10.1016/0016-7037(93)90109-A, 1993.

von Langen, P. J., Johnson, K. S., Coale, K. H. and Elrod, V. a.: Oxidation kinetics of manganese (II) in seawater at nanomolar concentrations, Geochim. Cosmochim. Acta, 61(23), 4945-4954, doi:10.1016/S0016-7037(97)00355-4, 1997.

Manheim, F. T.: Marine Cobalt resources, Science (80-. )., 1986.

Matsumoto, K.: Radiocarbon-based circulation age of the world oceans, J. Geophys. Res. Ocean., 112(9), 1-7, doi:10.1029/2007JC004095, 2007.

McLennan, S. M.: Relationships between the trace element composition of sedimentary rocks and upper continental crust, Geochemistry, Geophys. Geosystems, 2(4), n/a-n/a, doi:10.1029/2000GC000109, 2001.

Milliman, J. D. and Farnsworth, K. L.: River Discharge to the Coastal Ocean, Cambridge University Press, Cambridge., 2011.

Moffett, J. W.: The importance of microbial Mn oxidation in the upper ocean: a comparison of the Sargasso Sea and equatorial Pacific, Deep Sea Res. Part I Oceanogr. Res. Pap., 44(8), 12771291, doi:10.1016/S0967-0637(97)00032-0, 1997.

Moffett, J. W. and Ho, J.: Oxidation of cobalt and manganese in seawater via a common microbially catalyzed pathway, Geochim. Cosmochim. Acta, 60(18), 3415-3424, doi:10.1016/0016-7037(96)00176-7, 1996.

Morse, J. W. and Luther, G. W.: Chemical influence on trace metalsulphide interactions in anoxic sediments, Geochim. Cosmochim. Acta, 63(3373-3378), 3378, 1999.

Noble, A. E., Lamborg, C. H., Ohnemus, D. C., Lam, P. J., Goepfert, T. J., Measures, C. I., Frame, C. H., Casciotti, K. L., DiTullio, G. R., Jennings, J. and Saito, M. A.: Basin-scale inputs of cobalt, iron, and manganese from the Benguela-Angola front to the South Atlantic Ocean, Limnol. Oceanogr., 57(4), 989-1010, doi:10.4319/lo.2012.57.4.0989, 2012.

Ohnemus, D. C. and Lam, P. J.: Cycling of lithogenic marine particles in the US GEOTRACES North Atlantic transect, Deep Sea Res. Part II Top. Stud. Oceanogr., 116, 283-302, doi:10.1016/j.dsr2.2014.11.019, 2015.

Ohnemus, D. C., Rauschenberg, S., Cutter, G. A., Fitzsimmons, J. N., Sherrell, R. M. and Twining, B. S.: Elevated trace metal content of prokaryotic plankton communities associated 
with marine oxygen deficient zones, Limnol. Oceanogr., (2014), Accepted, doi:10.1002/lno.10363, 2016.

Peucker-Ehrenbrink, B.: Land2Sea database of river drainage basin sizes, annual water discharges, and suspended sediment fluxes, Geochemistry, Geophys. Geosystems, 10(6), 1-10, doi:10.1029/2008GC002356, 2009.

Rauschenberg, S. and Twining, B. S.: Evaluation of approaches to estimate biogenic particulate trace metals in the ocean, Mar. Chem., 171, 67-77, doi:10.1016/j.marchem.2015.01.004, 2015.

Robinson, R. S., Etourneau, J., Martinez, P. M. and Schneider, R.: Expansion of pelagic denitrification during early Pleistocene cooling, Earth Planet. Sci. Lett., 389, 52-61, doi:10.1016/j.eps1.2013.12.022, 2014.

Saito, M. A. and Moffett, J. W.: Complexation of cobalt by natural organic ligands in the Sargasso Sea as determined by a new high-sensitivity electrochemical cobalt speciation method suitable for open ocean work, Mar. Chem., 75(1-2), 49-68, doi:10.1016/S0304-4203(01)00025$1,2001$.

Saito, M. A. and Moffett, J. W.: Temporal and spatial variability of cobalt in the Atlantic Ocean, Geochim. Cosmochim. Acta, 66(11), 1943-1953, doi:10.1016/S0016-7037(02)00829-3, 2002.

Saito, M. A., Moffett, J. W., Chisholm, S. W. and Waterbury, J. B.: Cobalt limitation and uptake in Prochlorococcus, Limnol. Oceanogr., 47(6), 1629-1636, doi:10.4319/lo.2002.47.6.1629, 2002.

Saito, M. A., Goepfert, T. J., Noble, A. E., Bertrand, E. M., Sedwick, P. N. and DiTullio, G. R.: A seasonal study of dissolved cobalt in the Ross Sea, Antarctica: micronutrient behavior, absence of scavenging, and relationships with Zn, Cd, and P, Biogeosciences, 7(12), 4059-4082, doi:10.5194/bg-7-4059-2010, 2010.

Sañudo-Wilhelmy, S. A., Olsen, K. A., Scelfo, J. M., Foster, T. D. and Flegal, A. R.: Trace metal distributions off the antarctic peninsula in the weddell sea, Mar. Chem., 77(2-3), 157-170, doi:10.1016/S0304-4203(01)00084-6, 2002.

Scholz, F., Hensen, C., Noffke, A., Rohde, A., Liebetrau, V. and Wallmann, K.: Early diagenesis of redox-sensitive trace metals in the Peru upwelling area - response to ENSO-related oxygen fluctuations in the water column, Geochim. Cosmochim. Acta, 75(22), 7257-7276, doi:10.1016/j.gca.2011.08.007, 2011.

Scholz, F., McManus, J., Mix, A. C., Hensen, C. and Schneider, R. R.: The impact of ocean deoxygenation on iron release from continental margin sediments, Nat. Geosci., 7(May), 433437, doi:10.1038/ngeo2162, 2014.

Shaked, Y., Xu, Y., Leblanc, K. and Morel, F. M. M.: Zinc availability and alkaline phosphatase activity in Emiliania huxleyi: Implications for Zn-P co-limitation in the ocean, Limnol. Oceanogr., 51(1), 299-309, doi:10.4319/lo.2006.51.1.0299, 2006.

Shelley, R. U., Sedwick, P. N., Bibby, T. S., Cabedo-Sanz, P., Church, T. M., Johnson, R. J., Macey, A. I., Marsay, C. M., Sholkovitz, E. R., Ussher, S. J., Worsfold, P. J. and Lohan, M. C.: 
Controls on dissolved cobalt in surface waters of the Sargasso Sea: Comparisons with iron and aluminum, Global Biogeochem. Cycles, 26(2), n/a-n/a, doi:10.1029/2011GB004155, 2012.

Shelley, R. U., Morton, P. L. and Landing, W. M.: Elemental ratios and enrichment factors in aerosols from the US-GEOTRACES North Atlantic transects, Deep. Res. Part II Top. Stud. Oceanogr., 116(October 2016), 262-272, doi:10.1016/j.dsr2.2014.12.005, 2015.

Stramma, L., Johnson, G. C., Sprintall, J. and Mohrholz, V.: Expanding Oxygen-Minimum Zones in the Tropical Oceans, Science (80-. )., 320(5876), 655-658, doi:10.1126/science.1153847, 2008.

Sunda, W. G. and Huntsman: Diel cycles in microbial manganese oxidation and manganese redox speciation in coastal waters of the Bahama Islands, Limnol. Oceanogr., 35(2), 325-338, doi:10.4319/lo.1990.35.2.0325, 1990.

Sunda, W. G. and Huntsman, S. A.: Microbial oxidation of manganese in a North Carolina estuary, Limnol. Oceanogr., 32(3), 552-564, doi:10.4319/lo.1987.32.3.0552, 1987.

Sunda, W. G. and Huntsman, S. a.: Effect of sunlight on redox cycles of manganese in the southwestern Sargasso Sea, Deep Sea Res. Part A. Oceanogr. Res. Pap., 35(8), 1297-1317, doi:10.1016/0198-0149(88)90084-2, 1988.

Sunda, W. G. and Huntsman, S. A.: Cobalt and zinc interreplacement in marine phytoplankton: Biological and geochemical implications, Limnol. Oceanogr., 40(8), 1404-1417, doi:10.4319/lo.1995.40.8.1404, 1995.

Swanner, E. D., Planavsky, N. J., Lalonde, S. V., Robbins, L. J., Bekker, A., Rouxel, O. J., Saito, M. A., Kappler, A., Mojzsis, S. J. and Konhauser, K. O.: Cobalt and marine redox evolution, Earth Planet. Sci. Lett., 390, 253-263, doi:10.1016/j.eps1.2014.01.001, 2014.

Teng, Y., Primeau, F. W., Moore, J. K., Lomas, M. W. and Martiny, A. C.: Global-scale variations of the ratios of carbon to phosphorus in exported marine organic matter, Nat. Geosci., 7(December), 2-5, doi:10.1038/NGEO2303, 2014.

Tovar-Sánchez, A., Sañudo-Wilhelmy, S. a. and Flegal, A. R.: Temporal and spatial variations in the biogeochemical cycling of cobalt in two urban estuaries: Hudson River Estuary and San Francisco Bay, Estuar. Coast. Shelf Sci., 60(4), 717-728, doi:10.1016/j.ecss.2004.03.010, 2004.

Willenbring, J. K. and von Blanckenburg, F.: Long-term stability of global erosion rates and weathering during late-Cenozoic cooling., Nature, 465(7295), 211-4, doi:10.1038/nature09044, 2010 .

Yee, D. and Morel, F. M. M.: In vivo substitution of zinc by cobalt in carbonic anhydrase of a marine diatom, Limnol. Oceanogr., 41(3), 573-577, doi:10.4319/lo.1996.41.3.0573, 1996.

Zhang, Y., Rodionov, D. A., Gelfand, M. S. and Gladyshev, V. N.: Comparative genomic analyses of nickel, cobalt and vitamin B12 utilization., BMC Genomics, 10, 78, doi:10.1186/1471-2164-10-78, 2009.

Zhou, L. and Kyte, F. T.: Sedimentation history of the south pacific pelagic clay province over 
the last 85 million years inferred from the geochemistry of deep sea drilling project hole 596, Paleoceanography, 7(4), 441-465, 1992. 
Table 1. $\Delta{ }^{14} \mathrm{C}$ and dCo comparison averaged across domains for Geotraces transects.

\begin{tabular}{|c|c|c|c|c|c|c|c|c|c|}
\hline & \multirow[t]{2}{*}{ Dataset } & \multirow{2}{*}{$\begin{array}{l}\text { Box Dimensions } \\
\text { GEOTRACES/GLODAP } \\
{[\mathrm{N}, \mathrm{S}, \mathrm{E}, \mathrm{W}]}\end{array}$} & \multirow{2}{*}{$\begin{array}{l}\text { Depth } \\
\text { Range } \\
\mathrm{km}\end{array}$} & \multicolumn{6}{|c|}{ Box Averages } \\
\hline & & & & $\Delta^{14} \mathrm{C}$ & $\sigma$ & $\mathrm{n}$ & $\mathrm{dCo}$ & $\sigma$ & $\mathrm{n}$ \\
\hline \multirow[t]{6}{*}{ Atlantic } & GA03 & {$[40,17,-10,-70] /$} & $1.5-3$ & -84 & 9 & 253 & 73.7 & 9.9 & 133 \\
\hline & & {$[44,12,-10,-74]$} & $>3$ & -101 & 11 & 288 & 53.2 & 10.8 & 93 \\
\hline & GAc01 & {$[-11,-25,13,-30] /$} & $1.5-3$ & -105 & 11 & 103 & 72.1 & 17.2 & 41 \\
\hline & & {$[-6,-30,9,-35]$} & $>3$ & -139 & 26 & 136 & 50.9 & 12.2 & 37 \\
\hline & GA10 & {$[-34,-40,17,-52] /$} & $1.5-3$ & -121 & 11 & 109 & 52.5 & 5.4 & 118 \\
\hline & & {$[-29,-45,19,-51]$} & $>3$ & -152 & 26 & 136 & 36.6 & 7.4 & 130 \\
\hline \multirow[t]{2}{*}{ Southern Ocean } & GIPY4 & {$[-34,-58,0,-14] /$} & $1.5-3$ & -128 & 12 & 75 & 43.4 & 7.8 & 25 \\
\hline & & {$[-29,-55,2.3,-19]$} & $>3$ & -143 & 15 & 90 & 37.6 & 7.1 & 11 \\
\hline \multirow[t]{4}{*}{ Pacific } & GP16 & {$[-10,-16,-78,-152] /$} & $1.5-3$ & -198 & 12 & 101 & 31.1 & 6.6 & 230 \\
\hline & & {$[-6,-20,-85,-151]$} & $>3$ & -204 & 11 & 78 & 24.7 & 4.5 & 114 \\
\hline & Metzyme & {$[17,-15,-154,-175] /$} & $1.5-3$ & -208 & 15 & 61 & 26.8 & 6.2 & 48 \\
\hline & & {$[18,-17,150,179]$} & $>3$ & -205 & 13 & 88 & 24.7 & 4.1 & 42 \\
\hline
\end{tabular}


Table 2. Literature estimates of the Cobalt flux to marine sediments.

\begin{tabular}{|c|c|c|}
\hline Location & 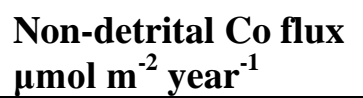 & Source \\
\hline \multicolumn{3}{|l|}{ Mn crusts and nodules } \\
\hline Central Pacific & 0.40 & Manheim et al. 1983 \\
\hline Atlantic, Pacific and Indian & 0.32 & Frank et al. 1999 \\
\hline \multicolumn{3}{|l|}{ Pacific sediments, Cenozoic } \\
\hline North Pacific Gyre & $0.44 \pm 0.07$ & Kyte et al. 1993 \\
\hline South Pacific Gyre & $0.34 \pm 0.06$ & Dunlea et al. 2015 \\
\hline South Pacific Gyre & 0.34 & Zhao and Kyte 1992 \\
\hline \multicolumn{3}{|l|}{ Pacific sediments, Quaternary } \\
\hline Pacific Surface Sediments & $0.93 *$ & Krishnaswami 1976 \\
\hline North Pacific Gyre & 1.16 & Kyte et al. 1993 \\
\hline Northeast Pacific & $1.2 * *$ & Kadko 1985 \\
\hline South Pacific Gyre & 1.2 & Windom 1970 \\
\hline \multicolumn{3}{|l|}{ Atlantic sediments, Quaternary } \\
\hline Sargasso Sea & $2.3 \pm 0.4$ & Thomson et al. 1984 \\
\hline Sargasso Sea & $1.2 \pm 1.0$ & Bacon and Rosholt 1982 \\
\hline Hatteras Continental Rise & $2-3$ & Heggie and Lewis, 1984 \\
\hline South Atlantic gyre & $1.6 \pm 0.7 * *$ & Turekian 1968 \\
\hline Bermuda Sediment Traps, $3000 \mathrm{~m}$ & $2.3 \pm 0.1^{*}$ & Huang and Conte, 2009 \\
\hline
\end{tabular}


Table 3. Phosphate export parameters derived from Teng et al. 2014. Fluxes are modified to reflect export at $100 \mathrm{~m}$. Averages of Tropical and Subtropical domains, weighted by total P export, are used to calculate $\mathrm{Co}: \mathrm{P}_{\text {remin }}$.

\begin{tabular}{lcccc}
\hline & $\begin{array}{c}\text { P export } \\
\text { Tmol year }^{-1}\end{array}$ & $\begin{array}{c}\text { P export, 100m } \\
\text { mmol m}^{-2} \text { year }^{-1}\end{array}$ & $\begin{array}{c}\text { P-attenuation } \\
\text { 'b' exponent }\end{array}$ & $\begin{array}{c}\text { Export weighted } \\
\text { Co: } \mathrm{P}_{\text {remin }}, \mu \text { mol:mol }\end{array}$ \\
\hline $\begin{array}{l}\text { North Atlantic (GA03) } \\
\text { Subtropical }\end{array}$ & 0.21 & & & \\
Tropical & 0.29 & 17.8 & 1.3 & $60.8 \pm 6.5$ \\
Weighted Average & & 13.5 & 0.76 & $56.0 \pm 4.9$ \\
& & & 0.99 & $58.4 \pm 5.6$ \\
Eastern South Pacific (GP16) & 0.35 & 10.9 & 1.33 & \\
Subtropical & 0.90 & 17.9 & 0.71 & $81.2 \pm 7.0$ \\
Tropical & & 15.9 & 0.88 & $72.1 \pm 5.2$ \\
Weighted Average & & & & \\
\hline
\end{tabular}


Table 4. Mesopelagic cobalt scavenging calculations, calculated based on the difference between particulate Co degradation rates and dissolved Co remineralization rates. Remineralization rates are calculated as the product of $\mathrm{P}$ remineralization and the $\mathrm{dCo}: \mathrm{P}$ ratio on isopycnal surfaces (see Figures 5 and 6). Degradation rates are calculated as the product of $\mathrm{P}$ remineralization and the Co:P ratio of exported biomass (Co:P $\mathrm{P}_{\text {export }}$, see Figure 7$)$.

\begin{tabular}{|c|c|c|c|c|c|c|c|c|c|}
\hline \multirow{2}{*}{\multicolumn{6}{|c|}{ South Pacific (GP16) }} & \multicolumn{4}{|c|}{ Areal Fluxes } \\
\hline & & & & & & \multirow{2}{*}{$\begin{array}{c}\mathrm{mmol} \mathrm{m}^{-2} \text { year }^{-1} \\
\text { P remin }\end{array}$} & \multicolumn{3}{|c|}{$\mu \mathrm{mol} \mathrm{m}{ }^{-2}$ year $^{-1}$} \\
\hline$\sigma_{\theta}$ & $z_{\text {ypner }}$ & $\mathrm{dz}$ & $\mathrm{dCo}: \mathrm{P}$ & \pm & $\mathrm{R}^{2}$ & & pCo degrad.* & dCo remin & Scavenging \\
\hline 25.5 & 100 & 67 & 104.4 & 13.3 & 0.75 & 5.8 & 0.68 & 0.61 & 0.07 \\
\hline 25.75 & 167 & 28 & 129.3 & 13.8 & 0.91 & 1.3 & 0.15 & 0.17 & -0.02 \\
\hline 26 & 195 & 27 & 90.0 & 5.5 & 0.95 & 0.9 & 0.11 & 0.08 & 0.02 \\
\hline 26.25 & 222 & 27 & 46.5 & 6.4 & 0.84 & 0.8 & 0.09 & 0.04 & 0.05 \\
\hline 26.5 & 249 & 75 & 25.7 & 6.2 & 0.57 & 1.5 & 0.17 & 0.04 & 0.13 \\
\hline 26.75 & 325 & 126 & 33.1 & 12.9 & 0.52 & 1.4 & 0.16 & 0.05 & 0.12 \\
\hline 27 & 451 & 246 & 15.9 & 5.4 & 0.19 & 1.3 & 0.16 & 0.02 & 0.13 \\
\hline 27.25 & 697 & 322 & 22.9 & 5.1 & 0.32 & 0.8 & 0.09 & 0.02 & 0.08 \\
\hline \multirow[t]{2}{*}{27.5} & 1020 & 480 & 38.3 & 4.7 & 0.51 & 0.6 & 0.07 & 0.02 & 0.05 \\
\hline & 1500 & & & & & & & & \\
\hline \multirow{2}{*}{\multicolumn{3}{|c|}{$P$ weighted average }} & 72.1 & & Sum & \multirow[t]{2}{*}{14.4} & 1.68 & 1.04 & 0.64 \\
\hline & & & 5.7 & & range & & $1.52-1.86$ & $0.89-1.19$ & $0.42-0.88$ \\
\hline
\end{tabular}

North Atlantic (GA03)

$$
\begin{array}{cc}
\text { mmol m}^{-2} \text { year }^{-1} & \text { Areal Fluxes } \\
\text { P remin } & \mu \mathrm{mol} \mathrm{m} \mathrm{m}^{-2} \text { year }^{-1}
\end{array}
$$

\begin{tabular}{|c|c|c|c|c|c|c|c|c|c|}
\hline$\sigma_{\theta}$ & $Z_{\text {upper }}$ & $\mathrm{dz}$ & $\mathrm{dCo}: \mathrm{P}$ & \pm & $\mathrm{R}^{2}$ & 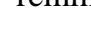 & pCo degrad.* & $\mathrm{dCo}$ remin & Scavenging \\
\hline 26.25 & 100 & 64 & 65.3 & 12.9 & 0.56 & 5.4 & 0.89 & 0.35 & 0.54 \\
\hline 26.5 & 167 & 86 & 67.1 & 2.0 & 0.94 & 3.1 & 0.52 & 0.21 & 0.31 \\
\hline 26.75 & 272 & 104 & 63.2 & 3.7 & 0.85 & 1.2 & 0.20 & 0.08 & 0.12 \\
\hline 27 & 359 & 186 & 57.6 & 5.7 & 0.65 & 1.2 & 0.20 & 0.07 & 0.13 \\
\hline 27.25 & 530 & 253 & 27.1 & 5.4 & 0.37 & 0.9 & 0.15 & 0.02 & 0.12 \\
\hline 27.5 & 806 & 313 & 11.4 & 3.0 & 0.21 & 0.5 & 0.08 & 0.01 & 0.07 \\
\hline 27.75 & 1100 & 278 & -1.8 & 3.7 & 0.00 & 0.3 & 0.06 & 0.00 & 0.06 \\
\hline \multicolumn{3}{|c|}{$\begin{array}{r}P \text { weighted average } \\
1 \sigma \text { range }\end{array}$} & $\begin{array}{r}58.4 \\
5.6\end{array}$ & & $\begin{array}{l}\text { Sum } \\
\text { range }\end{array}$ & 12.6 & $\begin{array}{c}1.86 \\
1.63-2.21\end{array}$ & $\begin{array}{c}0.74 \\
0.63-0.84\end{array}$ & $\begin{array}{c}\mathbf{1 . 3 6} \\
1.09-1.73\end{array}$ \\
\hline
\end{tabular}

*calculated using Co:Pexport stoichiometry of 116 for the South Pacific and 166 for the North Atlantic. 
Table 5. Comparison of statistics for calculating Co: $\mathrm{P}_{\text {export }}$ from measurements of large ( $\left.>51 \mu \mathrm{m}\right)$ particles in the upper ocean $(0-100 \mathrm{~m})$. All values are in $\mu$ mol:mol. Ti-correction for detrital cobalt was conducted with a Co:Ti ratio of $3.37 \times 10^{-3} \mathrm{~mol}: \mathrm{mol}$. Histograms are determined using a bin size of $0.25 \mathrm{log}$ units (Figure 7). Scavenging calculations employ the Ti-corrected histogram center values, in bold.

\begin{tabular}{|c|c|c|}
\hline & Uncorrected & Ti-corrected \\
\hline \multicolumn{3}{|c|}{ Eastern Tropical South Pacific } \\
\hline Range & $42-2065$ & $0-2051 *$ \\
\hline Mean & 196 & 157 \\
\hline Median & 128 & 108 \\
\hline Histogram center & 137 & 116 \\
\hline $\mathrm{X}_{0}$ uncertainty & & 111-132 \\
\hline Dissolved Co: $P_{\text {remin }} * * *$ & \multicolumn{2}{|c|}{$72.1 \pm 5.7$} \\
\hline \multicolumn{3}{|c|}{ Subtropical North Atlantic } \\
\hline Range & $105-5560$ & $0-1552 * *$ \\
\hline Mean & 1036 & 300 \\
\hline Median & 355 & 145 \\
\hline Histogram center & 308 & 166 \\
\hline $\mathrm{X}_{0}$ uncertainty & \multirow{2}{*}{\multicolumn{2}{|c|}{$58.4 \pm 5.6^{\mathbf{1 5 2 - 2 0 9}}$}} \\
\hline Dissolved Co: $P_{\text {remin }}{ }^{* * *}$ & & \\
\hline
\end{tabular}


Table 6. Balance sheet for the marine cobalt cycle

\begin{tabular}{|c|c|c|c|}
\hline & \multirow{2}{*}{$\begin{array}{r}\text { Global } \\
\left(\times 10^{6} \text { mol year }^{-1}\right) \\
\end{array}$} & \multicolumn{2}{|c|}{ Areal $\left(\mu \mathrm{mol} \mathrm{m}\right.$ year $\left.^{-1}\right)$} \\
\hline & & North Atlantic & South Pacific \\
\hline \multicolumn{4}{|l|}{ Sources } \\
\hline Rivers/Estuaries ${ }^{1}$ & 420 & 1.41 & 0.25 \\
\hline $\mathrm{OMZs}^{2}$ & 160 & 0.65 & 0.38 \\
\hline Dust $^{3}$ & 12 & 0.13 & 0.01 \\
\hline Hydrothermal $^{4}$ & 2 & & \\
\hline Sum & 594 & 2.19 & 0.64 \\
\hline \multicolumn{4}{|l|}{ Sinks } \\
\hline Upper Ocean & 280 & 1.36 & 0.64 \\
\hline Deep Ocean & 33 & 0.09 & 0.09 \\
\hline Sum & 313 & 1.45 & 0.73 \\
\hline Sediments $^{5}$ & 450 & $1.2-3$ & $0.3-1.2$ \\
\hline
\end{tabular}

${ }^{1}$ Bewers and Yeats (1977), includes dissolved and particulate sources. Regional scaling based on fluvial sediment delivery maps in Milliman and Farnsworth (2011).

${ }^{2}$ Assumes $40 \%$ release of cobalt in sediments deposited on low oxygen coastlines in the Arabian Sea, West Africa, and the western coasts of Mexico, Central America and Northern South America, equal to $1.66 \times 10^{3}$ MT year $^{-1}$ (Milliman and Farnsworth, 2011). See text.

${ }^{3}$ Based on 9.3\% solubility (Shelley et al., 2012) and dust deposition maps of Jickells et al. (2005).

${ }^{4}$ Swanner et al. 2014

${ }^{5}$ Range of sediments in Table 2 


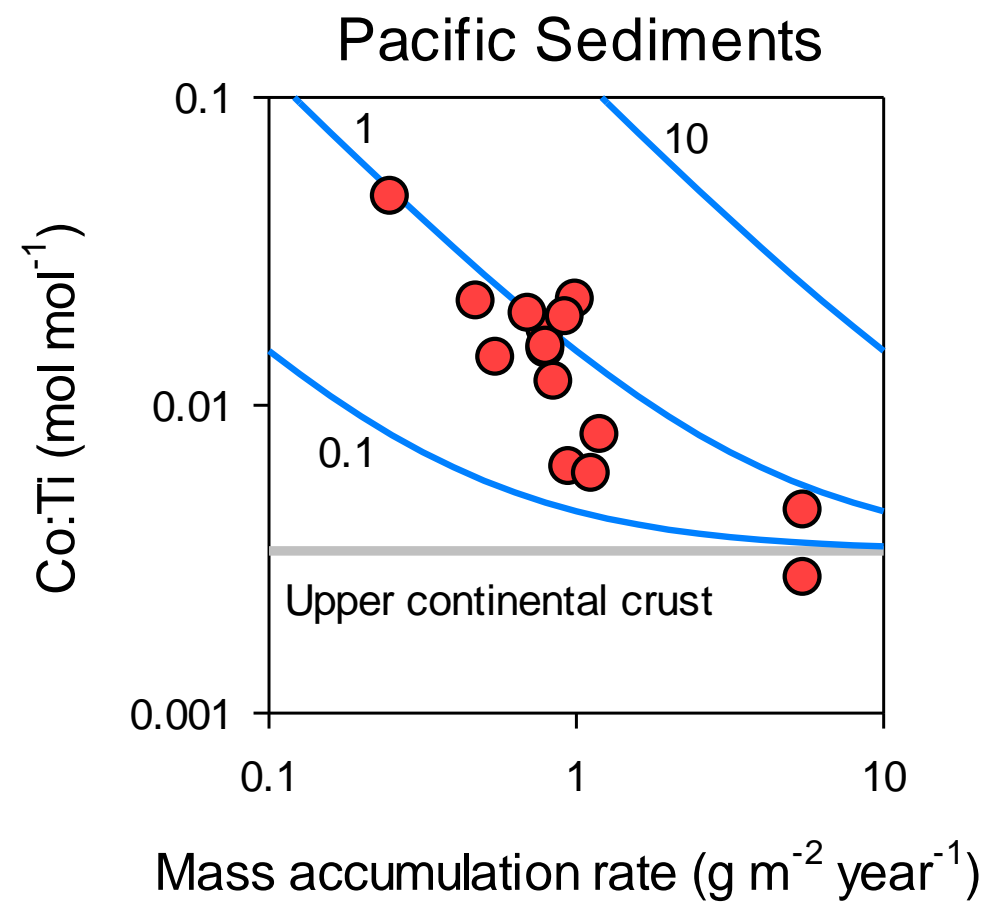

Figure 1. The Co/Ti ratio in Quaternary Pacific Ocean sediments. Co/Ti increases with decreasing mass accumulation rate. At high accumulation rates, $\mathrm{Co} / \mathrm{Ti}$ matches Upper Continental Crust (3.37 x 10-3 $\mathrm{M} \mathrm{M}^{-1}$, McLennan (2001)). Blue lines show calculated rates of authigenic Co flux, K, in $\mu \mathrm{mol} \mathrm{m} \mathrm{m}^{-2}$ year $^{-1}$. Replotted from Krishnaswami (1976). 


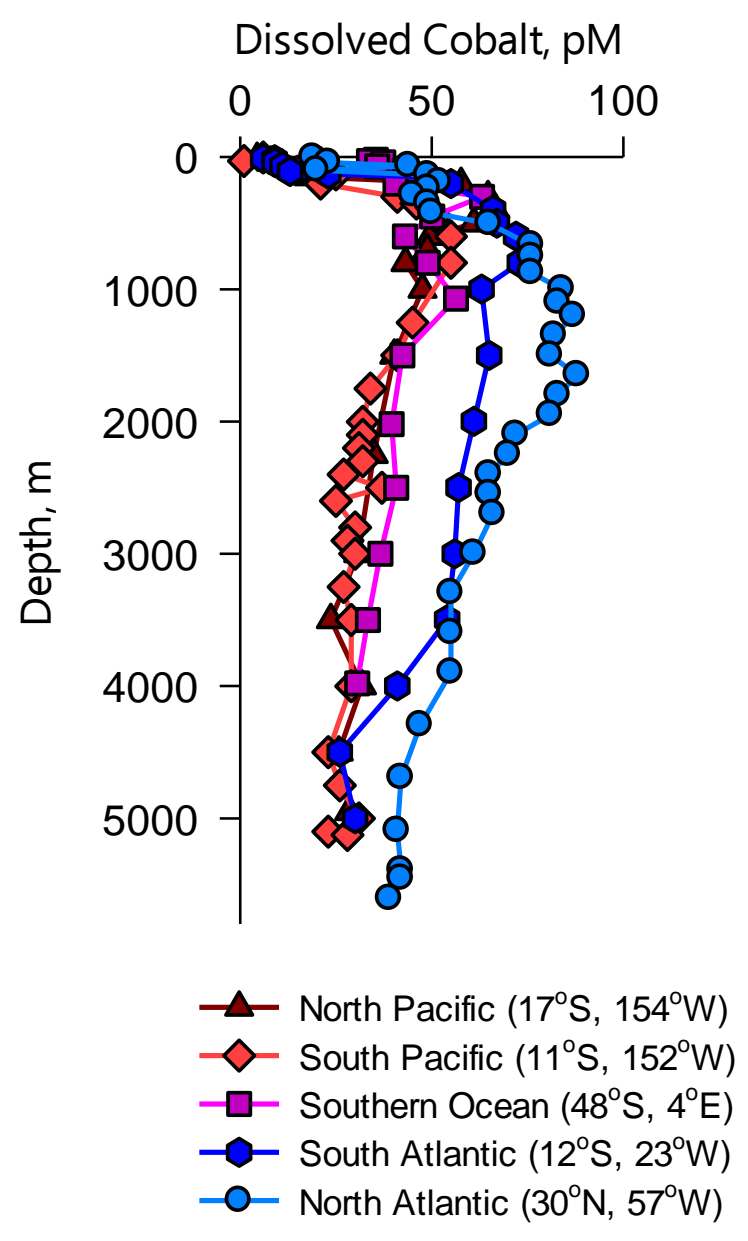

Figure 2. Dissolved cobalt profiles throughout the ocean. 
A

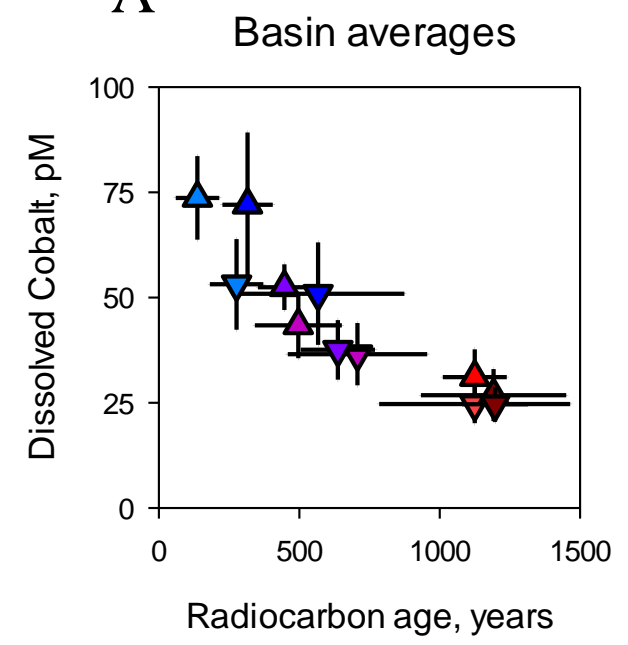

B

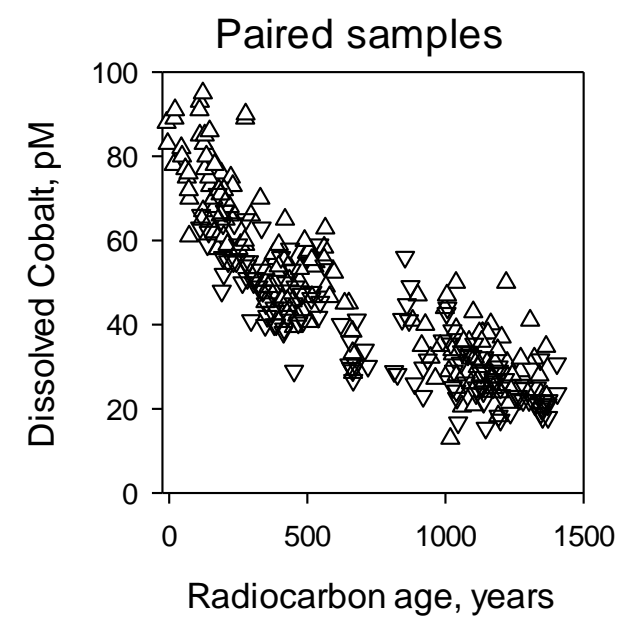

Figure 3. Removal of cobalt from the deep ocean. A) Mean dissolved cobalt concentrations for different sections with the natural radiocarbon age averaged over a similar spatial scale in the GLODAP database (Table 1). Colors of datasets are the same as Figure 2. B) Paired dissolved cobalt measurements from Geotraces datasets with co-located measurements of the natural radiocarbon age from GLODAP (see methods). 
Sinking Particles $(>51 \mu \mathrm{m})$
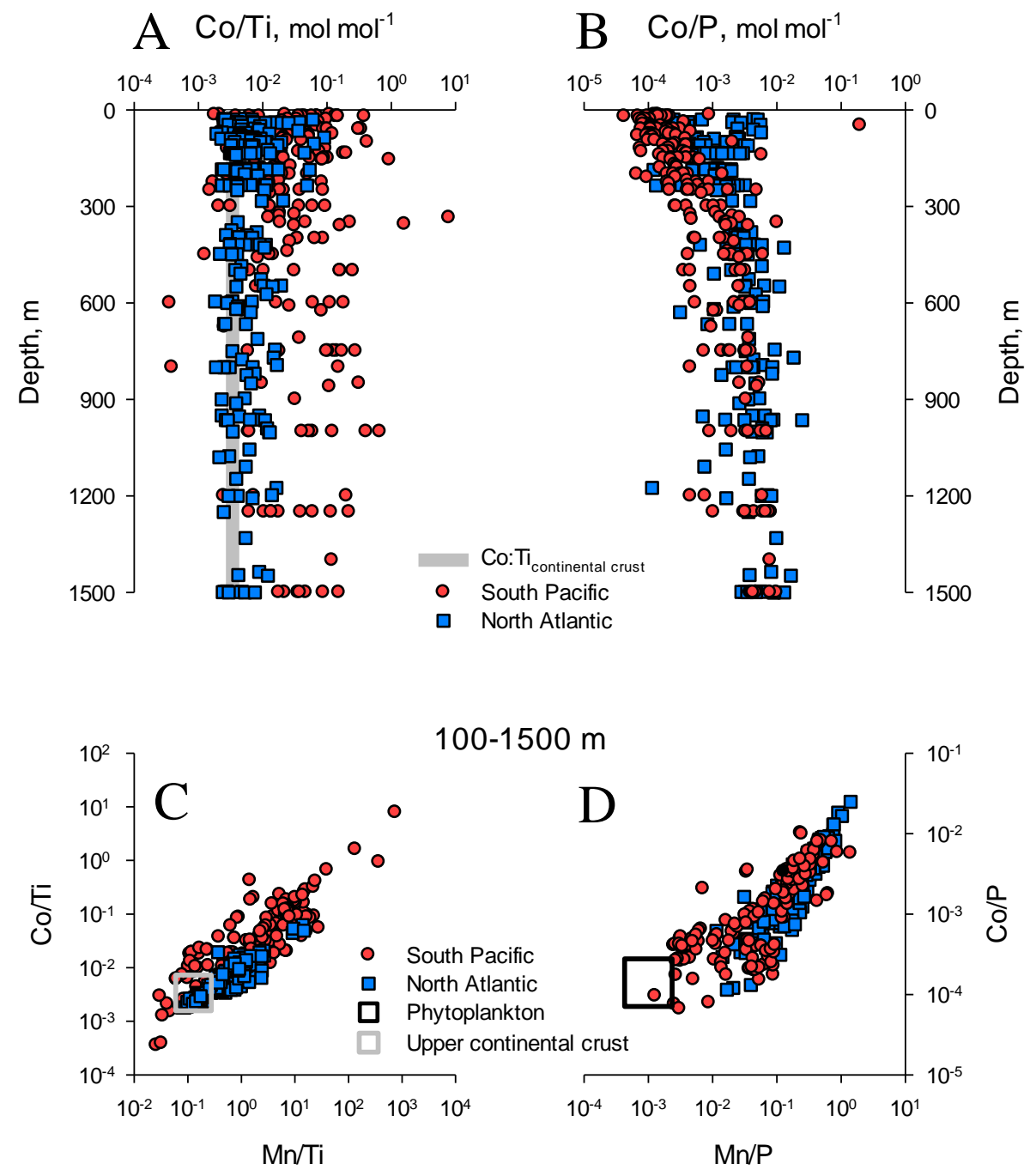

Figure 4. Cobalt in large $(>51 \mu \mathrm{m})$ particles in the North Atlantic and South Pacific. A) The Co:Ti ratio in large sinking particles from the North Atlantic (blue squares) and South Pacific (red circles) transects. The grey line shows the Co:Ti ratio of upper continental crust $\left(3.37 \times 10^{-3}\right.$ mol mol ${ }^{-1}$ from McLennan 2001). B) The Co:P ratios in the same datasets. C) Correlations between Ti-normalized $\mathrm{Co}$ and $\mathrm{Mn}$ in the mesopelagic. Crustal ratios from McLennan (2001) are plotted as a grey square. D) P-normalized Co and Mn. The abundance of both metals in phytoplankton biomass, estimated from Twining and Baines (2013), is plotted as a black square in panel D. Because particulate Co and Mn in the mesopelagic (100-1500m) are in excess of phytoplankton and crustal sources, cobalt is probably in a manganese oxide phase. 

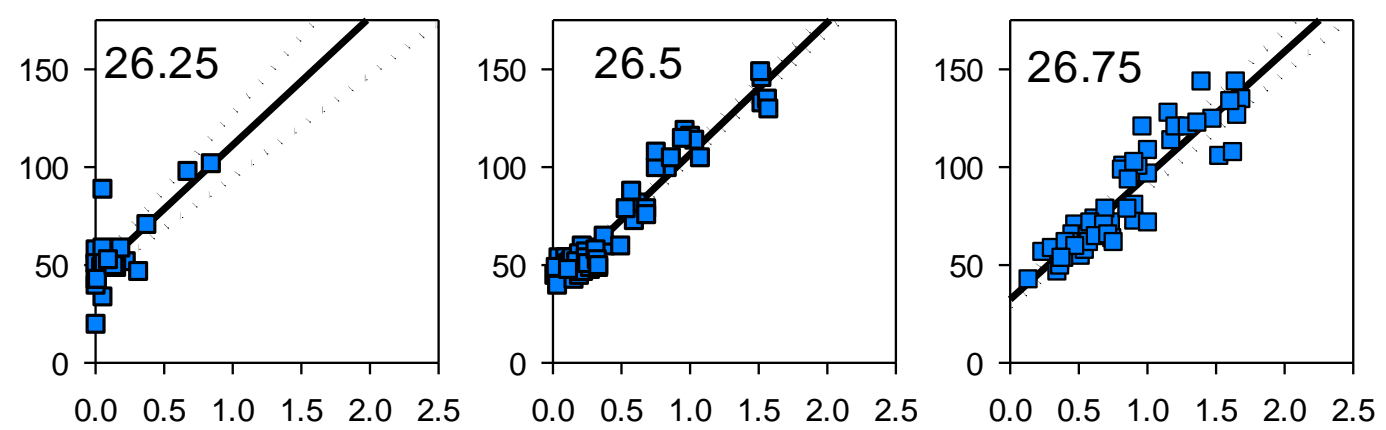

$\sum$
0
$=10$
0
0
0
0
0
20
0
0
0
0
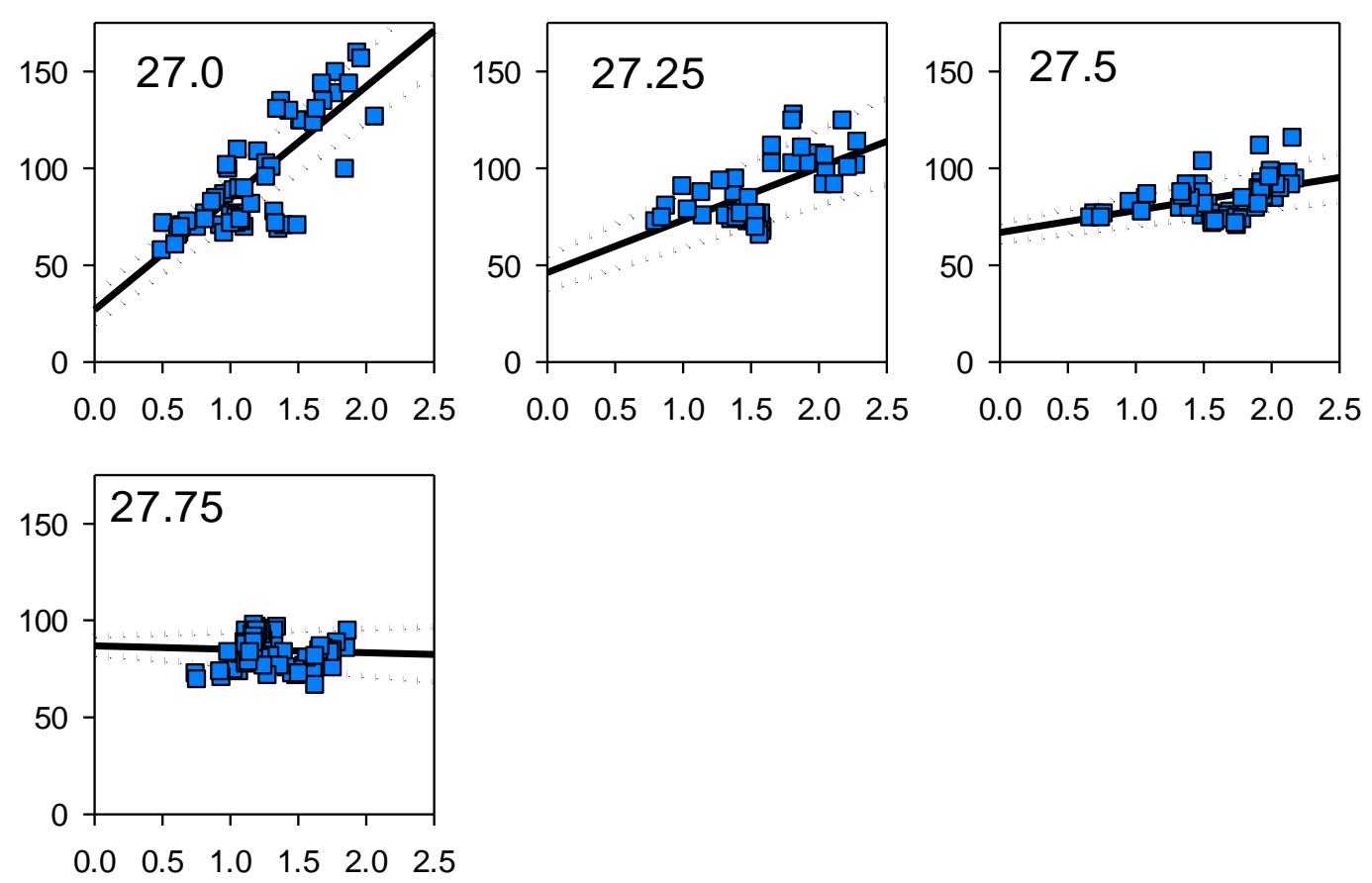

Dissolved Phosphate, $\mu \mathrm{M}$

Figure 5. Isopycnal relationships between dissolved cobalt and phosphate in the North Atlantic Ocean (GA03). Best fit lines are shown as $1 \sigma$ range of the regression (slope and intercept). See Table 4. 

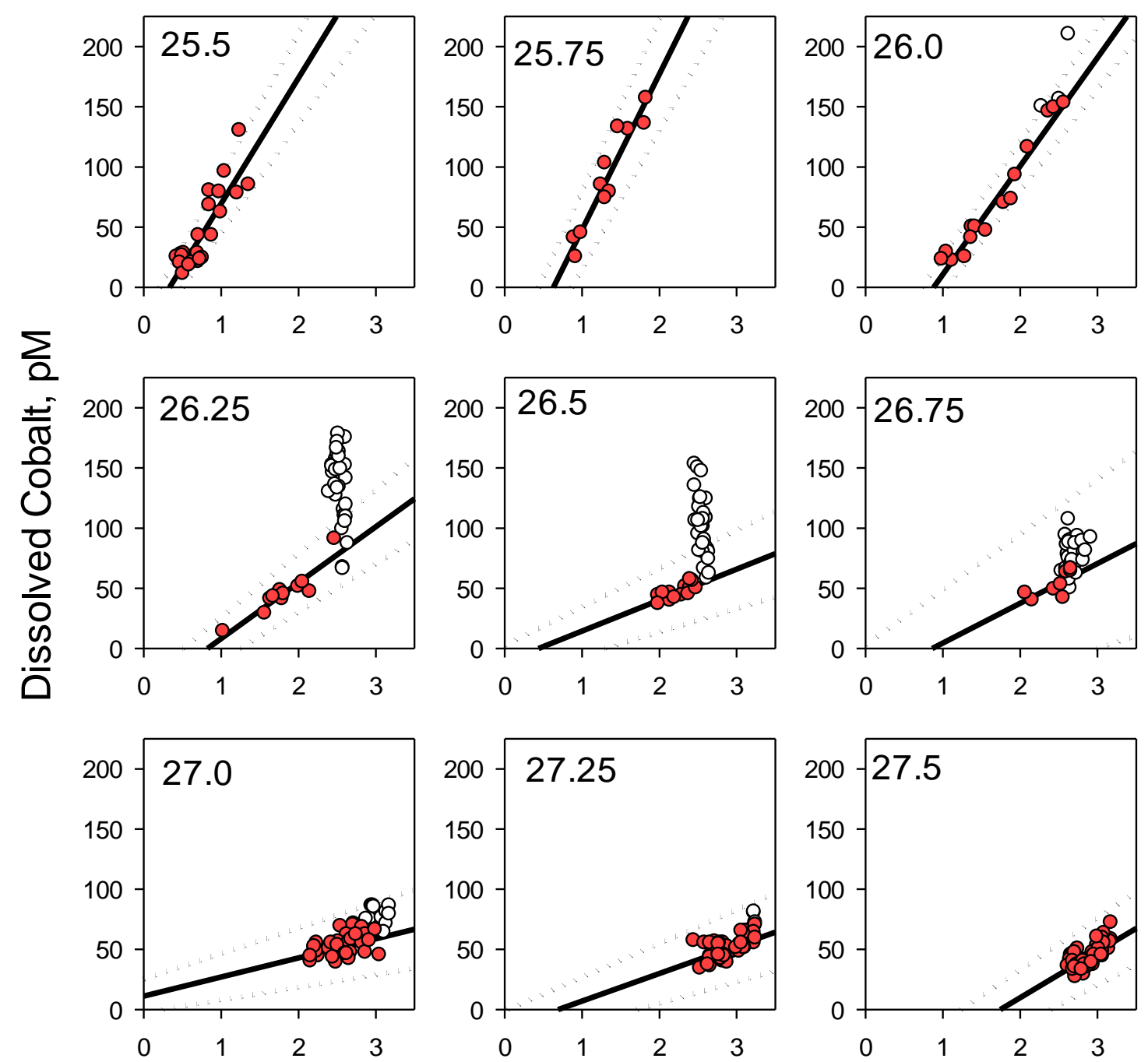

Dissolved Phosphate, $\mu \mathrm{M}$

Figure 6. Isopycnal relationships between dissolved cobalt and phosphate in the South Pacific Ocean (GP16). Low oxygen samples $\left(\mathrm{O}_{2}<20 \mu \mathrm{M}\right.$, white circles) are highlighted and excluded from calculation of $\mathrm{dCo}: \mathrm{PO} 4$ slopes due to the influence of a large cobalt source from the Peru shelf. Best fit lines are shown as $1 \sigma$ range of the regression (slope and intercept). See Table 4. 
North Atlantic, 0-100m

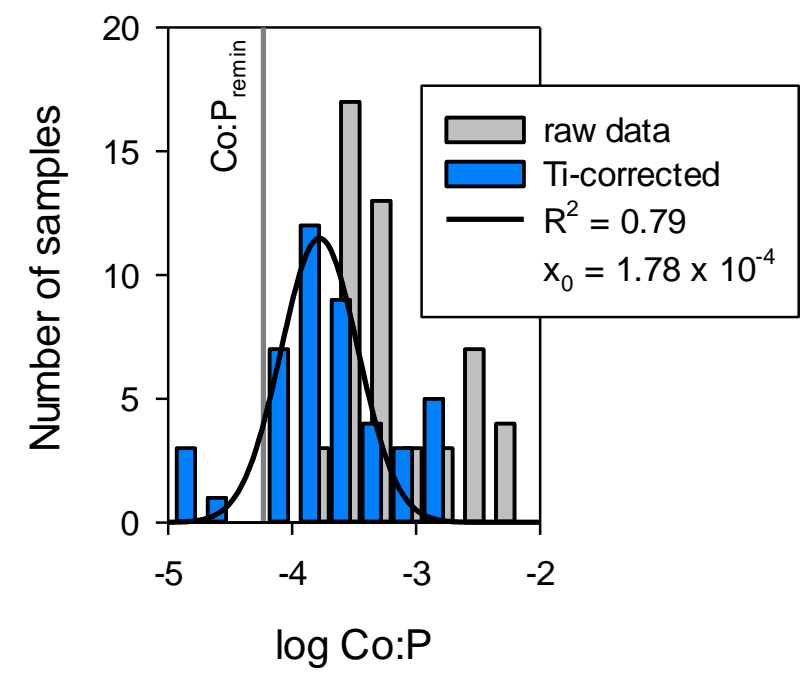

South Pacific, 0-100m

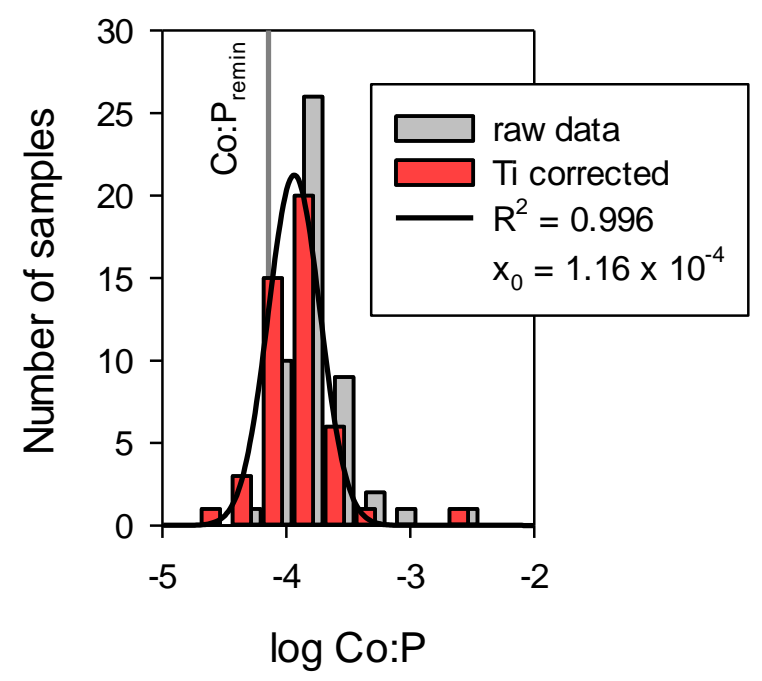

Figure 7. The stoichiometry of biogenic cobalt and phosphorus in the North Atlantic and South Pacific. Histograms of Co:P ratios in large particles for the North Atlantic (A) and South Pacific (B) show log-normal distributions. Lithogenic cobalt was subtracted using particulate $\mathrm{Ti}$ concentrations and the Co:Ti ratio of continental crust (3.37 x $10^{-3} \mathrm{~mol} \mathrm{~mol}^{-1}$, McLennan 2001). A small number of samples showed negative values after this correction, and could not be included. Gaussian curves were fit to the Ti-corrected values. The center $\left(\mathrm{X}_{0}\right)$ and width of each curve was used to constrain the average pCo:pP stoichiometry of biological export for each basin. Vertical grey lines show export weighted values of $\mathrm{Co}: \mathrm{P}_{\text {remin }}$, calculated from Table 4 . 

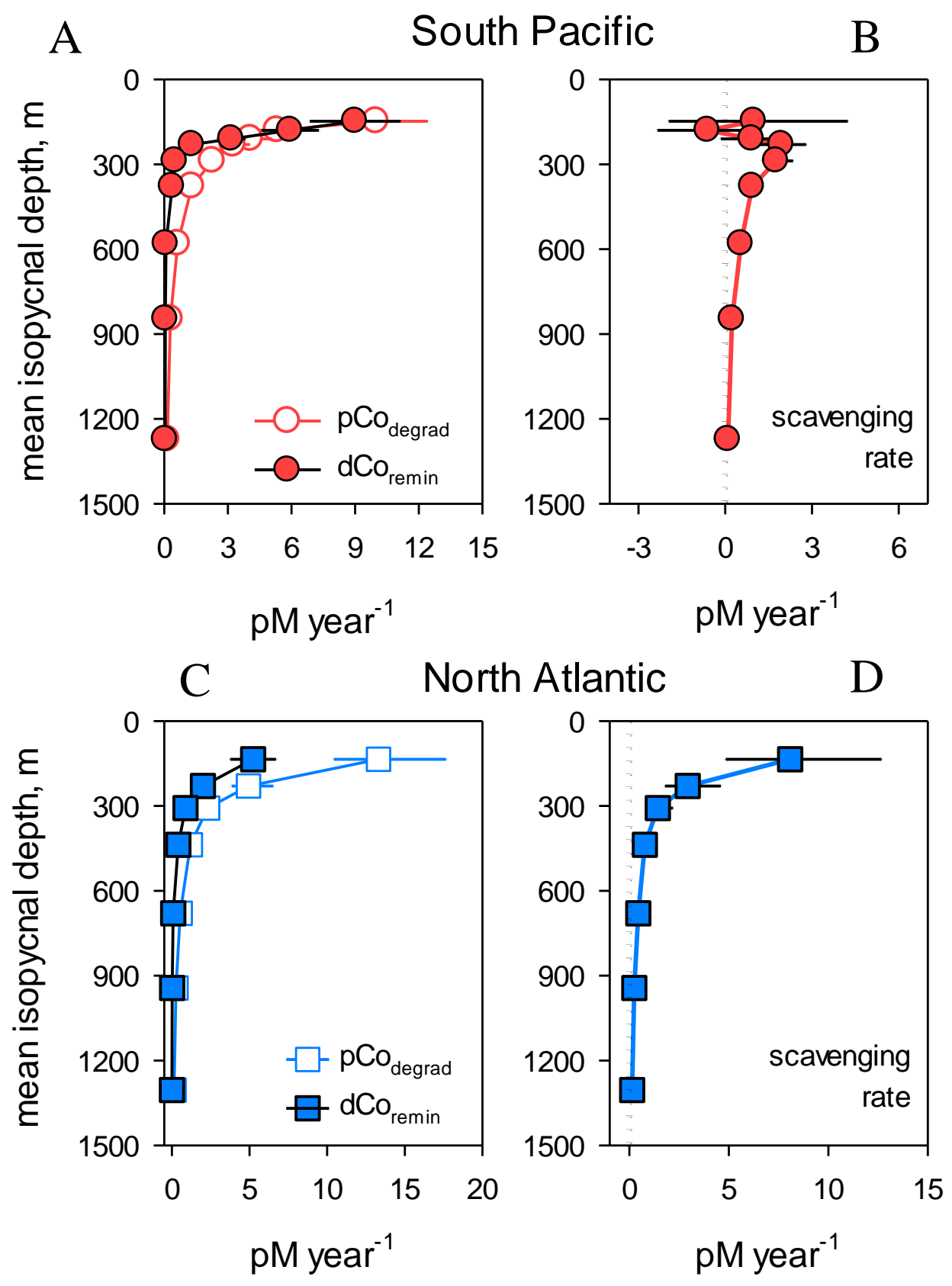

Figure 8. Mesopelagic cobalt scavenging in the South Pacific (A, B) and North Atlantic (C, D). A, C) particulate Co degradation rates (open squares, from Eq. 7) and dissolved Co remineralization rates (blue squares, Eq. 5). C, D) dCo scavenging rates, calculated as the difference between remineralization and ingrowth rates. Volumetric rates in C, D are calculated from aerial rates in Table 4, divided by the height of each isopycnal box. 


\section{Aerial Cobalt ScavengingFlux}

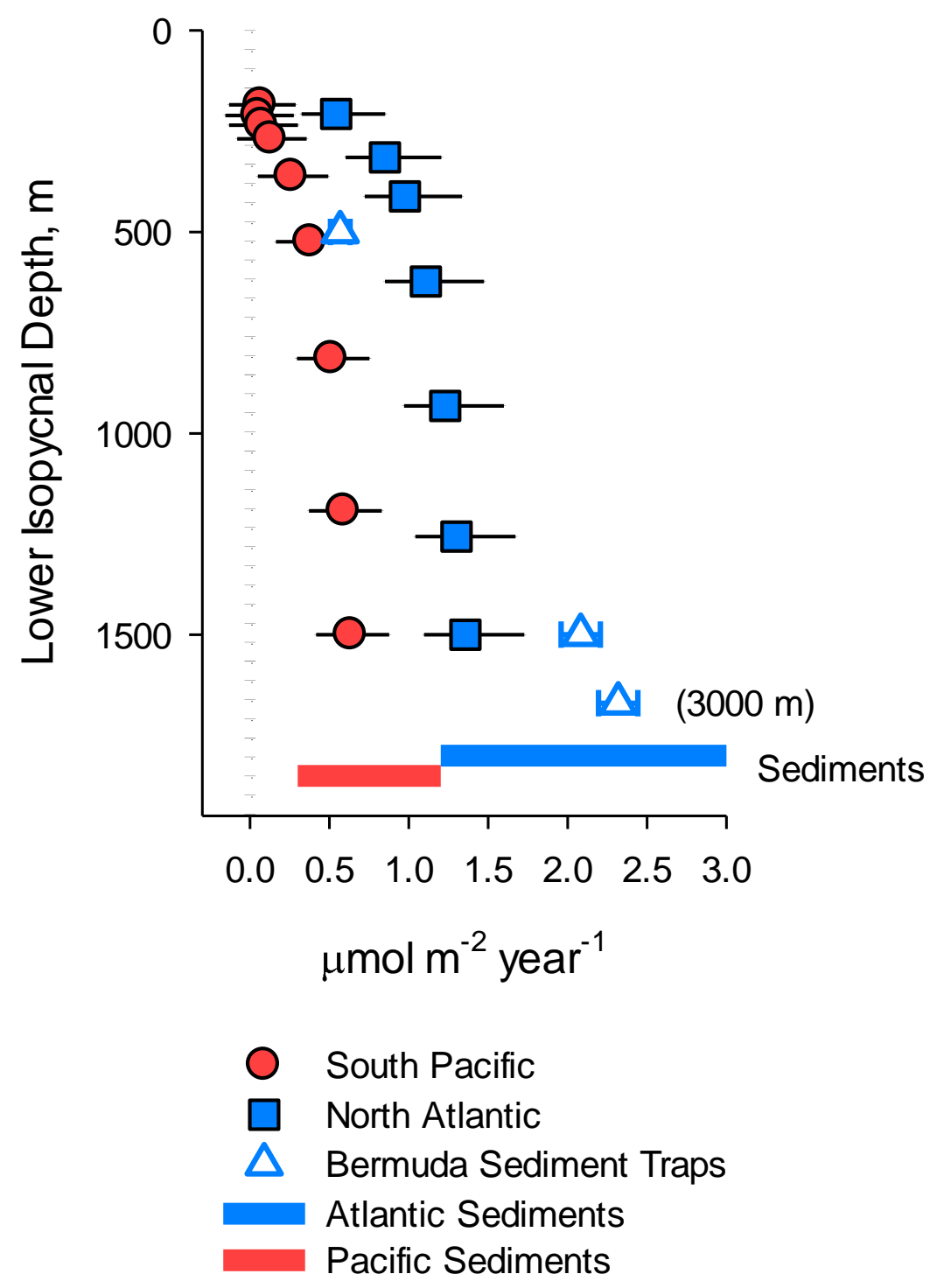

Figure 9. Integrated cobalt scavenging rates in the North Atlantic (blue squares) and the South Pacific (red circles). The value at each depth represents the contribution from that isopycnal surface and the sum of all overlying isopycnals, akin to what would be collected in a sediment trap. These rates are similar to multiyear averages of Ti-corrected sediments traps from Bermuda (triangles) and excess Co accumulation rates in marine sediments for the Pacific (red line) and Atlantic (blue line) from Table 1. 


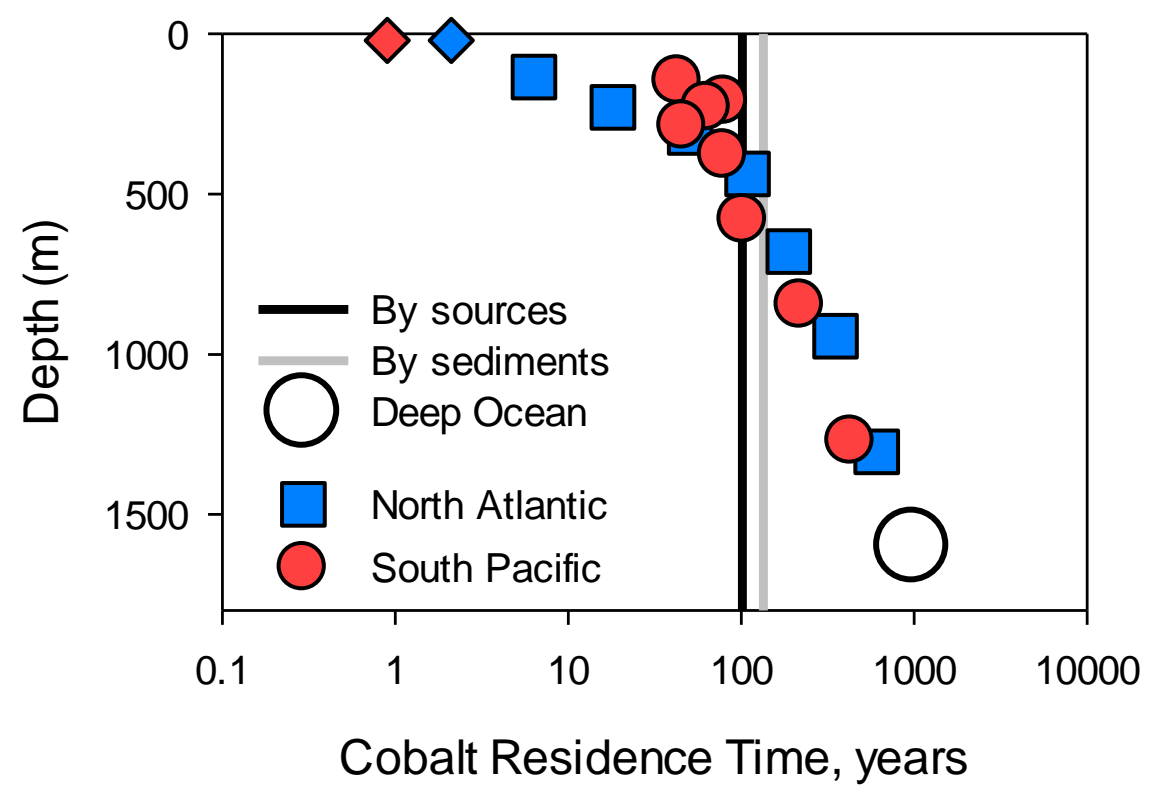

Figure 10. The residence times of dissolved cobalt in the ocean. Scavenging residence times of cobalt on isopycnal surfaces in the South Pacific (red circles) and North Atlantic (blue squares) are calculated from median dissolved Co concentrations on isopycnal surfaces, divided by water column scavenging rates from Figure $8 \mathrm{~B}$ and $8 \mathrm{D}$. Increasing residence time with depth for both basins intercepts the residence time of deep ocean cobalt, determined by correlation with radiocarbon age, (white circle). Bulk residence times by sources (100 years) and Quaternary sediment accumulation rates (130 years) are plotted as black and grey lines, respectively. The residence time of dissolved cobalt in the surface ocean $(0-100 \mathrm{~m})$ relative to biological export is plotted as diamonds. 

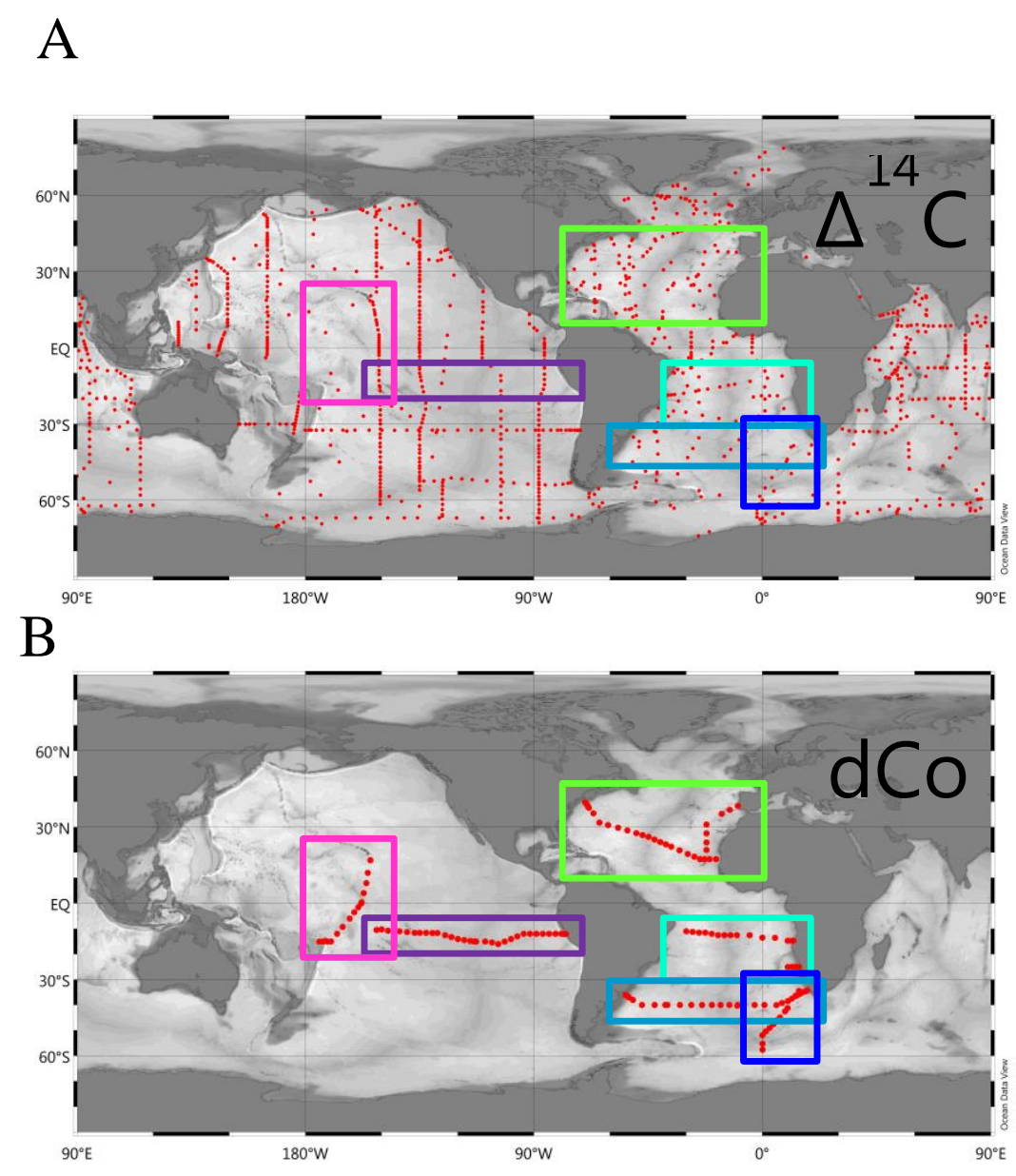

Figure S1. A) Maps of stations containing radiocarbon samples from the GLODAP database (Key et al. 2004) and B) dissolved cobalt (dCo) data from GEOTRACES sections. Colored rectangles show the domain over which $\Delta^{14} \mathrm{C}$ data are averaged for Fig. 3a. (See Table 1). Color scheme: GA03, Lime green; CoFeMUG/GAc-01, Cyan; GA10, Dark Green; GIPY4, Blue; GP16, purple; Metzyme, pink. 

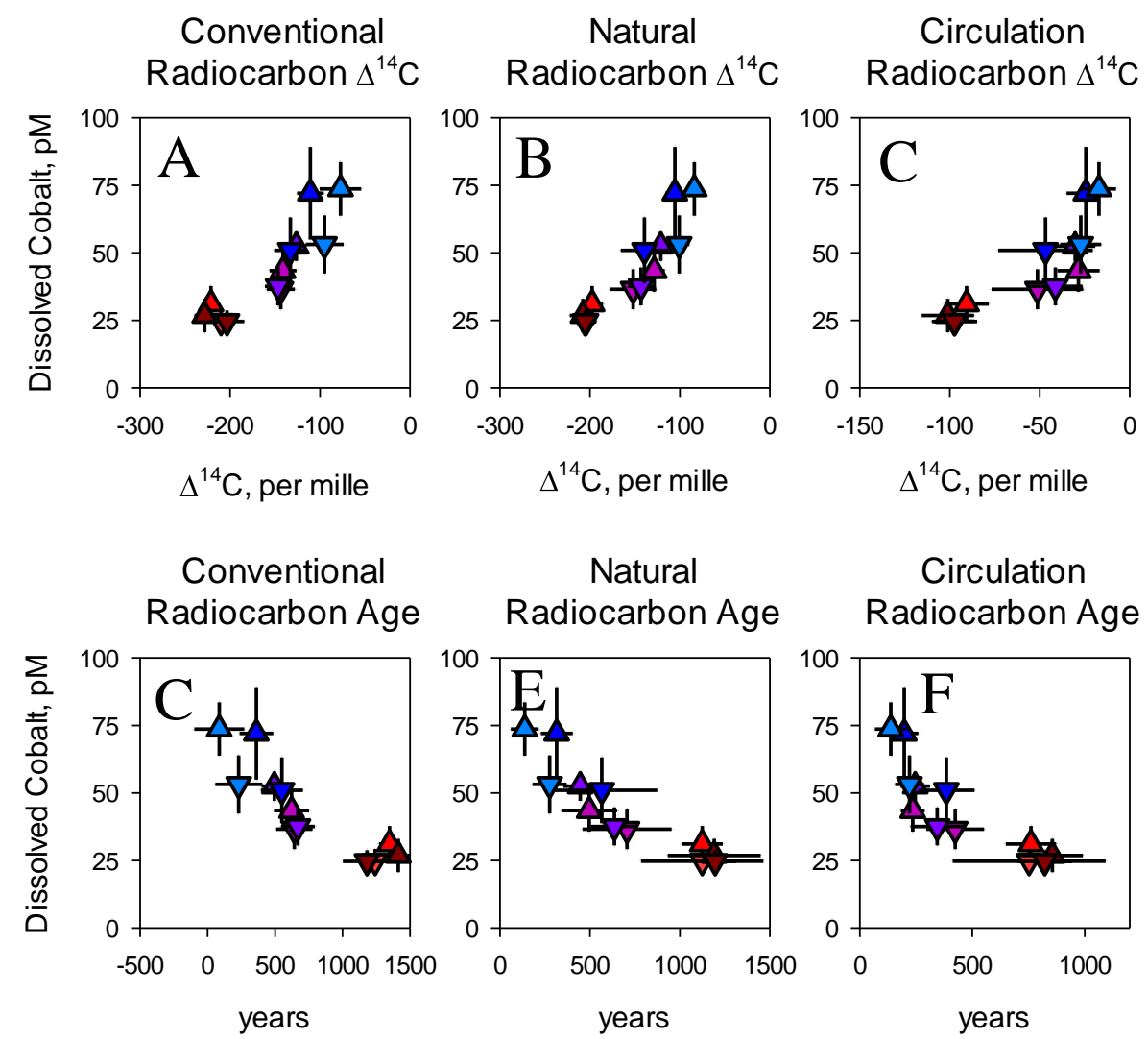
$\triangle$ 40S, south atlantic
$\triangle$ BONUS, southern ocean
$\triangle$ CoFeMUG, southern ocean
$\triangle$ GP16, south pacific
$\Delta$ metzyme, equatorial pacific
$\triangle$ GA03, North Atlantic

Figure S2. Cobalt-radiocarbon relationships in the deep ocean, using various corrections for $\Delta^{14} \mathrm{C}$ of seawater dissolved inorganic carbon. Conventional radiocarbon $\Delta^{14} \mathrm{C}$ is the measured value. Natural radiocarbon contains a subtraction of $\Delta^{14} \mathrm{C}$ added from atmospheric nuclear weapons testing (both conventional and natural $\Delta^{14} \mathrm{C}$ are parameters in GLODAP (Key et al. 2004)). Circulation $\Delta^{14} \mathrm{C}$ is corrected for reservoir $\Delta^{14} \mathrm{C}$ and ages of North Atlantic and Southern Ocean surface waters using the $\mathrm{P}^{*}$ tracer of water mass origin according to Matsumoto (2007). A-C are plotted in per mille notation while D-F are plotted in years. Panel E is identical to Figure $3 a$. 


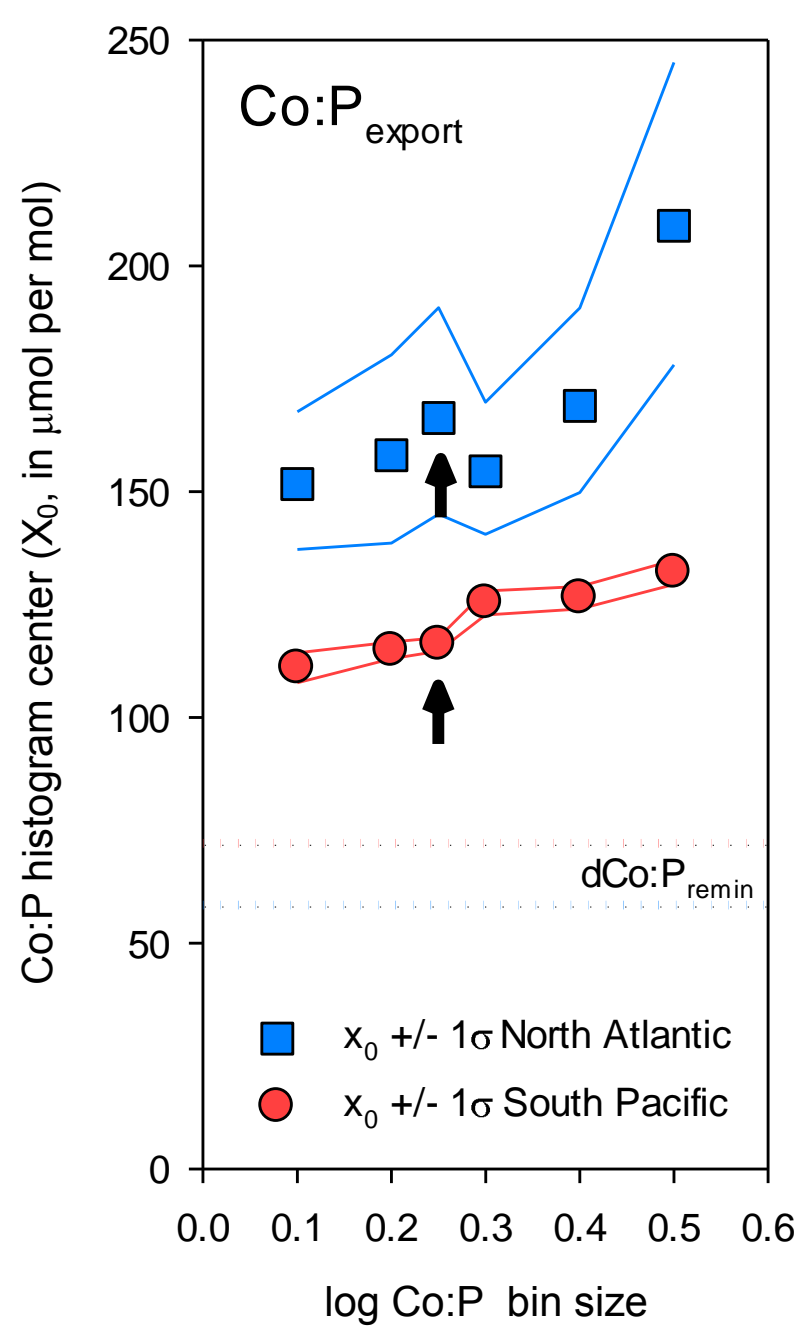

Figure S3. The sensitivity of Co:P export to differences in histogram bin size for the North Atlantic (blue squares) and South Pacific (red circles), as in Figure 7. The histogram center $\left(\mathrm{X}_{0}\right)$, as determined by Gaussian fit to log-transformed Co and P measurements in large $(>51 \mu \mathrm{m})$ particles, is shown as blue squares for the North Atlantic and red circles for the South Pacific. Uncertainty in $\mathrm{X}_{0}$ at each bin size is shown as solid blue and red lines. Also plotted are values of Co: $P_{\text {remin }}$ used for the North Atlantic and South Pacific (dotted blue and red lines, respectively). Black arrows point to $\mathrm{X}_{0}$ values determined with a bin size of $0.25 \log$ units, shown in Figure 7 , which was used for scavenging calculations. 

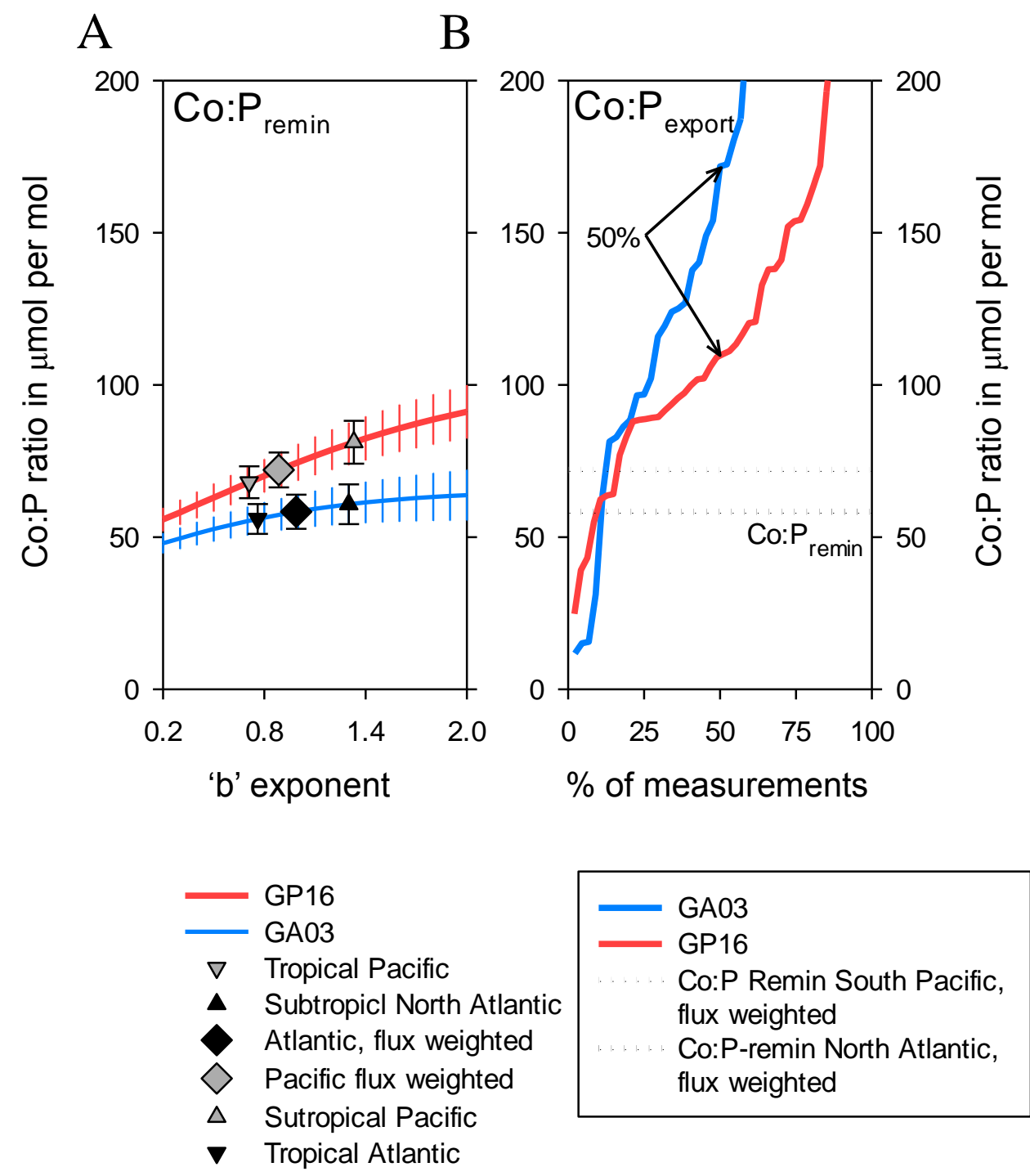

$\triangle$ Sutropical Pacific

Figure S4. Sensitivity of $\mathrm{Co}: \mathrm{P}_{\text {remin }}$ to changing values of the attenuation flux parameter ' $\mathrm{b}$ ' for the North Atlantic (blue line) and South Pacific.(red line). Values for subtropical (upward triangles) and tropical (downward triangles) determined by Teng et al. 2014 are also plotted. The weighted average of ' $b$ ' based on the P flux from tropical and subtropical regions at $100 \mathrm{~m}$ is shown as a diamond. These data are also presented in Table 3. B) Comparison of Co: $\mathrm{P}_{\text {remin }}$ values (diamonds in panel A) and the Ti-corrected values of Co:P from the surface ocean $(0-100 \mathrm{~m})$ used to calculate Co:Pexport. The 50\% point represents the median of each dataset, which are well above values of Co:P remin for both basins (grey and black lines). 

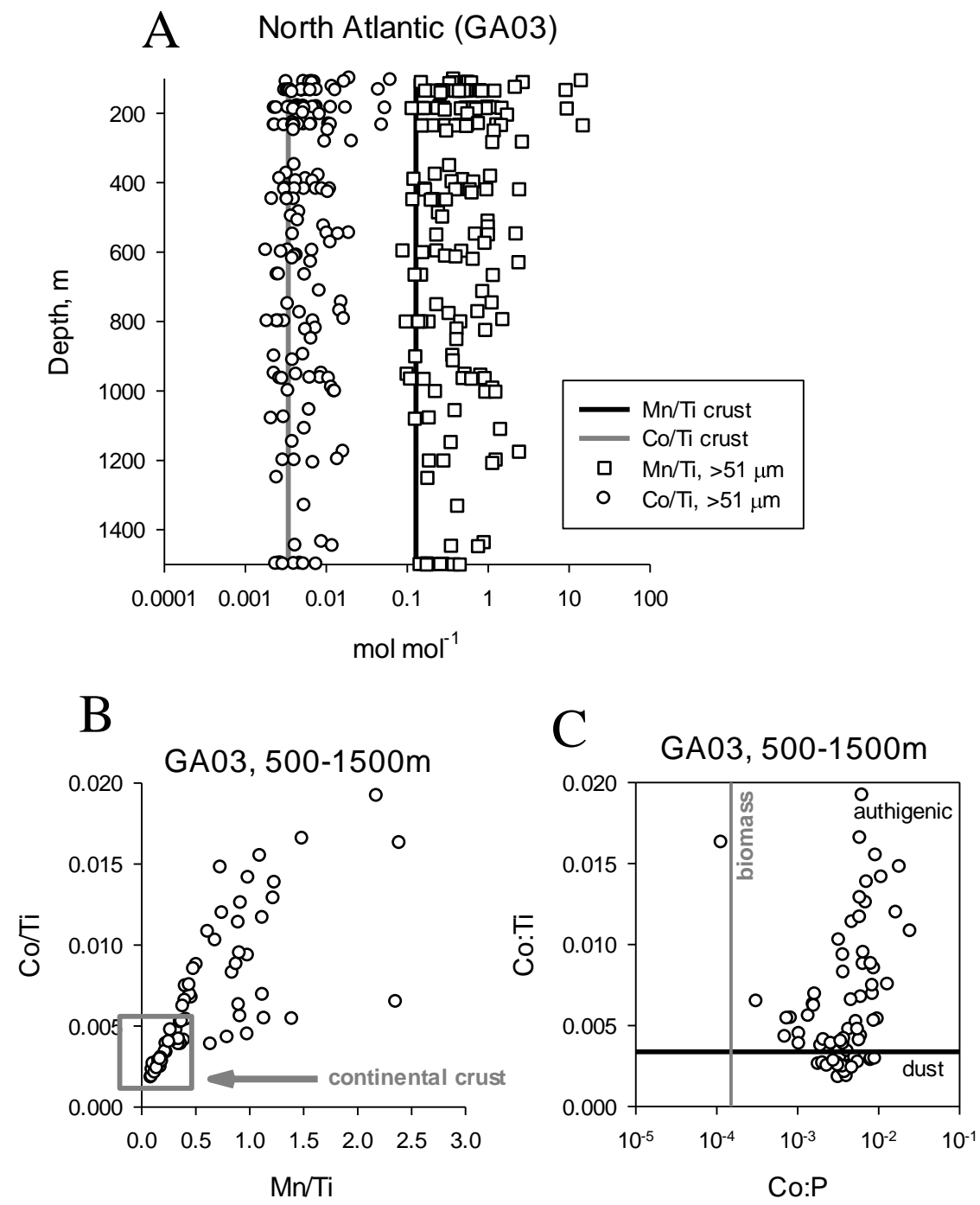

Figure S5. Evidence for authigenic cobalt in sinking particles from the mesopelagic North Atlantic Ocean. A) Co:Ti (circles) and Mn:Ti (squares) ratios in the North Atlantic. Crustal Co:Ti and Mn:Ti ratios from McLennan (2001) are plotted as grey and black lines, respectively. Both elements are in excess of these crustal ratios through $1500 \mathrm{~m}$. B) Correlation between Co:Ti and Mn:Ti in particles between 500-1500 m, suggesting that particles containing high Co and also Mn rich. C) Comparison of Co:Ti and Co:P ratios between 500-1500 m. The plotted biomass ratio corresponds to a Co:P ratio of $150 \mu \mathrm{mol}$ Co per mol P. 


\title{
Chapter 4.
}

\section{The minimum cobalt and iron requirement of Prochlorococcus: implications for cobalt limitation in the Equatorial Pacific Ocean.}

\begin{abstract}
Due to its low abundance in continental crust and its propensity to scavenge from the water column, cobalt is the least abundant inorganic nutrient in the ocean. Because Prochlorococcus has an absolute requirement for cobalt, it has been hypothesized that seawater cobalt scarcity may limit Prochlorococcus productivity in certain regions. We investigated the cobalt-limited physiology of Prochlorococcus MIT 9215, a strain originally isolated from Equatorial Pacific Ocean, and compared it to the oceanographic distribution of dissolved cobalt in this region. Prochlorococcus can sustain growth with an extremely small cobalt quota of $\sim 50$ atoms per cell, a significant fraction of which can be attributed to two cobalamin enzymes: methionine synthase and ribonucleotide reductase, needed for protein and DNA synthesis. Minimum iron quotas for Prochlorococcus MIT9215 are also low (5-10 x 10 3 atoms per cell), especially in comparison to marine Synechococcus. While concentrations of dissolved cobalt were extremely low in the surface of the Equatorial Pacific, Co:P ratios in Prochlorococcusdominated biomass were approximately 10-fold higher than expected from cobalt limitation experiments in culture. Prevailing iron limitation in the region may allow Prochlorococcus to maintain high cobalt quotas despite its apparent scarcity.
\end{abstract}

\section{Introduction}

The unicellular cyanobacterium Prochlorococcus dominates the ocean's oligotrophic gyres, reaching cell densities on the order of $10^{8}$ per liter and representing a significant fraction of primary production in these nutrient poor ecosystems (Liu et al., 1997; Rii et al., 2016). While small size and specialized metabolism contribute to their success in these environments, their 
growth is still curtailed by the low stocks of bioavailable nitrogen, iron and phosphorus in seawater (Goericke and Welschmeyer, 1993; Mann and Chisholm, 2000; Van Mooy et al., 2006; Saito et al., 2014). Behind these three nutrients, however, lie at least a dozen other elements also needed for photosynthesis and metabolism that are either present in sufficient quantities or their use is minimized so that they do not seem to limit Prochlorococcus growth (Moore et al., 2013a, 2007).

Of these additional nutrients, cobalt is found at the lowest concentrations in seawater (Moore et al., 2013a). Cobalt concentrations in oligotrophic gyres, where Prochlorococcus thrive, are often below 10 pM (Hawco et al., 2016; Noble et al., 2008, 2012). On the basis of this scarcity, and the fact that Prochlorococcus' cobalt quota cannot be substituted by other elements (e.g. zinc), it has been hypothesized that Prochlorococcus and related cyanobacteria may experience cobalt limitation in certain regions of the oceans (Moffett and Ho, 1996; Saito et al., 2002, 2005). Indeed, additions of cobalt to surface seawater in the Costa Rica upwelling dome increased the growth of the cyanobacterium Synechococcus (Saito et al., 2005). It is tempting to speculate that cobalt-limitation of these organisms also occurs elsewhere, but quantitative estimates of cyanobacterial cobalt requirements are few and, in the case of Prochlorococcus, nonexistent.

Most known biological uses of cobalt are in cobalamin-dependent enzymes (Zhang et al., 2009). Before such enzymes can be active, cobalt must be transformed into cobalamin, a corrin ring with cobalt as the central atom and a lower ligand of varying composition (Rodionov et al., 2003). There is growing evidence that cyanobacteria actually synthesize psuedocobalamin, a similar molecule to canonical vitamin $\mathrm{B}_{12}$, whose lower ligand is an adenosine moiety rather than dimethylbenzamidozole (Heal et al., 2016; Helliwell et al., 2016; Watanabe et al., 1999). As a group, cobalamins (including pseudocobalamin) can form stable cobalt-carbon bonds that can be exploited by enzymes to perform methyl-group transfers and difficult isomerization reactions (Banerjee and Ragsdale, 2003; Zhang et al., 2009). Like most other cyanobacteria, Prochlorococcus genomes contain a full pseudocobalamin biosynthetic pathway, capable of synthesizing this compound from simple metabolites and cobalt ions (Heal et al., 2016; Kettler et al., 2007; Rodionov et al., 2003).

Genomic analyses of cyanobacteria indicate two important pseudocobalamin-dependent enzymes for metabolism (Figure 1). Methionine synthase (MetH) uses methyl-cobalamin to 
catalyze the formation of the amino acid methionine from homocysteine via a methyl group transfer (Banerjee et al., 1990; Goulding et al., 1997). The product methionine can then be used for protein synthesis, or its methyl group can be donated to S-adenosyl methionine (SAM) to be used elsewhere in metabolism, including the nucleotide cytosine. Unlike MetH, cobalamindependent ribonucleotide reductase $(\mathrm{Nrd} \mathbf{J})$ relies on adenosylcobalamin for catalysis (Booker et al., 1994; Sintchak et al., 2002). Ribonucleotide reductase performs a crucial deoxygenation step to produce the four deoxy-ribonucleotides (dNTPs) needed for DNA replication: dATP, dGTP, $\mathrm{dCTP}$, and dTTP, from their corresponding ribonucleotide metabolites. When bound by NrdJ, adenosyl-cobalamin generates a thiyl radical that facilitates the critical isomerization reaction to generate dNTPs, a slow catalysis that is often considered the rate limiting step of dNTP synthesis (Booker et al., 1994; Herrick and Sclavi, 2007). Genomic surveys have not found evidence for other cobalt- or cobalamin-dependent enzymes in Prochlorococcus, although use of cobalt in canonical zinc enzymes has been postulated (e.g. carbonic anhydrase and alkaline phosphatase) (Saito et al., 2002; Zhang et al., 2009)(Saito et al. submitted).

Here we report minimum cobalt and iron quotas for Prochlorococcus MIT 9215 determined from limitation experiments in culture and the distribution of dissolved and particulate cobalt in the equatorial Pacific Ocean from the Metzyme transect (KM1128). The combination of these datasets allows the possibility of cobalt limitation of wild Prochlorococcus to be evaluated for this region.

\section{Methods}

\subsection{Culturing}

Cultures of Prochlorococcus strain MIT9215, originally isolated from the Equatorial Pacific Oct. 1992 (Moore and Chisholm, 1999), were obtained from the Chisholm lab at MIT and grown at $27^{\circ} \mathrm{C}$ in a custom incubator under a 14:10 light:dark cycle. Light intensity was progressively increased during morning hours, reaching a peak light intensity of $\sim 75 \mu \mathrm{mol}$ photon $\mathrm{m}^{-2} \mathrm{~s}^{-1}$, and decreased continuously over the afternoon. All sampling was conducted within a 3 hour window overlapping with peak irradiance. Growth was monitored primarily by chlorophyll fluorescence on a TD700 fluorometer (Turner), calibrated prior to measurement with a solid standard. All cultures were grown in round-bottom $28 \mathrm{ml}$ polycarbonate centrifuge tubes (Nalgene) that are compatible with a TD700 fluorometer, which enabled measurements to be 
taken without exposing cultures to contaminating metals. Growth rates were calculated as the slope of the increase in the natural logarithm of chlorophyll fluorescence over a 4-measurement (usually 4 day) period. Maximum values for each experiment are reported and were linear for all treatments.

For all experiments, cells were inoculated at $1 \%$ media volume or lower from cultures in mid-late exponential phase. Experiments were conducted with recently generated axenic strains, provided by the Chisholm lab at MIT. Purity of these cultures was occasionally tested by inoculating log-phase cultures in a broth composed of seawater, yeast extract and peptone (Waterbury et al., 1986). Visual inspection of these assays showed no growth over several weeks.

Cell number was measured by flow cytometry on a Guava Easycyte HT instrument with Incyte 3.1 software. Cultures were serially diluted in filtered oligotrophic seawater and counted using a red fluorescence gate until 5000 events were recorded. This instrument was calibrated monthly with beads. Dilutions with cell concentrations in the range of $0.5-2 \times 10^{5}$ cells per $\mathrm{ml}$ were used to calculate original cell number. Nutrient replete cultures entered stationary phase at $\sim 2 \times 10^{8}$ cell $/ \mathrm{ml}$, consistent with reports for this strain by Morris and colleagues (Morris et al., 2008). Due in part to the high cell concentrations observed in culture, no difference was observed in cells preserved with 5\% paraformaldehyde (cobalt-limitation series) and frozen at $80{ }^{\circ} \mathrm{C}$ versus cells that were solely frozen at $-80{ }^{\circ} \mathrm{C}$ (iron-limitation series).

\subsection{Preparation of trace-metal clean media}

All media was prepared in a class-100 clean room and transferring of cultures was conducted in a laminar flow hood within the clean room. All bottles were thoroughly cleaned by first soaking 10 days in a $1 \%$ detergent solution (Citranox), rinsed with ultrapure $>18 \mathrm{M} \Omega$ water (Milli-Q, Millipore) and soaked in 10\% hydrochloric acid (J.T. Baker) for an additional 10 days. Culture tubes were rinsed thoroughly with $10 \mathrm{mM} \mathrm{HCl}$ and microwaved sterilized with $\sim 10 \mathrm{~mL}$ of ultrapure water. Before pipetting, sterile micropipette tips were rinsed three times with $10 \%$ $\mathrm{HCl}$ and three times with microwave sterilized $10 \mathrm{mM} \mathrm{HCl}$ immediately before use. When cultures were transferred, pipette tips were also rinsed in microwave-sterilized, ultra-pure water to remove trace acid. 
Cultures were grown in a modified ProTM media (Moore et al., 2007). The base of this media was oligotrophic seawater collected from the surface of the South Pacific Ocean collected using a trace metal clean Tow-fish system used to collect non-contaminated seawater for the GEOTRACES GP16 transect. Seawater was $0.22 \mu \mathrm{m}$ filtered and microwave-sterilized until boiling. Nutrient stocks were added to cooled, sterile seawater and allowed to equilibrate overnight before addition of Prochlorococcus cells. Ammonium chloride and sodium phosphate salts were dissolved in ultra-pure water ( $>18 \mathrm{M} \Omega$, Millipore) and cleaned of contaminating metals using cleaned chelex beads (Price et al., 1989). Ammonia and phosphate stocks were filter sterilized and were added to final concentrations of 800 and $50 \mu \mathrm{M}$, respectively. EDTA was added as a metal ion buffer to a concentration of $11.7 \mu \mathrm{M}$. For all growth experiments, Mo, $\mathrm{Se}, \mathrm{Mn}$ and Ni stocks were added to a solution of $11.7 \mathrm{mM}$ EDTA, added to the culture media as a single 1000x stock. To limit contamination, we decreased Fe in the media 100-fold (11.7 nM), which is still an order of magnitude larger than iron-limiting concentrations for this strain, as determined here. Cobalt concentration in background media were measured by cathodic stripping voltammetry after a 1-hour UV-oxidation protocol. Background cobalt was $10 \mathrm{pM}$, similar to determinations conducted in surface waters of the South Pacific Ocean, where the seawater was collected (Hawco et al., 2016). The ratio of Co', the sum of inorganic cobalt complexes, to the total cobalt concentration was $10^{-2.81}$, equivalent to the value used by Saito et al. 2002 at the same concentration of EDTA.

\subsection{Measuring Cell Quotas by Inductively Coupled Plasma Mass Spectrometry (ICPMS)}

Biomass from replicate $28 \mathrm{ml}$ cultures was pooled and centrifuged at 11,000 RPM for 20 minutes at $4{ }^{\circ} \mathrm{C}$. The cell pellet was resuspended in $\sim 1 \mathrm{~mL}$ media, transferred to an acid-cleaned microcentrifuge tube and centrifuged again for $30 \mathrm{~min}$ at $14,100 \mathrm{RPM}$ at $4{ }^{\circ} \mathrm{C}$. The remaining pellet was frozen at $-80^{\circ} \mathrm{C}$. To minimize processing blanks, no effort was taken to remove metal bound to the cell surface by washing with various chelators and, as a result, the measured quotas reflect contributions of intracellular and extracellular metals. The whole cell pellet was acidified in $800 \mu \mathrm{l}$ of $5 \%$ trace metal grade nitric acid (Optima) containing 1 ppb Indium for several days. Cells were resuspended multiple times and solids were removed by centrifugation. Blank digestions containing acid but no cells were performed in parallel. Digests were diluted by a factor of 9 with additional 5\% nitric acid (also containing 1 ppb Indium) before being analyzed 
on an ICAP-Q plasma mass spectrometer (Thermo), calibrated to a multi-element standard curve (Spex, Certiprep) over a range of $1-100$ ppb. Samples were analyzed in KED mode using helium as a collision gas after a 85 s sample uptake window. Mass windows were scanned 3times during measurements. Variation in ${ }^{59} \mathrm{Co}$ and ${ }^{56} \mathrm{Fe}$ counts per second was less than $5 \%$ for an individual sample, when above detection limits. Indium was used to correct for variation in sample delivery and plasma suppression between samples.

Duplicate analyses of cell digests agreed within $5 \%$ for both Co and Fe, except at Co levels below 30 atoms per cell which agreed to $\sim 20 \%$. Blanks were subtracted from measured concentrations. The mean blank for this dataset was $0.022 \mathrm{pmol}$ for Co and $12.4 \mathrm{pmol}$ for Fe. Detection limits (as 3-times the standard deviation of the blank, $n=12$ ) were 0.044 pmol for Co and 30 pmol for Fe. Phosphorus concentrations were also measured by ICPMS and calibrated to a separate standard curve ranging from 100-1500 ppb using a stock solution of sodium phosphate. This laboratory solution was cross-calibrated to a certified standard from the WHOI ICPMS facility. Cell number was determined by flow cytometry for all samples where quotas were measured. Cell number is supernatant after centrifugation was also measured by flow cytometry. In general, harvesting efficiency by centrifugation was $>95 \%$, except at low cell densities where harvesting efficiency was still $>80 \%$. Metal and $\mathrm{P}$ concentrations in digestions were scaled to original culture volume and divided by cell number to derive per cell quotas. Agreement between cellular P quotas $\left(1.1 \pm 0.4 \times 10^{7}\right.$ atoms per cell) and literature data for this strain (0.4-0.7 x 10 ${ }^{7}$ atoms per cell (Martiny et al., 2016)) and Prochlorococcus Med4 (0.2-2 x $10^{7}$ atoms per cell, (Bertilsson et al., 2003)) indicate that ICPMS and flow cytometry determinations are robust. The 1.7 M bp genome of Prochlorococcus MIT9215 alone accounts for $0.3 \times 10^{7} \mathrm{P}$ atoms per cell, a considerable fraction of the cellular $\mathrm{P}$ quota.

All curve fitting was performed with using least-squares routines in Sigma Plot 12.

\subsection{Quantitative Protein measurements}

Larger volume cultures of cobalt-limited Prochlorococcus MIT9215 cultures were grown in $8 \mathrm{~L}$ polycarbonate carboys and sampled over several days during exponential growth. Four 30 $\mathrm{mL}$ aliquots were taken at the start of exponential phase and grown in $28 \mathrm{~mL}$ polycarbonate tubes alongside larger carboys to measure growth rate under similar light and media conditions. Cobalt was added to two of these aliquots to ensure that growth rate was limited by cobalt. 
Chlorophyll fluorescence of aliquots collected in $8 \mathrm{~L}$ carboys during sample harvesting agreed with levels in $28 \mathrm{~mL}$ cultures, suggesting that growth in both bottles grew similarly over these short timescales ( $<7$ days). Biomass for metal and protein measurements was harvested at the same time and frozen at $-80{ }^{\circ} \mathrm{C}$. Cell quotas were measured as described above.

Soluble proteins were extracted and digested using a detergent-free method. Biomass was resuspended in $100 \mathrm{mM}$ ammonium bicarbonate and sonicated on ice at $70 \%$ duty for two 4 minute intervals and then centrifuged at 14000 RPM for 20 minutes at $4{ }^{\circ} \mathrm{C} .200 \mu \mathrm{l}$ of supernatant was precipitated in $800 \mu$ acetone at $-20{ }^{\circ} \mathrm{C}$ over several days. The supernatant solution was removed after spinning at $14000 \mathrm{rpm}$ at $4{ }^{\circ} \mathrm{C}$ and precipitated proteins were dried on a speed-vac (Thermo) for several minutes. Aliquots of the acetone supernatant were evaporated to dryness by speed-vac and digested in 50\% nitric acid and measured by ICPMS as above. Measurements of the cobalt concentration in these aliquots indicated that between 30 $70 \%$ of the cobalt quota was released during sonication and, by inference, a similar percentage of cobalt-using proteins. Because detergent-free protein extractions discriminate against lipophilic proteins associated with plasma or photosynthetic membranes, cobalt bound to these proteins may account for the 'missing' cobalt quota. However, the higher reagent blanks associated with measuring cobalt in protein extracts compared to acid digestions make the former determinations more uncertain.

Extracted protein was resuspended with $125 \mu \mathrm{l}$ of $6 \mathrm{M}$ urea in $100 \mathrm{mM}$ ammonium bicarbonate and heated to $95{ }^{\circ} \mathrm{C}$ to dissolve. $100 \mu$ of this sample was then incubated with $5 \mu \mathrm{l}$ of $200 \mathrm{mM}$ dithiothreitol (DTT) for 1 hour at $56^{\circ} \mathrm{C}, 20 \mu \mathrm{l}$ of $200 \mathrm{mM}$ iodoacetamide for 1 hour at room temperature, and finally for 1 hour at room temperature with an additional $20 \mu 1$ of 200 mM DTT. Samples were diluted to $1 \mathrm{ml}$ in $100 \mathrm{mM}$ ammonium bicarbonate and trypsin (Promega Gold) was added at a 50:1 ratio to total protein, quantified by a detergent compatible (DC) colorimetric assay (Bio-Rad) at $750 \mathrm{~nm}$ on a UV-Vis spectrophotometer (Shimadzu), and samples were digested overnight at $37^{\circ} \mathrm{C}$. Peptides were concentrated by speed-vac and then diluted with an LC-MS buffer containing $98 \%$ water, $2 \%$ acetonitrile, and $0.1 \%$ formic acid to a final protein concentration of $0.1 \mu \mathrm{g} / \mu \mathrm{l}$.

Prochlorococcus MIT9215 methionine synthase (metH, P9215_10151) and ribonucleotide reductase (nrdJ, 9215_07641) peptides were quantified by selected reaction monitoring (SRM) by targeted liquid chromatography mass spectrometry. Although an estimated 
$30-70 \%$ of the cobalt quota was recovered during protein extraction, it is likely that a greater fraction of $\mathrm{NrdJ}$ and MetH were extracted. Biochemical studies with homologous enzymes have demonstrated that both proteins are soluble in aqueous solution, suggesting that the protein extraction procedure employed is able to recover these enzymes (Goulding et al., 1997; Licht et al., 1999). In contrast, hydrophobic proteins are not likely to be quantitatively extracted without detergents and probably cannot be accurately measured using these methods.

Isotope labeled peptide standards were generated by overexpression of a plasmid containing sequences for Prochlorococcus nrdJ, metH and horse myoglobin peptides in E. coli, following a new method developed by McIlvin and Saito (in prep). Labeled peptides were analyzed by LC-MS to ensure complete trypsin digestion and the absence of detectible peptides with natural isotope abundance.

Labeled peptides were calibrated relative to commercial horse myoglobin (Fischer), which was resuspended in ammonium bicarbonate to $100 \mathrm{nM}$ and digested overnight with $6 \mu \mathrm{g}$ trypsin at room temperature. Addition of a known quantity of commercial horse myoglobin peptides (unlabeled) was used to quantify the concentration of ${ }^{15} \mathrm{~N}$-labeled myoglobin peptides that were overexpressed in E. coli. Because ${ }^{15} \mathrm{~N}$-labeled Prochlorococcus peptides and ${ }^{15} \mathrm{~N}$ labeled myoglobin peptides were cloned from a single sequence, the measured concentration of ${ }^{15} \mathrm{~N}$-labeled myoglobin peptides is equal to concentration of ${ }^{15} \mathrm{~N}$-labeled Prochlorococcus $\mathrm{NrdJ}$ and MetH peptides as well (McIlvin et al., In prep). Digested, ${ }^{15} \mathrm{~N}$-labeled peptides were added to digested Prochlorococcus peptides $(0.1 \mu \mathrm{g} / \mu \mathrm{l}$ total protein) to a final concentration of $3.3 \mathrm{fmol} / \mu \mathrm{l}$ of labeled peptide. $10 \mu \mathrm{l}$ of sample was injected onto a $5 \mu \mathrm{m}$ C18 peptide trap connected to a 3 $\mu \mathrm{m}$ C18 column. Peptides were separated with a Microhm Advance liquid chromatography system over a gradient of $0-95 \%$ acetonitrile over a 40 minute window. This gradient increased linearly from 2 to $40 \%$ over the first 30 minutes and increased to $95 \%$ acetonitrile over the next 5 minutes. Secondary mass spectra $\left(\mathrm{MS}^{2}\right)$ were collected with a Q-Exactive mass spectrometer (Thermo) using an inclusion list containing heavy and light peptides (Figures 2, 3). The ratio of labeled and unlabeled peptides was then used to determine the concentration of $\mathrm{NrdJ}$ and MetH in protein digests (fmol/ $\mu \mathrm{g}$ protein digested, Table 1, Fig. 4). Skyline targeted proteomics software (https://skyline.ms/project/home/begin.view?) was used to process $\mathrm{MS}^{2}$ spectra and calculate peptide ratios. 
Peptide concentrations were corrected for dilution and sample splitting during protein digestion to arrive at a cellular quota. Due to disagreement between peptide concentrations belonging to the same protein (Table 1), enzyme quotas derived from these measurements carry an uncertainty of $\sim 50 \%$.

\subsection{Dissolved and particulate cobalt distributions in the Equatorial Pacific Ocean.}

All samples were collected on the Metzyme cruise (KM1128) between Honolulu, Hawaii and Apia, Western Samoa during October 2011 (Saito et al., 2014). The transect followed a North-South line at $155^{\circ} \mathrm{W}$ to the equator and proceeded southwest-ward to $15^{\circ} \mathrm{S}, 170^{\circ} \mathrm{W}$. Seawater samples were collected with 8L X-Niskin bottles attached to a metal free rosette as described in Saito et al. 2014. Samples for dissolved cobalt determinations were $0.2 \mu \mathrm{m}$ filtered with $47 \mathrm{~mm}$ Supor filters in a clean space maintained by HEPA filtration. Filtered samples were stored in $60 \mathrm{ml}$ acid-clean polyethylene bottles at $4{ }^{\circ} \mathrm{C}$ and preserved with metal-free gas absorbing satchels (Mitsubishi Gas and Chemical) in heat sealed bags, with 3 satchels and 6 samples per bag.

Dissolved cobalt concentrations were determined by cathodic stripping voltammetry (CSV) using dimethylglyoxime (DMG) as a competing ligand. Analyses were conducted identically to preserved samples in Chapter 2 and, with the exception of a subset of data from Stations 1, 3, and 5 that appeared in Saito et al. 2014, samples were measured concurrently with samples for that GP16 dataset. Stations 1, 3, and 5 were re-run and agreed with published values for these samples, except for samples from the oxygen minimum zone in Station 3, where some cobalt ( $20 \mathrm{pM}$ ) seemed to have been lost over $\sim 2$ years since removal from air tight bags, an effect that has been documented in the North Atlantic (Noble et al., submitted).

Cobalt concentrations in community reference materials determined during this period are published in Hawco et al. 2016, as are more complete details of CSV procedures. All analyses were conducted using a hanging drop mercury electrode using a Metrohm 663 VA stand and connected to a Metrohm 858 Sample Processor. Approximately $15 \mathrm{~mL}$ seawater was poured into quartz vials and UV-oxidized for 1 hour to destroy organic ligands using a Metrohm 705 UV digester. Afterwards, $11 \mathrm{~mL}$ of sample was transferred to cleaned polypropylene tubes. DMG and EPPS buffer were added to $400 \mu \mathrm{M}$ and $3.8 \mathrm{mM}$, respectively (Saito and Moffett, 2001). Once in the analyses cup $1.5 \mathrm{~mL}$ of $1.5 \mathrm{M}$ sodium nitrite was added and the sample was purged 
for $180 \mathrm{~s}$ with ultra-high purity $\mathrm{N}_{2}$ gas. Samples were deposited on a hanging mercury drop for $90 \mathrm{~s}$ at $-0.6 \mathrm{~V}$ and analyzed by a fast $10 \mathrm{~V} / \mathrm{s}$ sweep between -1.4 and $0.6 \mathrm{~V}$. The baseline cobalt peak was measured three times, followed by four $25 \mathrm{pM}$ Co additions, each conducted $25 \mathrm{pM}$ Co standard addition by a Dosino 800 burette (Metrohm), diluted from a 1 ppm certified reference solution (SPEX Certiprep). The cobalt peak was measured after each addition and the cobalt concentration was determined from the mean of the baseline peak measurements divided by the sample specific sensitivity (in $\mathrm{nA}$ per $\mathrm{pM}$ ), determined by linear regression of the height of the cobalt reduction peak at $-1.15 \mathrm{~V}$ for all seven scans. A blank of $4.6 \mathrm{pM} \pm 0.7 \mathrm{pM}$ was determined from 19 analyses of chelexed seawater that was UV oxidized both before and after treatment to remove natural cobalt ligands and those leached during chelex treatment (Saito and Moffett, 2001). This blank reflects cobalt added from reagents and other sources during analyses. The detection limit of this dataset, calculated as 3 times the standard deviation of the blank, was 2.1 $\mathrm{pM}$.

Particulate cobalt and particulate phosphate were measured on $0.2 \mu \mathrm{m}$ Supor filters (47 $\mathrm{mm}$ ) used for filtering seawater collected in $8 \mathrm{~L}$ X-Niskin bottles (T.J. Goepfert, Master's Thesis)(Saito et al., 2014). Filters returned to the lab frozen and were digested in $50 \%$ trace metal grade nitric acid with $1 \mathrm{ppb}$ Indium at $90{ }^{\circ} \mathrm{C}$ for 3 hours, diluted to $5 \%$ nitric acid with ultrapure water (Milli-Q), and analyzed on an Element 2 mass spectrometer in the WHOI ICPMS facility. Indium was used as an internal standard to correct for sample injection and dilution. The instrument was calibrated using external standards diluted from certified standards (SPEX) and filter blanks were subtracted from measured values.

Samples for dissolved phosphate measurements were collected from $0.2 \mu \mathrm{m}$ filtered seawater and stored, frozen in acid-washed high density polyethylene bottles. Frozen nutrient samples were thawed and analyzed by Joe Jennings at Oregon State University using a modified version of the molybdenum blue method, as described previously (Noble et al., 2012). Dissolved oxygen concentrations were determined using a factory calibrated SBE19plusV2 system (Seabird Electronics) as described by Saito et al. 2014. 


\section{Results}

\subsection{Iron and cobalt limitation of Prochlorococcus growth}

Decreasing media cobalt concentrations resulted in growth limitation of Prochlorococcus MIT9215. Under our experimental conditions, Prochlorococcus was unable to grow when less than $300 \mathrm{pM}$ cobalt was added (equivalent to $0.46 \mathrm{pM} \mathrm{Co}^{\prime}$, the sum of $\mathrm{Co}^{2+}$ ion and all inorganic cobalt complexes, Fig. 5a)). Under limiting conditions, cellular cobalt quotas were extremely low, but increased as growth rate increased. When growing at a rate of 0.09 per day $\left(16 \% \mu_{\max }\right)$, Prochlorococcus contained $\sim 21$ atoms per cell (Table 2, Fig. 5 b). At 0.33 per day $\left(60 \% \mu_{\max }\right)$, cobalt quotas increased to 54 atoms of cobalt per cell. The need for higher quotas to support faster growth is predicted by the Droop model of nutrient limitation, which can be expressed according to the equation:

$\mu=\mu_{\max } *\left(1-\frac{K_{C o}}{Q}\right)$

where $\mathrm{Q}$ is the cellular cobalt quota and $\mathrm{K}_{\mathrm{Co}}$ represents the absolute minimum quota that is required to support a growth rate equal to zero (Droop, 1973). The relationship between Prochlorococcus growth rate and cobalt quota is best fit at a value of $\mathrm{K}_{\mathrm{Co}}$ equal to 17 atoms per cell (Fig. $5 b, r^{2}=0.98$ ). According to this formulation, growth is within $90 \%$ of its maximum value as long as cellular cobalt exceeds 170 atoms per cell, equivalent to a Co:P ratio of $13 \mu \mathrm{mol}$ Co:mol P (Fig. 5c, $\mathrm{r}^{2}=0.97$ ). Interestingly, cellular cobalt quotas (and P-normalized quotas) increased linearly with increases in media Co', the sum of the concentration of inorganic Co complexes (Fig. 5d, $\mathrm{R}^{2}=0.996$ ), including when cobalt concentrations were not limiting growth. This strong dependence of cellular cobalt quotas on Co' indicates that cobalt transport is not easily saturated at Co' concentrations below $16 \mathrm{pM}$, which are higher than that found in most oceanic settings (Bown et al., 2012b; Hawco et al., 2016; Noble et al., 2012)

Prochlorococcus iron quotas exhibited a more complex response to iron limitation. As with cobalt, lower dissolved Fe decreased both cellular Fe quotas and growth rates (Fig. 5b, red circles). At a cellular quota of $\sim 5000$ atoms per cell, Prochlorococcus was able to grow at $72 \%$ of its maximum rate. However, under stronger iron limitation $\left(42 \% \mu_{\max }\right)$, our measurements suggest that the iron quota increased to 10,000 atoms per cell (Table 2, Fig. 5b). The concentration of iron measured in this sample ( $130 \mathrm{pM}$, not shown) was 2.5 -fold higher than the mean analytical blank and double analytical detection limits (equivalent to a culture concentration of $70 \mathrm{pM}$ ), suggesting that the measurement is robust. At higher Fe', iron quotas 
appeared to saturate, unlike cobalt quotas, but when growth was suppressed by cobalt limitation, cellular iron quotas increased significantly. Despite the same concentration of iron, Fe:P quotas at 0.33 per day increased by $50 \%$ compared to cultures growing at maximum growth rates $(0.55$ per day, Fig. 5e), similar to increased Co uptake under iron limitation (Fig. 5d, Table 2). These results are consistent with the concept of biodilution, which predicts higher cell quotas at lower growth rates in the absence of regulation of metal transporters (See Section 4.2; Sunda and Huntsman, 2000).

Prochlorococcus cell size was dynamic across gradients of iron and cobalt limitation. Ratios of in vivo chlorophyll fluorescence to cell number increased as cobalt limitation intensified (Fig. 6a), suggesting an increase in cell size. This finding is consistent with cell cycle studies of Prochlorococcus Med4, which showed a build-up of larger, G2 phase cells when cobalt-limited (M.A. Saito, Ph.D. Thesis). The opposite trend was observed in iron-limited cultures: the ratio of in vivo chlorophyll fluorescence to cell number decreased. This is consistent with decreasing cell size associated with iron limitation in other phytoplankton (Sunda and Huntsman, 1995b), or impaired chlorophyll biosynthesis under iron limitation (chlorosis). Per cell phosphorus quotas had a similar trend: $\mathrm{P}$ quotas were largest under cobalt limitation and the smallest under iron limitation (Fig. 6b). The similarity between $\mathrm{P}$ and fluorescence suggests that physiological changes are driven mostly by cell size, though, chlorosis due to iron-limitation is possible if the lower $\mathrm{P}$ quota is instead driven by a reduction of cellular ribosome, phospholipid content or other cellular reservoirs. Regardless, quotas normalized to phosphorus (measured concurrently with metals via ICPMS) is a convenient way to correct for changing cell size and also facilitates comparison to cell quotas in the field. Relative to $\mathrm{P}$, absolute minimum iron and cobalt quotas for Prochlorococcus are $260 \pm 40 \mu \mathrm{mol}$ Fe per mol P and $1.30 \pm 0.07 \mu \mathrm{mol} \mathrm{Co} \mathrm{per}$ mol P (Fig. 5c).

\subsection{Quantitative peptide measurements of pseudocobalamin-requiring enzymes}

Comparative genomics of a wide range of bacteria has indicated two major pseudocobalamin requiring enzymes in Prochlorococcus: methionine synthase (MetH) and ribonucleotide reductase enzymes (NrdJ, Fig. 1)(Zhang et al., 2009). These enzymes are critical for the biosynthesis of the amino acid methionine for protein synthesis (MetH) and deoxyribonucleotides needed for genome replication $(\mathrm{NrdJ})$. The abundance of these enzymes in 
cobalt-limited Prochlorococcus biomass was examined by targeted proteomics using LC-MS. Measurements of tryptic peptides specific to these proteins with isotopically labeled internal standards of the same peptides enabled quantification of Prochlorococcus NrdJ and MetH (Fig. 2-4). Cultures growing at approximately 0.2 per day held a cobalt quota of $~ 66$ atoms per cell, similar to quotas measured in earlier experiments (Table 3). Both $\mathrm{NrdJ}$ and MetH were present at low copy numbers: there are roughly 5 copies of MetH per cell and 20 copies per cell for NrdJ (Table 3). There is some disagreement between peptides: the peptide ENEIEDLSR suggests nrdJ levels about 3-fold higher than the other peptides for this protein, perhaps due to lower ionization efficiency for this peptide (Table 1).

Ribonucleotide reductase forms a 1:1 complex with adenosylcobalamin while methionine synthase forms a 1:1 complex with methylcobalamin (Drennan et al., 1994; Sintchak et al., 2002). Thus, the equivalent cobalt quota from the sum of these enzymes is between 15-35 atoms per cell. The metH enzyme also contains a Zn-binding site (Goulding and Matthews, 1997). Given the toxicity of $\mathrm{Zn}$ and the fact that most $\mathrm{Zn}$ enzymes are also functional with cobalt (Maret and Vallee, 1993; Maret, 2010; Yee and Morel, 1996), it is possible that a cobalt ion occupies this metal site and that there are 2 atoms of Co per copy of methionine synthase (although the same samples appear to have a $\mathrm{Zn}$ quota of $\sim 10,000$ atoms per cell, presumably enough to populate these binding sites). Under this scenario, cobalt allocated to these enzymes would increase by an additional 10\%. Regardless, the measured NrdJ and MetH quotas suggest that, of the approximately 66 cobalt atoms in cobalt-limited cells (as measured by ICPMS), roughly one third are actively deployed in cobalamin metabolism (Table 3).

Incomplete recovery of $\mathrm{Nrd} \mathrm{J}$ and MetH during protein extraction could lead to underestimation of enzyme quotas. Considering that homologues to these proteins are soluble, however, it is more likely that incomplete recovery of the cobalt quota during protein extraction is due to some cobalt being bound to other proteins embedded in the plasma membrane. Pseudocobalamin biosynthetic enzymes in cyanobacteria are thought to be membrane associated (Patterson et al., 2013); it may be that the remaining cobalt quota resides there. However, because the uncertainty in calculating enzyme quotas at these low copy numbers is on the order of $50 \%$ (Table 3), it is difficult to confidently assess this possibility. 


\subsection{The distribution of cobalt in the Equatorial Pacific Ocean}

The highest concentrations of dissolved cobalt ( $>100 \mathrm{pM}$ ) are found in oxygen minimum zones (OMZs) in the Equatorial Pacific Ocean, both north and south of the equator (Fig. 7). More detailed investigations into these low oxygen cobalt plumes in the GP16 section (Chapter 2) indicated that remineralization of biogenic cobalt, slower cobalt scavenging in low-oxygen waters, and large coastal sources all contribute toward high dissolved cobalt in OMZs (Hawco et al., 2016; Noble et al., 2012). Mixing of the high-cobalt, low-oxygen waters with other water masses in the thermocline and deep ocean generated a basin scale Co: $\mathrm{O}_{2}$ correlation that held for all samples below $200 \mathrm{~m}$. A similar Co: $\mathrm{O}_{2}$ relationship is observed from samples on the Metzyme transect in the Equatorial Pacific, suggesting that the same $\mathrm{Co}: \mathrm{O}_{2}$ covariation is characteristic of most waters in the tropical and subtropical Pacific (Fig. 8). Compared to the GP16 section, dissolved cobalt concentrations in the surface ocean of the South Pacific on the Metzyme transect is lower and nutriclines for cobalt and phosphate are deeper than observed on GP16. This indicates that oligotrophic surface waters are isolated from nutrient resupply by vertical mixing in the Central Pacific and that upwelling processes on the equator are an important mechanism for nutrient supply to these off-equatorial regions.

Upwelling on the equator - visible from the high surface phosphate concentrations draws mostly from the equatorial undercurrent (Fig. 9). This current originates in the western Pacific and gradually mixes with both surface waters and underlying, cooler waters $\left(13^{\circ} \mathrm{C}\right.$ water $)$ as it propagates eastward (Kessler, 2006; Stramma et al., 2010). The equatorial undercurrent is also responsible for supplying the majority of iron to this iron-limited ecosystem, drawing from strong sedimentary sources along Papua New Guinea and neighboring islands (Slemons et al., 2010; Winckler et al., 2016). In the Metzyme section, the equatorial undercurrent can be seen in the upward bowing of the $25^{\circ} \mathrm{C}$ thermostad at $80 \mathrm{~m}$ on the equator and the stable position of the $13^{\circ}$ thermostad at $200 \mathrm{~m}$ (Fig. 9a). This pattern indicates that upwelling does not draw from waters at depth (>200m) as much as it does by a lateral source from the west (Kessler, 2006; Slemons et al., 2010). A similar, downward bowing in the $100 \mu \mathrm{M}$ oxygen contour is further evidence of an oxygenated equatorial undercurrent (Fig. 9b) (Stramma et al., 2010). While cobalt concentrations in waters influenced by the EUC are higher than surface waters in the central Pacific, they are much less than cobalt concentrations present in the OMZ north and south of the 
equator (Fig. 9c). On the Metzyme transect, the effect of equatorial upwelling on the cobalt distribution is less apparent in the cobalt distribution than in the phosphate distribution (Fig. 9d).

Given that $\mathrm{Fe}$ tends to scavenge faster than $\mathrm{Co}$ and that the equatorial undercurrent is a well-documented iron source, it is surprising that the equatorial undercurrent is so low in cobalt (Coale et al., 1996; Noble et al., 2012; Slemons et al., 2010). On the equator, cobalt concentrations just below the chlorophyll maximum are just $30 \mathrm{pM}$ : higher than surface concentrations measured on this transect but a far cry from the $>100 \mathrm{pM}$ cobalt in the oxygen minimum zones, separated by only few degrees to the north and south. This observation is consistent with studies of metal cycling in coastal sediments along Papua New Guinea, which seem to be a poor source of cobalt to the coastal waters there (Alongi et al., 1996). In Chapters 2 and 3 , it was suggested that cobalt sources to the ocean are more efficient on deoxygenated coastlines like the Peru shelf than in the oxygenated regimes in East and Southeast Asia. Low cobalt in the equatorial undercurrent is consistent with this idea and suggests that cobalt supplied to the surface by equatorial upwelling depends on the extent of mixing between the EUC and low oxygen waters rather than a source in the western Pacific Ocean (Stramma et al., 2010; Toggweiler et al., 1991). In addition, biological export of cobalt from surface waters prior to entrainment into the equatorial undercurrent might also limit a western-boundary source from appearing in the central Pacific.

Relatively high phosphate $(>0.5 \mu \mathrm{M})$ in the surface ocean probably reflects widespread iron limitation at, and south of, the equator (Moore et al., 2013a; Saito et al., 2014). In contrast, dissolved cobalt returns to low concentrations immediately south of the equator, suggesting that iron limitation of phytoplankton does not seem to impede cobalt uptake (and export) to the same extent as phosphate. Indeed, the Co:P ratio of Prochlorococcus MIT9215 under iron limitation increased up to $40 \%$ compared to iron replete cells (Fig. 5d). Depression of growth rates by iron limitation in the Equatorial Pacific may enable high Prochlorococcus Co:P (measured in particles) despite widespread cobalt scarcity.

Consistent with the nutrient-like distribution of dissolved cobalt in the upper ocean, particulate cobalt is highest at the surface ocean and closely resembles particulate phosphate (Fig. 10a, b). The close correspondence between these two elements strongly suggests that particulate cobalt in the surface ocean is present mostly in biomass. Latitudinal gradients for particulate cobalt, particulate phosphorus, and divinyl chlorophyll A - a pigment unique to 
Prochlorococcus - are similar with highest values south of the equator (Fig. 10c) (Goericke and Welschmeyer, 1993). This is counter to the distribution of chlorophyll A (Fig. 10d) and pigments characteristic of eukaryotic phytoplankton such as fucoxanthin (not shown), which show peak concentrations at, and north of the equator. It seems that communities dominated by Prochlorococcus are responsible for the highest levels of cobalt uptake/accumulation in this environment.

\section{Discussion}

\subsection{The Cobalt requirement of marine cyanobacteria}

Acclimated cultures of Prochlorococcus MIT9215 were unable to grow in media lacking added cobalt. Along with observations of cobalt limitation in Prochlorococcus MED4, a member of the other major clade of high-light adapted lineages, and a low light strain, SS120, our results suggest that cobalt is probably required by all species of Prochlorococcus (Saito et al., 2002) (M. A. Saito, PhD. Thesis). Cobalt is also required for the growth of Synechococcus bacillaris (also known as WH5701) and Trichodesmium erythraeum, which suggests that most cyanobacteria have cobalt requirements (Rodriguez and Ho, 2015; Saito et al., 2003; Sunda and Huntsman, 1995a).

Under a state of cobalt limitation, a significant fraction of the Prochlorococcus MIT9215 cobalt quota is probably present as cobalamins (Fig. 1). Indeed, all Prochlorococcus genomes contain sequences corresponding to the cobalamin-dependent enzymes methionine synthase and ribonucleotide reductase, which are necessary for the biosynthesis of protein and DNA, respectively (Kettler et al., 2007; Zhang et al., 2009). Most cyanobacterial genomes also maintain a suite of over a dozen genes coding for the pseudocobalamin biosynthetic pathway (Heal et al., 2016; Rodionov et al., 2003; Zhang et al., 2009), which transforms cobalt metal into the enzyme cofactor, suggesting that their pseudocobalamin requirement is fulfilled by uptake of cobalt metal and de novo biosynthesis (Helliwell et al., 2016).

An interesting exception can be found in the Synechococcus strain PCC7002, which lacks the ability to synthesize cobalamin and therefore must acquire the vitamin from its growth media (Perez et al., 2016; Wilhelm and Trick, 1995). The genome of Synechococcus PCC7002 also lacks homologues to Prochlorococcus $n r d J$ and instead contains sequences that correspond to an iron-dependent ribonucleotide reductase more prevalent in eukaryotic organism 
(SYNPCC7002_A0382 and SYNPCC7002_A1350). Indeed, a recent study demonstrated that MetH is the sole use of vitamin $\mathrm{B}_{12}$ in this strain by genetically substituting the met $H$ gene with a cobalamin-independent form (Perez et al., 2016). A cobalamin quota for Synechococcus PCC7002 $\left(\sim 2 \mu \mathrm{m}^{3}\right)$ growing at 0.6 per day in vitamin $B_{12}$-limited chemostats had been previously estimated to be 256 atoms cell $^{-1}$ (Wilhelm and Trick, 1995). If this organism was the size of Prochlorococcus $\left(\sim 0.2 \mu \mathrm{m}^{3}\right)$ (Bertilsson et al., 2003), the Synechococcus PCC7002 quota would be just 26 atoms per cell, which is less than half the Co quota measured in Prochlorococcus MIT9215 at a comparable growth rate (Table 2, Fig. 5b). The Synechococcus PCC7002 cobalamin quota is closer to measurements of MetH peptides in cobalt-limited Prochlorococcus MIT9215, which indicate 4-10 MetH copies per cell. In the same samples, NrdJ abundance averaged $19 \pm 6$ copies per cell. The higher abundance of NrdJ is consistent with higher minimum cobalt quotas in Prochlorococcus than in Synechococcus PCC 7002, which lacks the NrdJ enzyme.

Because there are $\sim 3$ times more copies of ribonucleotide reductase than methionine synthase, the use of cobalt in DNA synthesis, more so than for protein synthesis, probably determines the sensitivity of Prochlorococcus to cobalt limitation. With estimated turnover times between 2-120 catalytic cycles per minute, the slow speed of ribonucleotide reductase (NrdJ) is often considered the rate limiting step in the biosynthesis of DNA bases (Gleason and Olszewski, 2002; Herrick and Sclavi, 2007; Licht et al., 1999). Cobalt limitation in Prochlorococcus might manifest as an inability to synthesize the number of DNA bases needed for the cells to replicate their genome. Indeed, cell cycle studies with Prochlorococcus MED4 have indicated that the G2 phase is prolonged in cobalt limited cells, perhaps due to slower dNTP production (Saito, Ph.D. Thesis). Having a genome size of approximately 1.6 million base pairs in length (Kettler et al., 2007), Prochlorococcus MIT9215 growing at a rate of 0.2 per day must synthesize just over 1 million DNA bases every day. Given the above range of NrdJ catalytic turnover times, the demand for DNA bases can be met with 4-200 copies per cell, a range that agrees with our measurements of the NrdJ enzyme: 19 copies per cell (Table 3). To an extent, the small, streamlined genome of Prochlorococcus decreases the dNTP demand for growth, enabling such low cobalt quotas.

Studies from cobalt-replete Prochlorococcus have documented strong diel periodicity in NrdJ transcript and protein abundance, with peak protein concentrations at dusk during peak 
concentrations of G2 phase cells (Waldbauer et al., 2012), which is consistent with other studies showing that the abundance of this enzyme is tightly regulated by bacteria (Herrick and Sclavi, 2007). The timing of sample harvesting (around midday) may have impacted measurements of NrdJ quotas in cobalt-limited cells, which may have been lower if sampling was conducted at night. It is unclear how diel periodicity in $\mathrm{NrdJ}$ abundance would be advantageous if $\mathrm{NrdJ}$ activity was the rate limiting step for cell division under cobalt-limited growth. However, given the diel periodicity of NrdJ under cobalt replete conditions (Waldbauer et al., 2012), it is unlikely that measurement of Prochlorococcus NrdJ abundance can be straightforwardly used to infer cobalt limitation in natural Prochlorococcus populations, unless this variability is taken into account. The extent that NrdJ is regulated in response to intracellular pseudocobalamin or cobalt levels is also unclear given that NrdJ abundance in strongly-limited cultures ( 0.20 per day) was similar (or slightly lower) than levels in faster-growing cultures ( 0.32 per day).

Prochlorococcus quotas of methionine synthase and ribonucleotide reductase sum to $\sim 25$ atoms per cell in cells growing at 0.20 per day, representing a significant fraction (but not all) of the 66 atoms also measured in these cells (Table 3). Based on this cell quota, the intracellular concentration of cobalt in growth-limited Prochlorococcus cells is approximately $0.6 \mu \mathrm{M}$, which will reflect the sum of several species: adenosyl-cobalamin, methyl-cobalamin, cobalt-bearing precursors in cobalamin synthesis, and free cobalt ions. The total concentration of cellular cobalt is near the in vitro affinity of ribonucleotide reductase from Lactobacillus leichmannii for adenosyl-cobalamin binding (0.2 $\mu \mathrm{M})$ (Booker et al., 1994; Licht et al., 1999). If intracellular adenosyl-pseudocobalamin is present at this concentration, only half of the cell's copies of NrdJ will be bound to adeosyl-pseudocobalamin; the other half will be inactive. Similarly, the cobaltochelatase enzyme that catalyzes the insertion of cobalt ion into the corrin ring of cobalamins has an affinity for cobalt ion of $\sim 4 \mu \mathrm{M}$ (Debussche et al., 1992), 10 times higher than cellular cobalt levels. While it is possible that the difference between cobalt and enzyme quotas represents a significant contribution of other cobalt/cobalamin enzymes required for Prochlorococcus growth, it may be that metabolic challenges associated with cobalt acquisition, pseudocobalamin biosynthesis, and deployment to these two enzymes are such that less than half of the minimum cobalt quota is actually in use at any given moment.

An important caveat to these minimum cobalt quotas is that they reflect the amount of cobalt required when all other nutrients are in excess. The use of cobalt in other Prochlorococcus 
enzymes, such as alkaline phosphatase and carbonic anhydrase, has previously been suggested (Saito et al. submitted) (Saito et al., 2002). In other phytoplankton, both carbonic anhydrase and alkaline phosphatase use zinc as a cofactor but the similar chemistry of cobalt and zinc results in functional diatom carbonic anhydrase when either metal is present in the active site (Yee and Morel, 1996). A similar situation probably occurs for alkaline phosphatase (Jakuba et al., 2008; $\mathrm{Xu}$ et al., 2007). While the Prochlorococcus strain used in this study does not have homologues to alkaline phosphatase, other strains do (Martiny et al., 2006; Moore et al., 2005). In environments where both zinc and phosphate concentrations are low, such as the Sargasso Sea, Prochlorococcus may require additional cobalt beyond the pseudocobalamin demand of MetH and NrdJ to support growth (Saito et al., submitted). Higher Co:P quotas observed in the North Atlantic ocean may reflect the increased cobalt demand there (Twining et al., 2015).

\subsection{Minimum iron requirements of Prochlorococcus MIT9215}

Iron is a critical limiting nutrient in over $30 \%$ of the ocean including the tropical Pacific (Moore et al., 2013b). Protein biomarkers measured on the Metzyme transect indicate that Prochlorococcus is iron-limited at, and south of the Equator, consistent with previous studies based on cell cycle analyses (Mann and Chisholm, 2000; Saito et al., 2014). While the iron requirement of eukaryotic phytoplankton has been studied thoroughly, there are no published Fe quotas for iron-limited Prochlorococcus (Hudson and Morel, 1990; Shaked et al., 2005; Sunda and Huntsman, 1995b). Studies with the related cyanobacteria Synechococcus have suggested higher iron quotas than found in eukaryotic phytoplankton that may relate to vestigial iron requirements from cyanobacterial evolution in an anoxic ocean (Saito et al., 2003; Sunda and Huntsman, 2015). Indeed, Synechococcus bacillaris show strong iron limitation at a Fe:C quota of $100 \mu \mathrm{mol}: \mathrm{mol}$ (Sunda and Huntsman, 2015), equivalent to a Fe:P ratio of $13 \mathrm{mmol}: \mathrm{mol}$ (assuming a C:P stoichiometry of 130 (Bertilsson et al., 2003)). In contrast, Prochlorococcus MIT9215 had a Fe:P ratio of 0.8-4 mmol:mol (Table 2). This is similar to measurements in nonlimited cultures of Prochlorococcus MED4 and MIT9313 (Fe:P 1 mmol:mol, A. Thompson, Ph.D. Thesis). Although C:P stoichiometry may change under strong iron limitation, the quota of Prochlorococcus MIT9215 appears to be much less than Synechococcus bacillaris and other Synechococcus strains (Brand, 1991). The range of Prochlorococcus Fe:P is more similar to that of eukaryotic phytoplankton such as Thalassiosira oceanica, which can grow at $>0.6$ per day at 
an approximate Fe:P ratio of $\sim 0.3 \mathrm{mmol}: \mathrm{mol}$ (3 $\mu \mathrm{mol}: \mathrm{mol}$ Fe:C / $106 \mathrm{C}: \mathrm{P}$ (Sunda and Huntsman, 1995b)).

Lower iron quotas in Prochlorococcus might reflect stronger selection pressures to minimize iron quotas than experienced by Synechococcus (Mackey et al., 2015). Growth on ammonium rather than nitrate may help decrease Fe requirements by $40 \%$ or so (Raven, 1988). The absence of nitrate reductase (an iron metalloenzyme) in the genome of Prochlorococcus MIT9215 can account for part of the difference between these minimum Fe quotas in ammoniasupported Prochlorococcus and nitrate-supported Synechococcus. Because most of the iron requirement in these cells is probably associated with photosynthesis, substitution of ironproteins with iron free alternatives (e.g. plastocyanin, flavodoxin) may help to minimize iron quotas further (Raven et al., 1999). From first principals, Raven (1990) estimated an iron cost of carbon fixation of $\sim 5 \mu \mathrm{mol} \mathrm{Fe} \mathrm{per} \mathrm{mol} \mathrm{C} \mathrm{per} \mathrm{day} \mathrm{for} \mathrm{a} \mathrm{pathway} \mathrm{similar} \mathrm{to} \mathrm{that} \mathrm{used} \mathrm{by}$ Prochlorococcus (C3 biochemistry with active bicarbonate influx (Hopkinson et al., 2014; Raven, 1990)). This prediction resembles our iron limited experiments: $2.6-8 \mu$ mol Fe per mol C per day (assuming a C:P ratio of 121 (Bertilsson et al., 2003)), suggesting that photosynthetic Fe demand is responsible for most of the iron quotas measured here. Assuming $23 \mathrm{Fe}$ atoms are required to power a single photosynthetic electron transport chain complex (Raven, 1990), the lowest measured iron quota of $\sim 5000$ atoms per cell suggests that growth is possible with fewer than 250 active complexes in Prochlorococcus.

Strangely, Prochlorococccus MIT9215 required about 2 times more iron to grow at 0.23 per day than it took to grow at 0.4 per day (Table 2). Increases in iron quotas under strong ironlimitation were also reported in iron-limited Synechococcus bacillaris, suggesting that this result is not due to analytical error (Sunda and Huntsman, 2015). Sunda and Huntsman (2015) interpreted the increase in the Fe quota under stronger iron limitation to reflect the absence of energy available for active transport of iron across the cell membrane. While the binding of iron to uptake proteins in the periplasm may be a spontaneous process, transport into the cell requires energy expenditure that is in short supply because of iron-limitation of the electron transport chain (Raven, 1990; Sunda and Huntsman, 2015). The high Fe quotas in Prochlorococcus MIT 9215 growing at 0.23 per day are also consistent with this mechanism, and suggest that much of the 'Fe quota' under strong iron limitation is not physiologically useful. Alternatively, the metabolic complexity associated with uptake, cofactor biosynthesis (heme, iron sulfur clusters, 
etc.) and deployment may cause only a small fraction of the measured iron quota to actually be in use in catalysis, as suggest above for cobalt-limited metabolism. Because our measurements were conducted without any washing steps to remove extracellular metals, it is difficult to distinguish if this high Fe-limited quota is intracellular (and has been actively transported into the cell) or if a significant fraction of Fe resides extracellularly in periplasmic binding proteins. Future investigations should seek to clarify between these two possibilities.

Excluding the high Fe quota measured under strong iron limitation due to the above ambiguity, the Droop equation (Eq. 1) can still be applied to compare cobalt and iron quotas at equivalent growth rates. The minimum calculated iron quota $\left(\mathrm{K}_{\mathrm{Fe}}\right)$ in Prochlorococcus MIT9215 is $1530 \pm 140$ atoms per cell (Fig. $5 \mathrm{~b}, \mathrm{r}^{2}=0.96$ ) and corresponds to a Fe:P ratio of 0.26 mmol:mol (Fig. 5c). At a limitation threshold of $90 \% \mu_{\max }$, these data predict an Fe:P ratio of 2.6 mmol:mol, a factor of two higher than Fe quotas of picoplankton measured previously in the equatorial Pacific (1.4 mmol:mol P) (Twining et al., 2011). At the latter stoichiometry, growth of Prochlorococcus MIT9215 would be iron-limited, consistent with cell cycle measurements of in situ and iron-fertilized growth rates for Prochlorococcus in the Equatorial Pacific (Mann and Chisholm, 2000).

\subsection{Potential for Cobalt limitation in Equatorial Pacific Ocean}

We can evaluate the potential for cobalt limitation in the Equatorial Pacific using Prochlorococcus Co and $\mathrm{P}$ quotas in culture as a reference. When limited by cobalt, the Co:P ratio of Prochlorococcus MIT9215 biomass was very low, but increased with increasing growth rate, as predicted by Droop models for cell growth. If a threshold for cobalt limitation of Prochlorococcus is defined by the ability to grow at $90 \% \mu_{\max }$, the best fit of Eq. 1 indicates that this level of growth is possible with a Co:P ratio of $13 \mu \mathrm{mol} \mathrm{Co} \mathrm{per} \mathrm{mol} \mathrm{P} \mathrm{(that} \mathrm{is,} 10$ times $\mathrm{K}_{\mathrm{Co}}$ ). Sunda and Huntsman (1995) measured a minimum Co:C quota of 8-12 nmol Co per mol C in Synechococcus bacillaris (WH5701), a brackish strain; using a typical C:P conversion for Preplete Synechococcus, their data also suggest a Co:P ratio between 10-20 $\mu \mathrm{mol}$ Co per mol P, similar to Prochlorococcus MIT9215 (Bertilsson et al., 2003; Sunda and Huntsman, 1995a).

Despite the extremely low levels of dissolved cobalt measured in the South Pacific gyre $\left(<3 \mathrm{pM}\right.$ in the upper $50 \mathrm{~m}$ at 9 and $\left.12^{\circ} \mathrm{S}\right)$, particulate $\mathrm{Co}: \mathrm{P}$ ratios were always greater than 60 $\mu \mathrm{mol}$ per mol, near the upper end of values obtained from our cobalt limitation series in culture 
(Fig. 5c). Indeed, the tight correlation between particulate Co and $\mathrm{P}$ in the Equatorial Pacific suggests an average stoichiometry of $110 \mu \mathrm{mol} \mathrm{Co} \mathrm{per} \mathrm{mol} \mathrm{P,} \mathrm{a} \mathrm{full} \mathrm{ten} \mathrm{times} \mathrm{greater} \mathrm{than} \mathrm{cobalt-}$ limited values in culture (Fig. 11). These values are similar to surface ocean $(0-100 \mathrm{~m})$ particles collected in the Eastern South Pacific on the GP16 transect 50-400 $\mu \mathrm{mol}$ Co per mol P (median of $140 \mu \mathrm{mol}$ per mol) (Hawco et al., 2016; Ohnemus et al., 2016). While it is possible that Prochlorococcus growing in the field have additional requirements for cobalt that are not reflected in our culture experiments (and therefore a higher threshold Co:P stoichiometry), it seems unlikely that Prochlorococcus growth is strongly limited by cobalt in the Equatorial Pacific.

The threshold Co:P ratio determined from culture experiments can also be applied to the dissolved $\mathrm{Co}: \mathrm{PO}_{4}$ ratio in seawater. This approach highlights two key areas where the cobalt inventory is insufficient relative to the phosphate inventory to support Prochlorococcus growth (Fig. 12, dCo: $\mathrm{PO}_{4}<13 \mu \mathrm{mol}$ per mol). The first is the upper $100 \mathrm{~m}$ of the South Pacific Ocean. As the particulate Co:P ratio in these waters is above this threshold, cobalt must be recycled more efficiently than phosphate if Prochlorococcus is able to effectively stave off cobalt limitation. Such efficiency may be enabled by biodilution:

$V_{\text {metal }}=Q_{\text {metal }} * \mu$

where constant metal uptake rates $\left(\mathrm{V}_{\text {metal }}\right)$ causes cell quotas to increase when growth rates are depressed by a different nutrient (Sunda and Huntsman, 2000). In the tropical South Pacific, where growth rates are low due to iron limitation, Prochlorococcus may be able to accumulate cobalt while waiting for bioavailable iron to diffuse to the cell surface (Mann and Chisholm, 2000; Moore et al., 2013b; Saito et al., 2014). If basin-scale iron limitation is relieved near islands via terrigenous input or by dust deposition events without also adding cobalt, temporary cobalt limitation may be possible as growth rates increase (Bown et al., 2012a; Shiozaki et al., 2014).

The second region where dissolved Co:P ratios fall below this threshold is in the deep Pacific Ocean below 1000m (Fig. 12). It is worth noting that Co:P ratios are above this threshold in North Atlantic deep water, where cobalt is higher and phosphate is lower. The combination of scavenging of cobalt and regeneration of phosphate make these waters deplete in cobalt by the time they arrive in the Pacific. A similar scenario occurs more intensely for iron, which is depleted relative to $\mathrm{P}$ in all deep waters (Moore et al., 2013a; Rijkenberg et al., 2014). For 
Prochlorococcus MIT9215, minimum Fe quotas are approximately 200-fold greater than minimum Co quotas (Table 2). In contrast, the deep Pacific has a dFe:dCo ratio of less than 50 mol:mol (Hawco et al., 2016; Resing et al., 2015). Even though ventilation of the deep ocean will create conditions whereby cobalt is insufficient relative to $\mathrm{P}$, iron insufficiency will likely be greater.

\section{Conclusions}

The extremely low cobalt requirement of Prochlorococcus could help them avoid cobalt limitation in environments where dissolved cobalt is scarce, such as the tropical Pacific Ocean. Based on targeted peptide measurements of cobalamin-requiring enzymes in cobalt-limited cells, the physiological basis for cobalt limitation in these organisms is related to slower rates of dNTP production by ribonucleotide reductase and, therefore, slower rates of a genome replication. Because the Co:P stoichiometry of cobalt limited cells is much less than those found in open ocean environments, it seems that cobalt is unlikely to be a limiting nutrient in these regions, unless there are other uses for cobalt in these cells that are underrepresented in culture experiments. Long term evolution of Prochlorococcus has led to streamlined, minimal genomes. As DNA synthesis is probably the rate-limiting step of cobalt limitation, genome minimization may have helped Prochlorococcus minimize their cobalt requirements as well.

\section{References}

Alongi, D. M., Boyle, S. G., Tirendi, F. and Payn, C.: Composition and Behaviour of Trace Metals in Post-oxic Sediments of the Gulf of Papua, Papua New Guinea, Estuar. Coast. Shelf Sci., 42(2), 197-211, doi:10.1006/ecss.1996.0015, 1996.

Banerjee, R. and Ragsdale, S. W.: The Many Faces of Vitamin B 12 : Catalysis by CobalaminDependent Enzymes1, Annu. Rev. Biochem., 72(1), 209-247, doi:10.1146/annurev.biochem.72.121801.161828, 2003.

Banerjee, R. V, Frasca, V., Ballou, D. P. and Matthews, R. G.: Participation of cob(I) alamin in the reaction catalyzed by methionine synthase from Escherichia coli: a steady-state and rapid reaction kinetic analysis., Biochemistry, 29(50), 11101-9, doi:10.1021/bi00502a013, 1990.

Bertilsson, S., Berglund, O., Karl, D. M. and Chisholm, S. W.: Elemental composition of marine Prochlorococcus and Synechococcus: Implications for the ecological stoichiometry of the sea, Limnol. Oceanogr., 48(5), 1721-1731, doi:10.4319/lo.2003.48.5.1721, 2003.

Booker, S., Licht, S., Broderick, J. and Stubbe, J.: Coenzyme B12-Dependent Ribonucleotide 
Reductase: Evidnce for the Participation of Five Cysteine Residues in Ribonucleotide Reduction, Biochemistry, 33(42), 12676-12685, doi:10.1021/bi00208a019, 1994.

Bown, J., Boye, M., Laan, P., Bowie, A. R., Park, Y. H., Jeandel, C. and Nelson, D. M.: Imprint of a dissolved cobalt basaltic source on the Kerguelen Plateau, Biogeosciences, 9(12), 52795290, doi:10.5194/bg-9-5279-2012, 2012a.

Bown, J., Boye, M. and Nelson, D. M.: New insights on the role of organic speciation in the biogeochemical cycle of dissolved cobalt in the southeastern Atlantic and the Southern Ocean, Biogeosciences, 9(7), 2719-2736, doi:10.5194/bg-9-2719-2012, 2012 b.

Brand, L. E.: Minimum iron requirements of marine phytoplankton and the implications for the biogeochemical control of new production, Limnol. Oceanogr., 36(8), 1756-1771, doi:10.4319/lo.1991.36.8.1756, 1991.

Coale, K. H., Fitzwater, S. E., Gordon, R. M., Johnson, K. S. and Barber, R. T.: Control of community growth and export production by upwelled iron in the equatorial Pacific Ocean Kenneth, Nature, 379(January), 1994-1997, doi:10.1038/379621a0, 1996.

Debussche, L., Couder, M., Thibaut, D., Cameron, B., Crouzet, J. and Blanche, F.: Assay, purification, and characterization of cobaltochelatase, a unique complex enzyme catalyzing cobalt insertion in hydrogenobyrinic acid a,c-diamide during coenzyme B12 biosynthesis in Pseudomonas denitrificans., J. Bacteriol., 174(22), 7445-51 [online] Available from: http://www.pubmedcentral.nih.gov/articlerender.fcgi?artid=207441\&tool=pmcentrez\&rendertyp $\mathrm{e}=$ abstract, 1992.

Drennan, C. L., Huang, S., Drummond, J. T., Matthews, R. G. and Ludwig, M. L.: How a protein binds $\mathrm{B}_{12}$ : a $3.0 \AA \mathrm{X}$-ray structure of $\mathrm{B}_{12}$-binding domains of methionine synthase, Science, 266(5191), 1669-74, doi:10.1126/science.7992050, 1994.

Droop, M. R.: Some thoughts on nutrient limitation in algae, J. Phycol., 9(3), 264-272, doi:10.1111/j.1529-8817.1973.tb04092.x, 1973.

Gleason, F. K. and Olszewski, N. E.: Isolation of the gene for the B12-dependent ribonucleotide reductase from Anabaena sp. strain PCC 7120 and expression in Escherichia coli, J. Bacteriol., 184(23), 6544-6550., doi:10.1128/JB.184.23.6544, 2002.

Goericke, R. and Welschmeyer, N. A.: The marine prochlorophyte Prochlorococcus contributes significantly to phytoplankton biomass and primary production in the Sargasso Sea, Deep. Res. Part I, 40(11-12), 2283-2294, doi:10.1016/0967-0637(93)90104-B, 1993.

Goulding, C. W. and Matthews, R. G.: Cobalamin-dependent methionine synthase from Escherichia coli: Involvement of zinc in homocysteine activation, Biochemistry, 36(50), 1574915757, doi:10.1021/bi9719881, 1997.

Goulding, C. W., Postigo, D. and Matthews, R. G.: Cobalamin-dependent methionine synthase is a modular protein with distinct regions for binding homocysteine, methyltetrahydrofolate, cobalamin, and adenosylmethionine, Biochemistry, 36(26), 8082-8091, doi:10.1021/bi9705164, 1997. 
Hawco, N. J., Ohnemus, D. C., Resing, J. A., Twining, B. S. and Saito, M. A.: A cobalt plume in the oxygen minimum zone of the Eastern Tropical South Pacific, Biogeosciences, 13, 56975717, doi:10.5194/bg-2016-169, 2016.

Heal, K. R., Qin, W., Ribalet, F., Bertagnolli, A. D., Coyote-Maestas, W., Hmelo, L. R., Moffett, J. W., Devol, A. H., Armbrust, E. V., Stahl, D. A. and Ingalls, A. E.: Two distinct pools of B 12 analogs reveal community interdependencies in the ocean, Proc. Natl. Acad. Sci., 114(2), 201608462, doi:10.1073/pnas.1608462114, 2016.

Helliwell, K. E., Lawrence, A. D., Holzer, A., Kudahl, U. J., Sasso, S., Kräutler, B., Scanlan, D. J., Warren, M. J. and Smith, A. G.: Cyanobacteria and Eukaryotic Algae Use Different Chemical Variants of Vitamin B12, Curr. Biol., 26(8), 999-1008, doi:10.1016/j.cub.2016.02.041, 2016.

Herrick, J. and Sclavi, B.: Ribonucleotide reductase and the regulation of DNA replication: An old story and an ancient heritage, Mol. Microbiol., 63(1), 22-34, doi:10.1111/j.13652958.2006.05493.x, 2007.

Hopkinson, B. M., Young, J. N., Tansik, a. L. and Binder, B. J.: The Minimal CO2Concentrating Mechanism of Prochlorococcus spp. MED4 Is Effective and Efficient, Plant Physiol., 166(4), 2205-2217, doi:10.1104/pp.114.247049, 2014.

Hudson, R. J. M. and Morel, F. M. M.: lron transport in marine phytoplankton: Kinetics of cellular and medium coordination reactions, Limnol. Oceanogr., 35(5), 1002-1020, doi:10.4319/lo.1990.35.5.1002, 1990.

Jakuba, R. W., Moffett, J. W. and Dyhrman, S. T.: Evidence for the linked biogeochemical cycling of zinc, cobalt, and phosphorus in the western North Atltic Ocean, Global Biogeochem. Cycles, 22(4), 1-13, doi:10.1029/2007GB003119, 2008.

Kessler, W. S.: The circulation of the eastern tropical Pacific: A review, Prog. Oceanogr., 69(24), 181-217, doi:10.1016/j.pocean.2006.03.009, 2006.

Kettler, G. C., Martiny, A. C., Huang, K., Zucker, J., Coleman, M. L., Rodrigue, S., Chen, F., Lapidus, A., Ferriera, S., Johnson, J., Steglich, C., Church, G. M., Richardson, P. and Chisholm, S. W.: Patterns and implications of gene gain and loss in the evolution of Prochlorococcus, PLoS Genet., 3(12), 2515-2528, doi:10.1371/journal.pgen.0030231, 2007.

Licht, S. S., Lawrence, C. C. and Stubbe, J.: Class II ribonucleotide reductases catalyze carboncobalt bond reformation on every turnover, J. Am. Chem. Soc., 121(33), 7463-7468, doi:10.1021/ja9913840, 1999.

Liu, H., Nolla, H. and Campbell, L.: Prochlorococcus growth rate and contribution to primary production in the equatorial and subtropical North Pacific Ocean, Aquat. Microb. Ecol., 12, 3947, doi:10.3354/ame012039, 1997.

Mackey, K. R. M., Post, A. F., McIlvin, M. R., Cutter, G. a, John, S. G. and Saito, M. a: Divergent responses of Atlantic coastal and oceanic Synechococcus to iron limitation, Proc. Natl. Acad. Sci., 112(32), 9944-9949, doi:10.1073/pnas.1509448112, 2015.

Mann, E. L. and Chisholm, S. W.: Iron limits the cell division rate of Prochlorococcus in the 
eastern equatorial Pacific, Limnol. Oceanogr., 45(5), 1067-1076, doi:10.4319/lo.2000.45.5.1067, 2000 .

Maret, W.: Metalloproteomics, metalloproteomes, and the annotation of metalloproteins., Metallomics, 2(2), 117-25, doi:10.1039/b915804a, 2010.

Maret, W. and Vallee, B. L.: Cobalt as probe and label of proteins, Methods Enzymol., 226(1973), 52-70, doi:10.1016/0076-6879(93)26005-T, 1993.

Martiny, A. C., Coleman, M. L. and Chisholm, S. W.: Phosphate acquisition genes in Prochlorococcus ecotypes: evidence for genome-wide adaptation., Proc. Natl. Acad. Sci. U. S. A., 103(33), 12552-7, doi:10.1073/pnas.0601301103, 2006.

Martiny, A. C., Ma, L., Mouginot, C., Chandler, J. W. and Zinser, E. R.: Interactions between thermal acclimation, growth rate, and phylogeny influence Prochlorococcus elemental stoichiometry, PLoS One, 11(12), e0168291, doi:10.1371/journal.pone.0168291, 2016.

Moffett, J. W. and Ho, J.: Oxidation of cobalt and manganese in seawater via a common microbially catalyzed pathway, Geochim. Cosmochim. Acta, 60(18), 3415-3424, doi:10.1016/0016-7037(96)00176-7, 1996.

Moore, C. M., Mills, M. M., Arrigo, K. R., Berman-Frank, I., Bopp, L., Boyd, P. W., Galbraith, E. D., Geider, R. J., Guieu, C., Jaccard, S. L., Jickells, T. D., La Roche, J., Lenton, T. M., Mahowald, N. M., Marañón, E., Marinov, I., Moore, J. K., Nakatsuka, T., Oschlies, A., Saito, M. a, Thingstad, T. F., Tsuda, A. and Ulloa, O.: Processes and patterns of oceanic nutrient limitation, Nat. Geosci., 6(9), 701-710, doi:10.1038/ngeo1765, $2013 \mathrm{a}$.

Moore, J. K., Lindsay, K., Doney, S. C., Long, M. C. and Misumi, K.: Marine ecosystem dynamics and biogeochemical cycling in the community earth system model [CESM1(BGC)]: Comparison of the 1990s with the 2090s under the RCP4.5 and RCP8.5 scenarios, J. Clim., 26(23), 9291-9312, doi:10.1175/JCLI-D-12-00566.1, 2013 b.

Moore, L. R. and Chisholm, S. W.: Photophysiology of the marine cyanobacterium Prochlorococcus: Ecotypic differences among cultured isolates, Limnol. Oceanogr., 44(3), 628638, doi:10.4319/lo.1999.44.3.0628, 1999.

Moore, L. R., Ostrowski, M., Scanlan, D. J., Feren, K. and Sweetsir, T.: Ecotypic variation in phosphorus-acquisition mechanisms within marine picocyanobacteria, Aquat. Microb. Ecol., 39(3), 257-269, doi:10.3354/ame039257, 2005.

Moore, L. R., Coe, A., Zinser, E. R., Saito, M. a., Sullivan, M. B., Lindell, D., Frois-Moniz, K., Waterbury, J. and Chisholm, S. W.: Culturing the marine cyanobacterium Prochlorococcus, Limnol. Oceanogr. Methods, 5(Table 1), 353-362, doi:10.4319/lom.2007.5.353, 2007.

Van Mooy, B. A. S., Rocap, G., Fredricks, H. F., Evans, C. T. and Devol, A. H.: Sulfolipids dramatically decrease phosphorus demand by picocyanobacteria in oligotrophic marine environments., Proc. Natl. Acad. Sci. U. S. A., 103(23), 8607-12, doi:10.1073/pnas.0600540103, 2006.

Morris, J. J., Kirkegaard, R., Szul, M. J., Johnson, Z. I. and Zinser, E. R.: Facilitation of robust 
growth of Prochlorococcus colonies and dilute liquid cultures by "helper" heterotrophic bacteria, Appl. Environ. Microbiol., 74(14), 4530-4534, doi:10.1128/AEM.02479-07, 2008.

Noble, A. E., Saito, M. A., Maiti, K. and Benitez-Nelson, C. R.: Cobalt, manganese, and iron near the Hawaiian Islands: A potential concentrating mechanism for cobalt within a cyclonic eddy and implications for the hybrid-type trace metals, Deep Sea Res. Part II Top. Stud. Oceanogr., 55(10-13), 1473-1490, doi:10.1016/j.dsr2.2008.02.010, 2008.

Noble, A. E., Lamborg, C. H., Ohnemus, D. C., Lam, P. J., Goepfert, T. J., Measures, C. I., Frame, C. H., Casciotti, K. L., DiTullio, G. R., Jennings, J. and Saito, M. A.: Basin-scale inputs of cobalt, iron, and manganese from the Benguela-Angola front to the South Atlantic Ocean, Limnol. Oceanogr., 57(4), 989-1010, doi:10.4319/lo.2012.57.4.0989, 2012.

Ohnemus, D. C., Rauschenberg, S., Cutter, G. A., Fitzsimmons, J. N., Sherrell, R. M. and Twining, B. S.: Elevated trace metal content of prokaryotic plankton communities associated with marine oxygen deficient zones, Limnol. Oceanogr., (2014), Accepted, doi:10.1002/lno.10363, 2016.

Patterson, C. J., Pernil, R., Dainty, S. J., Chakrabarti, B., Henry, C. E., Money, V. a, Foster, a W. and Robinson, N. J.: Co(ii)-detection does not follow Kco(ii) gradient: channelling in Co(ii)sensing, Metallomics, 5(4), 352-362, doi:10.1039/c3mt20241k, 2013.

Perez, A. A., Liu, Z., Rodionov, D. A., Li, Z. and Bryant, D. A.: Complementation of Cobalamin Auxotrophy in Synechococcus sp. Strain PCC 7002 and Validation of a Putative Cobalamin Riboswitch In Vivo, J. Bacteriol., 198(19), 2743-2752, doi:10.1128/JB.00475-16.Editor, 2016.

Price, N. M., Harrison, G. I., Hering, J. G., Hudson, R. J., Nirel, P. M. V., Palenik, B. and Morel, F. M. M.: Preparation and Chemistry of the Artificial Algal Culture Medium Aquil, Biol. Oceanogr., 6(5-6), 443-461, doi:10.1080/01965581.1988.10749544, 1989.

Raven, J., Evans, M. and Korb, R.: The role of trace metals in photosynthetic electron transport in 02-evolving organisms, Photosynth. Res., doi:10.1023/A:1006282714942, 1999.

Raven, J. a: The iron and molybdenum use efficiencies of plant growth with different energy, carbon and nitrogen sources, New Phytol., 109(3), 279-288, doi:10.1111/j.1469-

8137.1988.tb04196.x, 1988.

Raven, J. A.: Predictions of Mn and Fe use efficiencies of phototrophic growth as a function of light availability for growth and of C assimilation pathway, New Phytol., 116(1), 1-18, doi:10.1111/j.1469-8137.1990.tb00505.x, 1990.

Resing, J. A., Sedwick, P. N., German, C. R., Jenkins, W. J., Moffett, J. W., Sohst, B. M. and Tagliabue, A.: Basin-scale transport of hydrothermal dissolved metals across the South Pacific Ocean, Nature, 523(7559), 200-203, doi:10.1038/nature14577, 2015.

Rii, Y. M., Duhamel, S., Bidigare, R. R., Karl, D. M., Repeta, D. J. and Church, M. J.: Diversity and productivity of photosynthetic picoeukaryotes in biogeochemically distinct regions of the South East Pacific Ocean, Limnol. Oceanogr., 61(3), 806-824, doi:10.1002/lno.10255, 2016.

Rijkenberg, M. J. a, Middag, R., Laan, P., Gerringa, L. J. a, Van Aken, H. M., Schoemann, V., 
De Jong, J. T. M. and De Baar, H. J. W.: The distribution of dissolved iron in the West Atlantic Ocean, PLoS One, 9(6), 1-14, doi:10.1371/journal.pone.0101323, 2014.

Rodionov, D. a, Vitreschak, A. G., Mironov, A. a and Gelfand, M. S.: Comparative genomics of the vitamin B12 metabolism and regulation in prokaryotes., J. Biol. Chem., 278(42), 41148-59, doi:10.1074/jbc.M305837200, 2003.

Rodriguez, I. B. and Ho, T.-Y.: Influence of Co and B12 on the growth and nitrogen fixation of Trichodesmium, Front. Microbiol., 6(June), 1-9, doi:10.3389/fmicb.2015.00623, 2015.

Saito, M. A. and Moffett, J. W.: Complexation of cobalt by natural organic ligands in the Sargasso Sea as determined by a new high-sensitivity electrochemical cobalt speciation method suitable for open ocean work, Mar. Chem., 75(1-2), 49-68, doi:10.1016/S0304-4203(01)00025$1,2001$.

Saito, M. A., Moffett, J. W., Chisholm, S. W. and Waterbury, J. B.: Cobalt limitation and uptake in Prochlorococcus, Limnol. Oceanogr., 47(6), 1629-1636, doi:10.4319/lo.2002.47.6.1629, 2002.

Saito, M. A., Sigman, D. M. and Morel, F. M. .: The bioinorganic chemistry of the ancient ocean: the co-evolution of cyanobacterial metal requirements and biogeochemical cycles at the Archean-Proterozoic boundary?, Inorganica Chim. Acta, 356, 308-318, doi:10.1016/S00201693(03)00442-0, 2003.

Saito, M. A., Rocap, G. and Moffett, J. W.: Production of cobalt binding ligands in a Synechococcus feature at the Costa Rica upwelling dome, Limnol. Oceanogr., 50(1), 279-290, doi:10.4319/lo.2005.50.1.0279, 2005.

Saito, M. A., McIlvin, M. R., Moran, D. M., Goepfert, T. J., DiTullio, G. R., Post, A. F. and Lamborg, C. H.: Multiple nutrient stresses at intersecting Pacific Ocean biomes detected by protein biomarkers, Science (80-. )., 345(6201), 1173-1177, doi:10.1126/science.1256450, 2014.

Shaked, Y., Kustka, A. B. and Morel, F. M. M.: A general kinetic model for iron acquisition by eukaryotic phytoplankton, Limnol. Oceanogr., 50(3), 872-882, doi:10.4319/lo.2005.50.3.0872, 2005.

Shiozaki, T., Kodama, T. and Furuya, K.: Large-scale impact of the island mass effect through nitrogen fixation in the western South Pacific Ocean, Geophys. Res. Lett., 41(8), 2907-2913, doi:10.1002/2014GL059835, 2014.

Sintchak, M. D., Arjara, G., Kellogg, B. A., Stubbe, J. and Drennan, C. L.: The crystal structure of class II ribonucleotide reductase reveals how an allosterically regulated monomer mimics a dimer, Nat Struct Biol, 9(4), 293-300, doi:10.1038/nsb774, 2002.

Slemons, L. O., Murray, J. W., Resing, J., Paul, B. and Dutrieux, P.: Western Pacific coastal sources of iron, manganese, and aluminum to the Equatorial Undercurrent, Global Biogeochem. Cycles, 24(3), n/a-n/a, doi:10.1029/2009GB003693, 2010.

Stramma, L., Johnson, G. C., Firing, E. and Schmidtko, S.: Eastern Pacific oxygen minimum zones: Supply paths and multidecadal changes, J. Geophys. Res., 115(C9), C09011, 
doi:10.1029/2009JC005976, 2010.

Sunda, W. G. and Huntsman, S. A.: Cobalt and zinc interreplacement in marine phytoplankton: Biological and geochemical implications, Limnol. Oceanogr., 40(8), 1404-1417, doi:10.4319/lo.1995.40.8.1404, 1995a.

Sunda, W. G. and Huntsman, S. a.: Iron uptake and growth limitation in oceanic and coastal phytoplankton, Mar. Chem., 50(1-4), 189-206, doi:10.1016/0304-4203(95)00035-P, 1995b.

Sunda, W. G. and Huntsman, S. a.: Effect of Zn, Mn, and Fe on Cd accumulation in phytoplankton: Implications for oceanic Cd cycling, Limnol. Oceanogr., 45(7), 1501-1516, doi:10.4319/lo.2000.45.7.1501, 2000.

Sunda, W. G. and Huntsman, S. a.: High iron requirement for growth, photosynthesis, and lowlight acclimation in the coastal cyanobacterium Synechococcus bacillaris, Front. Microbiol., 6(June), 1-13, doi:10.3389/fmicb.2015.00561, 2015.

Toggweiler, J. R., Dixon, K. and Broecker, W. S.: The Peru upwelling and the ventilation of the south Pacific thermocline, J. Geophys. Res., 96(C11), 20467, doi:10.1029/91JC02063, 1991.

Twining, B. S., Baines, S. B., Bozard, J. B., Vogt, S., Walker, E. a. and Nelson, D. M.: Metal quotas of plankton in the equatorial Pacific Ocean, Deep Sea Res. Part II Top. Stud. Oceanogr., 58(3-4), 325-341, doi:10.1016/j.dsr2.2010.08.018, 2011.

Twining, B. S., Rauschenberg, S., Morton, P. L. and Vogt, S.: Metal contents of phytoplankton and labile particulate material in the North Atlantic Ocean, Prog. Oceanogr., 137, 261-283, doi:10.1016/j.pocean.2015.07.001, 2015.

Waldbauer, J. R., Rodrigue, S., Coleman, M. L. and Chisholm, S. W.: Transcriptome and Proteome Dynamics of a Light-Dark Synchronized Bacterial Cell Cycle, PLoS One, 7(8), doi:10.1371/journal.pone.0043432, 2012.

Watanabe, F., Katsura, H., Takenaka, S., Fujita, T., Abe, K., Tamura, Y., Nakatsuka, T. and Nakano, Y.: Pseudovitamin B12 is the predominant cobamide of an algal health food, spirulina tablets, J. Agric. Food Chem., 47(11), 4736-4741, doi:10.1021/jf990541b, 1999.

Waterbury, J., Watson, S., Valois, F. and Franks, D.: Biological and ecological characterization of the marine unicellular cyanobacterium Synechococcus, in Photosynthetic Picoplankton., 1986.

Wilhelm, S. W. and Trick, C. G.: Effects of Vitamin-B-12 Concentration on Chemostat Cultured Synechococcus Sp Strain Pcc-7002, Can. J. Microbiol., 41(2), 145-151 [online] Available from: $<$ Go to ISI $>$ ://A1995QM34600005, 1995.

Winckler, G., Anderson, R. F., Jaccard, S. L. and Marcantonio, F.: Ocean dynamics, not dust, have controlled equatorial Pacific productivity over the past 500,000 years, Proc. Natl. Acad. Sci., 201600616, doi:10.1073/pnas.1600616113, 2016.

Xu, Y., Tang, D., Shaked, Y. and Morel, F. M. M.: Zinc, cadmium, and cobalt interreplacement and relative use efficiencies in the coccolithophore Emiliania huxleyi, Limnol. Oceanogr., 52(5), 2294-2305, doi:10.4319/lo.2007.52.5.2294, 2007. 
Yee, D. and Morel, F. M. M.: In vivo substitution of zinc by cobalt in carbonic anhydrase of a marine diatom, Limnol. Oceanogr., 41(3), 573-577, doi:10.4319/lo.1996.41.3.0573, 1996.

Zhang, Y., Rodionov, D. A., Gelfand, M. S. and Gladyshev, V. N.: Comparative genomic analyses of nickel, cobalt and vitamin B12 utilization., BMC Genomics, 10, 78, doi:10.1186/1471-2164-10-78, 2009. 
Table 1. Quantitative peptide measurements in cobalt-limited Prochlorococcus MIT9215 biomass. All measured peptides are in fmol peptide per $\mu \mathrm{g}$ protein. Measurements from duplicate injections are shown for each sample and averaged in the right-hand column.

\begin{tabular}{|c|c|c|c|c|c|c|}
\hline \multicolumn{7}{|c|}{ Ribonucleotide reductase, NrdJ, P9215_07641 } \\
\hline Cell $/ \mathrm{mL}$ & SVSEVGITPK & GFGGMANPIK & VASLLGK & ENEIEDLSR & FSANATFPR & Average \\
\hline \multicolumn{7}{|c|}{0.32 per day } \\
\hline \multirow[t]{2}{*}{$4.6 \times 10^{7}$} & 1.5 & 1.1 & 1.6 & 3.6 & 1.5 & 1.9 \\
\hline & 1.5 & 1.2 & 1.6 & 3.7 & 1.5 & \\
\hline \multirow{2}{*}{$9.7 \times 10^{7}$} & 1.4 & 1.2 & 1.6 & 3.9 & 1.3 & 1.9 \\
\hline & 1.4 & 1.2 & 1.7 & 3.4 & 1.4 & \\
\hline \multirow{2}{*}{$1.3 \times 10^{8}$} & 2.0 & 1.7 & 2.1 & 6.1 & 2.0 & 2.7 \\
\hline & 2.0 & 1.6 & 2.2 & 5.3 & 1.8 & \\
\hline \multicolumn{7}{|c|}{0.20 per day } \\
\hline \multirow{2}{*}{$5.7 \times 10^{7}$} & 1.8 & 1.7 & 2.0 & 5.5 & 1.9 & 2.6 \\
\hline & 1.8 & 1.6 & 2.0 & 5.4 & 1.9 & \\
\hline \multirow{2}{*}{$6.9 \times 10^{7}$} & 2.1 & 1.6 & 2.3 & 7.0 & 1.9 & 3.0 \\
\hline & 2.0 & 1.7 & 2.4 & 6.9 & 1.9 & \\
\hline \multirow[t]{2}{*}{$4.6 \times 10^{7}$} & 1.5 & 1.8 & 1.8 & 5.8 & 1.6 & 2.6 \\
\hline & 1.5 & 1.8 & 2.2 & 5.8 & 1.6 & \\
\hline \multicolumn{7}{|c|}{ Methionine synthase, MetH, P9215_10151 } \\
\hline Cell/mL & FVAGSIGPTTK & AGLDSAIIAPNK & AFQDLSIQDFK & ISQFNFPR & VSDSNIQLSLLDAK & Average \\
\hline \multicolumn{7}{|c|}{0.32 per day } \\
\hline \multirow[t]{2}{*}{$4.6 \times 10^{7}$} & 0.7 & 1.2 & 0.3 & 0.8 & 0.9 & 0.8 \\
\hline & 0.7 & 1.2 & 0.2 & 0.8 & 1.0 & \\
\hline \multirow[t]{2}{*}{$9.7 \times 10^{7}$} & 0.7 & 1.1 & 0.2 & 0.8 & 0.9 & 0.8 \\
\hline & 0.7 & 1.3 & 0.2 & 0.7 & 1.0 & \\
\hline \multirow[t]{2}{*}{$1.3 \times 10^{8}$} & 1.1 & 1.9 & 0.5 & 1.2 & 1.7 & 1.3 \\
\hline & 1.0 & 2.0 & 0.4 & 1.2 & 1.6 & \\
\hline \multicolumn{7}{|c|}{0.20 per day } \\
\hline \multirow[t]{2}{*}{$5.7 \times 10^{7}$} & 0.6 & 1.0 & 0.2 & 0.7 & 0.7 & 0.6 \\
\hline & 0.5 & 1.0 & 0.2 & 0.7 & 0.7 & \\
\hline \multirow[t]{2}{*}{$6.9 \times 10^{7}$} & 0.7 & 1.2 & 0.3 & 0.8 & 0.9 & 0.8 \\
\hline & 0.8 & 1.3 & 0.3 & 0.9 & 1.0 & \\
\hline \multirow{2}{*}{$4.6 \times 10^{7}$} & 0.5 & 0.9 & 0.2 & 0.6 & 0.8 & 0.6 \\
\hline & 0.6 & 0.9 & 0.3 & 0.7 & 0.7 & \\
\hline
\end{tabular}


Table 2. Prochlorococcus MIT9215 cell quotas under cobalt and iron limitation from pooled, small-volume cultures. For cobalt limitation experiments, $n=9$; for iron limitation experiments, $\mathrm{n}=6$. Duplicate measurements by ICPMS are shown here. Averages for these data are plotted in Figures 5 and 6.

\begin{tabular}{|c|c|c|c|c|c|c|c|c|}
\hline $\begin{array}{c}\mu \\
\left(\text { day }^{-1}\right)\end{array}$ & $\begin{array}{l}\mathrm{Co}^{\prime} \\
\mathrm{pM}^{*}\end{array}$ & $\begin{array}{c}\mathrm{Fe}^{\prime} \\
\mathrm{pM}^{* *}\end{array}$ & $\begin{array}{l}\text { Cells } \\
\mathrm{mL}^{-1} \\
\end{array}$ & $\begin{array}{c}\mathrm{Q}_{\mathrm{P}} \\
\text { atoms cell }^{-1}\end{array}$ & $\begin{array}{c}\mathrm{Q}_{\mathrm{Co}}, \\
\text { atoms cell }^{-1}\end{array}$ & $\begin{array}{c}\mathrm{Q}_{\mathrm{Fe}}, \\
\text { atoms cell }^{-1}\end{array}$ & $\begin{array}{c}\text { Co:P } \\
\text { mol:mol }\end{array}$ & $\begin{array}{c}\mathrm{Fe}: \mathrm{P} \\
\text { mol:mol }\end{array}$ \\
\hline \multicolumn{9}{|c|}{ Cobalt Limitation } \\
\hline \multirow[t]{2}{*}{$0.55 \pm 0.04$} & 15.5 & 29.9 & $5.0 \mathrm{E}+07$ & $1.1 \mathrm{E}+07$ & 797 & $5.27 \mathrm{E}+04$ & $7.1 \mathrm{E}-05$ & 4.7E-03 \\
\hline & & & & $1.0 \mathrm{E}+07$ & 763 & $5.00 \mathrm{E}+04$ & 7.3E-05 & 4.8E-03 \\
\hline \multirow{2}{*}{$0.55 \pm 0.04$} & 7.8 & 29.9 & $4.9 \mathrm{E}+07$ & $9.4 \mathrm{E}+06$ & 238 & $4.71 \mathrm{E}+04$ & $2.5 \mathrm{E}-05$ & $5.0 \mathrm{E}-03$ \\
\hline & & & & $9.1 \mathrm{E}+06$ & 235 & $4.53 \mathrm{E}+04$ & $2.6 \mathrm{E}-05$ & $5.0 \mathrm{E}-03$ \\
\hline \multirow[t]{2}{*}{$0.43 \pm 0.05$} & 1.6 & 29.9 & $5.3 \mathrm{E}+07$ & $1.0 \mathrm{E}+07$ & 71 & $5.34 \mathrm{E}+04$ & $6.7 \mathrm{E}-06$ & $5.1 \mathrm{E}-03$ \\
\hline & & & & $1.1 \mathrm{E}+07$ & 74 & $5.62 \mathrm{E}+04$ & $6.7 \mathrm{E}-06$ & 5.1E-03 \\
\hline \multirow[t]{2}{*}{$0.33 \pm 0.02$} & 0.94 & 29.9 & $3.7 \mathrm{E}+07$ & $1.3 \mathrm{E}+07$ & 54 & $7.97 \mathrm{E}+04$ & 4.2E-06 & 6.3E-03 \\
\hline & & & & $1.2 \mathrm{E}+07$ & 54 & $8.01 \mathrm{E}+04$ & $4.4 \mathrm{E}-06$ & $6.5 \mathrm{E}-03$ \\
\hline \multirow{2}{*}{$0.09 \pm 0.01$} & 0.48 & 29.9 & $3.1 \mathrm{E}+06$ & $1.5 \mathrm{E}+07$ & 24 & $1.83 \mathrm{E}+05$ & $1.6 \mathrm{E}-06$ & $1.2 \mathrm{E}-02$ \\
\hline & & & & $1.3 \mathrm{E}+07$ & 18 & $1.82 \mathrm{E}+05$ & $1.4 \mathrm{E}-06$ & $1.4 \mathrm{E}-02$ \\
\hline \multicolumn{9}{|c|}{ Iron Limitation } \\
\hline \multirow[t]{2}{*}{$0.56 \pm 0.02$} & 7.8 & 23.5 & $5.0 \mathrm{E}+07$ & $9.7 \mathrm{E}+06$ & 347 & $3.85 \mathrm{E}+04$ & $3.6 \mathrm{E}-05$ & 4.0E-03 \\
\hline & & & & $9.6 \mathrm{E}+06$ & 335 & $3.81 \mathrm{E}+04$ & $3.5 \mathrm{E}-05$ & 4.0E-03 \\
\hline \multirow[t]{2}{*}{$0.53 \pm 0.02$} & 7.8 & 7.1 & $4.0 \mathrm{E}+07$ & $6.7 \mathrm{E}+06$ & 267 & $2.14 \mathrm{E}+04$ & $4.0 \mathrm{E}-05$ & $3.2 \mathrm{E}-03$ \\
\hline & & & & $6.7 \mathrm{E}+06$ & 262 & $2.12 \mathrm{E}+04$ & $3.9 \mathrm{E}-05$ & $3.2 \mathrm{E}-03$ \\
\hline \multirow[t]{2}{*}{$0.48 \pm 0.04$} & 7.8 & 2.4 & $3.3 \mathrm{E}+07$ & $5.9 \mathrm{E}+06$ & 241 & $1.25 \mathrm{E}+04$ & $4.1 \mathrm{E}-05$ & $2.1 \mathrm{E}-03$ \\
\hline & & & & $5.9 \mathrm{E}+06$ & 240 & $1.26 \mathrm{E}+04$ & $4.0 \mathrm{E}-05$ & 2.1E-03 \\
\hline \multirow[t]{2}{*}{$0.40 \pm 0.02$} & 7.8 & 0.71 & $3.0 \mathrm{E}+07$ & $6.6 \mathrm{E}+06$ & 282 & $5.47 \mathrm{E}+03$ & 4.2E-05 & 8.2E-04 \\
\hline & & & & $5.8 \mathrm{E}+06$ & 264 & $4.75 \mathrm{E}+03$ & 4.6E-05 & 8.2E-04 \\
\hline \multirow[t]{2}{*}{$0.23 \pm 0.05$} & 7.8 & 0.24 & $6.6 \mathrm{E}+06$ & $6.1 \mathrm{E}+06$ & 269 & $1.08 \mathrm{E}+04$ & $4.4 \mathrm{E}-05$ & $1.8 \mathrm{E}-03$ \\
\hline & & & & $5.6 \mathrm{E}+06$ & 281 & $9.71 \mathrm{E}+03$ & $5.0 \mathrm{E}-05$ & 1.7E-03 \\
\hline
\end{tabular}

$* \mathrm{Co} / \mathrm{Co}=10^{-2.82} * * \mathrm{Fe} ' / \mathrm{Fe}=10^{-2.63}$ 
Table 3. Cobalt protein mass balance in cobalt-limited Prochlorococcus, based on targeted mass spectrometry of peptides and ICPMS determinations of the cellular cobalt quotas. Mean values (and ranges) for peptides in Table 1 are shown.

\begin{tabular}{|c|c|c|c|c|c|c|}
\hline$\mu$ (per day) & \multicolumn{3}{|c|}{0.20} & \multicolumn{3}{|c|}{0.32} \\
\hline Cells/mL & $5.7 \times 10^{7}$ & $6.9 \times 10^{7}$ & $1.0 \times 10^{8}$ & $4.6 \times 10^{7}$ & $9.7 \times 10^{7}$ & $1.3 \times 10^{8}$ \\
\hline NrdJ, copies/cell & $\begin{array}{c}19 \\
(13-41)\end{array}$ & $\begin{array}{c}27 \\
(15-63)\end{array}$ & $\begin{array}{c}21 \\
(13-49)\end{array}$ & $\begin{array}{c}13 \\
(8-26)\end{array}$ & $\begin{array}{c}11 \\
(7-21)\end{array}$ & $\begin{array}{c}19 \\
(12-41)\end{array}$ \\
\hline MetH, copies/cell & $\begin{array}{c}5 \\
(2-8)\end{array}$ & $\begin{array}{c}7 \\
(3-11)\end{array}$ & $\begin{array}{c}5 \\
(2-8)\end{array}$ & $\begin{array}{c}6 \\
(2-8)\end{array}$ & $\begin{array}{c}4 \\
(1-7)\end{array}$ & $\begin{array}{c}9 \\
(3-14)\end{array}$ \\
\hline Sum & $\begin{array}{c}24 \\
(14-49)\end{array}$ & $\begin{array}{c}34 \\
(17-74)\end{array}$ & $\begin{array}{c}26 \\
(15-56)\end{array}$ & $\begin{array}{c}19 \\
(10-34)\end{array}$ & $\begin{array}{c}15 \\
(8-28)\end{array}$ & $\begin{array}{c}28 \\
(15-55)\end{array}$ \\
\hline Co, atoms/cell & 70 & 65 & 62 & 98 & 86 & 72 \\
\hline$\%$ Co in use & $\begin{array}{c}35 \\
(20-70)\end{array}$ & $\begin{array}{c}53 \\
(27-114)\end{array}$ & $\begin{array}{c}43 \\
(24-91)\end{array}$ & $\begin{array}{c}19 \\
(10-35)\end{array}$ & $\begin{array}{c}17 \\
(10-32)\end{array}$ & $\begin{array}{c}39 \\
(21-77)\end{array}$ \\
\hline
\end{tabular}




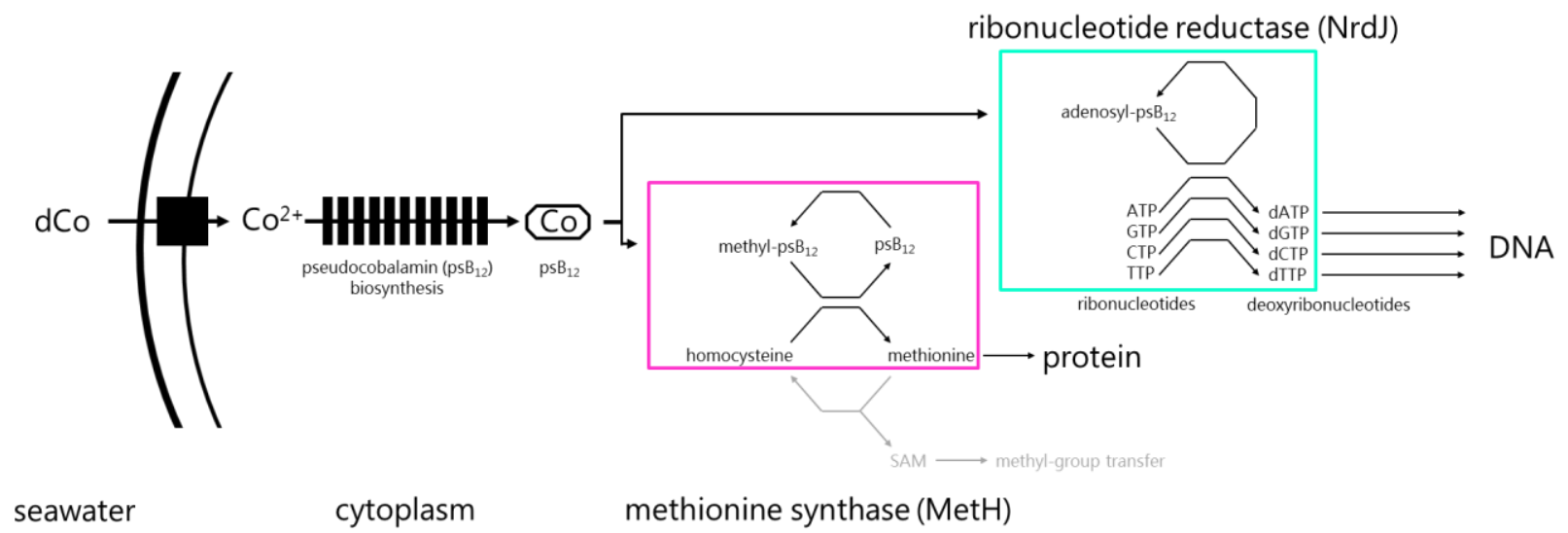

Figure 1. Cobalt acquired by Prochlorococcus must be synthesized into pseudocobalamin $\left(\mathrm{psB}_{12}\right)$ before use in metabolism. Prochlorococcus genomes contain sequences for methionine synthase (MetH), which generates methionine from homocysteine via a methyl-pseudocobalamin cofactor. Methionine is used for protein synthesis or is consumed to make S-adenosyl methionine, an important cellular metabolite. Methyl-pseudocobalamin is regenerated during each catalytic cycle from methyl-tetrahydrofolate. Ribonucleotide reductase (NrdJ) uses adenosyl-pseudocobalamin to convert ribonucleotides into deoxyribonucleotides that are needed for DNA synthesis. The minimal cobalt quota of Prochlorococcus probably contains contributions from both enzymes, as well as $\mathrm{Co}^{2+}$ ions that have not yet undergone transformation into pseudocobalamin, as well as $\mathrm{psB}_{12}$ biosynthetic intermediates. 

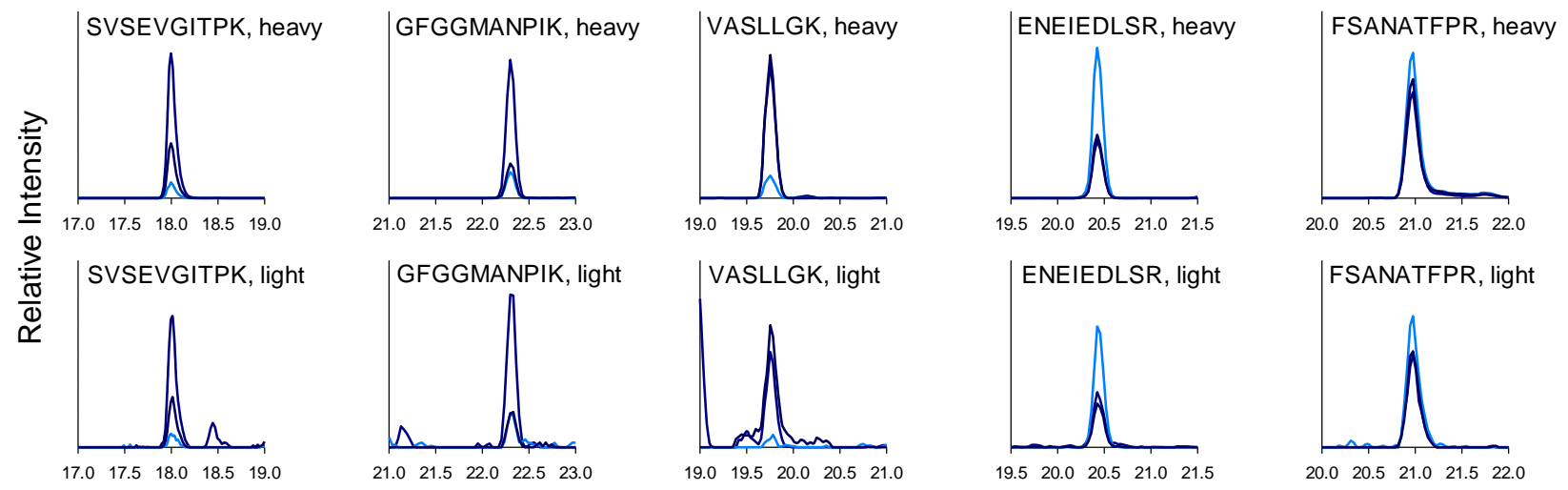

Retention Time (min)

Figure 2. Chromatograms of secondary ion mass spectra for peptides used to quantify Prochlorococcus ribonucleotide reductase (NrdJ). Different secondary ions for each peptide are represented as a different shade of blue, which corresponds to the same fragment in both heavy and light peptides. Light peptides are those present in actual Prochlorococcus biomass. Heavy peptides represent isotopically labeled standards. In all cases, light and heavy peptides co-elute with the same relative abundance of secondary ions. Note that the scale of the y-axis is unique to each plot. 

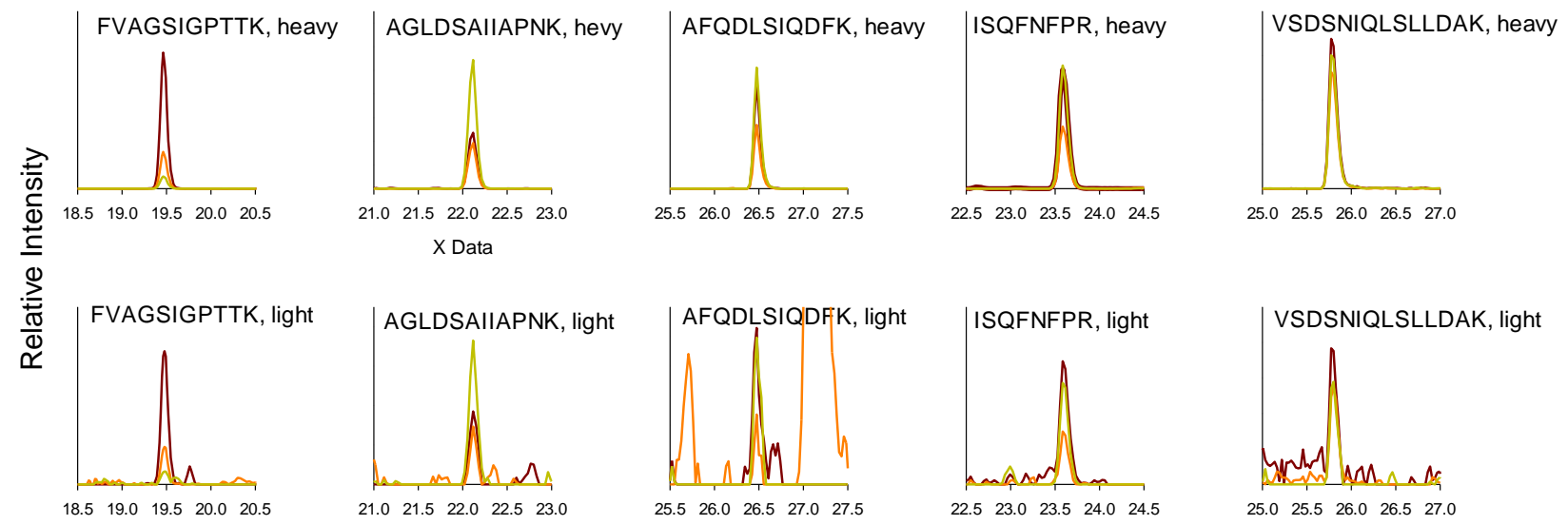

Retention Time (min)

Figure 3. Chromatograms of secondary ion mass spectra for peptides used to quantify Prochlorococcus methionine synthase (MetH). Different secondary ions for each peptide are represented as a different shade of orange and correspond for light and heavy peptides. Light peptides are those present in actual Prochlorococcus biomass. Heavy peptides represent isotopically labeled standards cloned by from a synthetic plasmid by $E$. coli in ${ }^{15} \mathrm{~N}$ labeled media. In all cases, light and heavy peptides co-elute and share the same relative abundance of secondary ions. 

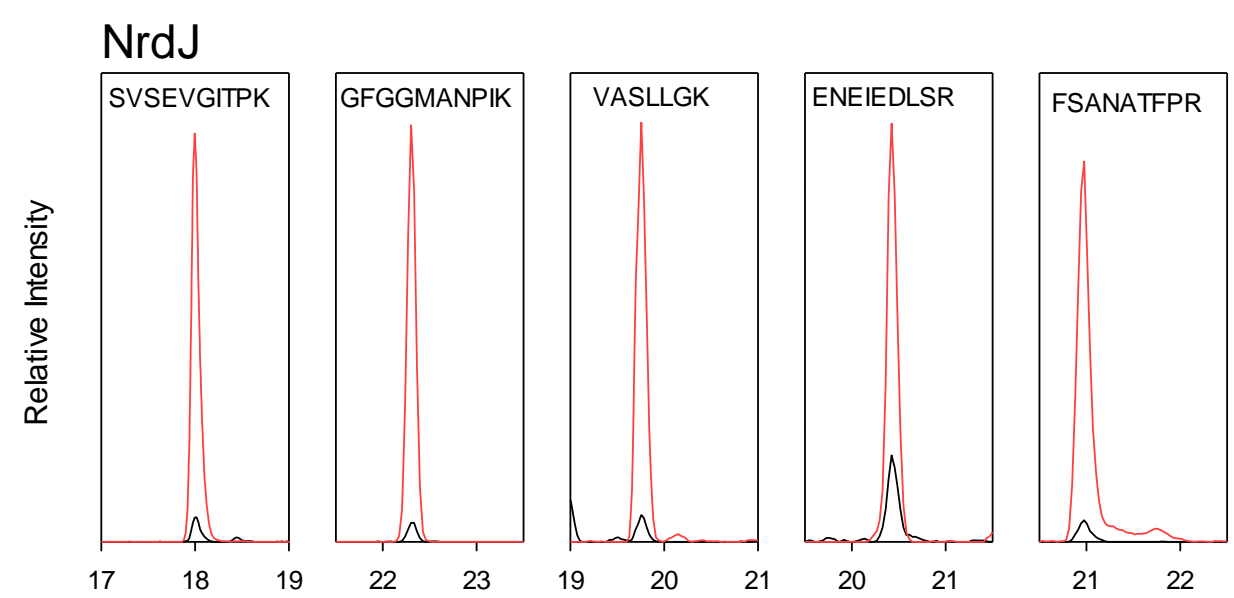

Retention time (minutes)

$$
\text { Sample (light) }
$$

Standard (heaw)
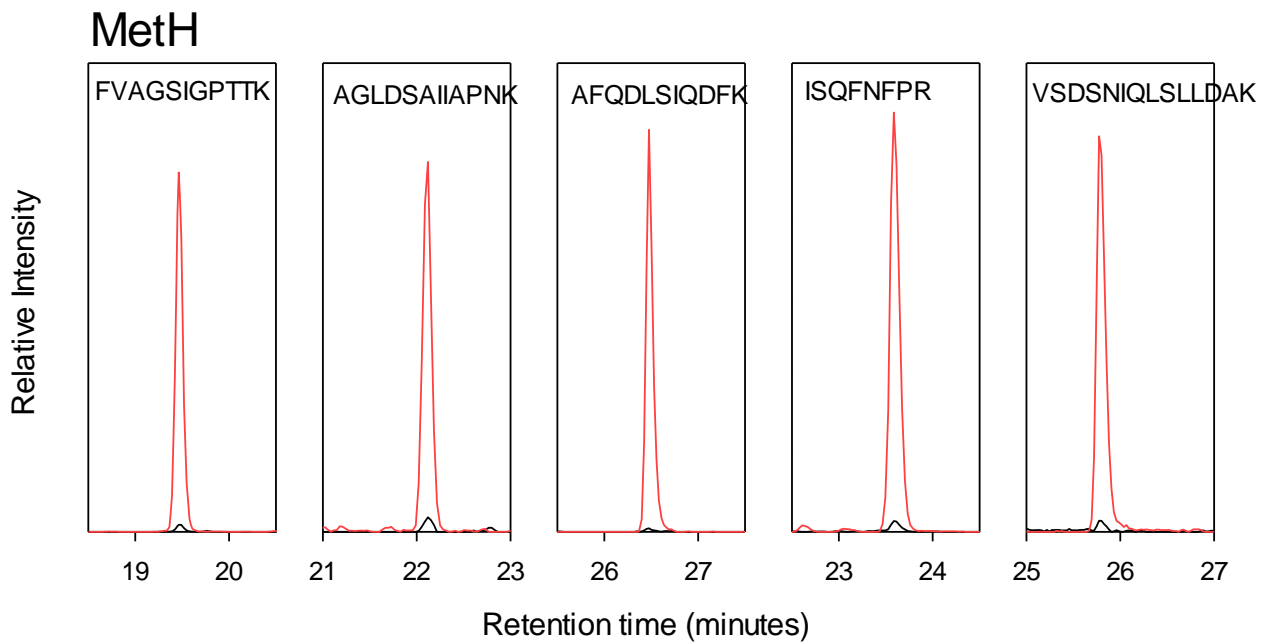

Retention time (minutes)

Figure 4. Chromatograms of secondary ion mass spectra for peptides used to quantify both NrdJ and MetH. Isotopically labeled standards (heavy ions) are shown in red while light peptides reflect the peptide concentration in Prochlorococcus protein digests, black lines. For the data shown, 33 fmol of standard was injected. 

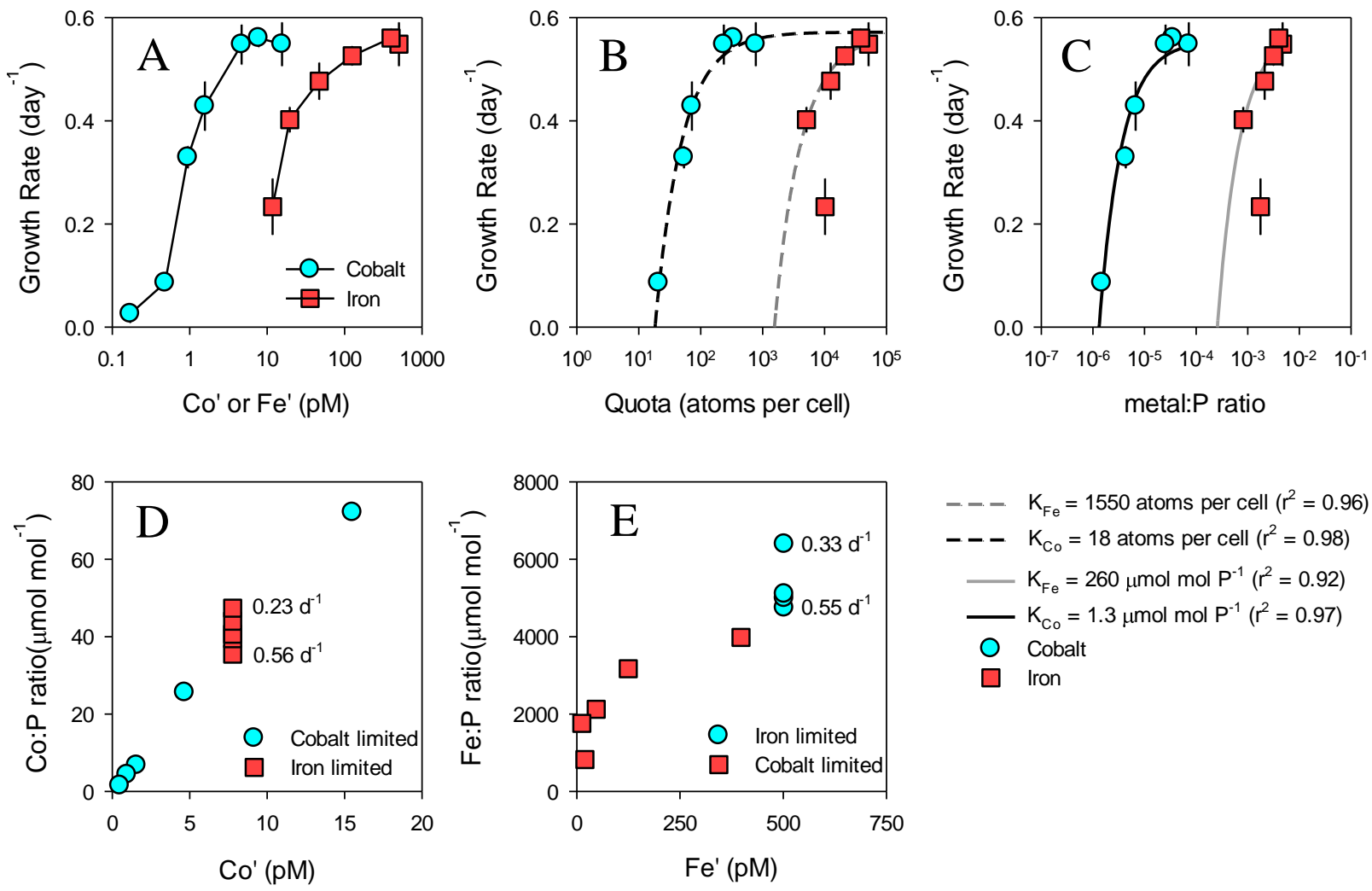

Figure 5. A) Cobalt and iron quotas under growth limitation in Prochlorococcus MIT9215. Growth rates declined at Co' $<5$ pM and Fe' $<100$ pM. Per cell (B) and phosphate (C) normalized Co (cyan circles) and Fe quotas (red squares) conform to predictions based on the Droop equation (Eq. 1). Best fit results for Eq. 1 for cobalt and iron are plotted in black and grey, respectively. Fits for iron quotas exclude the anomalously high iron quota at $\mu=0.23$ per day. Cellular Co:P increased linearly with Co' $\left(D, R^{2}=0.996\right)$ in cobalt limitation experiments (cyan circles) and also increased with decreasing growth rate during iron limitation experiments (red squares). Cellular Fe:P ratios appear to saturate at high Fe during iron limitation experiments (E, red squares), but further increased during cobalt limitation experiments (cyan circles). 

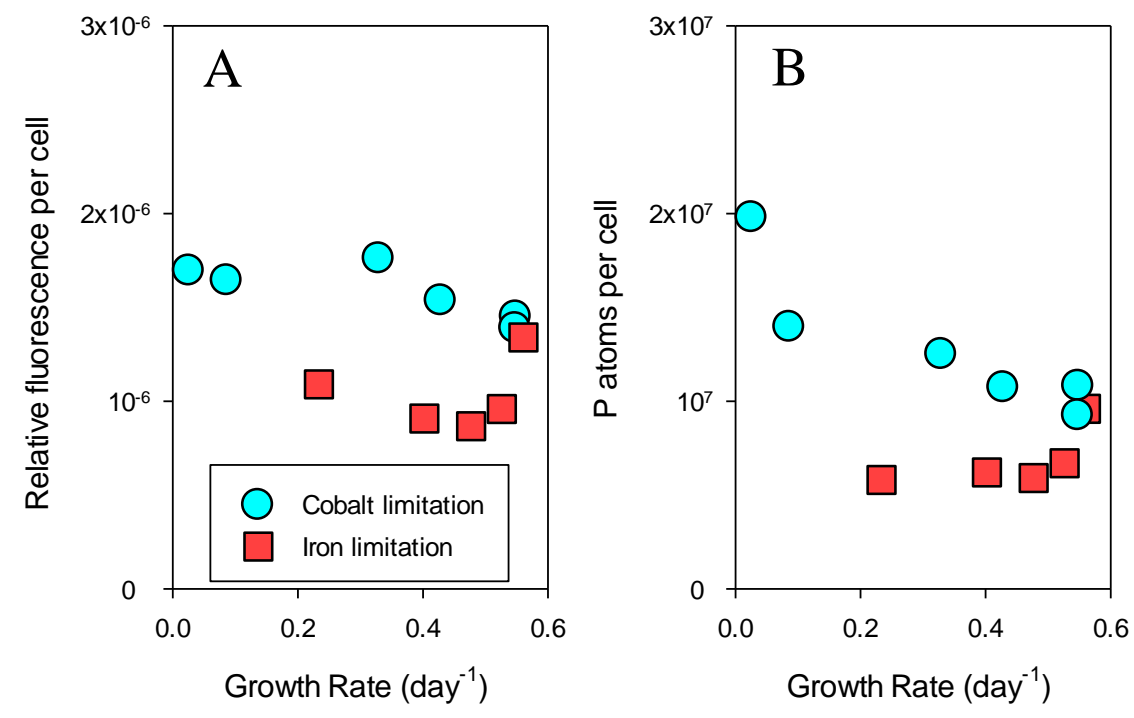

Figure 6. Cell size trends in iron and cobalt limited Prochlorococcus MIT9215. Relative chlorophyll fluorescence per cell (A) and $\mathrm{P}$ atoms per cell (B) increase during cobalt limitation and decrease during iron limitation. These results are consistent with a decrease in cell size during iron limitation and increasing cell size during cobalt limitation. 
A

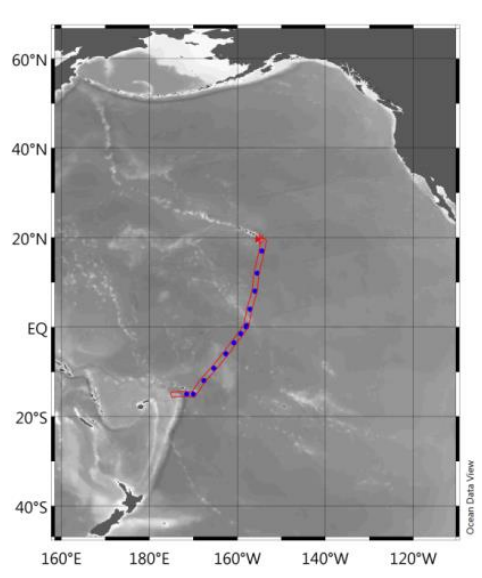

$\mathrm{B}$

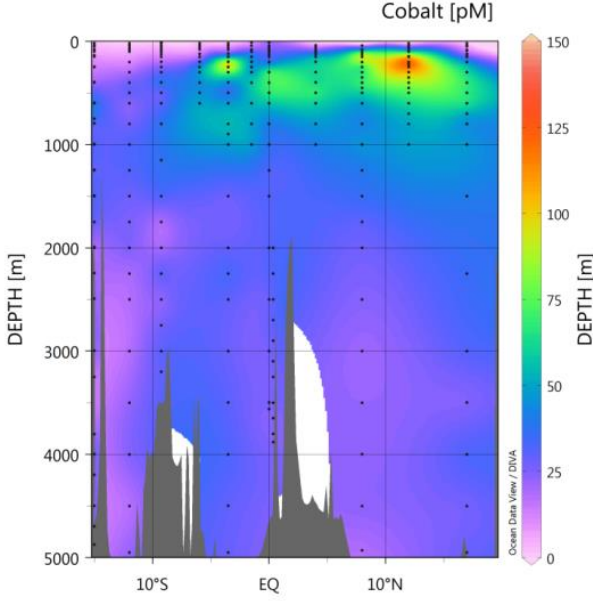

$\mathrm{C}$

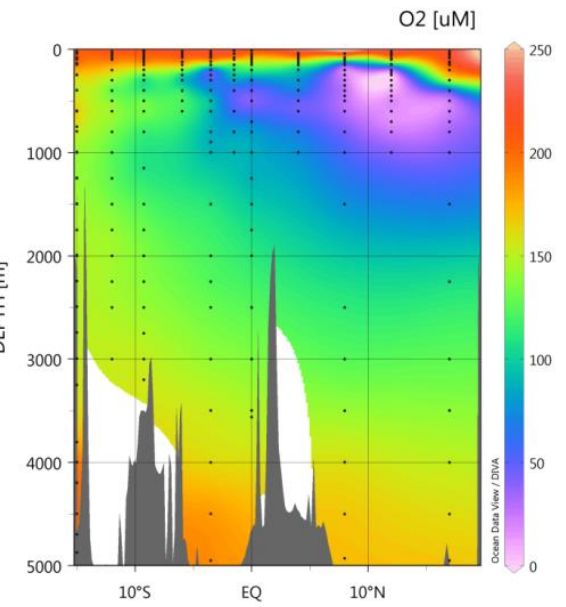

Figure 7. The Metzyme transect in the Equatorial Pacific (A). Ocean sections of dissolved cobalt (B) and oxygen (C) in the Equatorial Pacific Ocean. High concentrations of cobalt are found in oxygen minimum zones north and south of the Equator. Dissolved cobalt in oxygenated abyssal waters and oxygenated surface waters is low. 


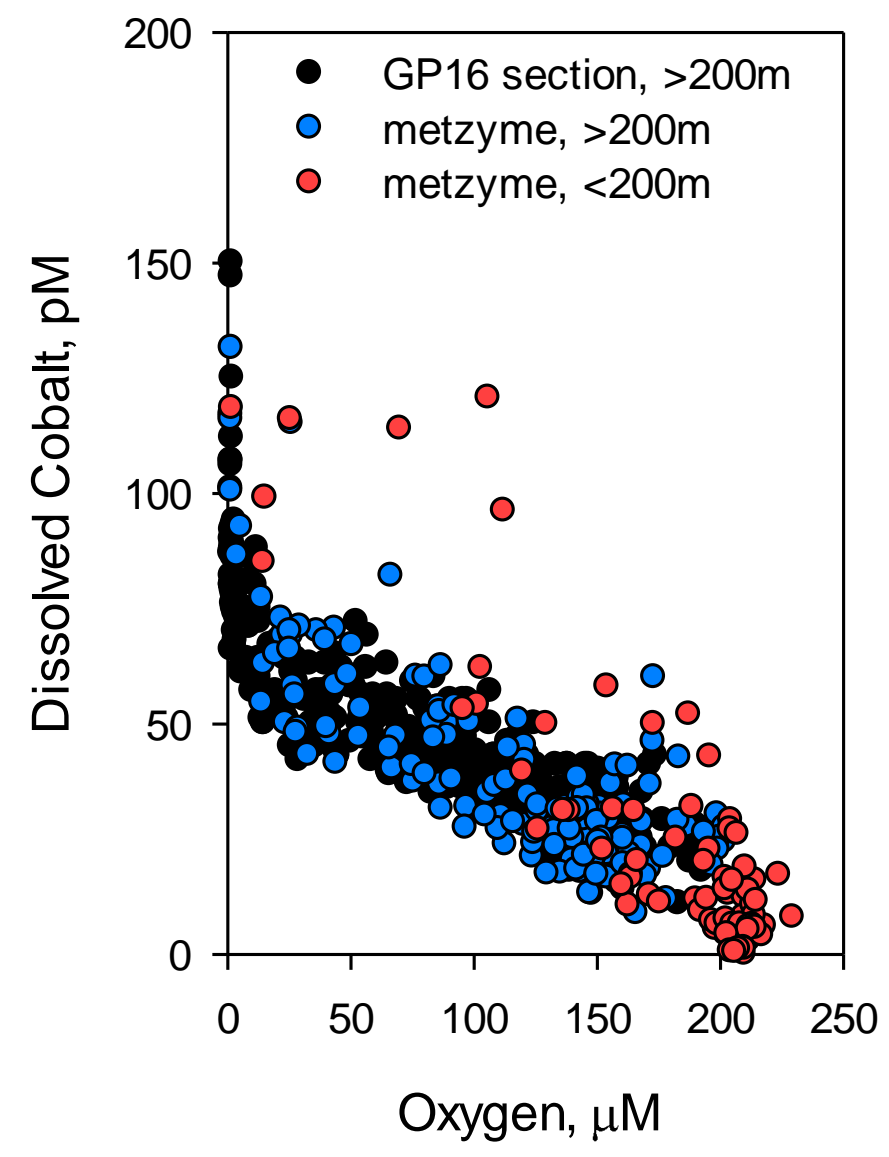

Figure 8. Dissolved cobalt and oxygen correlation in the tropical Pacific Ocean. For samples below $200 \mathrm{~m}$ on the Metzyme transect (blue circles), dissolved cobalt increases as oxygen decreases due to biogenic cobalt remineralization. A nearly identical relationship was observed on the GP16 section in the eastern South Pacific Ocean over the same depth range (black circles). Samples from the upper ocean ( $<200 \mathrm{~m}$, red circles) plot above the trend from deeper waters, as was observed for samples on the GP16 transect over a similar depth range (not shown). 

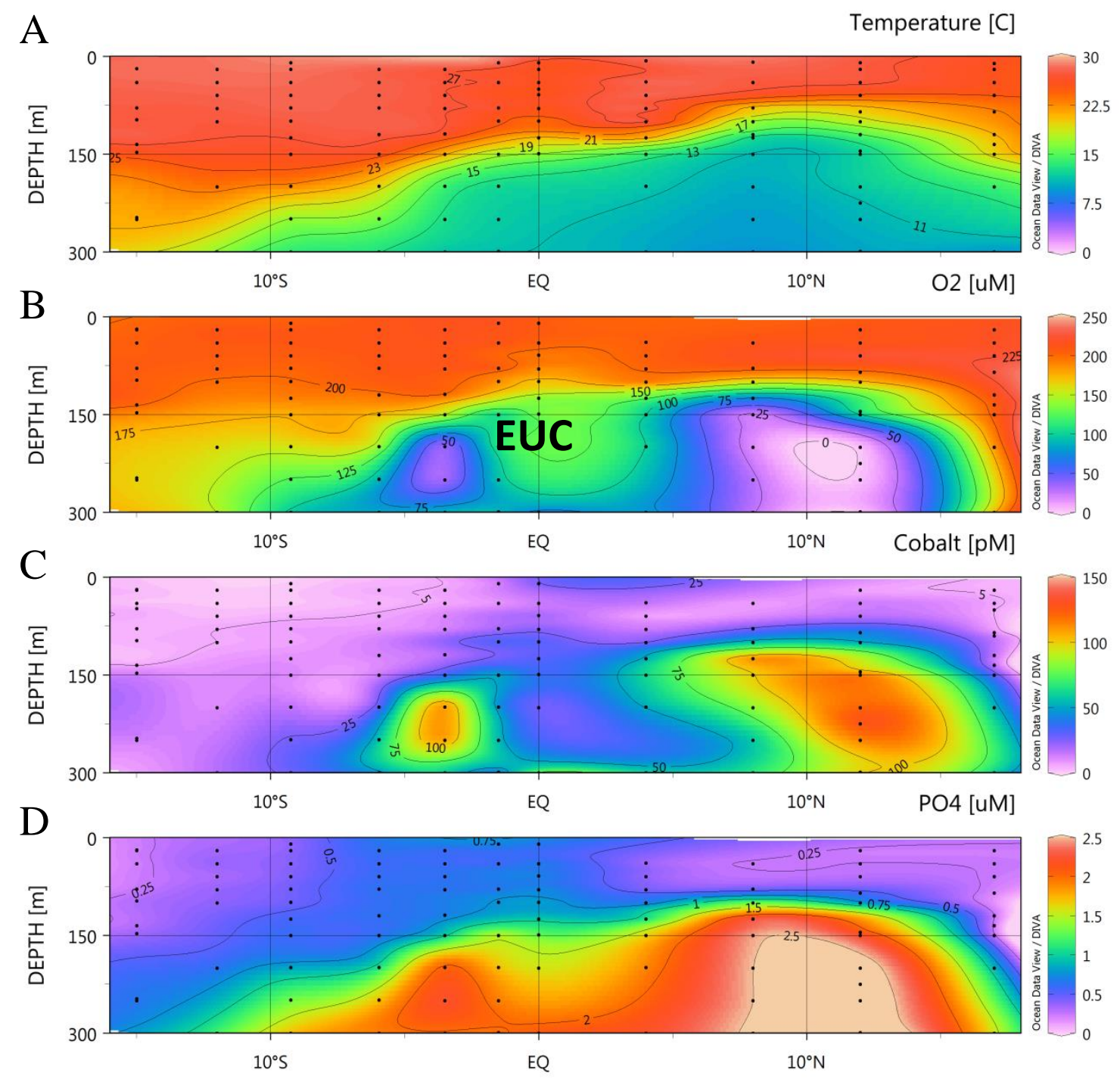

Figure 9. Equatorial upwelling and nutrient delivery to the surface of the central Pacific. Cooler surface temperatures and upward bowing of the $23{ }^{\circ} \mathrm{C}$ thermostad on the equator indicate active upwelling from the equatorial undercurrent (EUC) (A). Upwelling draws largely from oxygenated waters (B), which are poor in cobalt (C) and relatively phosphate rich (D). 

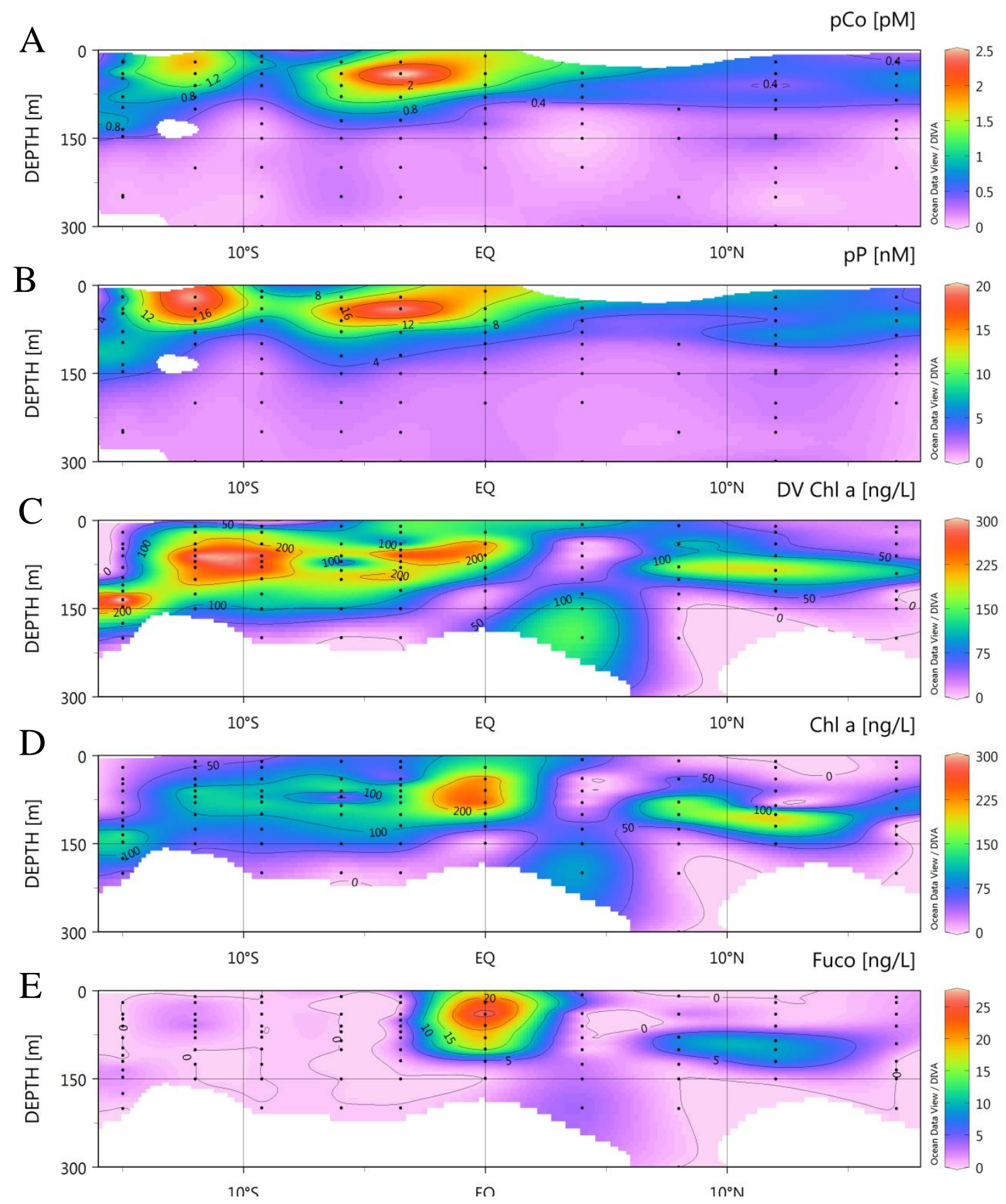

Figure 10. Phytoplankton pigment and elemental composition in the Equatorial Pacific. Particulate cobalt (pCo, panel A) and particulate phosphorus ( $\mathrm{pP}$, panel B) show similar distributions with maximum concentrations in the South Pacific. This is similar to the distribution of divinyl chlorophyll A, a pigment unique to Prochlorococcus (panel C) but not monovinyl chlorophyll A (panel D), or fucoxanthin (pale E), which are strongly influenced by eukaryotic phytoplankton. 


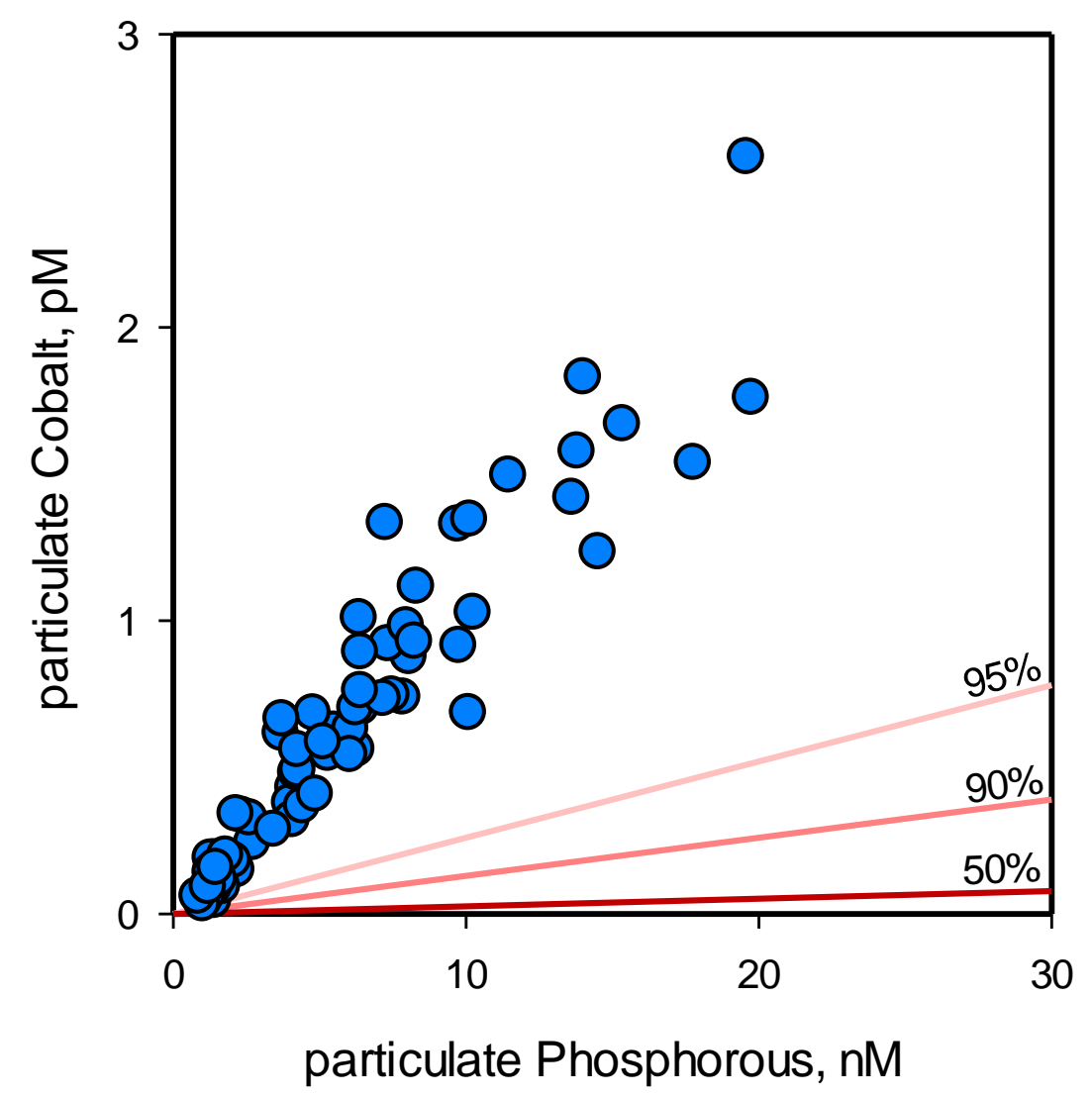

Cobalt-limited Prochlorococcus $\mu / \mu_{\max }$ Equatorial Pacific, $0-200 \mathrm{~m}$

Figure 11. Coupling of particulate phosphorus and particulate cobalt distributions in the upper $200 \mathrm{~m}$ of the equatorial Pacific (blue dots) indicates cobalt in particles is present in biomass. Predicted Co:P relationships under various degrees of cobalt limitation in Prochlorococcus MIT9215 (as a percentage of $\mu_{\max }$, red lines) are plotted as red lines. 


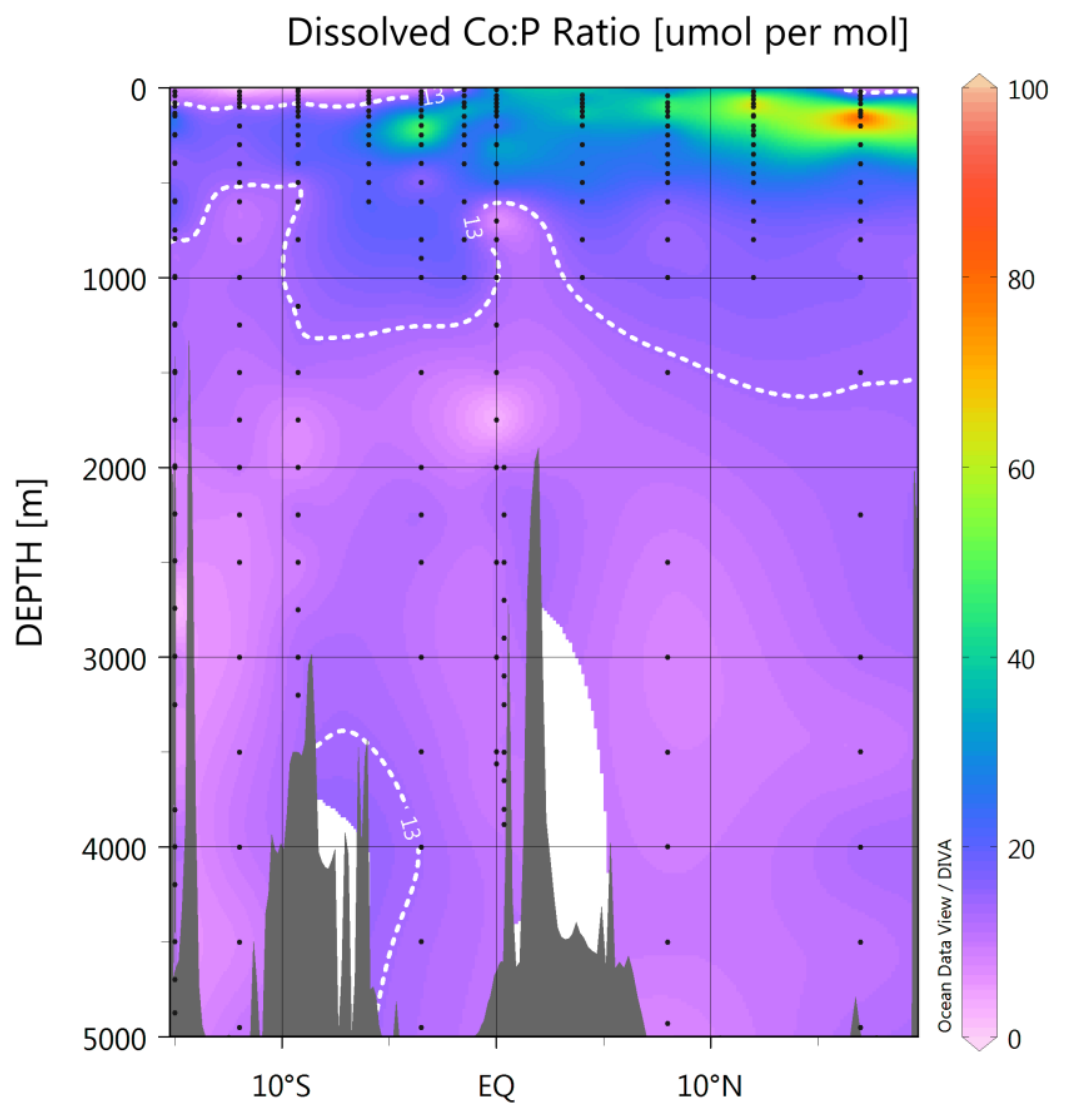

Figure 12. Seawater dissolved cobalt to phosphorous $(\mathrm{Co}: \mathrm{P})$ ratio in the equatorial pacific. The contour at $13 \mu \mathrm{mol}$ per mol (dotted white line) reflects the solution to Eq. 1 at $90 \% \mu_{\max }$. Two regions with $\mathrm{dCo}: \mathrm{PO} 4$ stoichiometry below this ratio are Pacific deep waters and surface waters in the South Pacific gyre. 


\title{
Chapter 5.
}

\section{Competitive inhibition of cobalt uptake by zinc and manganese in Prochlorococcus MIT9215.}

\begin{abstract}
In order to satisfy pseudocobalamin requirements for growth, marine cyanobacteria such as Prochlorococcus must acquire cobalt metal from seawater and synthesize pseudocobalamin de novo. A series of experiments with Prochlorococcus strain MIT9215 under cobalt limiting conditions were used to investigate the vulnerabilities of Prochlorococcus' cobalt metabolism to interference by other metals. When limited by cobalt, Prochlorococcus growth decreased in the presence of $\mathrm{Mn}$ and $\mathrm{Zn}$, which appeared to compete with cobalt for the same transporter. This effect was not observed under a wide range of $\mathrm{Fe}, \mathrm{Cu}$ and $\mathrm{Ni}$ concentrations. The strong inhibition between cobalt and zinc in Prochlorococcus contrasts with the observation of cobaltzinc substitution in eukaryotic phytoplankton and suggests that the ecological success of Prochlorococcus observed in the modern ocean is limited to waters with either very low $\mathrm{Zn}$ or high cobalt.
\end{abstract}

\section{Introduction}

Cyanobacteria evolved in an ancient anoxic ocean with a trace metal portfolio distinct from modern seawater (Anbar and Knoll, 2002). Metals prone to oxidative scavenging like Co, $\mathrm{Mn}$ and Fe were probably present in greater abundance in an ocean buffered by iron and sulfide instead of dioxygen, an environment that resembles the redox conditions of cytoplasm (Patterson et al., 2013b; Saito et al., 2003; Waldron and Robinson, 2009). In contrast, elements with strong affinities toward sulfide - copper, zinc, and cadmium - were probably scavenged from seawater more effectively than today (Anbar and Knoll, 2002; Saito et al., 2003). It has been suggested previously that metal requirements of modern cyanobacteria reflect these ancient conditions when these organisms first evolved, and that these organisms are more susceptible to toxicity from chalcophilic elements $(\mathrm{Cu}, \mathrm{Zn}, \mathrm{Cd})$ that were scarce during the Proterozoic (Dupont et al., 
2006, 2010; Saito et al., 2003). According to this hypothesis, the heavy use of zinc and copper in eukaryotic cells results from their emergence in an oxygenated ocean with higher concentrations of these metals (Dupont et al., 2010; Da Silva and Williams, 2001).

The increased availability of $\mathrm{Cu}$ and $\mathrm{Zn}$ presents a challenge for organisms like cyanobacteria, whose metal requirements were set prior to oxygenation. The smaller atomic radii and greater crystal field stabilization energy for copper, zinc and nickel cause these metals to form stronger complexes to organic ligands than other divalent cations (Irving and Williams, 1953; Waldron and Robinson, 2009). This phenomenon is often described as the Irving-Williams series $(\mathrm{Mn}<\mathrm{Fe}<\mathrm{Co}<\mathrm{Ni}<\mathrm{Cu}>\mathrm{Zn}$ ) and applies to a wide array of biogenic compounds including amino acids and proteins (Irving and Williams, 1953). At equal concentrations of $\mathrm{Cu}$ and $\mathrm{Mn}$, for instance, it is virtually impossible to supply a manganese-requiring enzyme (like the oxygen-evolving complex of photosystem II) with manganese because copper will outcompete Mn for binding (Tottey et al., 2008). In response to this dilemma, a wide variety of organisms have been observed to sequester $\mathrm{Cu}, \mathrm{Zn}$, and $\mathrm{Ni}$ in protein chaperones so that their free ion concentrations in the cell are essentially negligible ( $<1$ atom per cell) (Outten and O'Halloran, 2001; Patterson et al., 2013b; Rae et al., 1999; Tottey et al., 2012). Production of a cytosolic Cubinding protein by the cyanobacterium Synechocystis 6803, for instance, decreases $\mathrm{Cu}$ ' availability and enables Mn proteins to be properly metallated (Tottey et al., 2008). A second, connected strategy is simply to export toxic metals out of the cell by expressing periplasmic metal pumps (Badarau and Dennison, 2011; Huertas et al., 2014). Export systems for $\mathrm{Cu}, \mathrm{Zn}, \mathrm{Ni}$, and Co have all been identified in cyanobacteria (Huertas et al., 2014). These mechanisms combine such that free metal concentrations in cyanobacteria (Synechocystis) are the reverse of the Irving Williams series: $\mathrm{Cu}^{\prime}<<\mathrm{Ni}^{\prime}<\mathrm{Zn}^{\prime}<\mathrm{Co}^{\prime}$,Fe', and Mn' (Patterson et al., 2013b; Waldron and Robinson, 2009).

These adaptions are not universal among cyanobacteria. The unicellular cyanobacterium Prochlorococcus lacks homologous genes to most metal chaperones and export pumps that have been characterized in model cyanobacteria like Synechocystis (Table 1)(Huertas et al., 2014). The absence of the cyanobacterial copper chaperone Atxl and export system, $\operatorname{Cop} A B C$, as well as the Zn export pump ZiaA in Prochlorococcus genomes (Table 1) requires a drastically different approach to metal metabolism than found in related, better-studied cyanobacteria (Patterson et al., 2013b; Tottey et al., 2012). Adaptation of Prochlorococcus to oligotrophic environments 
(where many metals are scarce) has rendered some of these mechanisms unnecessary or too complex given their streamlined, minimal genome.

While the ecological success of Prochlorococcus in the modern ocean testifies to the biochemical competence of its metal metabolism, atypical oceanic conditions may make it challenging to deliver metals to their designated metalloproteins. Intracellular metal competition may underlie the sensitivity of Prochlorococcus to copper toxicity at high seawater Cu', which can increase significantly during periods of intense atmospheric deposition (Mann et al., 2002). These conflicts are perhaps most serious for cobalt, the scarcest of all inorganic nutrients in seawater and in the center of the Irving-Williams series (Saito and Moffett, 2001). Still, cobalt must be selected from a pool of other, more abundant and more competitive metals by cobaltochelatase, the first in a long series of steps in the biosynthesis of pseudocobalamin, which is needed to activate ribonucleotide reductase and methionine synthase enzymes (Debussche et al., 1992; Zhang et al., 2009). Cobaltochelatase catalyzes cobalt insertion into the corrin ring of cobalamins but cobalt binding by this enzyme is vulnerable to competitive inhibition by other metals. The in vitro affinity of this enzyme in Pseudomonas denitrificans for cobalt $\left(\mathrm{K}_{\mathrm{b}}=4.2\right.$ $\mu \mathrm{M})$ is almost ten times weaker than the enzyme's affinity for $\mathrm{Zn}\left(\mathrm{K}_{\mathrm{b}}=0.5 \mu \mathrm{M}\right)$ (Debussche et al., 1992). Competition between cobalt-binding proteins with other metals may underlie observations of cobalt co-limitation of cyanobacteria in the Costa Rica Upwelling Dome, and perhaps elsewhere (Moore et al., 2013; Saito et al., 2005).

Here, we investigate the cobalt-limited metabolism in Prochlorococcus strain MIT9215 and the sensitivity of this organism to competitive inhibition of cobalt uptake by other metals, notably zinc. Comparing metal uptake rates under different conditions enables a glimpse into cyanobacterial metal regulation and suggests a need for adaptive mechanisms in Prochlorococcus to survive in an ocean where cobalt is scarce.

\section{Methods}

\subsection{Culturing}

Cultures of MIT9215 were obtained from the Chisholm lab at MIT and grown at $27^{\circ} \mathrm{C}$ in a custom incubator under a 14:10 light:dark cycle. Light intensity was progressively increased during morning hours, reaching a peak light intensity of $\sim 75 \mu \mathrm{mol}$ photon $\mathrm{m}^{-2} \mathrm{~s}^{-1}$, and decreased continuously over the afternoon. All sampling was conducted within a 3 hour window 
overlapping with peak irradiance. Growth was monitored primarily by chlorophyll fluorescence on a TD700 fluorometer, calibrated prior to measurement with a solid standard. All cultures were grown in round-bottom $28 \mathrm{~mL}$ polycarbonate bottles (Nalgene) that are compatible with a TD700 fluorometer, which enabled measurements to be taken without exposing cultures to contaminating metals. Growth rates were calculated as the slope of the natural logarithm of the increase in chlorophyll fluorescence over a 4-measurement (usually 4 day) period. Maximum values for each experiment are reported and are linear except at very low growth rates $(<0.1$ per day).

Culturing experiments were performed in two sequences. The first, Experiment Group 1, used a seawater base that had relatively low background concentrations of zinc (see below). Experiment Group 2 used a seawater base that had higher concentrations of background zinc that affected culturing outcomes and were investigated in detail. For all experiments, cells were inoculated at $1 \%$ media volume or lower from cultures in mid-late exponential phase. Initial experiments - Experiment Group 1 - were conducted with non-axenic cultures. The presence of heterotrophs has been shown to be beneficial to Prochlorococcus MIT9215 because they help to scavenge reactive oxygen species from the seawater (Morris et al., 2008). Later experiments Experiment Group 2 - were conducted with recently generated axenic strains, provided by the Chisholm lab at MIT. Purity of these cultures was occasionally tested by inoculating log-phase cultures into sterile seawater enriched with yeast extract and peptone (Waterbury et al., 1986). Visual inspection of these assays showed no growth over several weeks.

Cell number was measured on a Guava Easycyte HT flow cytometer using Incyte 3.1 software. Cultures were serially diluted in filtered oligotrophic seawater and counted using a red fluorescence gate until 5000 events were recorded. This instrument was calibrated monthly with beads. Dilutions with cell concentrations in the range of 5-20 $10^{4}$ cells per $\mathrm{mL}$ were used to calculate original cell number. Nutrient replete cultures entered stationary phase as $\sim 2 \times 10^{8}$ cell/mL, consistent with reports for this strain by Morris and colleagues (Morris et al., 2008). For cobalt limitation and metal perturbation experiments, cells were preserved with 5\% paraformaldehyde and frozen at $-80^{\circ} \mathrm{C}$. For iron limitation experiments, cells were directly frozen at $-80^{\circ} \mathrm{C}$. Despite this difference in protocol, cellular P quotas at a maximum growth rate were the similar in the iron-limited $\left(0.56 \mathrm{day}^{-1}\right)$ and cobalt-limited series $\left(0.55 \mathrm{day}^{-1} ; \mathrm{P}\right.$ cell ${ }^{-1} 9.6$ and $10.8 \times 10^{6}$ atoms per cell, respectively). Ratios of in vivo chlorophyll fluorescence to cell 
number were also similar $(7.1$ and 6.6 cells/mL per relative fluorescence unit, for iron and cobalt, respectively), suggesting minimal cell loss.

All curve fitting was performed in Sigmaplot 12 using least squares regressions.

\subsection{Preparation of trace-metal clean media}

All media was prepared in a class-100 clean room and transferring of cultures was conducted in a laminar flow hood within the clean room. All bottles were thoroughly cleaned by first soaking 10 days in a $1 \%$ detergent solution (Citranox), rinsed with ultrapure $>18 \mathrm{M} \Omega$ water (Milli-Q, Millipore) and soaked in 10\% hydrochloric acid (J.T. Baker) for an additional 10 days. Culture tubes were rinsed thoroughly with $10 \mathrm{mM} \mathrm{HCl}$ and microwaved sterilized with $10 \mathrm{~mL}$ of ultrapure water. Before pipetting, sterile micropipette tips were rinsed three times with $10 \% \mathrm{HCl}$ and three times with microwave sterilized $10 \mathrm{mM} \mathrm{HCl}$ immediately before use. When cultures were transferred, pipette tips were also rinsed in microwave-sterilized, ultra-pure water to remove trace acid.

Cultures were grown in a modified ProTM media (Table S1) (Moore et al., 2007). The base of this media was oligotrophic seawater collected from the surface of the South Pacific Ocean using a trace metal clean Tow-fish system used for trace metal sampling on the GEOTRACES GP16 transect. Seawater was $0.22 \mu \mathrm{m}$ filtered and microwave-sterilized until boiling. Nutrient stocks were added to cooled, sterile seawater and allowed to equilibrate overnight before addition of Prochlorococcus cells. Ammonia and phosphate stocks were cleaned of contaminating metals using cleaned chelex beads (Price et al., 1989) and were added to final concentrations of 800 and $50 \mu \mathrm{M}$. EDTA was added to a concentration of $11.7 \mu \mathrm{M}$ in all experiments. The excess of EDTA buffers free ion concentrations of several metals. For most growth experiments, Mo, Se, Mn and Ni stocks were added to a 1000x (11.7 mM) EDTA solution stock and added to media as a single stock. For Mn and Ni manipulation experiments, a second, 1000x trace metal-EDTA stock was made containing only Mo and Se.

To limit contamination, we decreased Fe in the media 100-fold (11.7 nM) from concentrations previously used in ProTM media (Moore et al., 2007), which is still an order of magnitude larger than iron-limiting concentrations for this strain. This was necessary because even high purity metal reagents (e.g. 99\%, ACS grade iron chloride hexahydrate (Fischer)), contributed $\sim 500 \mathrm{pM}$ Co and $\sim 1 \mathrm{nM}$ Zn when iron was added to the $1.17 \mu \mathrm{M}$ concentration 
prescribed by ProTM media. The Co and $\mathrm{Zn}$ concentrations were enough to interfere in preliminary experiments. All experiments reported here use an iron concentration of $11.7 \mathrm{nM}$ or lower (Fe-limitation experiments).

Free ion concentrations of nickel, manganese, iron, and copper were calculated as the sum of inorganic metal complexes computed with Visual Minteq at $27^{\circ} \mathrm{C}$, a pH of 8.1 and a salinity of 36 (Gustafsson, 2011). In order to ensure compatibility between these and past experiments, inorganic concentrations of cobalt and zinc ( $\mathrm{Co}^{\prime}, \mathrm{Zn}$ ') were calculated using the $\mathrm{Me}^{2+}$ :total metal ratios of $10^{-2.94}$ for $\mathrm{Co}$ and $10^{-2.88}$ for $\mathrm{Zn}$ determined for seawater with $11.7 \mu \mathrm{M}$ EDTA as presented in Saito et al. 2002 (originally derived by Sunda and Huntsman 1995). Co' and $\mathrm{Zn}$ ' were calculated from $\mathrm{Co}^{2+}$ and $\mathrm{Zn}^{2+}$ using ratios of 1.35 for $\mathrm{Co}$ and 2.09 for $\mathrm{Zn}$.

The cobalt concentration in background media were measured by cathodic stripping voltammetry (CSV) after a 1 hour UV-oxidation protocol. Background cobalt was $10 \mathrm{pM}$, similar to determinations conducted in surface waters of the South Pacific Ocean. Cobalt concentrations in low-cobalt media $(<150 \mathrm{pM})$ used in Experiment Group 1 were validated by CSV. UV-oxidation time was increased to 2 hours to ensure destruction of EDTA. In a few of these experiments, cobalt concentrations in spent media (after $0.22 \mu \mathrm{m}$ filtration through an acidcleaned syringe and filter) were also measured by CSV. The precision of these measurements was approximately 3 pM (Hawco et al., 2016). The difference between initial and final dissolved cobalt concentrations was used to estimate cell quotas when biomass was too low to measure by ICPMS.

Although all seawater used for growth media was collected at the same time/location from the surface of the South Pacific Ocean, we observed significant differences in the growth of cultures using seawater stored in different carboys. We attribute these differences to metal contamination during storage, most likely by $\mathrm{Zn}$. The background cobalt concentration was unchanged in all carboys. In surface waters of the South Pacific, the zinc concentration is $\sim 0.1$ nM (Roshan et al., 2016), which we assumed to be the background $\mathrm{Zn}$ concentration for Experiment Group 1 (0.28 pM Zn'). For seawater used in Experiment Group 2, 3 nM zinc concentrations were measured in UV-oxidized media using anodic stripping voltammetry (ASV, $\left.8 \mathrm{pM} Z \mathrm{Zn}^{\prime}\right)$. The shift to higher background $\mathrm{Zn}$ affected the sensitivity of Prochlorococcus MIT9215 where more cobalt was needed to support the same level of growth (see section 3.1). 


\subsection{Measuring Cell Quotas by ICPMS}

Cellular metal quotas were measured by ICPMS. Biomass from replicate $28 \mathrm{~mL}$ cultures were pooled and centrifuged at 11,000 RPM for 20 minutes at $4{ }^{\circ} \mathrm{C}$. In cobalt and metal perturbation experiments, 8-9 replicate cultures with measured growth rates were pooled. For iron limitation experiments, 5-6 biological replicates were pooled. The cell pellet was resuspended in $\sim 1 \mathrm{~mL}$ media, transferred to an acid-cleaned microcentrifuge tube and centrifuged again for $30 \mathrm{~min}$ at $14,100 \mathrm{RPM}$ at $4{ }^{\circ} \mathrm{C}$. The supernatant was discarded. The remaining pellet was acidified in $800 \mu \mathrm{l}$ of $5 \%$ nitric acid containing $1 \mathrm{ppb}$ Indium for several days. Cells were resuspended multiple times during acid digestion and solids were removed by centrifugation. To minimize processing blanks, no attempt was made to remove extracellular metals by washing cells with additional metal chelators. As a result, quota determinations contain contributions from both intracellular and extracellular pools. Blank digestions containing acid but no cells were performed in parallel. Digests were diluted by a factor of 9 with more 5\% nitric acid $1 \mathrm{ppb}$ Indium solution before being analyzed in duplicate on an ICAP-Q plasma mass spectrometer (Thermo), calibrated to a multi-element standard curve over a range of 1-100 ppb. Samples were analyzed in KED mode after a 85s sample uptake window and element mass windows were scanned 3-times during measurements. Variation in ICPMS counts per second was usually $<5 \%$ for single analyses. $1 \mathrm{ppb}$ Indium was used as an internal standard to correct for variation in sample delivery and plasma suppression between samples.

Samples were run twice and averaged. Process blanks were subtracted from measured concentrations. Phosphorus concentrations were also measured by ICPMS and calibrated to a standard curve ranging from 100-1500 ppb using a laboratory standard solution that was externally validated by certified P stocks obtained from the WHOI ICPMS facility. ICPMS was also used to validate nutrient stocks and examine the presence of contaminating metals, which was sometimes necessary. Stocks were diluted in 5\% nitric acid and analyzed as above.

\section{Results}

\subsection{Zinc inhibition of cobalt uptake}

Growth rates of Prochlorococcus strain MIT9215, as determined by changes in chlorophyll fluorescence, decreased as cobalt concentrations in media decreased, consistent with prior observations in Prochlorococcus strain Med4 (Saito et al., 2002). For experiments in low- 
zinc media (Experiment Group 1), growth rates slowed at Co' concentrations below $0.2 \mathrm{pM}$ (Figure 1a), and were similar for multiple transfers, except when Co' was less than 0.03 pM, in which case, no growth was observed after initial transfer (Fig. 1b). Although cobalt-limited growth in this organism is better described by Droop kinetics (see Chapter 4), (Droop, 1973), the Monod Equation can be used to represent the concentration at which Prochlorococcus MIT9215's sensitivity to cobalt limitation manifests:

$$
\frac{\mu}{\mu_{\max }}=\frac{\left[\mathrm{Co}^{\prime}\right]}{\left[\mathrm{Co}^{\prime}\right]+K_{m}}
$$

and indicates that growth rate is halved at a free cobalt concentration of $\sim 0.07 \mathrm{pM} \mathrm{Co},\left(\mathrm{r}^{2}=\right.$ 0.79). Under a state of cobalt limitation $\left(\mathrm{Co}^{\prime}=0.09 \mathrm{pM}\right)$, adding low levels of $\mathrm{Zn}$ ' caused growth rates to decrease (Fig. 2a). At a Zn' concentration of 0.8 pM, growth rates were halved, but biomass eventually reached levels similar to cultures with no added Zn (Fig. 2a). At higher Zn' (3 pM), growth was almost fully suppressed (Fig. 2a). After 16 days of minimal growth, addition of cobalt to cultures with 3 pM Zn' was sufficient to induce exponential growth and biomass accumulation (Fig. 2b). In contrast, no change was observed when iron was added (Fig. 2c). Growth at 3 pM Zn’ was also possible at higher initial Co’ (Co’ =0.2pM, Fig. 2d), suggesting that $\mathrm{Zn}$ toxicity depends on the ambient cobalt concentration.

This phenomenon was further investigated using a different seawater base (Experiment Group 2). ASV measurements of UV-oxidized seawater indicated that media used for Experiment Group 2 had high dissolved $\mathrm{Zn}(\sim 3 \mathrm{nM})$, greater than zinc concentrations in the South Pacific gyre where this seawater was collected (Roshan et al., 2016) and probably greater than background zinc concentrations in Experiment Group 1 As a result, Prochlorococcus MIT9215 required higher concentrations of cobalt to grow at the same growth rate. Under these new conditions, cobalt-limited growth was halved at a Co' concentration of 0.8 pM Co' (Eq. 1, $\mathrm{r}^{2}$ $=0.87$ ), more than ten times higher than previous experiments (Fig. 3a). To confirm and expand on these results, $\mathrm{Zn}$ toxicity experiments were repeated. At $0.9 \mathrm{pM} \mathrm{Co}$, Prochlorococcus MIT 9215 growth rates were lowered at 17 pM Zn' and growth was totally inhibited at higher Zn' (Fig. 3b). As before, Zn toxicity was cobalt dependent and even growth at 340 pM Zn' was possible when additional cobalt was added (not shown).

In addition to describing Prochlorococcus' affinity for cobalt, the saturation constant, $\mathrm{K}_{\mathrm{m}}$, can be expanded to reflect competition by $\mathrm{Zn}$, such that: 
$K_{m}=K_{C o}\left(1+\frac{\left[Z n^{\prime}\right]}{K_{Z n}}\right)$

following the form of competitive enzyme inhibition for Michaelis-Menten kinetics (Morel and Hering, 1993). As Zn' approaches $0, K_{m}$ and $K_{C o}$ become identical. At higher $Z n$ ', $K_{m}>K_{C o}$ : more cobalt is needed to support the same level of growth, consistent with our results.

Combining and rearranging equations 1 and 2 returns an expression where growth rate is a direct function of the concentration of $\mathrm{Zn}$ ':

$$
\frac{\mu}{\mu_{\max }}=\frac{\left[C o^{\prime}\right] * \frac{K_{Z n}}{K_{C o}}}{\left[\mathrm{Co}^{\prime}\right] * \frac{K_{Z n}}{K_{C o}}+K_{Z n}+\left[Z n^{\prime}\right]}
$$

as above, at high $\mathrm{Zn}, \mu$ approaches 0 . Because the added concentration of $\mathrm{Zn}$ is known more precisely than the background $\mathrm{Zn}$ concentration, Eq. 3 can be can be rewritten so that these components are separated:

$$
\frac{\mu}{\mu_{\max }}=\frac{\left[C o^{\prime}\right] * \frac{K_{Z n}}{{ }_{K C o}}}{\left[C o^{\prime}\right] * \frac{K_{Z n}}{K_{C o}}+K_{Z n}+\left[Z n^{\prime}\right]_{\text {background }}+\left[Z n^{\prime}\right]_{\text {added }}}
$$

which follows the general form:

$$
Y=\frac{a}{a+b+X}
$$

where $a=\left[C o^{\prime}\right] * \frac{K_{Z n}}{K_{C o}}$ and $b=K_{Z n}+\left[Z n^{\prime}\right]_{\text {background }}$ and can be used to fit data in Fig. $3 \mathrm{~b}$ accordingly. The major advantage of this formulation is that the ' $b$ ' term contains the most uncertain parameters, especially background metal concentrations. As a result the ' $a$ ' constant can be fit by least-squares methods. When divided by the media Co' concentration, the ' $\mathrm{a}$ ' parameter reflects the relative sensitivity of Prochlorococcus MIT9215 growth to zinc inhibition, $\frac{K_{Z n}}{K_{C o}}$. Note that this term describes the response of Prochlorococcus growth rate and not the chemical affinity for Prochlorococcus' metal transporter.

For Experiment Group 1 (low background $\mathrm{Zn}$ ), growth rates are best fit with $\frac{K_{Z n}}{K_{C o}}$ of 11.8 $\pm 2.1 \mathrm{~mol} \mathrm{~mol}^{-1}\left(\mathrm{r}^{2}=0.96\right)$. That is, Prochlorococcus growth was inhibited by $50 \%$ when $\mathrm{Zn}$ ' was 12-times more abundant than Co'. Performing the same fit with Experiment Group 2, which had higher background $Z n^{\prime}$, returns a similar value of $\frac{K_{Z n}}{K_{C o}}: 11.6 \pm 2.3 \mathrm{~mol} \mathrm{~mol}^{-1}\left(\mathrm{r}^{2}=0.95\right)$. The extremely strong agreement in these two regressions indicates that $\mathrm{Zn}$ inhibition results are consistent despite different levels of background Zn' in the media. 


\subsection{Cobalt uptake inhibition by other metals}

In light of strong competitive inhibition by Zn', we examined the ability of other metals to compete with cobalt uptake (Fig. 4). When cobalt limits Prochlorococcus growth rates, increased abundance of a competing metal should cause growth rates to decrease, whereas lower metal concentrations should relax cobalt limitation and result in faster growth. We used this logic to investigate sensitivity of Prochlorococcus cobalt uptake for several metals.

In addition to $\mathrm{Zn}$ ', changing the inorganic manganese (Mn') concentration had a profound effect on cobalt-limited growth (Fig. 4a). Because it interacts weakly with EDTA and natural ligands, $\mathrm{Mn}$ ' is the most abundant transition metal ion in both seawater and Prochlorococcus media (Moore et al., 2007; Sunda et al., 2005). At a standard concentration of $90 \mathrm{nM}$ dissolved $\mathrm{Mn}$, the $\mathrm{Mn}$ ' concentration is approximately $35 \mathrm{nM}$, about 10,000 times more abundant than limiting concentrations of Co'. Like Zn, higher Mn' depressed growth rates (Fig. 4a), an effect that was reversed upon addition of extra cobalt (Fig. S1). At the same Co' concentration, faster growth was observed at lower Mn'. When Mn' was less than $5 \mathrm{nM}$, Prochlorococcus MIT9215 approached maximum growth rates. Therefore, both $\mathrm{Mn}$ and $\mathrm{Zn}$ appear to compete with cobalt for uptake, although $\mathrm{Mn}$ is a much weaker inhibitor than $\mathrm{Zn}$. When modeled by Eq. 4, the Mn inhibition data are best fit $\left(\mathrm{r}^{2}=0.95\right)$ with $\frac{K_{M n}}{K_{C o}}$ equal to $7 \times 10^{4}$ mol $\mathrm{mol}^{-1}$, much higher than $\mathrm{Zn}$ '.

Not all metals show competitive inhibition, however. A 1000-fold change in iron concentration, for instance, did little to alter growth, except at very low Fe' $(\sim 1 \mathrm{pM})$ where cells appeared to experience iron limitation (Fig. 4b). Growth curves at 8 pM Fe' was almost identical to growth at 710 pM Fe' (Fig. 5a, 4b). Similarly, increasing Cu' concentrations 100-fold above background (up to $9 \mathrm{pM} \mathrm{Cu}$ ') did not show large effects on growth rates (Fig. 4d, 5c). Iron and copper do not interfere with cobalt uptake at these concentrations ranges.

Nickel represents an intermediate case. As with $\mathrm{Cu}$ and $\mathrm{Fe}$, exponential growth rates were unchanged across a nearly 1000-fold range in Ni' (Fig. 4c). However, when Ni' was high, cultures required more time before beginning exponential growth (Fig. 5c). At 0.2 pM Ni', cultures reached exponential growth within 5 days of inoculation but required over two weeks at 18 pM Ni' despite identical inocula in all experiments (acclimated to $0.2 \mathrm{pM} \mathrm{Ni}$ '). Still, exponential growth rates were not drastically different between treatments $(0.39$ and 0.29 , 
respectively). The high fluorescence blank of polycarbonate bottles can make it difficult to distinguish true lag phase (lower growth rates that precede exponential growth) from exponential growth at very low cell abundance. Based on the inoculum size $(0.8 \%)$ and growth rate calculated from samples above this detection limit $\left(0.29\right.$ day $\left.^{-1}\right)$, the 18 pM Ni' treatment should have reached stationary phase 16 days after inoculation, instead of on day 23 (Fig. 5c). This delay was not observed with similar free ion concentrations of $\mathrm{Cu}$ or Fe (Fig. 5a, b) and addition of cobalt enabled cultures to initiate exponential growth immediately (Fig. S2), suggesting Prochlorococcus required long lag phases to reduce competition between cobalt and nickel, possibly by inducing intracellular Ni-binding proteins.

No growth was observed at total Ni concentrations of 3 and $10 \mu \mathrm{M}(70$ and $1200 \mathrm{pM} \mathrm{Ni}$, respectively; Fig. 4c), indicating an upper limit to this adaptive response. As metal concentrations approach the concentration of EDTA $(11.7 \mu \mathrm{M})$, as Ni did, uncomplexed EDTA, EDTA', is lowered and, as a result, increases free ion concentrations of all other metals (Sunda et al., 2005). Therefore, the lack of growth at high Ni' may not be interpreted as straightforwardly as $\mathrm{Mn}$ and Zn inhibition experiments. Still, high Ni':Co’ ratios ( 100) adversely affected Prochlorococcus growth at low cobalt.

\subsection{Prochlorococcus metal quotas and uptake experiments.}

To gain further insight into the mechanisms that drive competitive inhibition between cobalt and other metals, growth experiments were replicated so that cellular metal quotas could be quantified. In addition to a series of limiting and non-limiting concentrations of cobalt and iron (see chapter 4), cell quotas were also determined in cultures where concentrations of $\mathrm{Ni}$, $\mathrm{Mn}, \mathrm{Cu}$, and $\mathrm{Zn}$ were perturbed under cobalt limiting conditions. Due to changes in cell size along nutrient limitation gradients, quotas are presented normalized to cell phosphorus, which was measured simultaneously with metals.

Cellular metal quotas of Prochlorococcus MIT9215 at peak growth rate in our experiments $\left(0.56^{-1}\right.$ day) followed the order $\mathrm{Fe}>\mathrm{Mn}>\mathrm{Zn}>\mathrm{Ni}>\mathrm{Cu}>\mathrm{Co}$, which resembles the trend of phytoplankton observed in the field: $\mathrm{Fe}=\mathrm{Zn}>\mathrm{Mn}=\mathrm{Ni}=\mathrm{Cu}>\mathrm{Co}$ (Twining and Baines, 2013). Compared to these phytoplankton, which mostly represent eukaryotic species, Prochlorococcus seems to use less Zn and perhaps more Mn. High Prochlorococcus Mn quotas 
(2-4 mmol mol $\left.{ }^{-1} \mathrm{P}\right)$ in these experiments may be an artifact of the high $\mathrm{Mn}$ ' present in culture media $(36 \mathrm{nM})$ compared to the open ocean (typically $<3 \mathrm{nM})$.

Growth rate was a major factor affecting metal quotas. As growth rates were depressed by either iron or cobalt limitation P-normalized quotas for all other metals increased (Fig. 6). This phenomenon has been previously described as 'biodilution', which results from a nearlyconstant metal uptake rate (relative to either cell number or P quota) that is able to transport more metal as the time between cell division increases (Sunda and Huntsman, 2000). Therefore, a secular change in growth rate will modify the cell quota but not the steady state metal uptake rate, which can be expressed as:

$V_{\text {metal }}=\mu * Q_{\text {metal }}$

Indeed, $\mathrm{Mn} / \mathrm{P}$ ratios decreased with increasing growth rate but $\mathrm{P}$-normalized uptake rates were similar across most experiments (Fig. 7). This was true even when the Mn' concentration was tripled (+Mn treatment), indicating that Mn uptake was fully saturated under our culture conditions (Table 2). When no Mn was added to growth media, however, Mn uptake rates (and cell quotas) decreased substantially (Fig. 7; -Mn). At 35 nM Mn', Prochlorococcus Mn:P ratio was about 10-fold higher than Mn:P ratios in picoplankton cells in the North Atlantic and Equatorial Pacific oceans (Table 2) (Twining et al., 2011, 2015). Media Mn concentrations in ProTM media can probably be lowered significantly without affecting growth.

While growth experiments imply that $\mathrm{Zn}, \mathrm{Mn}$, and Co bind to the same transporter, cobalt transport was clearly not saturated under these experimental conditions and cobalt quotas increased linearly with increasing Co' (Table 2, Chapter 4). When Co' was varied, cobalt-limited growth rates were proportional to the cellular cobalt quota and followed predictions based on the Droop equation $\left(\mu / \mu_{\max }=1-1.3 / \mathrm{Q}_{\mathrm{Co}}\right.$, chapter 4$)$. In cultures with no added Mn but the same Co', Prochlorococcus growth rate increased with cellular Co:P along the same line as when Co' was increased (Fig. 8). The increased cobalt uptake rate at low Mn' (Fig. 7,-Mn) suggests that Mn toxicity manifests at the transporter site. Indeed, increasing Mn' or Zn' caused cellular Co:P ratios to decrease (Table 2). If $\mathrm{Zn}$ and Mn toxicity manifested intracellularly (for instance by competing for binding sites of cobaltochelatase), cellular cobalt would have to increase in the presence at high cytosolic Mn' and Zn' to outcompete these metals and reach the same levels of growth. This is the opposite of what was observed (Table 2): a higher cobalt quota corresponded 
to an increase in growth rate (Fig. 8). Based on these observations, it is likely that metal inhibition occurred in the periplasm, prior to transport, rather than in the cytoplasm.

Surprisingly, Zn uptake rates increased only slightly at $22 \mathrm{pM}$ Zn' compared to $8 \mathrm{pM} Z \mathrm{Zn}$ ' (Fig. 7, +Zn). This additional Zn' was enough to depress growth rates (Fig. 4). At first glance, this would suggest that $\mathrm{Zn}$ transport, like Mn transport, was saturated but, because Co uptake was unsaturated and both metals are at similar concentrations, it is unlikely that $\mathrm{Zn}$ uptake was actually saturated. Instead, there may be export mechanisms that regulate intracellular $\mathrm{Zn}$ accumulation (and decrease intracellular competition between cobalt and zinc) or zinc may bind to Prochlorococcus transporters (and therefore block Co uptake) while being unable to be transported across the plasma membrane. It is difficult to evaluate this hypothesis without further experimentation. As measurements of zinc are notoriously prone to contamination, it is also possible that $\mathrm{Zn}$ contamination in our measurements obscures a lower cellular quota. As such, our measurements should be treated an upper limit on possible Prochlorococcus $\mathrm{Zn}$ quotas. It should be noted, however, that Prochlorococcus $\mathrm{Zn:P}$ was similar to measurements from picoplankton cells in the North Atlantic and Equatorial Pacific oceans (Figure 6), suggesting that the measured Prochlorococcus quotas are not unreasonable (Twining et al., 2011, 2015).

$\mathrm{Ni}$ and $\mathrm{Cu}$ transport appeared to be independent of the $\mathrm{Co} / \mathrm{Mn}$ transport process. In ironlimited cultures, nickel quotas were substantially higher than under cobalt limitation (Fig. 6), perhaps due an increased need for Ni-superoxide dismutase enzyme to counter reactive oxygen stress generated from iron starvation (Dupont et al., 2008, 2012; Saito et al., 2014). At low Fe, $\mathrm{Mn}$ and Co quotas did not increase to the same degree, making it unlikely that $\mathrm{Ni}$ was acquired through the Mn transporter (Fig. 6). Additionally, Fe uptake rates were unchanged at high and low Ni (Fig. S3; +Ni, -Ni), suggesting that the high Ni observed during Fe limitation was also not due to transport through the Fe uptake system. Therefore, there is probably a dedicated Ni transporter in Prochlorococcus, which seems to be upregulated under iron stress and may be associated with supplying Ni to superoxide dismutase (Dupont et al., 2012). Similarly, high Cu' did not appear to affect uptake of any other metal except $\mathrm{Cu}$, suggesting the existence of a separate $\mathrm{Cu}$ transporter as well (Fig. 7, Fig. S3, +Cu). 


\subsection{Chemical Affinity of Prochlorococcus Metal Transport}

Competitive inhibition by $\mathrm{Mn}$ implies that cobalt and $\mathrm{Mn}$ share the same transport system in Prochlorococcus. The affinity of Co' towards this transporter can be calculated from measurements of cellular metal quotas (Sunda and Huntsman, 2000). Steady state metal uptake rates applied to competitive inhibition kinetics produces the equation:

$\mu * Q_{C o}=\frac{V_{\max } * K_{C o^{*}} *\left[C o^{\prime}\right]}{K_{c o} *\left[\mathrm{Co}^{\prime}\right]+K_{M n^{\prime}} *\left[n_{n} \prime\right]+K_{Z n} *\left[Z n^{\prime}\right]+1}$

Because the growth experiments (e.g. Fig. 4) imply transport via the same pathway, an analogous equation can be written for Mn:

$\mu * Q_{M n}=\frac{V_{\max } * K_{M n^{*}}\left[M n^{\prime}\right]}{K_{C o} *\left[O^{\prime}\right]+K_{M n^{*}}\left[M n n^{\prime}\right]+K_{Z n} *\left[Z n^{\prime}\right]+1}$

In each of these cases, $\mathrm{K}$ describes the equilibrium constant between the metal and the transporter. The relative affinity of this transporter for cobalt relative to $\mathrm{Mn}$ can be expressed by the relative enrichment of the cellular $\mathrm{Co} / \mathrm{Mn}$ ratio compared to their free ion ratio in growth media (i.e. by dividing Eq. 7 by Eq. 8), which simplifies to:

$\frac{Q_{C o}}{Q_{M n}}=\frac{K_{C o}}{K_{M n}} * \frac{\left[\mathrm{Co}^{\prime}\right]}{\left[M n^{\prime}\right]}$

Cobalt and manganese quotas averaged across the experiments in Table 2 point to a specificity $\mathrm{K}_{\mathrm{Co}} / \mathrm{K}_{\mathrm{Mn}}$ of $\sim 70: 1$. Given equimolar concentrations of Co and Mn, the Prochlorococcus transporter will acquire 70 times more cobalt than Mn, much lower than the 70,000:1 ratio determined by growth experiments described above.

Absolute values of these transport affinities can be calculated if it is assumed that $\mathrm{Mn}$ uptake in our experiments is saturated. If this is the case, $V_{\max }=\mu Q_{M n}$. Despite the small number of Mn concentrations tested, the lack of variation in Mn quotas suggests transporter saturation (Table 2). Mn uptake rates did not increase when Mn' concentrations were increased from $35 \mathrm{nM}$ (as in the $+\mathrm{Ni},-\mathrm{Ni},+\mathrm{Cu}$, and $+\mathrm{Zn}$ treatments) to $110 \mathrm{nM}$ (Fig. 7, $+\mathrm{Mn}$ ). As a result, Mn uptake rates can be modeled with simple Michaelis-Menten kinetics:

$\mu * Q_{M n}=V_{\max } * \frac{K_{M n} *[M n]}{K_{M n} *[M n]+1}$

The Mn uptake rate under nutrient replete conditions $\left(\mathrm{Co}^{\prime}=15.5 \mathrm{pM}, \mathrm{Mn}^{\prime}=35 \mathrm{nM}, 1.38 \mathrm{mmol}\right.$ $\mathrm{Mn}$ mol $\mathrm{P}^{-1} \mathrm{day}^{-1}$ ) is set equal to $\mathrm{V}_{\max }$. The Mn uptake rate at a background $\mathrm{Mn}$ ' concentration of

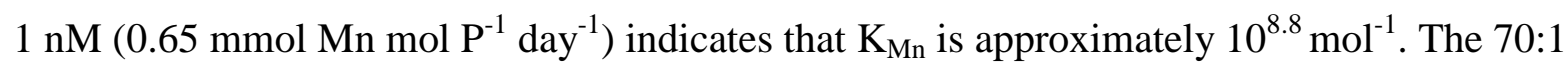
preference for cobalt to Mn, determined from Eq. 9 indicates the corresponding cobalt affinity of 
this mechanism $10^{10.7} \mathrm{~mol}^{-1}$. This affinity is about 6-fold weaker than dimethylglyoxime $\left(K_{D M G_{2}}^{\text {cond }}\right.$ $=10^{11.5}$ ), the analytical ligand typically used for measurements of cobalt speciation in seawater, and at least 10,000-fold weaker than lower limits of both natural cobalt ligands in seawater and cobalamin (Ellwood and van den Berg, 2001; Saito and Moffett, 2001).

\section{Discussion}

\subsection{Metal competition in Prochlorococcus cobalt uptake}

Cobalt limited quotas imply amazingly slow rates of uptake given measured growth rates. For instance, at growth rates of $0.33 \mathrm{~d}^{-1}$, cellular quotas of 54 cobalt atoms per cell correspond to a steady state uptake rate of less than 1 atom per cell per hour (Table 3 ). This transporter turnover time is significantly longer than most enzymatic reactions. Even 'slow' enzymes (such as ribonucleotide reductase) still have turnover times in the range of seconds to minutes (Booker et al., 1994; Gleason and Olszewski, 2002). The notoriously slow carboxylating enzyme RUBISCO has a catalytic turnover time of $\sim 10$ per second (Hopkinson et al., 2014). In the context of cobalt uptake, a single copy of a cobalt transporter operating 10,000-fold more slowly than RUBISCO could supply all of the cobalt needed to alleviate growth limitation. Growth experiments and quota measurements (Fig. 4, 7) indicate that cobalt and Mn are transported by the same process. Including Prochlorococcus ' Mn quota ( 30,000 atoms per cell) into the above calculation, it appears that each cell transports $\sim 10$ metal atoms per minute. If turnover times of transporters are in the range of seconds to minutes (Raimunda et al., 2011), uptake of both Mn and Co can be satisfied by a single transporter with an extremely low copy number. Combined transport of Co and Mn not only decreases membrane space needed for acquisition of these two metals, but also decreases the need to regulate two transporters independently. Under normal oceanic conditions, Mn' is less than 2 nM (Hatta et al., 2015; Resing et al., 2015) - much lower than in our experiments - and unlikely to inhibit growth, even at Co' as low as $0.1 \mathrm{pM}$. On evolutionary timescales, then, the metabolic/regulatory efficiency gained by combining transporters probably overshadows the threat of competitive inhibition at unusually high Mn.

Kinetics of cobalt uptake have been examined in eukaryotic phytoplankton, especially in the context of zinc limitation (Sunda and Huntsman, 1995). Zinc scarcity in diatoms and coccolithophores induces the expression of a transporter with high affinities for cobalt and cadmium, which the cells then use to substitute for zinc in metalloproteins (Sunda and 
Huntsman, 1995; Yee and Morel, 1996). Under this scenario, rates of cobalt uptake approach their theoretical limits based on the rate of diffusion of Co' to the cell surface, indicating that evolution of these phytoplankton has streamlined the binding/transport kinetics of the $\mathrm{Co}, \mathrm{Cd}$, and $\mathrm{Zn}$ uptake apparatus so that diffusion remains the major impediment to metal uptake (Sunda and Huntsman, 1992, 1995, 2000). This is decidedly not the case for Prochlorococcus, whose cobalt uptake rate under conditions of cobalt limitation is $<1 \%$ of the maximum flux allowed by diffusion (Table 3). Clearly, there exists a means for faster cobalt uptake that is realized in eukaryotic phytoplankton and is not realized in Prochlorococcus, although, compared to larger cells, the high surface area to volume ratios in Prochlorococcus may relieve selective pressures to maximize uptake rates.

If Prochlorococcus cobalt uptake is not optimized for speed, what is it optimized for? A key difference between Prochlorococcus and eukaryotic phytoplankton is that the latter must acquire cobalamin externally (if needed at all) whereas Prochlorococcus synthesizes pseduocobalamin de novo, starting with the uptake of cobalt metal from seawater (Bertrand et al., 2012; Helliwell et al., 2016; Zhang et al., 2009). In contrast, zinc enzymes often maintain activity when metallated with either cobalt or zinc, so the need for eukaryotic phytoplankton to distinguish between the two metals is probably low (Maret, 2010; Yee and Morel, 1996). Indeed, metal substitution for these organisms is an advantage, helping to fulfill higher $\mathrm{Zn} / \mathrm{Co}$ quota (Price and Morel, 1990; Sunda and Huntsman, 1995). The need to identify cobalt from other metals then may be unique to cobalamin synthesizers, a major challenge given that most organic ligands have a higher affinity for copper and nickel than they do for cobalt (the Irving-Williams series) and that these competing metals can be in much greater abundance in seawater (Irving and Williams, 1953; Saito and Moffett, 2001; Waldron and Robinson, 2009).

Such delicacy probably underlies the response of cobalt-limited Prochlorococcus to competing metals, especially $\mathrm{Zn}$ and Mn. At limiting concentrations of Co', the addition of either Mn or Zn suppressed growth rates (Fig. 4b, 5a, 5b). Inhibition could be alleviated by adding more cobalt to the growth media, or by adding less than the prescribed amount of Mn' to the culture (34 $\mathrm{nM}$ in ProTM) in the first place. It is interesting that competitive inhibition was not observed for $\mathrm{Cu}$, which forms the strongest complexes with amino acids and other organic ligands (Irving and Williams, 1953; Waldron and Robinson, 2009). Even at a 10:1 ratio of Cu' to Co', growth and Co uptake was unaffected. The highest $\mathrm{Cu}^{\prime}$ tested $\left(9 \mathrm{pM}, \mathrm{Cu}^{2+}=0.5 \mathrm{pM}\right)$ is 
about an order of magnitude lower than toxic concentrations in similar strains of Prochlorococcus (Mann et al., 2002), but higher than oceanic $\mathrm{Cu}^{2+}$ concentrations expected from measurements in the South Pacific and North Atlantic (Jacquot and Moffett, 2015; Jacquot et al., 2013), except during periods of intense atmospheric deposition (Mann et al., 2002).

Similarly, Ni should outcompete Co' and Zn' for uptake ligands, but exponential growth rates remained similar even when $\mathrm{Ni}^{\prime}$ was 20 -fold greater than $\mathrm{Co}^{\prime}$, although longer lag phases preceded growth at high $\mathrm{Ni}$. It is possible that this long lag phase is needed to upregulate $\mathrm{Ni}$ binding systems in the cytoplasm to decrease competition with cobalt. In Synechocystis cytoplasmic Co' is orders of magnitude higher than Ni' (Patterson et al., 2013a, 2013b), though none of the major genes involved in Ni homeostasis in Synechocystis are present in the Prochlorococcus MIT9215 genome (Table 1)(Huertas et al., 2014). The response to additional $\mathrm{Ni}$ ' is clearly distinct from the response to $\mathrm{Zn}$ ': at a similar ratio of $\mathrm{Zn}: \mathrm{Co}$, Prochlorococcus growth rates were depressed by $\sim 50 \%$.

Prochlorococcus MIT9215 has genes that are homologous to the MntABC transport system characterized in Synechocystis 6803 (Table 1) (Bartsevich and Pakrasi, 1996; Kettler et al., 2007). Similar to Prochlorococcus, the MntABC transporter in Synechocystis is also vulnerable to inhibition by $\mathrm{Zn}$ and $\mathrm{Co}$, but not $\mathrm{Cu}$ and $\mathrm{Fe}$, suggesting that that this protein operates by a similar mechanism (Bartsevich and Pakrasi, 1996). Characterization of an MntC homologue in Staphylococcus aureus indicate a manganese affinity of $10^{8.4} \mathrm{~mol}^{-1}$, which is similar to the strength of the Prochlorococcus Mn transporter (Gribenko et al., 2013). This protein also binds cobalt and zinc, though $\mathrm{Zn}$ binding seems to be irreversible unless $\mathrm{MntC}$ is denatured, perhaps accounting for the toxicity in cobalt-limited Prochlorococcus (Gribenko et al., 2013). Interestingly, Prochlorococcus' affinity for cobalt by this system $\left(10^{10.7} \mathrm{~mol}^{-1}\right)$ is an order of magnitude greater than that determined for $\mathrm{Zn}$ and Co by the high affinity $\mathrm{Zn}$ uptake system in Emiliania huxleyi $\left(\sim 10^{9.6} \mathrm{~mol}^{-1}\right.$ ) (Sunda and Huntsman, 1992, 1995). Although $E$. huxleyi acquires these metals at much faster rates than Prochlorococcus (near the diffusion limit), it appears that, in addition to its smaller cell size, Prochlorococcus have evolved higher selectivity in binding low levels of cobalt from seawater. Perhaps an aspect of Prochlorococcus' oligotrophic lifestyle is the optimization toward low nutrient concentrations, at the cost of maximum uptake rates. 
As there are no known ligands that bind $\mathrm{Co}(\mathrm{II})$ more strongly than $\mathrm{Ni}(\mathrm{II})$ or $\mathrm{Cu}(\mathrm{II})$, a driving logic of Prochlorococcus' metal metabolism may be to bind stronger metals $(\mathrm{Cu}, \mathrm{Ni})$, as observed with the cyanobacterium Synechocystis and other bacteria (Morel and Hering, 1993; Patterson et al., 2013b; Saito and Moffett, 2001). Low cytosolic Cu' and Ni' should decrease competition with weaker-binding metals like $\mathrm{Co}$ or $\mathrm{Mn}$. If $\mathrm{Cu}$ and $\mathrm{Ni}$ are bound, the stronger affinity for Co over Mn and Fe(II) (according to the Irving Williams series) may ensure delivery of cobalt to cobalamin synthesis enzymes at ambient Mn concentrations . However, most ligands (including amino acids) bind $\mathrm{Co}$ and $\mathrm{Zn}$ with similar strength, including the active site of cobaltochelatase (Debussche et al., 1992; Morel and Hering, 1993). It may be more challenging to separate cobalt from zinc than to separate cobalt from other metals. This similarity probably contributes to the extreme sensitivity to $\mathrm{Zn}$ when Prochlorococcus is cobalt limited.

\subsection{Implications for oceanic Prochlorococcus}

Most cobalt in the oceans is bound by strong organic ligands, especially in the surface ocean (Ellwood and van den Berg, 2001; Saito and Moffett, 2001). Ligand bound cobalt is less vulnerable to scavenging and presumably less bioavailable to organisms that rely on free ion mechanisms of cobalt uptake, such as diatoms and coccolithophores (Moffett and Ho, 1996; Sunda and Huntsman, 1995). Based on competitive uptake inhibition by $\mathrm{Zn}, \mathrm{Mn}$ and perhaps $\mathrm{Ni}$, it appears Prochlorococcus MIT9215 transporters also acquire inorganic cobalt ions. Growth of Prochlorococcus MIT9215 did not proceed without added cobalt, indicating either that background cobalt in our seawater media was not bioavailable or insufficient. The background cobalt concentration in the growth media was determined to be $10 \mathrm{pM}$, similar to cobalt concentrations measured in the South Pacific Ocean where this water was collected (Hawco et al., 2016). When inorganic cobalt was added, Prochlorococcus MIT9215 grew to cell densities of $\sim 9.5 \times 10^{7}$ cells per mL having only acquired $12-15 \mathrm{pM}$ of the dissolved cobalt (Table 3 ). Thus, if it were bioavailable, the $10 \mathrm{pM}$ background cobalt in unamended media should have been able to support nearly the same cell density.

Determining the concentration of Co' in seawater is difficult. Recent voltammetry studies have shown that cobalt ligands in the euphotic zone are equimolar with dissolved cobalt concentrations, even when dissolved cobalt is extremely low (Baars and Croot, 2015; Saito et al., 2005). As a result, competitive ligand equations used to infer free $\mathrm{Zn}, \mathrm{Cu}$, and $\mathrm{Fe}$ concentrations 
do not apply for cobalt, requiring electrochemically labile cobalt to be measured directly. Furthermore, definitions of labile cobalt (like other metals) are defined relative to an analytical ligand (often dimethylglyoxime (DMG)) and not by the actual apparatus used by Prochlorococcus to acquire cobalt. Some of the cobalt bound by DMG $\left(\log K_{D M G_{2}}^{\text {cond }}=11.5\right.$ (Saito and Moffett, 2001)) may not be accessible if uptake proteins have a significantly weaker affinity. In our experiments, a conditional stability constant for free ion uptake of cobalt is approximately $10^{10.8} \mathrm{~mol}^{-1}$, similar to $K_{D M G_{2}}^{c o n d}$. Therefore, labile cobalt measurements should reflect the amount of cobalt that is available to Prochlorococcus by this inorganic uptake mechanism. In contrast, the binding strength of cobalamin has been estimated to be $>10^{16}$ (although there are kinetic barriers to cobalt removal from this molecule) (Ellwood and van den Berg, 2001). It is clear that the Prochlorococcus transporter characterized here cannot access the cobalt from these molecules.

In part because the sensitivity of electrochemical methods tends to decrease in the presence of dissolved organic matter, labile cobalt detection limits are unfortunately high, often 3 pM or greater (Baars and Croot, 2014; Noble et al., 2012; Saito and Moffett, 2001). In our experiments, cobalt limitation with Prochlorococcus became relevant when Co' fell below $1 \mathrm{pM}$, similar to the range previously observed with Prochlorococcus MED4 and Synechococcus bacillaris, but below typical labile cobalt detection limits. With the exception of coastal and polar environments, most studies report concentrations of labile cobalt in the surface ocean that are below detection (Bown et al., 2012; Hawco et al., 2016; Noble et al., 2012)(Noble et al. submitted). This is especially true for the subtropical gyres, where Prochlorococcus represents a major fraction of the phytoplankton community. Therefore, additional method development is needed to resolve critical thresholds for cobalt limitation in environmental datasets.

The observed inhibition of cobalt uptake by $\mathrm{Zn}$ in Prochlorococcus can provide important constraints on the lower limit of $\mathrm{Co}^{\prime}$ in the environment. Because a majority of zinc in the oceans is bound by organic ligands, only a few percent of the $\sim 0.3 \mathrm{nM}$ dissolved zinc in the euphotic zone of the North Pacific subtropical gyre, for example, is present as Zn' (2-14 pM) (Bruland, 1989). This is similar to the range of $\mathrm{Zn}$ ' in which Prochlorococcus MIT9215 was susceptible to zinc inhibition of cobalt uptake. In seawater with $8 \mathrm{pM} \mathrm{Zn}$ ' (the estimated background Zn' concentration in Experiment Group 2, Fig. 3b), Prochlorococcus MIT9215 grew at $90 \% \mu_{\max }$ at a Co' concentration of $\sim 3 \mathrm{pM}$ (Fig. 3a), similar to the limit of detection for labile 
cobalt by CSV and close to the total dissolved cobalt concentration in this region (see Chapter 4) (Martin et al., 1989; Noble et al., 2008). Although it is difficult to say precisely at what concentration wild Prochlorococcus will experience cobalt limitation in this or other settings, our results indicate interference of cobalt uptake by $\mathrm{Zn}$ observed in culture is probably relevant to oligotrophic ecosystems.

In the absence of strong zinc ligands, however, Prochlorococcus would be totally unable to access inorganic cobalt species. If all of the $0.3 \mathrm{nM} \mathrm{Zn}$ in the North Pacific subtropical gyre was present as Zn' (Bruland, 1989), a simple extrapolation of the above calculation suggests that the same growth rate could only be achieved if Co' was $>100$ pM, much higher than labile cobalt measured in the open ocean (Hawco et al., 2016; Noble et al., 2012; Saito et al., 2010). Even higher $\mathrm{Zn}$ ' has been reported in intermediate and deep ocean waters, where most $\mathrm{Zn}$ is present as Zn', as well as in the Southern Ocean where these waters ventilate (Baars and Croot, 2011; Bruland, 1989; Jakuba et al., 2012). Although it is unclear if Prochlorococcus contributes to the synthesis of strong zinc ligands found in seawater, it is clear from these experiments that Prochlorococcus benefits from their presence when Co' is low.

In contrast to zinc inhibition of cobalt uptake observed in Prochlorococcus, cobalt and zinc can substitute for the same functions in eukaryotic phytoplankton such as Emiliania huxleyi (Sunda and Huntsman, 1995). For these eukaryotic phytoplankton, near-limiting values of Zn' in the North Pacific can be supplemented by Co uptake (Bruland, 1989; Sunda and Huntsman, 1995). Reliance on inorganic uptake systems may then result in competition between Prochlorococcus and eukaryotic phytoplankton over low levels of Co'. Comparing Prochlorococcus MIT9215 with E. huxleyi, it seems that, in the absence of $\mathrm{Zn}\left(\mathrm{Zn}{ }^{\prime}<0.5 \mathrm{pM}\right)$, Prochlorococcus can survive at much lower cobalt concentrations. For instance, Prochlorococcus can grow at its maximum growth rate at a Co' of $0.2 \mathrm{pM}$ whereas E. huxleyi can only achieve $20 \% \mu_{\max }$ (Fig. 9a). Maximized surface-volume ratios in Prochlorococcus and smaller cobalt quotas compared to E. huxleyi contribute to their success under this condition.

The chemical similarity between $\mathrm{Co}^{2+}$ and $\mathrm{Zn}^{2+}$ ions enables the same enzymes to be activated by either metal in many enzymes (Maret, 2010; Xu et al., 2007; Yee and Morel, 1996). Because the E. huxleyi Co quota can also be fulfilled by $\mathrm{Zn}$ (and vice versa), Zn addition relieves cobalt limitation in E. huxleyi (Fig. 9b; (Sunda and Huntsman, 1995)). When some zinc is present, not only does Prochlorococcus growth rate decrease (due to the competitive inhibition 
of Co' uptake), but E. huxleyi growth rate increases (Fig. 9b). At a Zn' of $\sim 8$ pM, relative growth rates of E. huxleyi are higher than Prochlorococcus, even at relatively high values of Co' (Fig. 9c). If Prochlorococcus survives by uptake of Co' alone, it may be restricted to regions where $\mathrm{Zn}$ limits the growth of eukaryotic phytoplankton.

Acquisition of organically bound cobalt by alternative mechanisms may circumvent some of the constraints imposed by uptake of inorganic cobalt species. Experiments with Prochlorococcus MIT9215 suggest that Co' uptake is an important pathway for cobalt acquisition in this strain. It may not be fair to assume this is the case for all Prochlorococcus strains. Using metal chelators with different strengths, Saito et al. 2002 demonstrated that growth of Prochlorococcus strain MED4 was proportional to dissolved cobalt concentration, not Co', due to the production of cobalt-binding ligands produced by Prochlorococcus (Saito et al., 2002). The production of extremely strong ligands during a Synechococcus bloom also suggests some of non-labile cobalt is bioavailable to marine cyanobacteria (Saito et al., 2005). Because cobalt bound in cobalamins is kinetically inert to ligand exchange, and because cyanobacterial genomes contain complete biosynthetic pathways for pseudocobalamin, it has been hypothesized that cobalt ligands are structurally related to vitamin $\mathrm{B}_{12}$ (perhaps photo-degradation products) and that cyanobacteria are their major source (Saito et al., 2005). The ability to salvage partially degraded cobalamins has been reported for several pathogenic bacteria (Escalante-Semerena, 2007). If ligand-bound cobalt does represent partially degraded cobalamins, the presence of a cobalamin-salvage pathway in Prochlorococcus might render ligand-bound cobalt bioavailable.

Alternatively, mechanisms to sequester periplasmic zinc could make inorganic cobalt uptake more efficient. Proteomes of marine Synechococcus have suggested the presence of a metallothionein-based trafficking system to deliver zinc to the alkaline phosphatase enzyme (Cox and Saito, 2013). While Prochlorococcus genomes lack metallothionein homologues (Blindauer, 2011), many Prochlorococcus and Synechococcus strains isolated from the Atlantic Ocean have genes for alkaline phosphatase and may require similar chaperones to coordinate zinc metabolism (Martiny et al., 2006; Moore et al., 2005). The response of these strains to cobalt limitation may therefore be distinct from Prochlorococcus MIT9215 and other Pacificoriginating strains, which lack alkaline phosphatase. Still, because the $m n t A B C$ transport system is conserved across Prochlorococcus, survival at low Co' probably requires a broadening of cobalt bioavailability or a narrowing of zinc's. 


\section{Conclusions}

A summary of Prochlorococcus divalent metal metabolism under cobalt limitation is presented in Figure 10. Cobalt, zinc, and manganese all shared an affinity for a single transporter in Prochlorococcus MIT9215. As a result, growth under cobalt limitation was strongly dependent on the concentration of zinc and manganese present in growth media. This sensitivity may ultimately result from streamlining of Prochlorococcus metal metabolism compared to other cyanobacteria and to the general scarcity of $\mathrm{Zn}$ in oligotrophic ecosystems. At the same inorganic metal concentration, inhibition by stronger binding metals - copper and nickel - was not observed to the same extent, suggesting that Prochlorococcus possesses mechanisms to avoid $\mathrm{Cu}$ and $\mathrm{Ni}$ toxicity that do not apply for $\mathrm{Zn}$. $\mathrm{Fe}, \mathrm{Ni}$ and $\mathrm{Cu}$ are likely transported into the cell by separate transporters distinct from the $\mathrm{Co} / \mathrm{Mn} / \mathrm{Zn}$ transporter. In oligotrophic ecosystems where Prochlorococcus is abundant, the presence of strong ligands that bind $>95 \%$ of dissolved zinc and the potential bioavailability of ligand-bound cobalt facilitates the growth of Prochlorococcus at low cobalt concentrations.

\section{References}

Anbar, A. D. and Knoll, A. H.: Proterozoic Ocean Chemistry and Evolution: A Bioinorganic Bridge?, Science (80-. )., 297(5584), 1137-1142, doi:10.1126/science.1069651, 2002.

Baars, O. and Croot, P. L.: The speciation of dissolved zinc in the Atlantic sector of the Southern Ocean, Deep. Res. Part II Top. Stud. Oceanogr., 58(25-26), 2720-2732, doi:10.1016/j.dsr2.2011.02.003, 2011.

Baars, O. and Croot, P. L.: Dissolved cobalt speciation and reactivity in the eastern tropical North Atlantic, Mar. Chem., doi:10.1016/j.marchem.2014.10.006, 2014.

Baars, O. and Croot, P. L.: Dissolved cobalt speciation and reactivity in the eastern tropical North Atlantic, Mar. Chem., 173, 310-319, 2015.

Badarau, A. and Dennison, C.: Thermodynamics of copper and zinc distribution in the cyanobacterium Synechocystis PCC 6803., Proc. Natl. Acad. Sci. U. S. A., 108(32), 13007-12, doi:10.1073/pnas.1101448108, 2011.

Bartsevich, V. V and Pakrasi, H. B.: Manganese Transport in the Cyanobacterium Synechocystis sp. PCC 6803, J. Biol. Chem. , 271 (42 ), 26057-26061, doi:10.1074/jbc.271.42.26057, 1996.

Bertrand, E. M., Allen, A. E., Dupont, C. L., Norden-Krichmar, T. M., Bai, J., Valas, R. E. and Saito, M. a: Influence of cobalamin scarcity on diatom molecular physiology and identification of a cobalamin acquisition protein., Proc. Natl. Acad. Sci. U. S. A., 109(26), E1762-71, doi:10.1073/pnas.1201731109, 2012. 
Blindauer, C. A.: Bacterial metallothioneins: Past, present, and questions for the future, J. Biol. Inorg. Chem., 16(7), 1011-1024, doi:10.1007/s00775-011-0790-y, 2011.

Booker, S., Licht, S., Broderick, J. and Stubbe, J.: Coenzyme B12-Dependent Ribonucleotide Reductase: Evidnce for the Participation of Five Cysteine Residues in Ribonucleotide Reduction, Biochemistry, 33(42), 12676-12685, doi:10.1021/bi00208a019, 1994.

Bown, J., Boye, M. and Nelson, D. M.: New insights on the role of organic speciation in the biogeochemical cycle of dissolved cobalt in the southeastern Atlantic and the Southern Ocean, Biogeosciences, 9(7), 2719-2736, doi:10.5194/bg-9-2719-2012, 2012.

Bruland, K. W.: Complexation of zinc by natural organic ligands in the central North Pacific, Limnol. Oceanogr., 34(2), 269-285, doi:10.4319/1o.1989.34.2.0269, 1989.

Cox, A. D. and Saito, M. A.: Proteomic responses of oceanic Synechococcus WH8102 to phosphate and zinc scarcity and cadmium additions, Front. Microbiol., 4(DEC), 1-17, doi:10.3389/fmicb.2013.00387, 2013.

Debussche, L., Couder, M., Thibaut, D., Cameron, B., Crouzet, J. and Blanche, F.: Assay, purification, and characterization of cobaltochelatase, a unique complex enzyme catalyzing cobalt insertion in hydrogenobyrinic acid a,c-diamide during coenzyme B12 biosynthesis in Pseudomonas denitrificans., J. Bacteriol., 174(22), 7445-51 [online] Available from: http://www.pubmedcentral.nih.gov/articlerender.fcgi?artid=207441\&tool=pmcentrez\&rendertyp $\mathrm{e}=$ abstract, 1992.

Droop, M. R.: Some thoughts on nutrient limitation in algae, J. Phycol., 9(3), 264-272, doi:10.1111/j.1529-8817.1973.tb04092.x, 1973.

Dupont, C. L., Yang, S., Palenik, B. and Bourne, P. E.: Modern proteomes contain putative imprints of ancient shifts in trace metal geochemistry., Proc. Natl. Acad. Sci. U. S. A., 103(47), 17822-17827, doi:10.1073/pnas.0605798103, 2006.

Dupont, C. L., Barbeau, K. and Palenik, B.: Ni uptake and limitation in marine Synechococcus strains., Appl. Environ. Microbiol., 74(1), 23-31, doi:10.1128/AEM.01007-07, 2008.

Dupont, C. L., Butcher, A., Valas, R. E., Bourne, P. E. and Caetano-Anollés, G.: History of biological metal utilization inferred through phylogenomic analysis of protein structures, Proc. Natl. Acad. Sci., 107(23), 10567-10572, doi:10.1073/pnas.0912491107, 2010.

Dupont, C. L., Johnson, D. a, Phillippy, K., Paulsen, I. T., Brahamsha, B. and Palenik, B.: Genetic identification of a high-affinity Ni transporter and the transcriptional response to $\mathrm{Ni}$ deprivation in Synechococcus sp. strain WH8102., Appl. Environ. Microbiol., 78(22), 7822-32, doi:10.1128/AEM.01739-12, 2012.

Ellwood, M. J. and van den Berg, C. M. .: Determination of organic complexation of cobalt in seawater by cathodic stripping voltammetry, Mar. Chem., 75(1-2), 33-47, doi:10.1016/S03044203(01)00024-X, 2001.

Escalante-Semerena, J. C.: Conversion of cobinamide into adenosylcobamide in bacteria and archaea, J. Bacteriol., 189(13), 4555-4560, doi:10.1128/JB.00503-07, 2007. 
Gleason, F. K. and Olszewski, N. E.: Isolation of the gene for the B12-dependent ribonucleotide reductase from Anabaena sp. strain PCC 7120 and expression in Escherichia coli, J. Bacteriol., 184(23), 6544-6550., doi:10.1128/JB.184.23.6544, 2002.

Gribenko, A., Mosyak, L., Ghosh, S., Parris, K., Svenson, K., Moran, J., Chu, L., Li, S., Liu, T., Woods, V. L., Jansen, K. U., Green, B. A., Anderson, A. S. and Matsuka, Y. V.: Threedimensional structure and biophysical characterization of Staphylococcus aureus cell surface antigen-manganese transporter MntC, J. Mol. Biol., 425(18), 3429-3445, doi:10.1016/j.jmb.2013.06.033, 2013.

Gustafsson, J. P.: Visual MINTEQ ver. 3.0, KTH Dep. L. Water Resour. Eng. Stock. Sweden. Based Allison JD, Brown DS, Novo-Gradac KJ, MINTEQA2 ver, 4, 1991, 2011.

Hatta, M., Measures, C. I., Wu, J., Roshan, S., Fitzsimmons, J. N., Sedwick, P. and Morton, P.: An overview of dissolved Fe and Mn distributions during the 2010-2011 U.S. GEOTRACES north Atlantic cruises: GEOTRACES GA03, Deep Sea Res. Part II Top. Stud. Oceanogr., 116, 117-129, doi:10.1016/j.dsr2.2014.07.005, 2015.

Hawco, N. J., Ohnemus, D. C., Resing, J. A., Twining, B. S. and Saito, M. A.: A cobalt plume in the oxygen minimum zone of the Eastern Tropical South Pacific, Biogeosciences, 13, 56975717, doi:10.5194/bg-2016-169, 2016.

Helliwell, K. E., Lawrence, A. D., Holzer, A., Kudahl, U. J., Sasso, S., Kräutler, B., Scanlan, D. J., Warren, M. J. and Smith, A. G.: Cyanobacteria and Eukaryotic Algae Use Different Chemical Variants of Vitamin B12, Curr. Biol., 26(8), 999-1008, doi:10.1016/j.cub.2016.02.041, 2016.

Hopkinson, B. M., Young, J. N., Tansik, a. L. and Binder, B. J.: The Minimal CO2Concentrating Mechanism of Prochlorococcus spp. MED4 Is Effective and Efficient, Plant Physiol., 166(4), 2205-2217, doi:10.1104/pp.114.247049, 2014.

Huertas, M. J., López-Maury, L., Giner-Lamia, J., Sánchez-Riego, A. M. and Florencio, F. J.: Metals in cyanobacteria: analysis of the copper, nickel, cobalt and arsenic homeostasis mechanisms., Life (Basel, Switzerland), 4(4), 865-86, doi:10.3390/life4040865, 2014.

Irving, B. H. and Williams, R. J. P.: 637. The stability of transition-metal complexes, J. Chem. Soc., (3192), 3192-3210, doi:10.1039/JR9530003192, 1953.

Jacquot, J. E. and Moffett, J. W.: Copper distribution and speciation across the International GEOTRACES Section GA03, Deep. Res. Part II Top. Stud. Oceanogr., 116, 187-207, doi:10.1016/j.dsr2.2014.11.013, 2015.

Jacquot, J. E., Kondo, Y., Knapp, A. N. and Moffett, J. W.: The speciation of copper across active gradients in nitrogen-cycle processes in the eastern tropical South Pacific, Limnol. Oceanogr., 58(4), 1387-1394, doi:10.4319/lo.2013.58.4.1387, 2013.

Jakuba, R. W., Saito, M. a., Moffett, J. W. and Xu, Y.: Dissolved zinc in the subarctic North Pacific and Bering Sea: Its distribution, speciation, and importance to primary producers, Global Biogeochem. Cycles, 26(2), 1-15, doi:10.1029/2010GB004004, 2012.

Kettler, G. C., Martiny, A. C., Huang, K., Zucker, J., Coleman, M. L., Rodrigue, S., Chen, F., 
Lapidus, A., Ferriera, S., Johnson, J., Steglich, C., Church, G. M., Richardson, P. and Chisholm, S. W.: Patterns and implications of gene gain and loss in the evolution of Prochlorococcus, PLoS Genet., 3(12), 2515-2528, doi:10.1371/journal.pgen.0030231, 2007.

Mann, E. L., Ahlgren, N., Moffett, J. W. and Chisholm, S. W.: Copper toxicity and cyanobacteria ecology in the Sargasso Sea, Limnol. Oceanogr., 47(4), 976-988, doi:10.4319/lo.2002.47.4.0976, 2002.

Maret, W.: Metalloproteomics, metalloproteomes, and the annotation of metalloproteins., Metallomics, 2(2), 117-25, doi:10.1039/b915804a, 2010.

Martin, J. H., Gordon, R. M., Fitzwater, S. and Broenkow, W. W.: Vertex: phytoplankton/iron studies in the Gulf of Alaska, Deep Sea Res. Part A. Oceanogr. Res. Pap., 36(5), 649-680, doi:10.1016/0198-0149(89)90144-1, 1989.

Martiny, A. C., Coleman, M. L. and Chisholm, S. W.: Phosphate acquisition genes in Prochlorococcus ecotypes: evidence for genome-wide adaptation., Proc. Natl. Acad. Sci. U. S. A., 103(33), 12552-7, doi:10.1073/pnas.0601301103, 2006.

Moffett, J. W. and Ho, J.: Oxidation of cobalt and manganese in seawater via a common microbially catalyzed pathway, Geochim. Cosmochim. Acta, 60(18), 3415-3424, doi:10.1016/0016-7037(96)00176-7, 1996.

Moore, C. M., Mills, M. M., Arrigo, K. R., Berman-Frank, I., Bopp, L., Boyd, P. W., Galbraith, E. D., Geider, R. J., Guieu, C., Jaccard, S. L., Jickells, T. D., La Roche, J., Lenton, T. M., Mahowald, N. M., Marañón, E., Marinov, I., Moore, J. K., Nakatsuka, T., Oschlies, A., Saito, M. a, Thingstad, T. F., Tsuda, A. and Ulloa, O.: Processes and patterns of oceanic nutrient limitation, Nat. Geosci., 6(9), 701-710, doi:10.1038/ngeo1765, 2013.

Moore, L. R., Ostrowski, M., Scanlan, D. J., Feren, K. and Sweetsir, T.: Ecotypic variation in phosphorus-acquisition mechanisms within marine picocyanobacteria, Aquat. Microb. Ecol., 39(3), 257-269, doi:10.3354/ame039257, 2005.

Moore, L. R., Coe, A., Zinser, E. R., Saito, M. a., Sullivan, M. B., Lindell, D., Frois-Moniz, K., Waterbury, J. and Chisholm, S. W.: Culturing the marine cyanobacterium Prochlorococcus, Limnol. Oceanogr. Methods, 5(Table 1), 353-362, doi:10.4319/lom.2007.5.353, 2007.

Morel, F. M. M. and Hering, J. G.: Principles and applications of aquatic chemistry, John Wiley \& Sons., 1993.

Morris, J. J., Kirkegaard, R., Szul, M. J., Johnson, Z. I. and Zinser, E. R.: Facilitation of robust growth of Prochlorococcus colonies and dilute liquid cultures by "helper" heterotrophic bacteria, Appl. Environ. Microbiol., 74(14), 4530-4534, doi:10.1128/AEM.02479-07, 2008.

Noble, A. E., Saito, M. A., Maiti, K. and Benitez-Nelson, C. R.: Cobalt, manganese, and iron near the Hawaiian Islands: A potential concentrating mechanism for cobalt within a cyclonic eddy and implications for the hybrid-type trace metals, Deep Sea Res. Part II Top. Stud. Oceanogr., 55(10-13), 1473-1490, doi:10.1016/j.dsr2.2008.02.010, 2008.

Noble, A. E., Lamborg, C. H., Ohnemus, D. C., Lam, P. J., Goepfert, T. J., Measures, C. I., 
Frame, C. H., Casciotti, K. L., DiTullio, G. R., Jennings, J. and Saito, M. A.: Basin-scale inputs of cobalt, iron, and manganese from the Benguela-Angola front to the South Atlantic Ocean, Limnol. Oceanogr., 57(4), 989-1010, doi:10.4319/lo.2012.57.4.0989, 2012.

Outten, C. E. and O'Halloran, T. V: Femtomolar sensitivity of metalloregulatory proteins controlling zinc homeostasis., Science, 292(5526), 2488-2492, doi:10.1126/science.1060331, 2001.

Patterson, C. J., Pernil, R., Dainty, S. J., Chakrabarti, B., Henry, C. E., Money, V. a, Foster, a W. and Robinson, N. J.: Co(ii)-detection does not follow Kco(ii) gradient: channelling in Co(ii)sensing, Metallomics, 5(4), 352-362, doi:10.1039/c3mt20241k, 2013a.

Patterson, C. J., Pernil, R., Foster, A. W. and Robinson, N. J.: Metal Homeostasis:

Cyanobacterial Models That Address Cross-Talk, Encycl. Inorg. Bioinorg. Chem., 1-12, doi:10.1002/9781119951438.eibc2112, 2013b.

Price, N. M. and Morel, F. M. M.: Cadmium and cobalt substitution for zinc in a marine diatom, Nature, 344(6267), 658-660, doi:10.1038/344658a0, 1990.

Price, N. M., Harrison, G. I., Hering, J. G., Hudson, R. J., Nirel, P. M. V., Palenik, B. and Morel, F. M. M.: Preparation and Chemistry of the Artificial Algal Culture Medium Aquil, Biol. Oceanogr., 6(5-6), 443-461, doi:10.1080/01965581.1988.10749544, 1989.

Rae, T. D., Schmidt, P. J., Pufahl, R. A., Culotta, V. C. and O'Halloran, T. V.: Undetectable Intracellular Free Copper: The Requirement of a Copper Chaperone for Superoxide Dismutase, Science (80-. )., 284(5415), 805-808, doi:10.1126/science.284.5415.805, 1999.

Raimunda, D., González-Guerrero, M., Leeber, B. W. and Argüello, J. M.: The transport mechanism of bacterial Cu+-ATPases: Distinct efflux rates adapted to different function, BioMetals, 24(3), 467-475, doi:10.1007/s10534-010-9404-3, 2011.

Resing, J. A., Sedwick, P. N., German, C. R., Jenkins, W. J., Moffett, J. W., Sohst, B. M. and Tagliabue, A.: Basin-scale transport of hydrothermal dissolved metals across the South Pacific Ocean, Nature, 523(7559), 200-203, doi:10.1038/nature14577, 2015.

Roshan, S., Wu, J. and Jenkins, W. J.: Long-range transport of hydrothermal dissolved Zn in the tropical South Pacific, Mar. Chem., 183(May), 25-32, doi:10.1016/j.marchem.2016.05.005, 2016.

Saito, M. A. and Moffett, J. W.: Complexation of cobalt by natural organic ligands in the Sargasso Sea as determined by a new high-sensitivity electrochemical cobalt speciation method suitable for open ocean work, Mar. Chem., 75(1-2), 49-68, doi:10.1016/S0304-4203(01)00025$1,2001$.

Saito, M. A., Moffett, J. W., Chisholm, S. W. and Waterbury, J. B.: Cobalt limitation and uptake in Prochlorococcus, Limnol. Oceanogr., 47(6), 1629-1636, doi:10.4319/lo.2002.47.6.1629, 2002.

Saito, M. A., Sigman, D. M. and Morel, F. M. .: The bioinorganic chemistry of the ancient ocean: the co-evolution of cyanobacterial metal requirements and biogeochemical cycles at the 
Archean-Proterozoic boundary?, Inorganica Chim. Acta, 356, 308-318, doi:10.1016/S00201693(03)00442-0, 2003.

Saito, M. A., Rocap, G. and Moffett, J. W.: Production of cobalt binding ligands in a Synechococcus feature at the Costa Rica upwelling dome, Limnol. Oceanogr., 50(1), 279-290, doi:10.4319/lo.2005.50.1.0279, 2005.

Saito, M. A., Goepfert, T. J., Noble, A. E., Bertrand, E. M., Sedwick, P. N. and DiTullio, G. R.: A seasonal study of dissolved cobalt in the Ross Sea, Antarctica: micronutrient behavior, absence of scavenging, and relationships with Zn, Cd, and P, Biogeosciences, 7(12), 4059-4082, doi:10.5194/bg-7-4059-2010, 2010.

Saito, M. A., McIlvin, M. R., Moran, D. M., Goepfert, T. J., DiTullio, G. R., Post, A. F. and Lamborg, C. H.: Multiple nutrient stresses at intersecting Pacific Ocean biomes detected by protein biomarkers, Science (80-. )., 345(6201), 1173-1177, doi:10.1126/science.1256450, 2014.

Da Silva, J. J. R. F. and Williams, R. J. P.: The biological chemistry of the elements: the inorganic chemistry of life, Oxford University Press., 2001.

Sunda, W., Price, N., Morel, F., Service, N. O. and Road, P. I.: Trace metal ion buffers and their use in culture studies, in Algal Culturing Techniques, pp. 35-63, Academic Press., 2005.

Sunda, W. G. and Huntsman, S. A.: Feedback interactions between zinc and phytoplankton in seawater, Limnol. Oceanogr., 37(1), 25-40, doi:10.4319/lo.1992.37.1.0025, 1992.

Sunda, W. G. and Huntsman, S. A.: Cobalt and zinc interreplacement in marine phytoplankton: Biological and geochemical implications, Limnol. Oceanogr., 40(8), 1404-1417, doi:10.4319/lo.1995.40.8.1404, 1995.

Sunda, W. G. and Huntsman, S. a.: Effect of Zn, Mn, and Fe on Cd accumulation in phytoplankton: Implications for oceanic Cd cycling, Limnol. Oceanogr., 45(7), 1501-1516, doi:10.4319/lo.2000.45.7.1501, 2000.

Tottey, S., Waldron, K. J., Firbank, S. J., Reale, B., Bessant, C., Sato, K., Cheek, T. R., Gray, J., Banfield, M. J., Dennison, C. and Robinson, N. J.: LETTERS Protein-folding location can regulate manganese- binding versus copper-or zinc-binding, Nature, 455(October), 1138-1142, doi:10.1038/nature07340, 2008.

Tottey, S., Patterson, C. J., Banci, L., Bertini, I., Felli, I. C., Pavelkova, A., Dainty, S. J., Pernil, R., Waldron, K. J., Foster, A. W. and Robinson, N. J.: Cyanobacterial metallochaperone inhibits deleterious side reactions of copper., Proc. Natl. Acad. Sci. U. S. A., 109(1), 95-100, doi:10.1073/pnas.1117515109, 2012.

Twining, B. S. and Baines, S. B.: The Trace Metal Composition of Marine Phytoplankton, Ann. Rev. Mar. Sci., 5(1), 191-215, doi:10.1146/annurev-marine-121211-172322, 2013.

Twining, B. S., Baines, S. B., Bozard, J. B., Vogt, S., Walker, E. a. and Nelson, D. M.: Metal quotas of plankton in the equatorial Pacific Ocean, Deep Sea Res. Part II Top. Stud. Oceanogr., 58(3-4), 325-341, doi:10.1016/j.dsr2.2010.08.018, 2011. 
Twining, B. S., Rauschenberg, S., Morton, P. L. and Vogt, S.: Metal contents of phytoplankton and labile particulate material in the North Atlantic Ocean, Prog. Oceanogr., 137, 261-283, doi:10.1016/j.pocean.2015.07.001, 2015.

Waldron, K. J. and Robinson, N. J.: How do bacterial cells ensure that metalloproteins get the correct metal?, Nat. Rev. Microbiol., 7(1), 25-35, doi:10.1038/nrmicro2057, 2009.

Waterbury, J., Watson, S., Valois, F. and Franks, D.: Biological and ecological characterization of the marine unicellular cyanobacterium Synechococcus, in Photosynthetic Picoplankton., 1986.

Xu, Y., Tang, D., Shaked, Y. and Morel, F. M. M.: Zinc, cadmium, and cobalt interreplacement and relative use efficiencies in the coccolithophore Emiliania huxleyi, Limnol. Oceanogr., 52(5), 2294-2305, doi:10.4319/lo.2007.52.5.2294, 2007.

Yee, D. and Morel, F. M. M.: In vivo substitution of zinc by cobalt in carbonic anhydrase of a marine diatom, Limnol. Oceanogr., 41(3), 573-577, doi:10.4319/lo.1996.41.3.0573, 1996.

Zhang, Y., Rodionov, D. A., Gelfand, M. S. and Gladyshev, V. N.: Comparative genomic analyses of nickel, cobalt and vitamin B12 utilization., BMC Genomics, 10, 78, doi:10.1186/1471-2164-10-78, 2009. 
Table 1. Comparison of some genes involved in metal trafficking, sensing and use in the model organism Synechocystis PCC 6803 and Prochlorococcus MIT9215, the strain used in this study. Synechocystis annotations are consistent with a recent review by Huertas et al. 2014.

\begin{tabular}{llll}
\hline Gene in Synechocystis 6803 & Functon & In Prochlorococcus MIT 9215? \\
\hline pacS & Sll1920 & Cu import to thylakoid? & P9215_01481 \\
ctaA & slr1950 & Cytosolic Cu exporter? & P9215_05261 \\
plastocyanin & sll0199 & Electron transport & P9215_06631 \\
atx 1/copZ & ssr2857 & Cytosolic Cu chaperone & ND \\
copABC & Slr6042-4 & Inducible Cu exporter & ND \\
copS & sll0790 & Cu sensing histidine kinase & ND* \\
copR & sll0789 & Cu export regulator & ND* \\
ziaA & Sll0798 & Zn exporter & ND \\
ziaR & Sll0792 & Zinc regulator & ND \\
nrsR & sll0797 & Ni regulator & ND* \\
nrsABC & Sll793-5 & Inducible Ni exporter & ND \\
nrsD & Sll0796 & Ni exporter & ND \\
hypA/B & sll1078-9 & Ni chaperone (putative) & ND \\
coaR & Sll0794 & Cobalt transcriptional regulator & ND* \\
cbiMOQ & sll0383-5 & Cobalt transporter & ND \\
cbiQ? & Slr1978 & Possible cobalt permease? & P9215_04691 \\
mntABC & sll1598 & Manganese transport system & P9215_06831 \\
& sll1599 & & P9215_06841 \\
& sll1600 & & P9215_06851 \\
\hline
\end{tabular}

$\mathrm{ND}=$ not detected; $\mathrm{ND}^{*}=$ two component systems (metal regulators and histidine kinases) homologous domains that cover part of the protein sequence (e.g. DNA binding, ATP hydrolysis domains) but do not have homology to metal binding domains. BLAST searches for coaR, copR, and nrsR return all twocomponent systems in the Prochlorococcus MIT9215 genome at the same score (>1e-30). 
Table 2. Prochlorococcus MIT9215 metal quotas $\left(\mathrm{mmol} \mathrm{mol}^{-1} \mathrm{P}\right)$ from Experiment Group 2.

\begin{tabular}{lccccccc}
\hline & $\mu$ & $\mathrm{Mn} / \mathrm{P}$ & $\mathrm{Fe} / \mathrm{P}$ & $\mathrm{Co} / \mathrm{P}$ & $\mathrm{Ni} / \mathrm{P}$ & $\mathrm{Cu} / \mathrm{P}$ & $\mathrm{Zn} / \mathrm{P}$ \\
\hline $\begin{array}{l}\text { Cobalt limitation } \\
\text { Co' (pM)* }\end{array}$ & & & & & & & \\
$\quad 15.5$ & 0.55 & 2.5 & 4.7 & 0.072 & 0.10 & 0.07 & 0.84 \\
$\quad 4.7$ & 0.55 & 2.4 & 5.0 & 0.026 & 0.08 & 0.06 & 0.34 \\
1.6 & 0.43 & 2.6 & 5.1 & 0.007 & 0.09 & 0.08 & 0.62 \\
$\quad 0.9$ & 0.33 & 2.7 & 6.4 & 0.004 & 0.11 & 0.09 & 0.58 \\
$\quad 0.5$ & 0.09 & 2.6 & 13.2 & 0.001 & 0.12 & 0.10 & 1.53 \\
& & & & & & & \\
Metal perturbation*** & & & & & & & \\
+Mn (110 nM Mn') & 0.34 & 3.1 & 6.2 & 0.004 & 0.33 & 0.05 & 0.71 \\
-Mn (1 nM Mn') & 0.50 & 1.3 & 6.4 & 0.022 & 0.39 & 0.05 & 0.62 \\
+Ni (1.8 pM Ni') & 0.41 & 3.0 & 5.5 & 0.005 & 0.10 & 0.05 & 0.62 \\
-Ni (0.07 pM Ni') & 0.41 & 3.1 & 5.7 & 0.006 & 0.28 & 0.59 & 0.60 \\
+Cu (9 pM Cu') & 0.40 & 2.8 & 5.3 & 0.006 & 0.38 & 0.06 & 0.61 \\
+Zn (22 pM Zn') & 0.32 & 3.5 & 6.6 & 0.004 & 0.38 & 0.08 & 0.81
\end{tabular}

Fe limitation***

$\mathrm{Fe}^{\prime}(\mathrm{pM})$

$\begin{array}{rrrrrrrr}24 & 0.56 & 2.3 & 4.0 & 0.035 & 0.10 & 0.05 & 0.35 \\ 7.1 & 0.53 & 2.3 & 3.2 & 0.039 & 0.12 & 0.07 & 0.17 \\ 2.4 & 0.48 & 2.5 & 2.1 & 0.041 & 0.16 & 0.09 & 0.51 \\ 0.7 & 0.40 & 2.7 & 0.8 & 0.044 & 0.20 & 0.08 & 0.47 \\ 0.2 & 0.23 & 3.0 & 1.8 & 0.047 & 0.40 & 0.12 & 1.61\end{array}$

Picoplankton Single Cell metal Quotas

North Atlantic Ocean

Equatorial Pacific

$0.34 \quad 5.0$

$0.15 \quad 0.48$

$4.6 \quad 1.2$

(Twining et al. 2011)

$\begin{array}{llll}0.34 & 1.4 & 0.49 & 0.68\end{array}$

${ }^{*} \log \left(\mathrm{Co}^{\prime} /\right.$ total Co $)=-2.81 ; 35 \mathrm{nM}$ Mn', $28 \mathrm{pM} \mathrm{Fe}, 0.2 \mathrm{pM} \mathrm{Ni}, 0.07 \mathrm{pM} \mathrm{Cu}, 8 \mathrm{pM}$ Zn'

** baseline media composition: 0.9 pM Co', 35 nM Mn', 0.2 pM Ni', 28 pM Fe', 0.07 pM Cu', 8 pM $\mathrm{Zn}$ '. Note that growth rates are slightly higher at than at an equivalent $\mathrm{Co}$ ' concentration in the cobalt limitation dataset and, as a result, most metal quotas are slightly lower in the metal perturbation experiments.

*** Fe added, $\log (\mathrm{Fe}$ '/total $\mathrm{Fe})=-2.63 ; 35$ nM Mn', 7.8 pM Co', 0.2 pM Ni', 0.07 pM Cu', 8 pM Zn' 
Table 3. Cobalt uptake under cobalt-limiting conditions in Experiment Group 1.

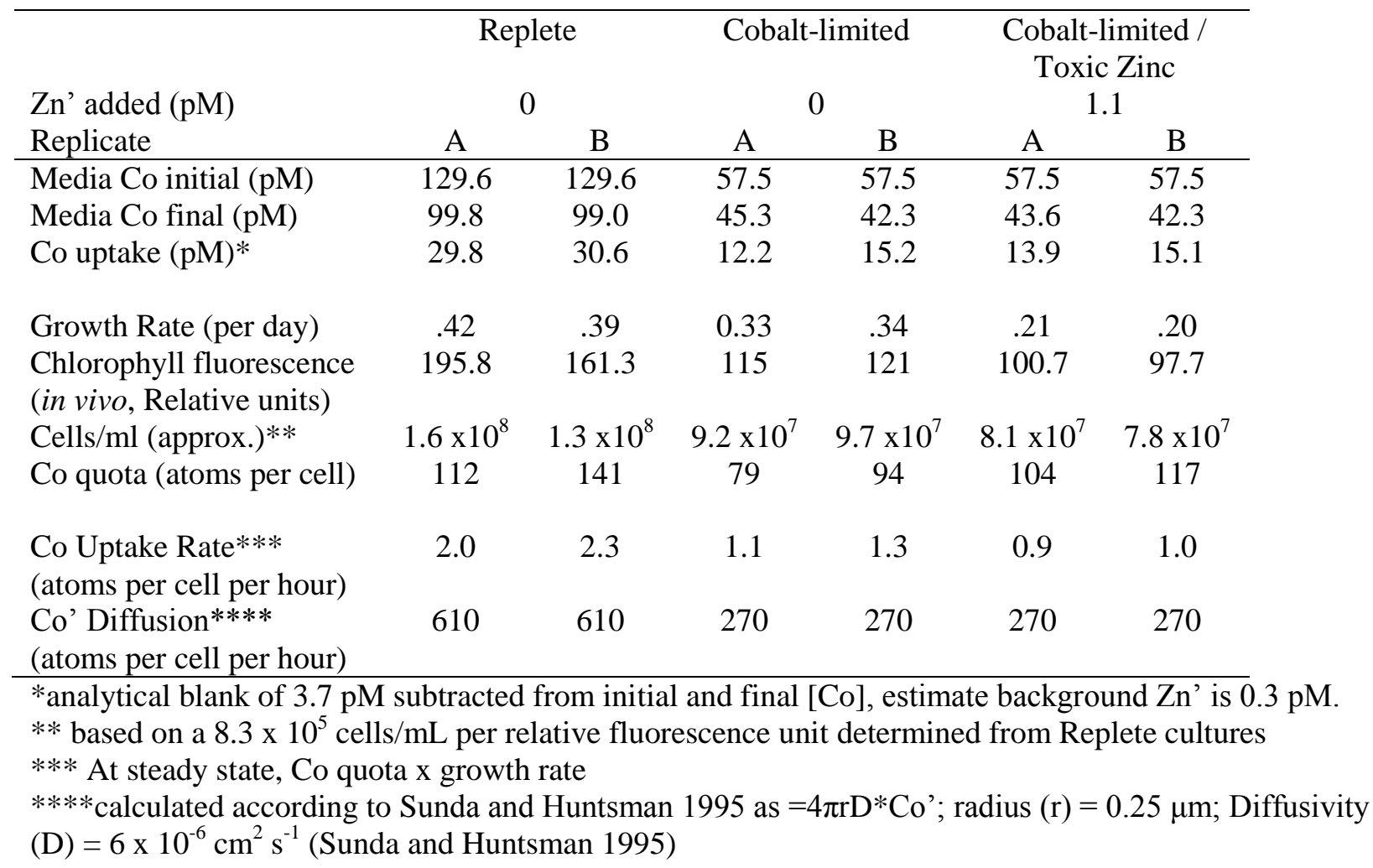


A

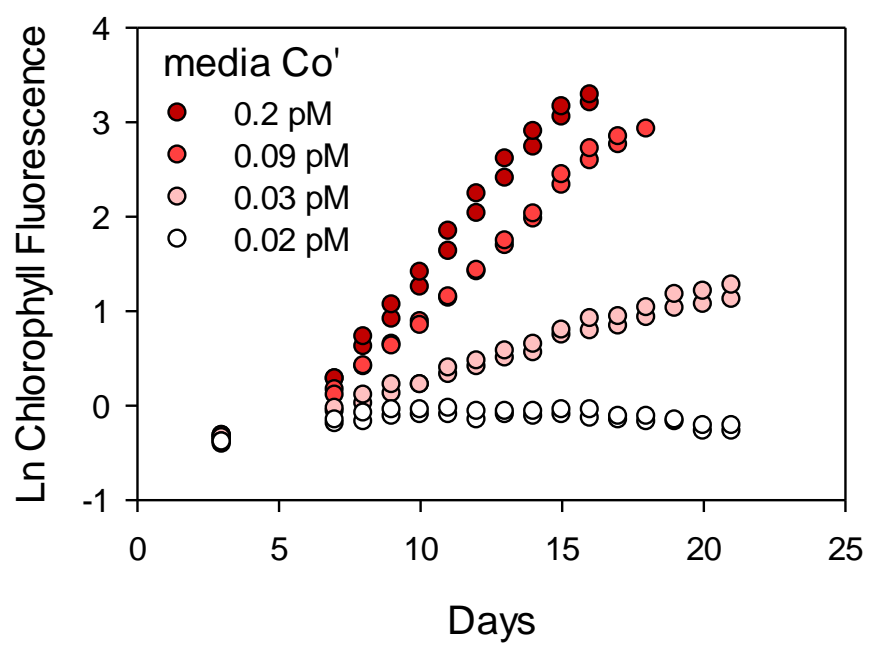

B

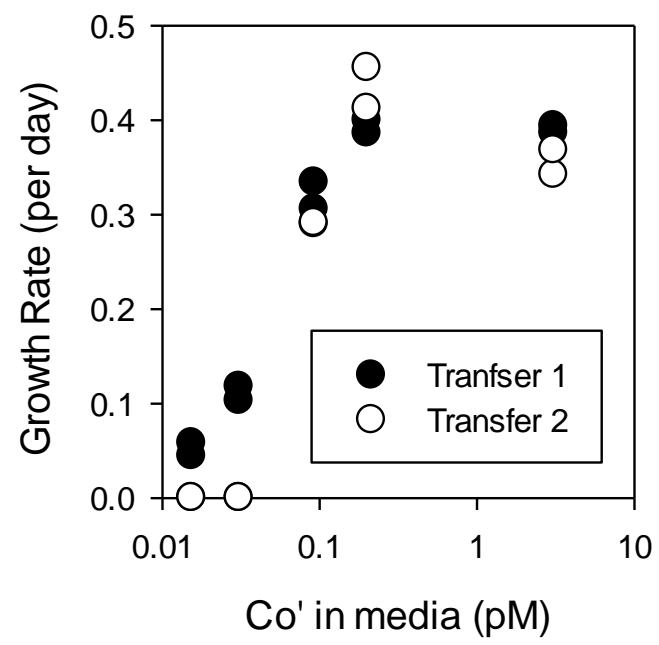

Figure 1. Growth experiments with Prochlorococcus in to media with low background Zn' (Experiment Group 1). A) In situ chlorophyll fluorescence, a proxy for Prochlorococcus biomass, decreased as cobalt concentrations in growth media decreased. B) Growth rates were stable for at least two transfers at Co' $>0.05 \mathrm{pM}$. Prochlorococcus was acclimated to media with $\sim 1$ pM Co' for several weeks prior to experiments. Biological duplicates are plotted for both panels. 
A

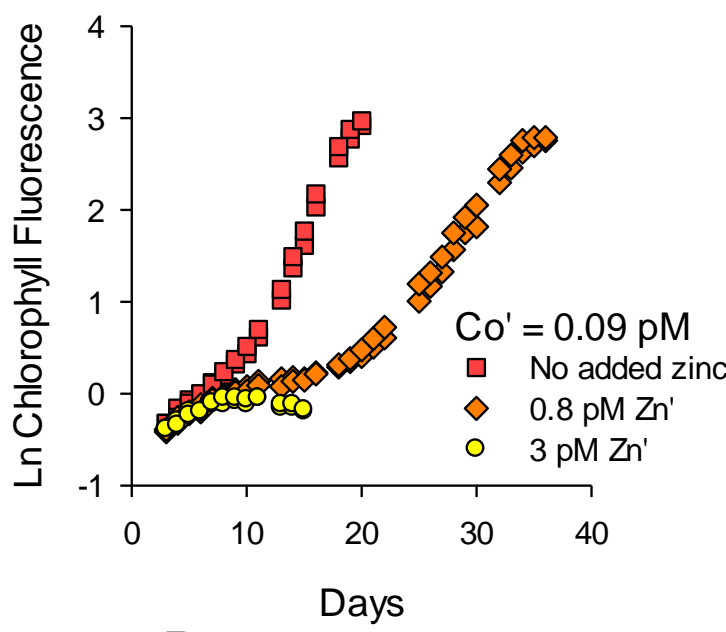

B

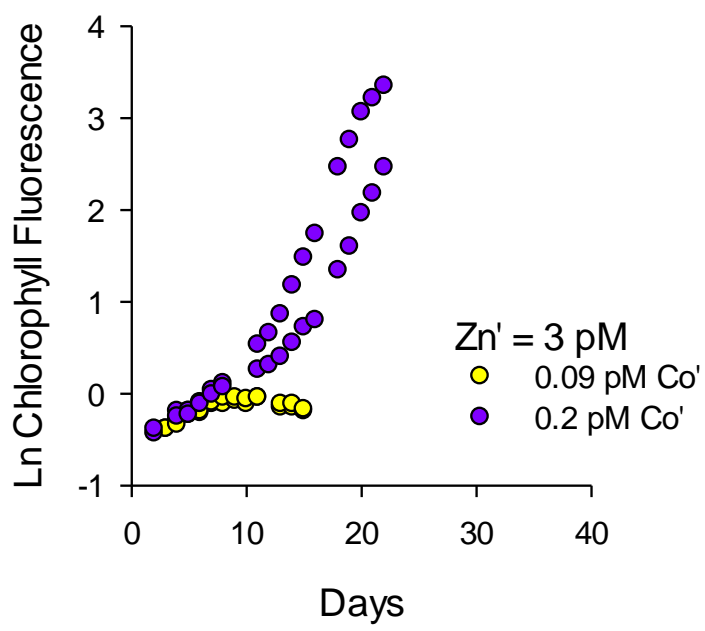

$\mathrm{C}$

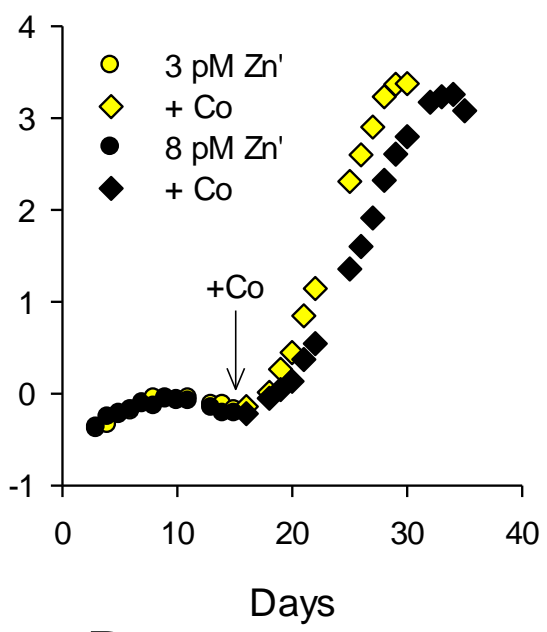

$\mathrm{D}$

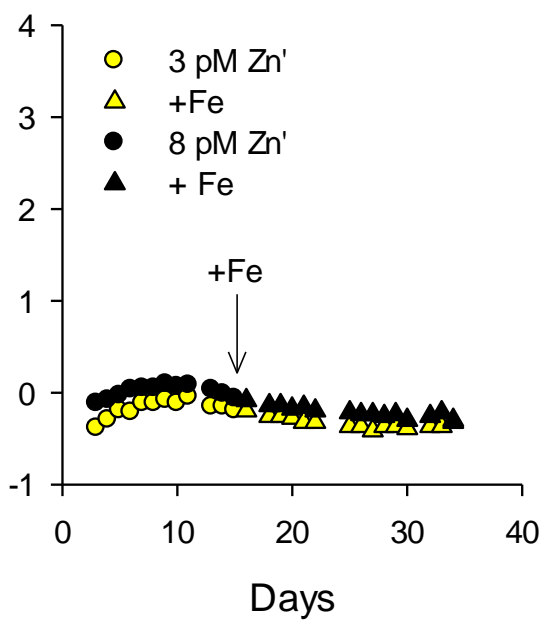

Figure 2. Zinc sensitivity of Prochlorococcus growth under cobalt limited conditions. A) Increasing Zn' concentrations decreased growth rates at the same cobalt concentration. B) Zinc toxicity at 3 and $8 \mathrm{pM} \mathrm{Zn'} \mathrm{was} \mathrm{rescued} \mathrm{by} \mathrm{addition} \mathrm{of} 200 \mathrm{pM}$ cobalt to stalled cultures. C) Growth at $3 \mathrm{pM} Z \mathrm{Zn}$ ' was possible at higher (0.2 pM) Co' concentrations. D) No stimulation was observed when $60 \mathrm{nM}$ Fe was added to stalled cultures. 

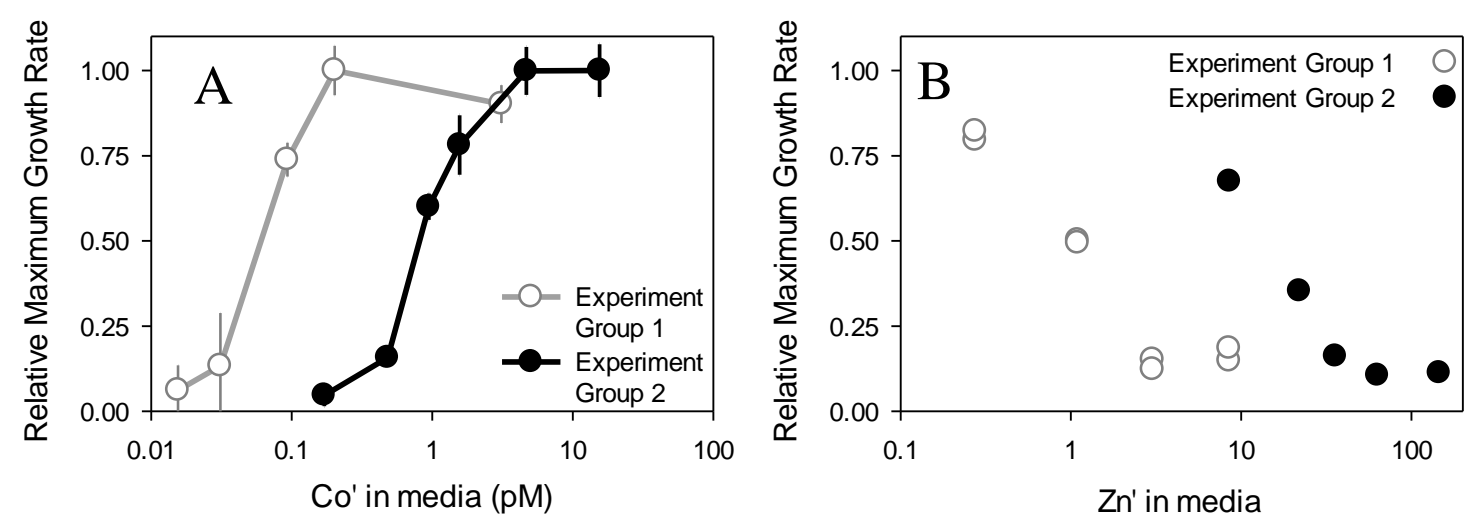

Figure 3. Cobalt limitation and zinc toxicity of Prochlorococcus MIT9215 in media with different levels of background Zn. A) Experiment Group 1used media with low background Zn' $(\sim 0.2 \mathrm{pM})$. Media used in Experiment Group 2 had a higher background Zn' concentration (8 $\mathrm{pM})$ and required a higher concentration of Co' to grow. B) Zinc toxicity of cobalt limited cultures. Co' in Experiment Group 1 cultures was 0.093 pM and 0.94 in Experiment Group 2. The offset between different experiments is due to different background concentrations of $\mathrm{Zn}$ ' in the growth media. 

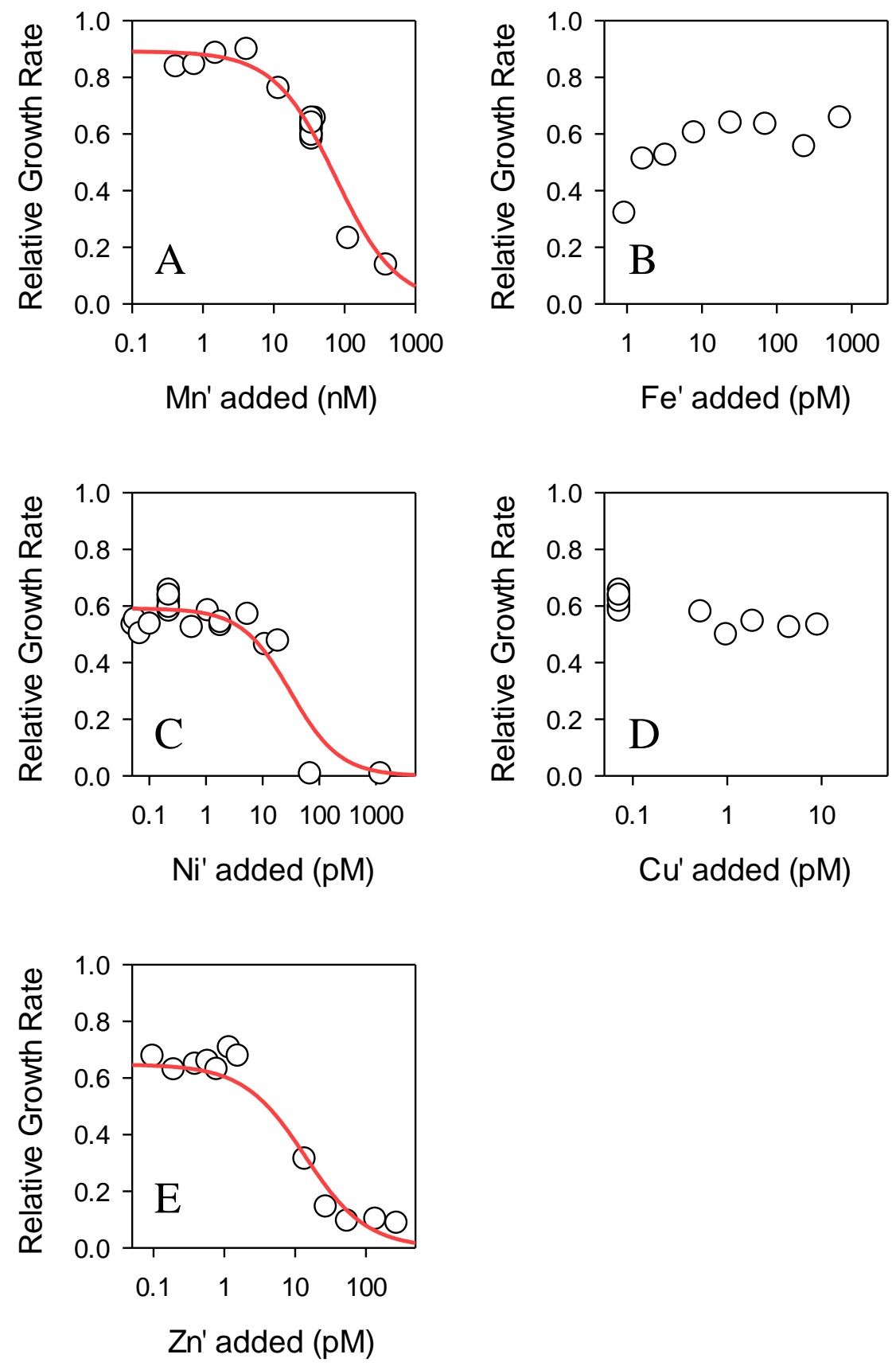

Figure 4. Metal inhibition of Prochlorococcus growth at cobalt limiting conditions. In all experiments, Co' $=0.94$ pM. Decreased growth rates at high Mn' (A), Ni' (C), and Zn' (E) suggest some level of competition between cobalt uptake and uptake of these metals. Red lines show results of modeled competitive inhibition according to Eq. 4. In contrast, presence of Fe (B) and $\mathrm{Cu}$ (D) did not impact cobalt-limited growth. Standard media contained $35 \mathrm{nM} \mathrm{Mn}$, $0.17 \mathrm{pM} \mathrm{Ni}$ ' and $28 \mathrm{pM} \mathrm{Fe',} \mathrm{and} 0.07 \mathrm{pM} \mathrm{Cu}$ '. 

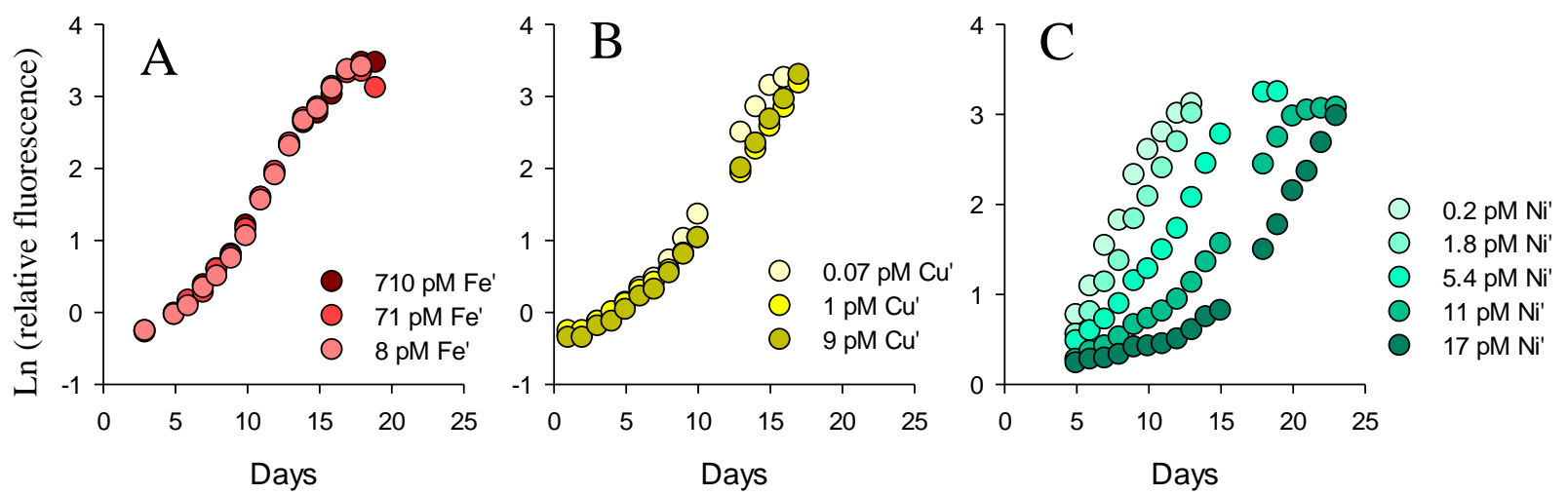

Figure 5. Cobalt-limited growth of Prochlorococcus under a gradient of Fe' (A), Cu' (B), and Ni' concentrations (C). All cultures have similar exponential growth rates but at high Ni', cultures experiences a significant lag before entering exponential growth. This effect is not observed at similar concentrations of $\mathrm{Fe}$ ' and $\mathrm{Cu}$ '. 

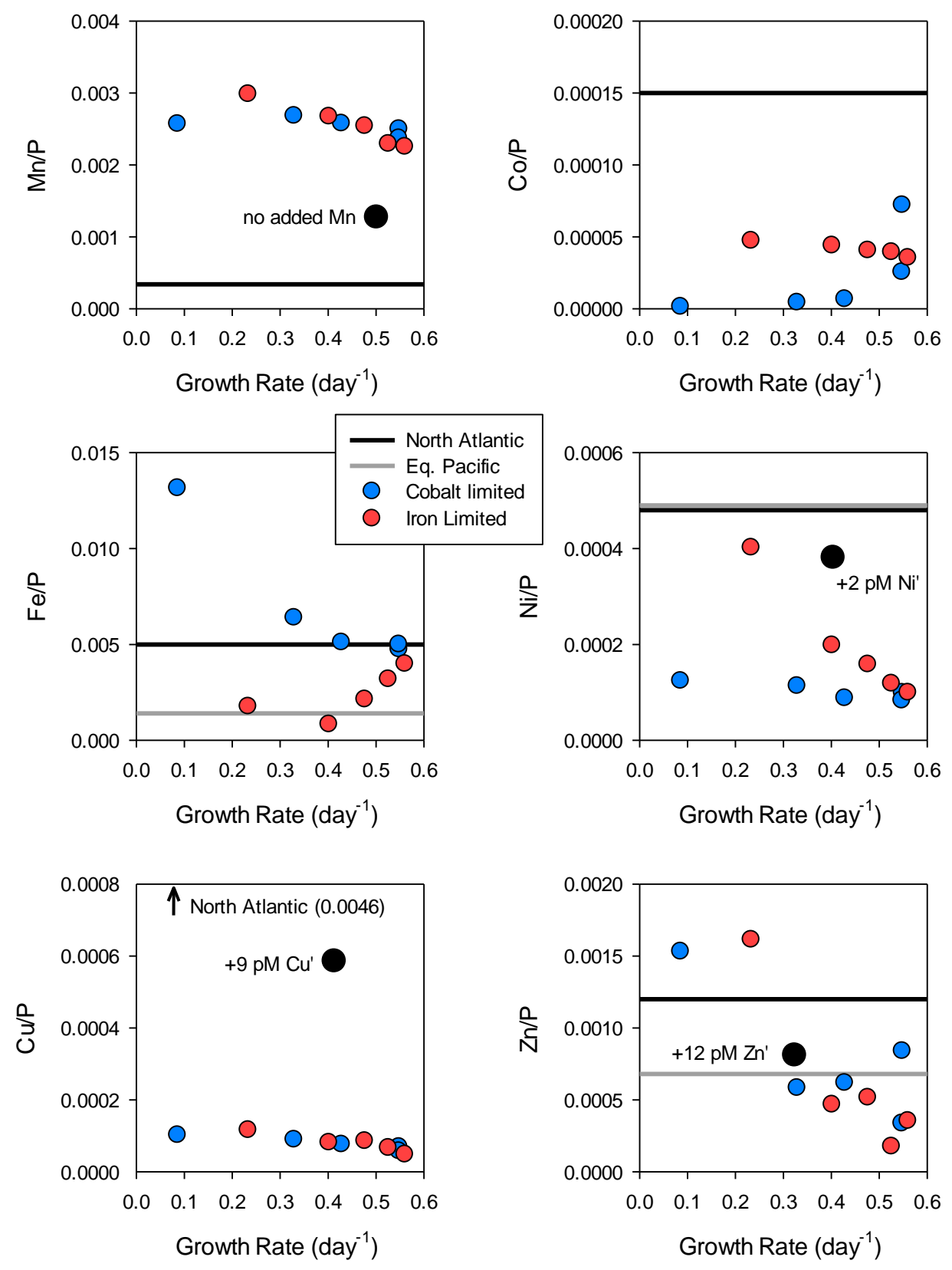

Figure 6. Metal quotas of Prochlorococcus MIT9215. Metal:P ratios determined by ICPMS under iron and cobalt limitation. Bio-dilution of most metals is apparent from increasing metal quotas at lower growth rates. Select metal perturbation experiments are shown to demonstrate sensitivity of metal:P stoichiometry to changing metal availability. Metal:P stoichiometry of single cell measurements of picophytoplankton elemental quotas in the North Atlantic (black bars, Twining et al. 2015) and Equatorial Pacific (grey bars, Twining et al. 2011) are shown for comparison (there are no copper and cobalt quotas in the Equatorial Pacific). In some cases, experiment conditions result in quotas that were lower than observed in the environment $(\mathrm{Co}, \mathrm{Ni}$, $\mathrm{Cu}$ ), with the notable exception of $\mathrm{Mn}$, which is much higher. 


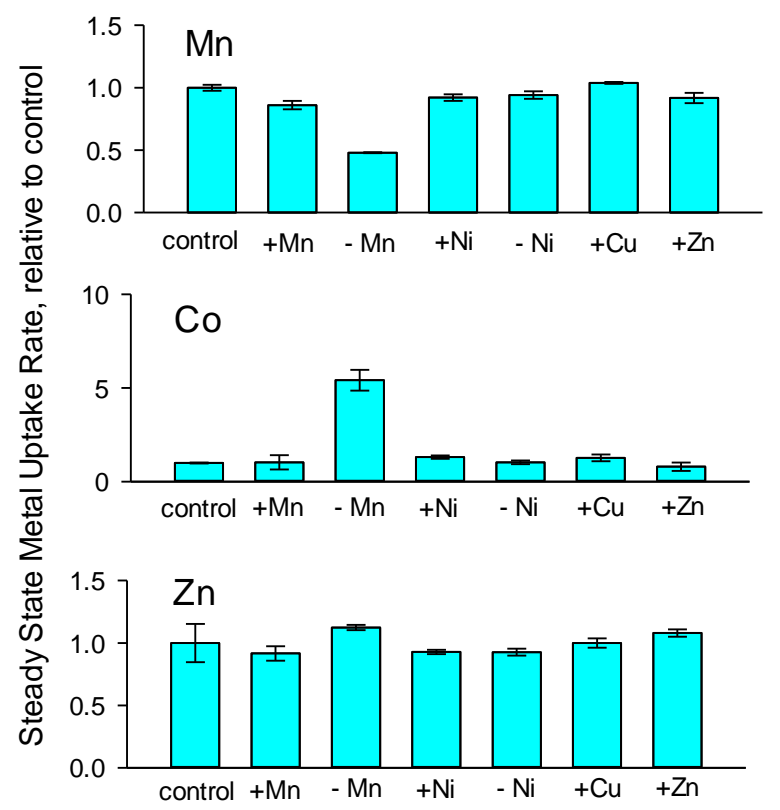

Figure 7. Sensitivity of metal uptake rates to changes in media composition. Prochlorococcus steady state metal uptake rates were calculated as the product of metal:P ratio and growth rate from Table 2. All data are normalized to metal uptake rates for the $0.9 \mathrm{pM} \mathrm{Co}$ ' in the cobalt limitation series (control). For perturbation experiments, media was altered by adding or removing additional metals (+Mn, -Mn, etc.). Decreased Mn' resulted in lower Mn uptake rates, as well as higher Co uptake rates. See Table 2 for media conditions. Error bars represent standard deviation of technical duplicates. 


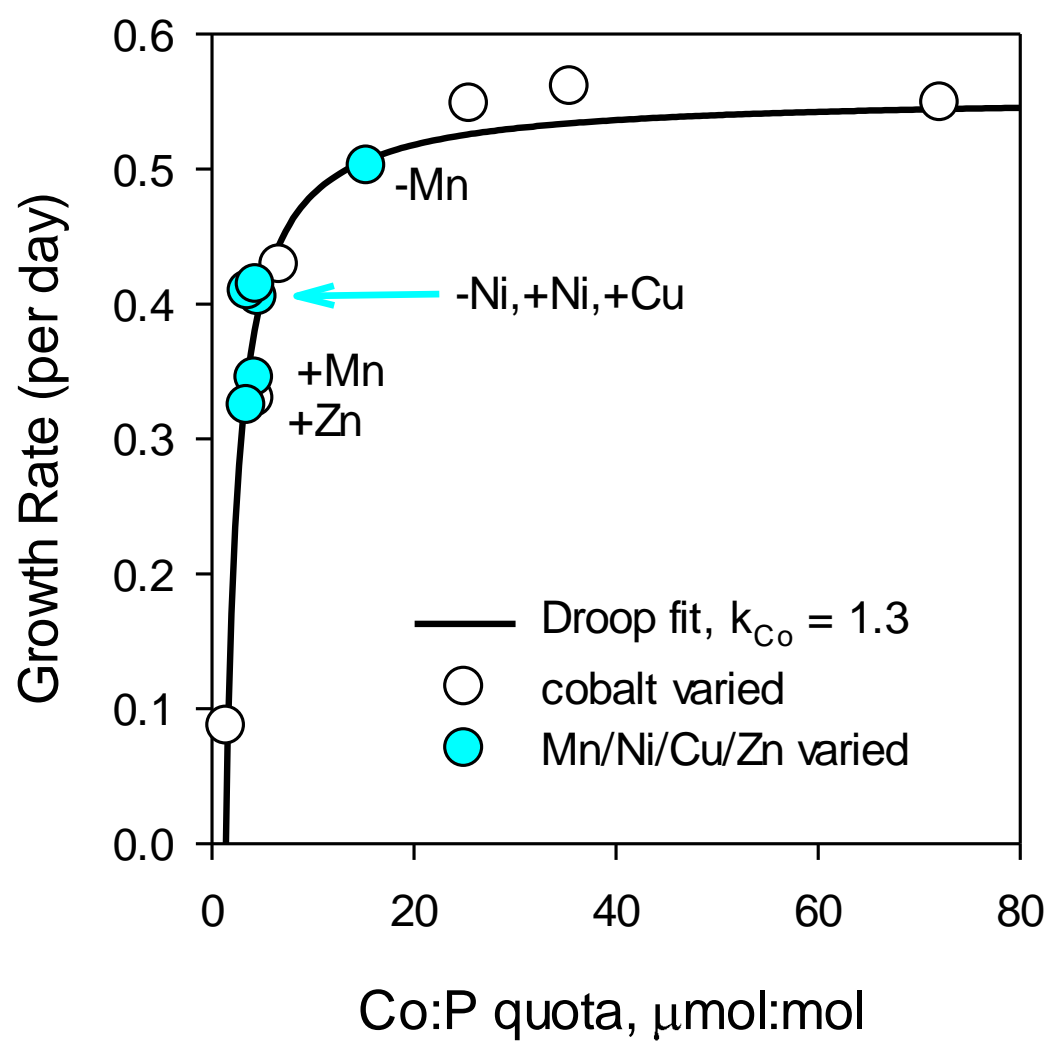

Figure 8. Cobalt quotas in Prochlorococcus MIT9215. Open circles show changes in Prochlorococcus Co:P ratio by changing Co' in growth media. The Droop Equation fit to these data from Chapter $4\left(r^{2}=0.97\right)$ is replotted. Cyan circles show Co:P quotas under cobalt limitation, but with the concentration of other metals varied. Decreasing $\mathrm{Mn}(-\mathrm{Mn})$ resulted in a higher Co:P quota and faster growth rate. These data are also presented in Table 3. 

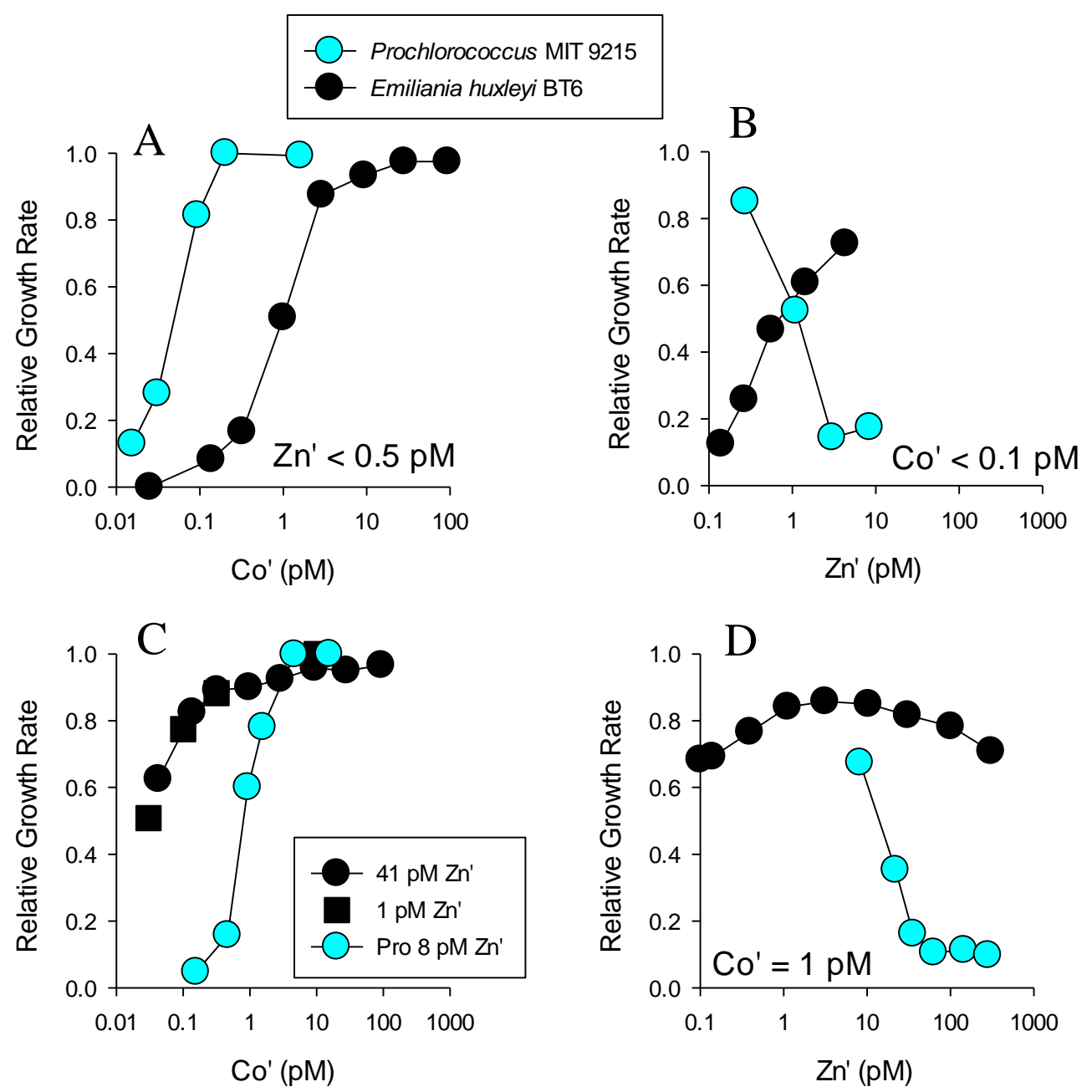

Figure 9. The opposing response to Co and Zn scarcity in Prochlorococcus MIT9215 and the coccolithophore Emiliania huxleyi. At very low Zn' (A), Prochlorococcus achieves maximum growth rates at lower Co' than E. huxleyi. At very low Co (B), Prochlorococcus can compete with E. huxleyi only when $\mathrm{Zn}$ ' is $<1 \mathrm{pM}$. At $8 \mathrm{pM} \mathrm{Zn}^{\prime}$ and higher (C) Prochlorococcus is outcompeted by E. huxleyi at low Co' and high Zn (D). Emiliania huxleyi data are replotted from Sunda and Huntsman 1995, $\mu_{\max }=1.2$ per day. Prochlorococcus data from Experiment Group 1 are plotted in the upper panel, $\mu_{\max }=0.39$ per day, and Experiment Group 2 are plotted in the lower panel $\left(\mu_{\max }=0.56\right.$ per day). 


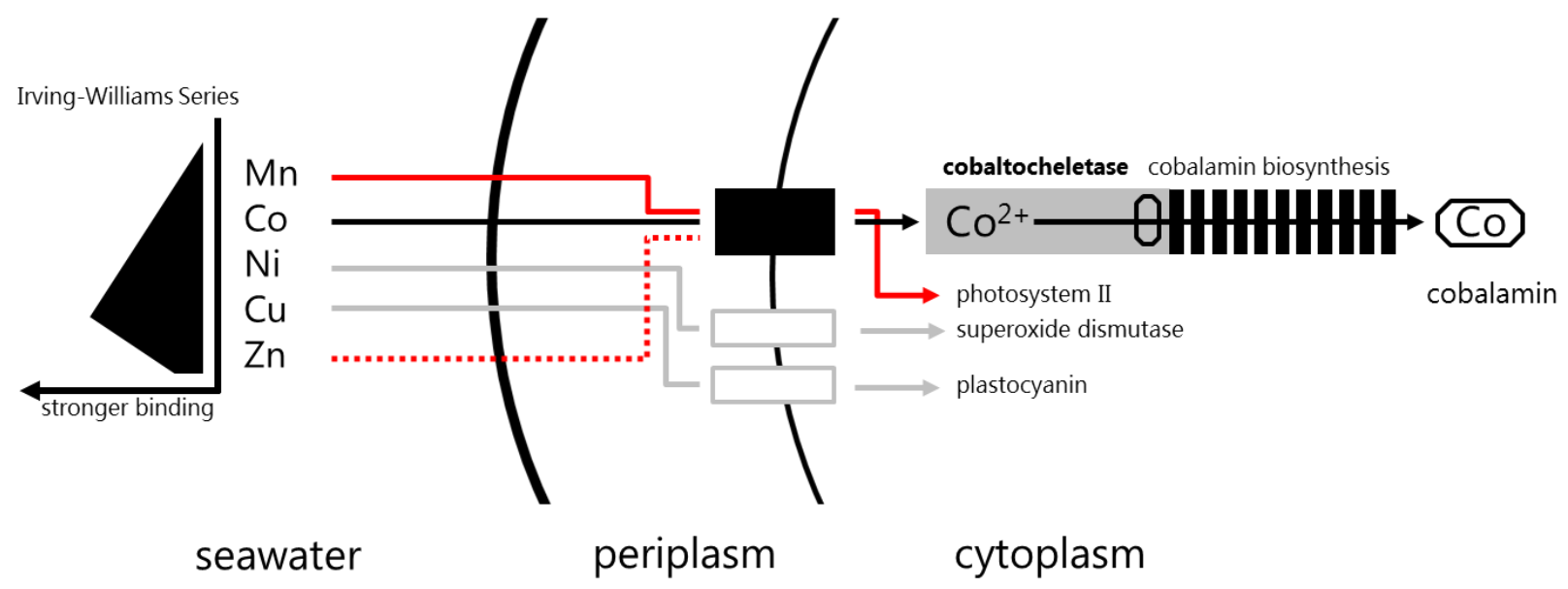

Figure 10. Schematic of cobalt uptake in cobalt-limited Prochlorococcus MIT9215. Cu and Ni appear to be acquired without influencing Co uptake whereas $\mathrm{Mn}$, Co and $\mathrm{Zn}$ compete for the same transporter. It is unclear if $\mathrm{Zn}$ is actually transported by this mechanism or if it just binds to the periplasmic binding site. 
Table S1. Media composition and speciation used for regressions. Ammonium added to $800 \mu \mathrm{M}$ and Phosphate added to $50 \mu \mathrm{M}$.

\begin{tabular}{lcccc}
\hline & Final & Added & Background & $\log \left[\mathrm{Me}^{\prime}\right] /[\mathrm{Me}]_{\text {total }}$ \\
\hline EDTA & 11700 & 11700 & 0 & \\
Manganese & 93 & 90 & 2.5 & -0.42 \\
Iron & 11.9 & 11.7 & 0.2 & -2.63 \\
Cobalt & $0.1-10$ & $0.1-10$ & 0.010 & -2.81 \\
Nickel & 14 & 10 & 4 & -4.75 \\
Copper & 0.8 & 0 & 0.8 & -4.04 \\
Zinc & 0.1 & 0 & $0.1^{*}, \mathbf{3}^{* *}$ & -2.56 \\
\hline
\end{tabular}

*Experiment Group 1

**Experiment Group 2 


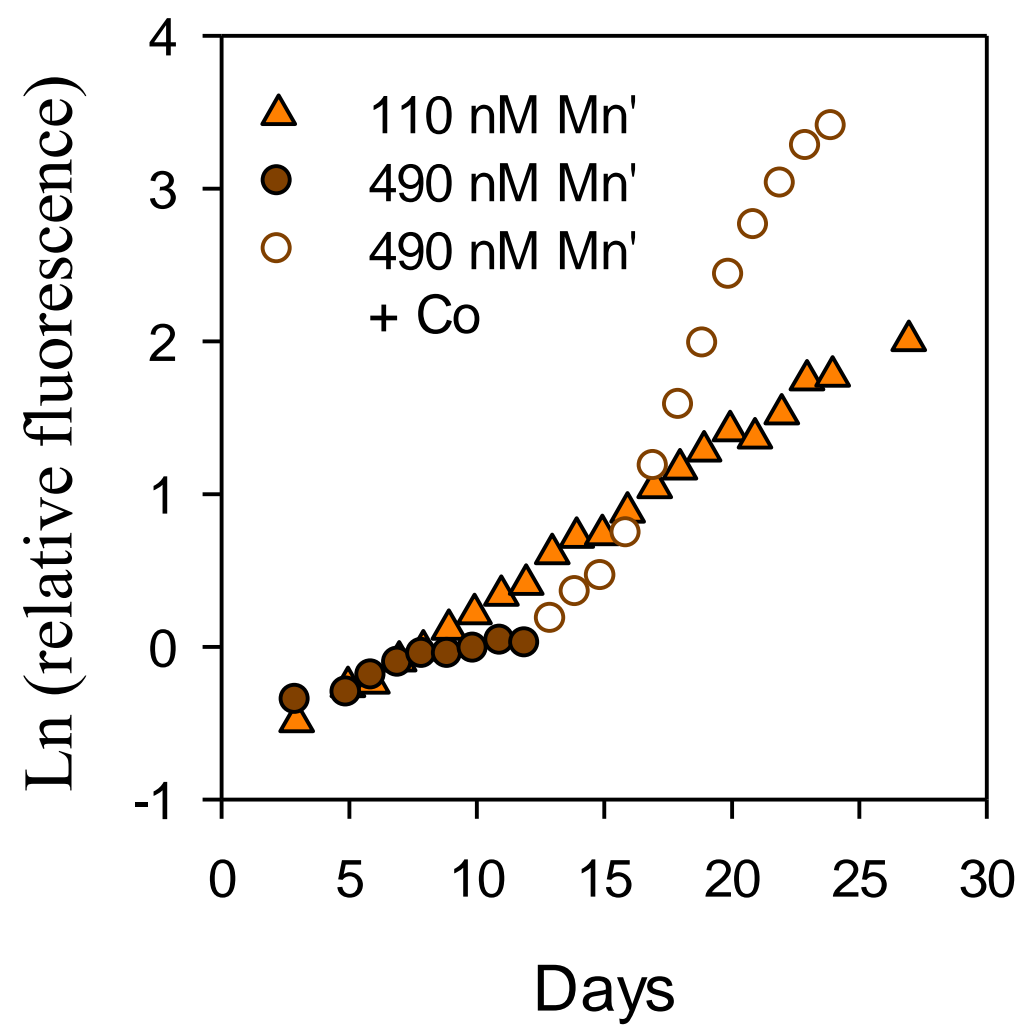

Figure S1. Reversibility of Mn-inhibition of Cobalt limited growth. Initial media concentrations is 0.9 pM Co' for both experiments. At $110 \mathrm{nM} \mathrm{Mn',} \mathrm{growth} \mathrm{rate} \mathrm{is} \mathrm{suppressed.} \mathrm{At} 490 \mathrm{nM} \mathrm{Mn}$ ' almost no growth was observed and culture entered stationary phase around day 10 . Addition of additional cobalt at day 13 was sufficient to stimulate exponential growth and achieve larger fluorescence yields than at a lower concentration of Mn'. 


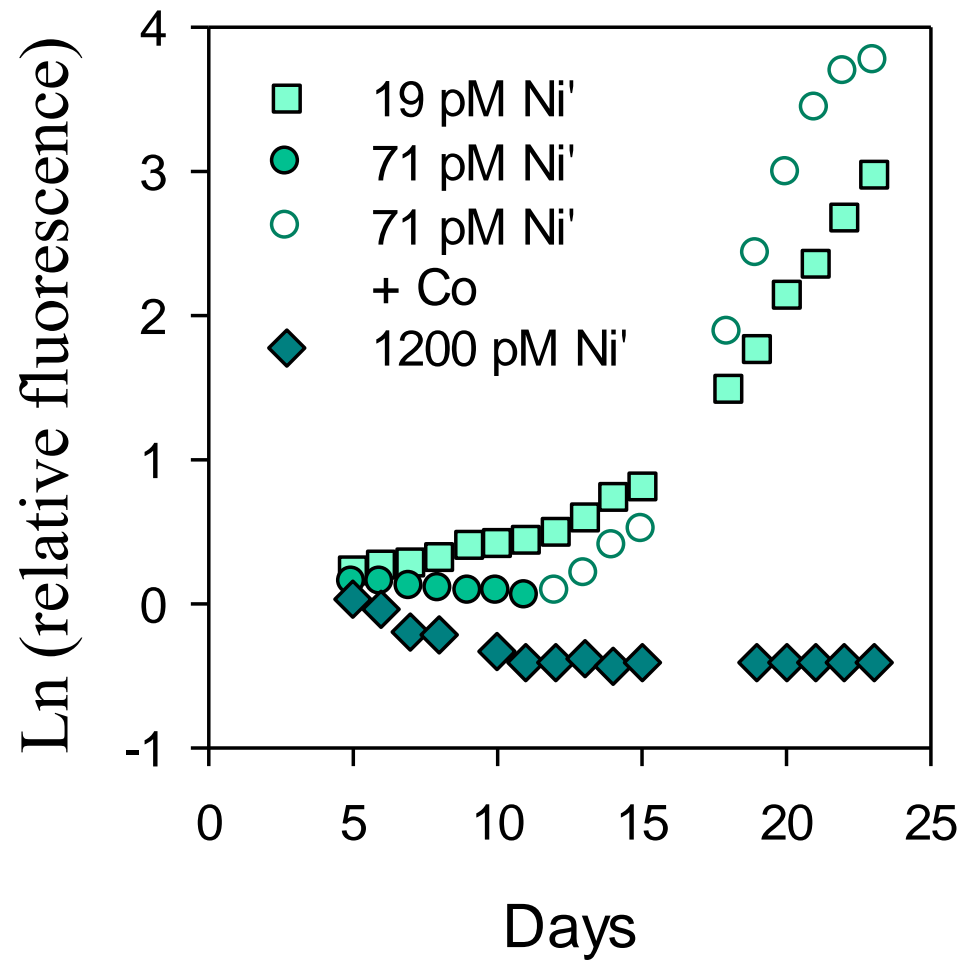

Figure S2. Reversibility of Nickel inhibition of cobalt limited growth. At the beginning of all experiments, Co' was 0.9 pM. Cultures with $19 \mathrm{pM} \mathrm{Ni}$ ' had a longer lag phase and slower growth rate than cultures with less Ni'. Cultures with $71 \mathrm{pM}$ N' did not grow and fluorescence yields decreased for several days until Co was added at Day 11, which enable faster growth rates than what were observed with cultures with less Ni' and less Co'. No growth was observed at higher Ni'. Because the total Ni' concentrations in these experiments approaches the EDTA concentration, the change in $\mathrm{Ni}^{\prime}$ is nonlinear with increasing total Ni. At $1200 \mathrm{pM} \mathrm{Ni}$, total nickel was $10 \mu \mathrm{M}$. At $71 \mathrm{pM}$ Ni', added nickel was $3 \mu \mathrm{M}$. At $19 \mathrm{pM}$ Ni' total nickel was $1 \mu \mathrm{M}$. 


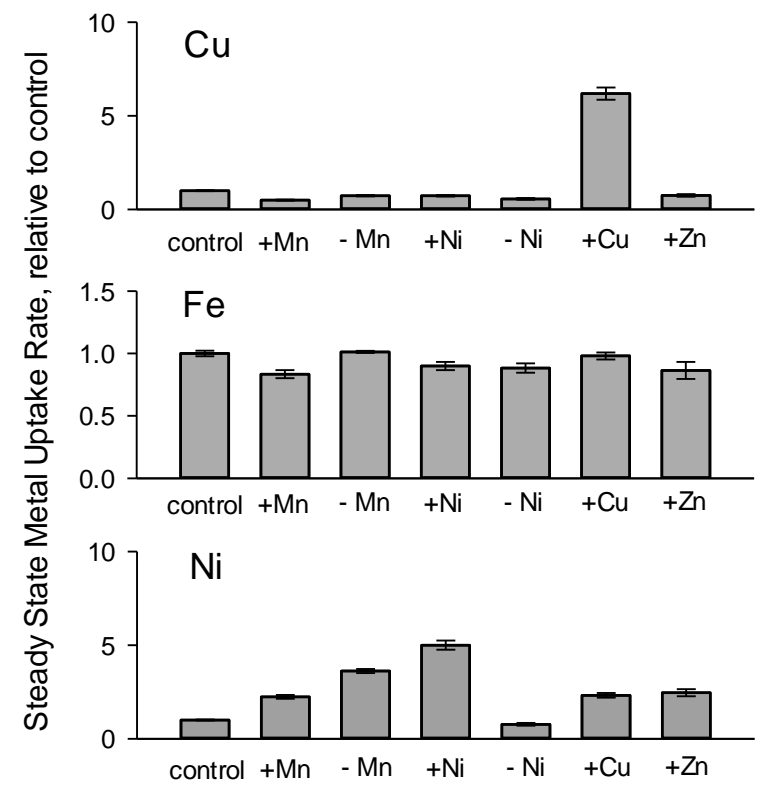

Figure S3. Sensitivity of $\mathrm{Cu}, \mathrm{Fe}$, and Ni uptake rates to changes in media composition.

Prochlorococcus steady state metal uptake rates were calculated as the product of metal:P ratio and growth rate from Table 2. All data are normalized to metal uptake rates for the $0.9 \mathrm{pM} \mathrm{Co}$ in the cobalt limitation series (control). Decreased Mn' resulted in lower Mn uptake rates, as well as higher Co uptake rates. See Table 2 for media conditions. Standard deviation based on technical duplicates are shown in error bars. 


\section{Chapter 6.}

\section{Conclusions}

Is production in the ocean limited by the scarcity of cobalt? Ultimately, this question comes down to supply and demand: does the supply of cobalt in seawater meet the demands of phytoplankton? This thesis provides constraints on both ends. In Chapters 2 and 3, processes examining the seawater cobalt supply are deconstructed and analyzed.

In Chapter 2, I described the distribution of dissolved cobalt and labile dissolved cobalt across the Eastern Tropical Pacific Ocean. This dataset represents one of only a handful of highresolution, full-depth ocean sections for this metal and the first of its kind in the Pacific Ocean. Similar to transects in the Atlantic Ocean, the central role of oxygen minimum zones in controlling the distribution of cobalt in Pacific Ocean is unmistakable. Remineralization of cobalt exported below the surface ocean contributes to a negative correlation between cobalt and oxygen, leading to a build-up of cobalt in oxygen-depleted regions. Large cobalt sources from the Peru margin and the absence of cobalt scavenging in the oxygen minimum zone - evident in lower inventories of particulate cobalt and manganese compared to surrounding waters - lead to a cobalt plume that is larger than what would be expected solely by this basin scale remineralization trend. Compared to regions in the western Pacific, the Peru margin cobalt source may be particularly prolific due to low oxygen concentrations, which limit scavenging in coastal waters and enable a more efficient source to the oceans.

I built off of these conclusions in Chapter 3, which represents a synthesis of the geochemical cobalt fluxes into and out of the modern ocean, informed both by patterns of cobalt accumulation in marine sediments and by recent high-resolution datasets of dissolved and particulate cobalt that are nearly global in scope. The combination of these datasets provide much needed constraints on cobalt-scavenging from the water column, a process that results in small deep ocean inventories of dissolved cobalt and a fast residence time (100-150 years). Surprisingly, cobalt removal in deep ocean waters $(>1000 \mathrm{~m})$ is slow, accounting for only a small 
fraction of the flux of scavenged cobalt to marine sediments. Discrepancies between the amount of cobalt exported from the surface ocean in sinking biomass and the amount of cobalt that is remineralized in the mesopelagic zone confirms that cobalt scavenging is most active in relatively shallow waters. With these constraints on the major sink for cobalt, the magnitude of cobalt sources could be estimated and compared. Consistent with water column observations in Chapter 2, these calculations suggest that $\sim 25 \%$ of cobalt supplied to the ocean derives from low oxygen settings in the Arabian Sea and on the west coasts of Africa and the Americas. This description of the geochemical cobalt cycle provides an empirical (albeit coarse) benchmark to compare with future transects, process studies and modelling syntheses as the GEOTRACES program continues.

With cobalt supply and removal rates estimated, Chapters 4 and 5 turn to microbial demand for cobalt. Although its use by organisms is vast and diverse, these chapters focus on a crucial organism, Prochlorococcus, which is responsible for a large fraction of primary production in the oligotrophic ocean and has a known (but unquantified) requirement for cobalt (Saito et al., 2002). On a cellular level, dissecting cobalt metabolism in Prochlorococcus represents an additional problem of demand and supply: what is the enzymatic demand for cobalt, and how does the cell supply it? The two questions were addressed in Chapters 4 and 5 respectively.

Chapter 4 quantifies the minimum requirement for cobalt in Prochlorococcus MIT9215. Use of this strain was key because it was isolated from the equatorial Pacific, a region that was sampled for cobalt during the Metzyme cruise (KM1128). Cobalt limitation in this organism was effectively described by quota models of phytoplankton growth, which suggest that Prochlorococcus will experience cobalt limitation when there are $\sim 150$ atoms per cell or less. This extremely low quota could be partially accounted for by measurements of two pseudocobalamin-requiring enzymes. Slow rates and higher copy numbers of the ribonucleotide reductase enzyme indicate genome replication is probably the rate limiting step to cell division in a cobalt-limited metabolism. Despite widespread cobalt scarcity in the Equatorial Pacific - due in part to lackluster cobalt supply from the equatorial undercurrent - Prochlorococcus appear to acquire more than enough cobalt so that cobalt limitation is probably avoided in this region. Depression of Prochlorococcus growth rates by iron scarcity may explain the surprisingly high cobalt quotas in this region. 
Chapter 5 further examines how Prochlorococcus MIT9215 acquires cobalt. Competitive inhibition by zinc and manganese indicates that inorganic cobalt is the preferred species for uptake and that cobalt is probably acquired by the same transport system as manganese. Zinc inhibition of cobalt uptake represents a number of challenges for Prochlorococcus. Extrapolating these data to oligotrophic environments suggests that the abundance of inorganic cobalt and zinc are such that Prochlorococcus MIT9215 would be expected to experience cobalt limitation, and that it would be outcompeted by phytoplankton like Emiliania huxleyi (to which cobalt and zinc are equivalent nutrients). As these conclusions are in direct conflict with those of Chapter 4, it is likely that wild Prochlorococcus possess additional mechanisms to acquire organically-bound cobalt that may not be reflected under these experimental conditions. If this is the case, it seems unlikely that Prochlorococcus is strongly cobalt limited in the tropical Pacific Ocean.

Why is cobalt metabolism so sensitive to interference? The explanation emphasized in Chapter 5 is that distinguishing cobalt from other metals is a fundamental challenge for cells, especially those that have a metabolic imperative to select cobalt for (pseudo)cobalamin production. Has this always been the case? The argument has been made before that, because cyanobacteria evolved prior to atmospheric oxygenation, their intracellular chemistry retains some vestige of the ancient ocean (Saito et al., 2003). Indeed, cytosolic redox buffering by cysteine and glutathione bears some similarity to the sulfide rich oceans of the Archaean and Proterozoic eras. The extremely low abundance of $\mathrm{Cu}$ and $\mathrm{Zn}$ ions in cyanobacterial cytoplasm matches the expectation that, in an anoxic ocean, these metals would be scavenged to low concentrations by free sulfide (Saito et al., 2003; Waldron and Robinson, 2009). In addition, prior to oxygenation, oceanic Co content was probably higher due to the inhibition of oxidative scavenging. The cobalt plumes in modern oxygen minimum zones hint of a much greater cobalt inventory when the entire ocean was anoxic. Thus, the sensitivity of cobalt uptake by Zn may have only become problematic for these ancestral cyanobacteria after oxygenation of the ocean and expansion of oceanic zinc inventories to modern levels.

However, it is worth reiterating that in much of the ocean, zinc concentrations (and especially Zn') are quite low. Studies on the speciation of zinc in the open ocean are few, making it difficult to gauge what proportion of Prochlorococcus in the modern ocean would be subject to zinc inhibition. Prevailing zinc scarcity throughout much of the geologic past - at least in the open ocean - probably allowed Prochlorococcus to shed some of the zinc protection 
mechanisms evolved by its ancestors. It is clear that other members of the cyanobacteria, such as Synechocystis, have a much fuller arsenal of protection mechanisms, though the response of this organism to cobalt-limitation has not, to date, been examined. If the ability to distinguish cobalt from zinc is not improved by these additional proteins, cobalt-limited Synechocystis may be in a similar predicament. Thus, it is difficult to discern the relative influences of genome streamlining and vestigial metal availability on the results in Chapter 5 without future experiments that explore the phylogenic breadth of this sensitivity.

Similarly, there is also much to learn about how Prochlorococcus regulates and partitions its intracellular metal inventories, especially zinc. At present, the major intracellular reservoirs for these metals are generally assumed from bioinformatics extrapolation and it may be possible that important metalloenzymes in cyanobacteria remain undiscovered. Identification of intracellular metal pools by native chromatography can help discern if there are key metal reservoirs missing from our understanding. Application of these methods to cobalt-limited Prochlorococcus could help partition the remaining cobalt quota that could not be accounted by ribonucleotide reductase or methionine synthase. Metalloproteomics could also be usefully applied to trace the locus of competitive inhibition observed for $\mathrm{Zn}, \mathrm{Mn}$ and $\mathrm{Ni}$.

Our minimum quotas in Prochlorococcus were determined under ideal conditions where all other nutrients are in excess. It is possible that cobalt use in additional enzymes - such as alkaline phosphatase - will increase minimum cobalt quotas when phosphate or other nutrients are scarce, as they are in the North Atlantic Subtropical Gyre. The role of zinc as a toxin or nutrient to Prochlorococcus is also uncertain. Cobalt-limited Prochlorococcus were extremely sensitive to zinc, but their genomes also contain annotations for putative zinc-dependent proteases, phosphatases, and carbonic anhydrases. Perhaps these enzymes are powered by other metals instead. The specter of zinc contamination prevented more detailed investigations into the somewhat high, but invariant zinc quotas measured in Chapter 5. If these numbers are real, how does Prochlorococcus acquire and regulate $\mathrm{Zn}$ (and $\mathrm{Cu}$ and $\mathrm{Ni}$ for that matter)? In a case where background $\mathrm{Zn}$ was lower than what was achieved in culture experiments in Chapters 4 and 5, would additional cobalt be required to fill these roles in Prochlorococcus, like it seems to do in zinc-limited diatoms and coccolithophores? Only future experiments can tell. In the meantime, a conservative approach would be to treat the results from Chapter 4 as a lower bound on cobaltlimited quotas in Prochlorococcus. 
The competitive inhibition of cobalt acquisition by zinc may have consequences for other organisms besides cyanobacteria. In addition to a complete cobalamin biosynthetic pathway and genes for methionine synthase and ribonucleotide reductase, the genome of the ammoniaoxidizing archaeon Nitrosopelagicus brevis encodes a cobalamin-dependent methylmalonyl CoA mutase enzyme that is crucial for autotrophic carbon fixation (Santoro et al., 2015). As such, its minimum cobalt quota is probably much larger than that of Prochlorococcus, but $N$. brevis may experience similar difficulties in selecting Co from $\mathrm{Zn}$ for uptake and ultimately, cobalamin synthesis. Cobalt-limitation in these organisms could have ramifications for the nitrogen cycle in oligotrophic regions. Notably, stations with the lowest dissolved cobalt on the Metzyme cruise (Stations 7-9, 6-12 $\mathrm{S}$ ) also had the highest ammonium concentrations below the euphotic zone $(>0.5 \mu \mathrm{M}$ at $100 \mathrm{~m})$, suggesting that something besides nitrogen availability was limiting the rate of ammonium oxidation in these waters. Perhaps cobalt limits their growth here and elsewhere...

While Chapters 2 and 3 present a consistent view of the cobalt cycle on regional and global scales, there are still vast areas that are devoid of measurement. There are literally no measurements of dissolved cobalt in the Indian Ocean. Given the amount of terrigenous sediments delivered to the Arabian Sea and Bay of Bengal and the large oxygen minimum zones present in both seas, it is likely that cobalt sources there are massive. But how massive? Future sampling in these environments will serve as opportunities to test the hypotheses built on Atlantic and Pacific datasets and hopefully can more precisely define redox thresholds that seem important in regulating the magnitude of coastal sources and the rate of water column scavenging. Water column sampling in the marginal seas of East Asia - and comparison to enclosed basins such as the Arctic Ocean and Mediterranean Sea - will clarify large uncertainties in the magnitude of terrigenous cobalt sources and their impact relative to fluxes from deoxygenated coasts. Building biogeochemical cobalt models may be the best way to ensure a concise and consistent description of the marine cobalt cycle as the number of measurements of cobalt in seawater continues its exponential increase. It will be exciting, too, to construct records of seawater cobalt from sediment, coral, and rock archives to understand the past changes to this geochemical cycle.

While this thesis has emphasized natural cycles of cobalt in the ocean, anthropogenic influences may also become more apparent. A smartphone battery has 5-10g of cobalt (Frankel, 2016), equivalent to a million $\mathrm{m}^{3}$ of seawater at average oceanic concentrations. An electric car 
battery has $15 \mathrm{~kg}$ Co (Frankel, 2016). There is $400 \mathrm{~kg}$ cobalt in a commercial jet engine. Life cycle analyses suggest that $2.8 \times 10^{10} \mathrm{~g}$ cobalt $\left(4.7 \times 10^{8} \mathrm{~mol}\right)$ is discarded in landfills annually (Harper et al., 2012). Even more is mined. As such, the cobalt flux to landfills is nearly equal to the estimate of global cobalt sources to the ocean in Chapter $3\left(5.9 \times 10^{8}\right.$ mol per year). Repeat analyses of ocean sections like those presented in Chapter 2 and 4 may be helpful for assessing if (or when) this potential anthropogenic contribution is realized.

\section{References}

Harper, E. M., Kavlak, G. and Graedel, T. E.: Tracking the metal of the goblins: Cobalt's cycle of use, Environ. Sci. Technol., 46(2), 1079-1086, doi:10.1021/es201874e, 2012.

Saito, M. A., Moffett, J. W., Chisholm, S. W. and Waterbury, J. B.: Cobalt limitation and uptake in Prochlorococcus, Limnol. Oceanogr., 47(6), 1629-1636, doi:10.4319/lo.2002.47.6.1629, 2002.

Saito, M. A., Sigman, D. M. and Morel, F. M. .: The bioinorganic chemistry of the ancient ocean: the co-evolution of cyanobacterial metal requirements and biogeochemical cycles at the Archean-Proterozoic boundary?, Inorganica Chim. Acta, 356, 308-318, doi:10.1016/S00201693(03)00442-0, 2003.

Santoro, A. E., Dupont, C. L., Richter, R. A., Craig, M. T., Carini, P., McIlvin, M. R., Yang, Y., Orsi, W. D., Moran, D. M. and Saito, M. A.: Genomic and proteomic characterization of Candidatus Nitrosopelagicus brevis: an ammonia-oxidizing archaeon from the open ocean., Proc. Natl. Acad. Sci. U. S. A., 112(4), 1173-8, doi:10.1073/pnas.1416223112, 2015.

Waldron, K. J. and Robinson, N. J.: How do bacterial cells ensure that metalloproteins get the correct metal?, Nat. Rev. Microbiol., 7(1), 25-35, doi:10.1038/nrmicro2057, 2009.

Frankel, T. C., "The Cobalt Pipeline.” The Washington Post, 9/30/2016. 